Final Report

\title{
FHWA/IN/JTRP-2004/7
}

\section{An Analysis of Cost Overruns and Time Delays of INDOT Projects}

\author{
by \\ Claire Bordat \\ Graduate Research Assistant \\ Bob G. McCullouch \\ Research Scientist \\ Samuel Labi \\ Visiting Assistant Professor of Civil Engineering \\ and \\ Kumares C. Sinha \\ Olson Distinguished Professor of Civil Engineering \\ School of Civil Engineering \\ Purdue University \\ Joint Transportation Research Program \\ Project No.: C-36-73V \\ File No.: 3-4-22 \\ SPR-2811 \\ Prepared in Cooperation with the \\ Indiana Department of Transportation and the \\ U.S. Department of Transportation \\ Federal Highway Administration
}

The contents of this report reflect the views of the author who is responsible for the facts and the accuracy of the data presented herein. The contents do not necessarily reflect the official views or policies of the Indiana Department of Transportation or the Federal Highway Administration at the time of publication. This report does not constitute a standard, specification, or regulation.

Purdue University

West Lafayette, Indiana

December 2004 


\section{TECHNICAL Summary}

INDOT Research

Technology Transfer and Project Implementation Information

TRB Subject Code: 33-1 Construction Control

Publication No.: FHWA/IN/JTRP-2004/7, SPR-2811

December 2004

Final Report

\section{An Analysis of Cost Overruns and Time Delays of INDOT Projects}

\section{Introduction}

A commonality among state Departments of Transportation is the inability to complete projects on time and within budget. This is a chronic problem for the Indiana Department of Transportation (INDOT) as well. Time delays, cost overruns and change orders are generally due to factors such as design errors, unexpected site conditions, increases in project scope, weather conditions, and other project changes. In 2001, INDOT incurred approximately $\$ 17,028,000$ in cost overruns, representing approximately $9 \%$ of the total amount for all contracts in 2001. As the construction program grows this is causing planning and budgeting problems within INDOT, For example, with a current annual construction program of $\$ 700$ million at this percentage, this is costing INDOT in excess of $\$ 60$ million. The money has to be set-aside and creates scheduling problems for determining what projects cannot be let. For these and other reasons, INDOT requested a study to analyze the extent of the cost overrun and time delay problem and to make appropriate recommendations.

\section{Findings}

The results of the agency survey showed that with regard to the problem of cost overruns, INDOT has an average rank compared to other states. The overall rate for cost overrun amounts for INDOT projects between 1996 and 2001 was 4.5\%. It was found that $55 \%$ of all INDOT contracts experienced cost overruns. Also, 12\% of all INDOT contracts experience time delays, and the average delay per contract was 115 days. The study also determined average cost overrun amount and arte and time delay for each type of contract. From the various statistical analyses, it was determined that factors influential to cost overruns, time delays, and change orders are contract bid amount, difference between the winning bid and second bid, difference between the winning bid and the engineer's estimate, project type and location by district. The study also found that the dominant category of reasons for change orders is "errors and omissions", a finding which is suggestive of possible shortcomings in current design practices. The study found that in the past, change orders were typically not recorded until the end of the contract.

For addressing the problem of change orders, the following recommendations are proposed: a Change Order Management process should be developed and implemented. This will consist of: (i) developing a mindset geared towards monitoring and addressing the problem of change orders, in the department, (ii) developing procedures and instructions for recording change order information in the existing contract management tool (SiteManager), (iii) developing a system of controls that routes change order information to the appropriate personnel in Operations Support and Design Divisions. With implementation of these recommendations, it would be possible for SiteManager to record and monitor change order information as it develops. The incidence of so many "no-recorded-reason" change orders is suggestive of lapses in the identification and recording of appropriate reasons for some change orders. Bidding documents for most projects (with the exception 
resurfacing projects) are typically prepared by consultants. A system of instructions and more definitive definitions can help assign appropriate reasons for all change orders and improve documentation. Therefore, a standard report for each consultant and for each contract could be prepared to identify preventive change orders and how such situations may be avoided in future. Moreover, "real time" recording of change orders would likely accelerate the process of feedback to designers and field personnel. If data about change orders is collected on a daily basis, it is possible to create a "weekly change order report" and route it to the appropriate personnel.

INDOT personnel should be given ample opportunity to carry out a detailed review of change orders reports and their consequences. Also, such personnel should be encouraged to continually improve their methods. Obviously, implementing additional requirements will be a challenge, given the current staffing levels and work loads at INDOT. However it is expected that an electronic routing system that collects and distributes change order information would lessen this burden.

It is recommended that INDOT should design an annual report that reviews the performance of consultants. Such a report would assign "grades" to each consultant, taking into account the frequency and dollar amount of preventable change orders that are attributable to the consultant. If grades are to be assigned in such manner, INDOT's change order classification may be adapted to this new objective in order to better distinguish the responsibilities of each change order type. Finally, INDOT's current change order classification code can be improved such that an appropriate change order code can be assigned to any situation.

\section{Implementation}

In evaluating the problem of cost overruns, time delays, and change orders at INDOT, this research effort is consistent with INDOT's strategic objectives for resource management which include reduction in INDOT overhead costs and increase in the efficiency of the capital program expenditures. The present study provided some initial answers to address problems in the present system. Using the results herein as a starting point, it is possible to carry out future work such as the implementation of a methodology to enhance contract management at INDOT. Another activity is to develop an evaluation procedure to efficiently manage the collection, analysis, and presentation of information on change orders, cost overruns, and time delays. At the present time, there are indications that INDOT is mulling the establishment a new online system that would directly record change orders from the construction site. The next step would be to enhance the organization of an accompanying database to facilitate monitoring and analysis of change order information and preparation of periodic consultant performance reports.

Implementation assistance will be available from Purdue University by contacting the JTRP office or Dr. Bob McCullouch (bgm@ecn.purdue.edu, 765-494-0643).

\section{Contacts}

For more information:

Dr. Bob G. McCullouch

Principal Investigator

Purdue University School of Civil Engineering

West Lafayette IN 47907

Phone: (765) 494-0643

Fax: (765) 494-0644

E-mail: bgm@ecn.purdue.edu

Prof. Kumares C. Sinha

Co-Principal Investigator

Purdue University School of Civil Engineering

West Lafayette IN 47907

Phone: (765) 494-2211

Fax: (765) 496-7996

E-mail: $\underline{\text { sinha@ecn.purdue.edu }}$
Indiana Department of Transportation

Division of Research

1205 Montgomery Street

P.O. Box 2279

West Lafayette, IN 47906

Phone: (765) 463-1521

Fax: (765) 497-1665

\author{
Purdue University \\ Joint Transportation Research Program \\ School of Civil Engineering \\ West Lafayette, IN 47907-1284 \\ Phone: (765) 494-9310 \\ Fax: (765) 496-7996 \\ E-mail: jtrp@ecn.purdue.edu \\ http://www.purdue.edu/jtrp
}


TECHNICAL REPORT STANDARD TITLE PAGE

\begin{tabular}{|c|c|c|}
\hline $\begin{array}{l}\text { 1. Report No. } \\
\text { FHWA/IN/JTRP-2004/7 }\end{array}$ & 2. Government Accession No. & 3. Recipient's Catalog No. \\
\hline \multirow{2}{*}{\multicolumn{2}{|c|}{$\begin{array}{l}\text { 4. Title and Subtitle } \\
\text { An Analysis of Cost Overruns and Time Delays of INDOT Projects }\end{array}$}} & $\begin{array}{l}\text { 5. } \quad \text { Report Date } \\
\text { December } 2004\end{array}$ \\
\hline & & 6. Performing Organization Code \\
\hline \multicolumn{2}{|c|}{$\begin{array}{l}\text { 7. Author(s) } \\
\text { Claire Bordat, Bob G. McCullouch, Samuel Labi, and Kumares C. Sinha }\end{array}$} & $\begin{array}{l}\text { 8. Performing Organization Report No. } \\
\text { FHWA/IN/JTRP-2004/7 }\end{array}$ \\
\hline \multirow{2}{*}{\multicolumn{2}{|c|}{$\begin{array}{l}\text { 9. Performing Organization Name and Address } \\
\text { Joint Transportation Research Program } \\
1284 \text { Civil Engineering Building } \\
\text { Purdue University } \\
\text { West Lafayette, IN 47907-1284 }\end{array}$}} & 10. Work Unit No. \\
\hline & & $\begin{array}{l}\text { 11. Contract or Grant No. } \\
\text { SPR-2811 }\end{array}$ \\
\hline \multirow{2}{*}{\multicolumn{2}{|c|}{$\begin{array}{l}\text { 12. Sponsoring Agency Name and Address } \\
\text { Indiana Department of Transportation } \\
\text { State Office Building } \\
100 \text { North Senate Avenue } \\
\text { Indianapolis, IN } 46204\end{array}$}} & $\begin{array}{l}\text { 13. Type of Report and Period Covered } \\
\text { Final Report }\end{array}$ \\
\hline & & 14. Sponsoring Agency Code \\
\hline
\end{tabular}

15. Supplementary Notes

Prepared in cooperation with the Indiana Department of Transportation and Federal Highway Administration.

\section{Abstract}

A commonality among state Departments of Transportation is the inability to complete projects on time and within budget. This project assessed the extent of the problem of cost overruns, time delays, and change orders associated with Indiana Department of Transportation (INDOT) construction projects, identified the reasons for such problems, and finally developed a set of recommendations aimed at their future reduction. For comparison purposes, data from other states were collected and studied using a questionnaire instrument. The analysis of the cost overrun, time delay and change order data was done using an array of statistical methods. The literature review and agency survey showed that time delays, cost overruns and change orders are generally due to factors such as design, unexpected site conditions, increases in project scope, weather conditions, and other project changes. The results of the agency survey showed that with regard to the problem of cost overruns, INDOT has an average rank compared to other states. Between 1996 and 2001, the overall rate for cost overrun amounts for INDOT projects was determined as $4.5 \%$, and it was found that $55 \%$ of all INDOT contracts experienced cost overruns. It was determined that the average cost overrun amount and rate, as well as the contributory cost overrun factors differ by project type. The average cost overrun rates were as follows: bridge projects -- $8.1 \%$, road construction -- 5.6\%, road resurfacing -- $2.6 \%$, traffic projects -- 5.6\%, maintenance projects -- 7.5\%. With regard to time delays, it was found that $12 \%$ of all INDOT contracts experience time delays, and the average delay per contract was 115 days. With regard to change orders, the study found that the dominant category of reasons for change orders is "errors and omissions", a finding which is suggestive of possible shortcomings in current design practices The statistical analyses in the present study showed that the major factors of cost overruns, time delays, and change orders in Indiana are contract bid amount, difference between the winning bid and second bid, difference between the winning bid and the engineer's estimate, project type and location by district. Besides helping to identify or confirm influential factors of cost overruns, time delay and change orders, the developed regression models may be used to estimate the extent of future cost overruns, time delay and change orders of any future project given its project characteristics and any available contract details. Such models can therefore be useful in long-term budgeting and needs assessment studies. Finally, the present study made recommendations for improving the management of projects and the administration of contracts in order to reduce cost overruns, time delays and change orders.

\section{Key Words}

Change orders, cost overruns, time delays, construction delays, liquidated damages, errors and omissions, site conditions.

\section{Distribution Statement}

No restrictions. This document is available to the public through the National Technical Information Service, Springfield, VA 22161

\begin{tabular}{|c|c|c|c|}
\hline 19. Security Classif. (of this report) & 20. Security Classif. (of this page) & 21. No. of Pages & 178 \\
Unclassified & Unclassified & 22. Price \\
\hline
\end{tabular}

Form DOT F 1700.7 (8-69) 


\section{TABLE OF CONTENTS}

LIST OF TABLES.............................................................. vi

LIST OF FIGURES.............................................................. viii

CHAPTER 1: $\quad$ INTRODUCTION.............................................. 1

$1.1 \quad$ Background and Problem Statement..................................... 1

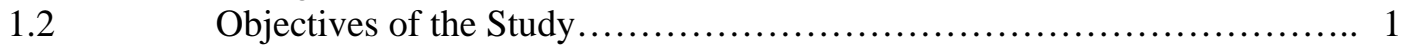

$1.3 \quad$ Study Scope.............................................................. 2

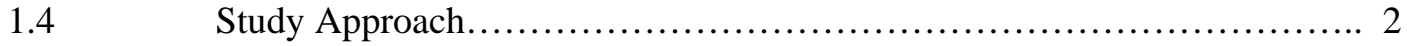

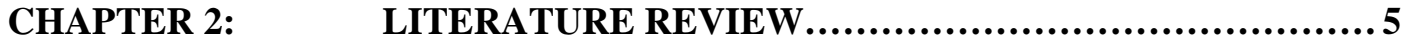

$2.1 \quad$ Introduction.............................................................. 5

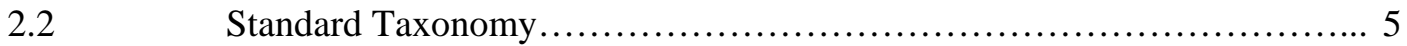

Causes of Time Delays................................................ 7

$2.4 \quad$ Factors Affecting Cost-Overruns.................................... 10

$2.5 \quad$ Reasons for Change Orders........................................... 12

$2.6 \quad$ Audit Reports....................................................... 13

$2.7 \quad$ Discussion of Literature Review........................................ 16

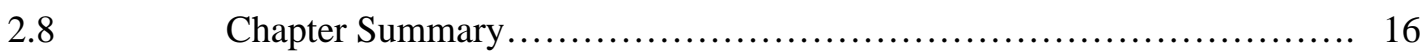

CHAPTER 3: $\quad$ AGENCY SURVEY $\quad$............................................... 18

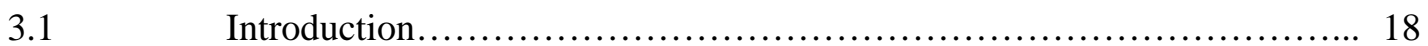

3.2 Cost Overruns and Time Delays: Results of the Agency Survey........... 18

Cost and Time Overruns: Comparison among States....................... 24

T.4 Tracking Change Orders: Comparison among States.................... 27

$3.5 \quad$ Chapter Summary................................................... 28

CHAPTER 4: $\quad$ STUDY METHODOLOGY................................. 29

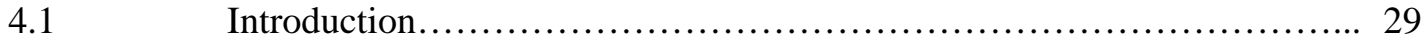

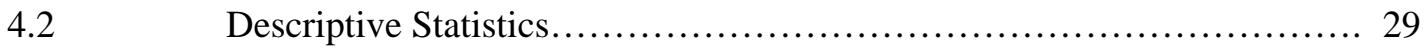

$4.3 \quad$ Statistical Analysis................................................ 31

4.3.1 Correlation Matrix Analysis.................................. 31

4.3.2 Analysis of Variance (ANOVA) ................................ 31

4.3.3 Pair-wise Tests............................................... 32

4.3.4 Graphical Trend Investigation............................... 33

4.4

Description of the Modeling Process............................... 33

R.4.1 Response Variables......................................... 33

4.4.1.1 Cost Overrun.............................................. 34

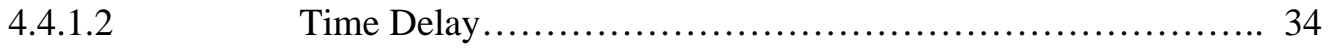

4.4.1.3 Change Orders.......................................... 34

Independent Variables.......................................... 34 


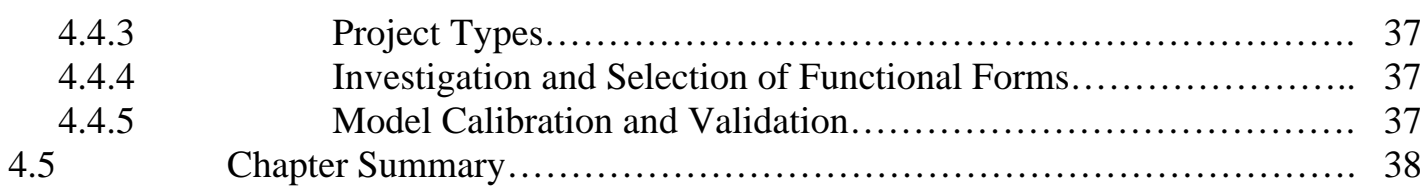

\begin{tabular}{|c|c|c|}
\hline CHAPTER 5: & : $\quad$ DATA COLLECTION........................................ & 39 \\
\hline 5.1 & Introduction & 39 \\
\hline 5.2 & Data Collection................. & 39 \\
\hline 5.2 .1 & INDOT Information.... & \\
\hline 5.2 .2 & Weather Data............ & \\
\hline 5.3 & Database Development....... & 42 \\
\hline 5.3.1 & Refinement of the Dataset... & \\
\hline 5.3 .2 & Weather Database................................................... & \\
\hline 5.3 .3 & 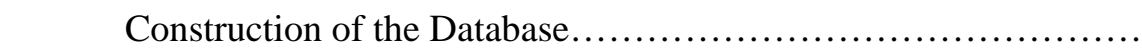 & \\
\hline 5.4 & Chapter Summary............................. & \\
\hline
\end{tabular}

CHAPTER 6: $\quad$ DESCRIPTIVE STATISTICS................................ 46

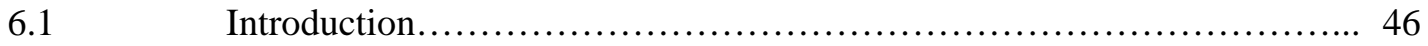

$6.2 \quad$ General Description.............................................. 46

6.2.1 Distribution of Contracts by District.......................... 46

6.2.2 Distribution of Contracts by Project Type....................... 47

6.3 Time Overruns...................................................... 47

6.3.1 Analysis of Liquidated Damages.............................. 47

6.3.2 Analysis of Time Delays...................................... 49

$6.4 \quad$ Cost Overruns and Underruns........................................ 53

6.4.1 Cost Underruns.............................................. 54

Cost Overruns.................................................... 60

$6.5 \quad$ Change Orders...................................................... 61

6.5.1 General Description of the Change Orders...................... 63

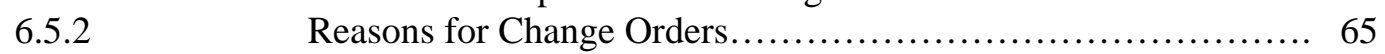

Chapter Summary .............................................. 82

CHAPTER 7: $\quad$ STATISTICAL ANAL YSIS PART I..........................83

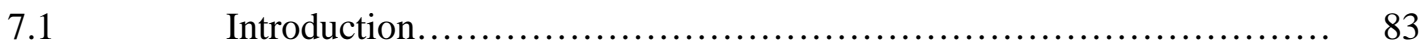

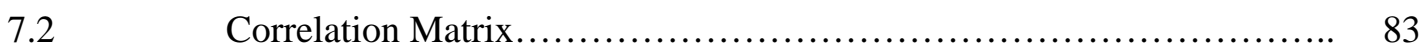

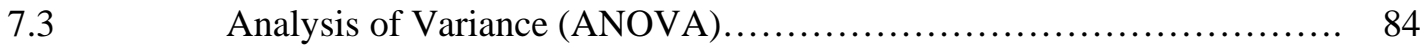

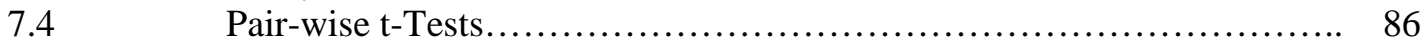

7.4.1 "Bid Amount” Pairs.................................... 86

7.4.2 "Duration” Pairs....................................... 87

7.4.3 "Proportion of Inclement Weather Days” Pairs................. 87

7.4.4 "Level of Competition” Pairs............................ 87

7.4.5 "Proportion of the Difference between the Winning and Second

Bid" Pairs............ 88

7.4.6 "Proportion of the Difference between the Bid and the Engineer's

7.4.7 Pair-wise t-Test Conclusions.............................. 88

7.5 Preliminary Graphical Analysis of the Influence of Independent Variables on the Dependent Variables....................................... 89

7.5.1 Cost Overrun................................................. 89

Time Overrun.............................................. 92 
7.5.3 Number of Change Orders................................. 95

7.5.4 Conclusion of the Graphical Analysis......................... 97

Chapter Summary ................................................ 98

CHAPTER 8: $\quad$ STATISTICAL ANALYSIS PART II (MODELING)..........99

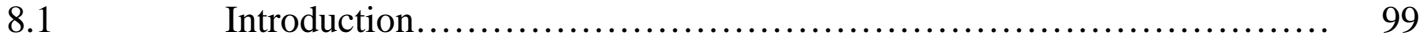

8.2 Models for Change Orders...................................... 101

8.2.1 Models that Estimate the Frequency of Change Orders............ 101

8.2.1.1 Frequency of Change Orders for All Project Types Combined ... 101

8.2.1.2 Frequency of Change Orders for Bridge Projects............... 102

8.2.1.3 Frequency of Change Orders for Maintenance Projects............103

8.2.1.4 Frequency of Change Orders for Road Construction Projects..... 104

8.2.1.5 Frequency of Change Orders for Traffic Projects................. 105

8.2.1.6 Frequency of Change Orders for Resurfacing Projects......... 107

8.2.2 Models that Estimate Change Order Amount............................ 107

8.3 Models for Estimating Time Delay................................. 109

8.3.1 Time Delay for All Project Types Combined.................... 109

8.3.2 Time Delay for Bridge Projects.............................. 110

8.3.3 Time Delay for Maintenance Projects......................... 111

8.3.4 Time Delay for Road Construction Projects.................... 112

8.3.5 Time Delay for Traffic Projects................................ 113

8.3.6 Time Delay for Resurfacing Projects......................... 113

8.3.7 Discussion for Time Delay Models........................... 114

8.4 Models for Estimating Cost Overruns....................... 115

8.4.1 Estimation of Cost Overrun Amounts............................ 115

8.4.1.1 Cost Overrun Amounts All Project Types Combined........ 115

8.4.1.2 Cost Overrun Amounts for Bridge Projects................. 116

8.4.1.3 Cost Overrun Amounts for Maintenance Projects............ 117

8.4.1.4 Cost Overrun Amounts for Road Construction Projects...... 117

8.1.4.5 Cost Overrun Amounts for Traffic Projects................. 118

8.1.4.6 Cost Overrun Amounts for Resurfacing Projects........... 118

8.4.2 Cost Overrun Rate............................................ 120

C.5 Chapter Discussion..................................... 120

Chapter Summary ................................. 122

CHAPTER 9: $\quad$ CONCLUSIONS.............................................. 123

CHAPTER 10: $\quad$ RECOMMENDATIONS................................ 126

CHAPTER 11: $\quad$ IMPLEMENTATION.................................. 128

CHAPTER 12: $\quad$ REFERENCES.......................................... 129

APPENDIX A: $\quad$ E-MAIL SOLICITATION LETTER TO AGENCIES ..... 131

APPENDIX B: $\quad$ INDOT'S CHANGE ORDER ORGANIZATION.......... 132

APPENDIX C: $\quad$ CHANGE ORDER CLASSIFICATION AT STATE DOTS 135

APPENDIX D: $\quad$ WEATHER DATA ORGANIZATION.................... 142 
APPENDIX E: $\quad$ DESCRIPTIVE STATISTICS.......................... $\quad 144$

APPENDIX F: $\quad$ STATISTICAL ANALYSIS............................... 163

APPENDIX G: $\quad$ ARIZONA DOT MANAGEMENT OF COST

AND TIME OVERRUN........................ 177 


\section{LIST OF TABLES}

Table 2.1

Table 2.2

Table 2.3

Table 2.4

Table 3.1

Table 3.2

Table 3.3

Table 3.4

Table 3.5

Table 3.6

Table 3.7

Table 3.8

Table 3.9

Table 3.10

Table 3.11

Table 4.1

Table 4.2

Table 5.1

Table 5.2

Table 5.3

Table 6.1

Table 6.2

Table 6.3

Table 6.4

Table 6.5

Table 6.6

Table 6.7

Table 6.8

Table 6.9

Table 6.10

Table 6.11

Table 6.12

Table 6.13

Table 6.14

Table 6.15

Table 7.11

Table 7.12

Table 7.13

Table 7.14

Table 7.15
Ranking of Contributory Factors of Non-Excusable Delay........... 9

Root Causes of Highway Construction Delays.......................... 11

Reasons for Change Orders Identified by FHWA..................... 13

Recommendations for Addressing Cost Overruns at DelDOT............ 15

Cost Overruns and Time Delays in Arkansas.......................... 19

Cost Overruns in Idaho between Fiscal Years 1997 and 2001........... 19

Cost Overruns at Missouri DOT between Fiscal Years 1999 and 2002... 20

Ohio DOT Cost Overruns, 1994 - 1997................................. 21

Ohio DOT Cost Overruns 1998 - 2001.............................. 21

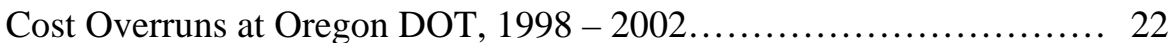

Cost Overruns for Paid-off Tennessee DOT Projects, 7/01/98

to $9 / 13 / 02 \ldots \ldots \ldots \ldots \ldots \ldots \ldots \ldots . . . . . . . . .23$

Cost and Time Overruns at Texas DOT, $1998-2000 \ldots \ldots \ldots \ldots \ldots \ldots \ldots . . . . .23$

Cost and Time Overruns at Texas DOT, 2001, 2002 and $1998-2002 \ldots \ldots \ldots \ldots \ldots \ldots \ldots . . \ldots \ldots$

Comparison of Cost Overruns at Selected States...................... 24

Relative Simplicity of Change Order Classification at Selected

State DOTs...................... 27

Selected Levels for Each Independent Variable....................... 31

Definition of the Proportions for each Variable........................ 33

Raw Contract Data Provided by INDOT............................. 39

Items in the Database................................................ 44

Number of Observations for Variable............................... 45

Distribution of Contracts by District................................ 47

Distribution of Contracts by Project Type.......................... 47

Average Contract Time Delays (in Days) .......................... 50

Basic Statistics of the Cost Overrun Rate........................... 53

Bid Amount Categories........................................... 55

Average Cost Overrun Amounts..................................... 56

Descriptive Statistics of Change Order Frequency.................... 63

Distribution of Daily Change Order Frequency....................... 64

Reasons for Change Orders........................................ 66

Responsibility of Change Orders................................ 70

Average Frequency of Bridge Contract Change Orders................. 75

Average Frequency of Maintenance Contract Change Orders............ 76

Average Frequency of Road Construction Contract Change Orders...... 77

Average Frequency of Resurfacing Contract Change Orders............ 78

Average Frequency of Traffic Contract Change Orders................. 79

Correlation Matrix of the Independent Variables....................... 84

Analysis of Variance Using Selected Variables...................... 85

Analysis of Variance Using Selected Independent Variables........... 86

Results of the Pair-wise t-Tests..................................... 89

Effects of each Independent Variable on the Dependent Variables...... 98 
Table 8.1 Linear Change Order Model Excluding the "Bid Comparison”

$$
\text { Variables................ } 101
$$

Table 8.2 Model for Frequency of Change Orders for Bridge Projects, Excluding “Bid Comparison” Variables................ 103

Table 8.3 Model for Frequency of Change Orders for Maintenance Projects, Including the "Bid Comparison" Variables............... 104

Table 8.4 Change Order Model Excluding the "Bid Comparison” Variables for Road Construction Projects............... 105

Table 8.5 Model for Frequency of Change Orders for Traffic Projects Including the "Bid Comparison" Variables................ 106

Table 8.6 Model for Frequency of Change Orders for Resurfacing Projects Excluding the "Bid Comparison" Variables.................. 107

Table 8.7 Average Change Order Amounts by Project Type and by District...... 108

Table 8.8 Model for Time Delay for All Project Types Combined, Excluding the "Bid Comparison" Variables................. 109

Table 8.9 Logarithmic Time Delay Model Including the "Bid Comparison” Variables for Bridge Projects..................

Table 8.10 Time Delay Model Excluding the "Bid Comparison” Variables for Maintenance Projects................ 112

Table 8.11 Time Delay Model Excluding the "Bid Comparison” Variables for Road Construction Projects........... 112

Table 8.12 Time Delay Model Excluding the "Bid Comparison” Variables for Traffic Projects...................

Table 8.13 Time Delay Model Excluding the "Bid Comparison” Variables for Resurfacing Projects................ 114

Table 8.14 Model for Cost Overrun Amount Excluding the "Bid Comparison” Variables ................. 115

Table 8.15 Cost Overrun Amount Model Excluding the "Bid Comparison” Variables for Bridge Projects................ 117

Table 8.16 Cost Overrun Amount Model Excluding the "Bid Comparison” Variables for Road Construction Projects................ 117

Table 8.17 Logarithmic Cost Overrun Amount Model Including the "Bid Comparison” Variables for Resurfacing Projects................ 119

Table 8.18 Categories of Calibrated Models and Their Coefficients of Determination.................. 120

Table 8.19

Table B.1

Table B.2

Table D.1

Table F.1

Table F.2

Table F.3

Table F.4

Table F.5

Significant Variables of the Models............................... 121

INDIANA Classification of Reasons for Change Orders.............. 132

Classification Code used by INDOT................................ 134

Quality and Correction of the Weather Data......................... 142

Analysis of Means of the Combination of 5 Variables.................. 163

Analysis of Means of the Combination of Three Variables............ 164

Pair-wise Comparison of Cost Overrun by Bid Amount............... 165

Analysis of Means of the Combination of Three Variables............. 166

Pair-wise Comparison of Cost Overrun by Bid Amount.............. 167 
Table F.6 Pair-wise Comparison of Time Delay by Bid Amount................... 168

Table F.7 air-wise Comparison of Number of Change Orders by Bid Amount...... 169

Table F.8 Pair-wise Comparison of Time Delay by Duration...................... 169

Table F.9 Pair-wise Comparison of Cost Overrun by Proportion of Inclement Weather Days......................... 170

Table F.10 Pair-wise Comparison of Time Delay by Proportion of Inclement Weather Days.......................... 171

Table F.11 Pair-wise Comparison of Cost Overrun by Level of Competition.......... 172

Table F.12 Pair-wise Comparison of Number of Change Orders by Level of Competition........................... 173

Table F.13 Pair-wise Comparison of Cost Overrun by Proportion of the Difference between the First and Second Bid................. 174

Table F.14 Pair-wise Comparison of Time Delay by Proportion of the Difference between the First and Second Bid................ 175

Table F.15 Pair-wise Comparison of Cost Overrun by Proportion of the Difference between the Bid and the Engineer's Estimate... 176 


\section{LIST OF FIGURES}

Figure 1.1

Figure 2.1

Figure 2.2

Figure 3.1

Figure 3.2

Figure 3.3

Figure 3.4

Figure 4.1

Figure 5.1

Figure 5.2

Figure 6.1

Figure 6.2

Figure 6.3

Figure 6.4

Figure 6.5

Figure 6.6

Figure 6.7

Figure 6.8

Figure 6.9

Figure 6.10

Figure 6.11

Figure 6.12

Figure 6.13

Figure 6.14

Figure 6.15

Figure 6.16

Figure 6.17

Figure 6.18

Figure 6.19

Figure 6.20

Figure 6.21

Figure 6.22

Figure 6.23

Figure 6.24

Figure 6.25

Figure 6.26

Figure 6.27
Overall Study Approach....

Contributory Factors of Non-Excusable Delay

(Majid and McCaffer, 1998)....

Relationship between Literature Review and Other Aspects of the Study

Yearly Distribution of Cost Overruns at Selected States.................. 25

Average Annual Amount of Cost Overruns at Selected States............. 25

Yearly Distribution of Cost Overrun Rates at Selected States............. 26

Average Annual Cost Overrun Rates at Selected States.................. 26

Approaches Used in Statistical Analysis................................ 30

Highway Administrative Districts in Indiana.......................... 41

Weather Data Availability by County............................... 43

Annual Frequency of Contracts with Liquidated Damages and Amount of Liquidated Damages, 1996 - 2001.............. 48

Annual Average Liquidated Damage Amounts per Contract, 1996 - 2001... 48

Distribution of Time Delays........................................... 49

Variation of Average Time Delay, 1996 - 2001....................... 51

Variation of Average Time Delay by Project Type, 1996 - 2001.......... 52

Variation of Average Time Delay by District, 1996 - 2001................ 52

Distribution of Contracts with Cost Overruns or Underruns............... 53

Frequency Distribution of Cost Overrun Rates........................ 54

Annual Frequency and Amounts of Cost Overruns, 1996 - 2001......... 55

Average Cost Overrun per Contract, per Year.......................... 55

Variation of the Average Cost Overrun Amounts by Project Type and by District.................................. 58

Frequency of Cost Overrun Rates by Project Type....................... 59

Relative Frequency of Cost Overrun Rates by Project Type............... 59

Number of Contracts by Cost Underrun Category...................... 60

Value of Underrun Amounts by Underrun Category...................... 60

Number of Contracts by Cost Overrun Category......................... 61

Cost Overrun Amounts by Overrun Category........................... 61

Cost Over/Underrun Amount by Over/Underrun Category............... 62

Distribution of the Number of Daily Change Orders per Contract......... 63

Plot of the Observed Values, Normal, and Log Normal Distributions for the Number of Daily Change Orders.......... 64

Distribution of the Number of Contract Change Orders.................. 65

Annual Number of Change Orders for which Reasons are Provided...... 67

Available Change Order Reason Data per Project Type.................. 67

Available Change Order Reason Data per District...................... 68

Distribution of the Number of Change Orders by Reason Type for all Types of Projects ................... 69

Distribution of Total Change Order Amounts by Change Order Type...

69

Distribution of the Average Amount per Change Order by Reason Type

for all Types of Projects........................ 
Figure 6.28 Average Number of Change Orders per Contract and Percentage of

Contracts with Change Order, by District........... 80

Figure 6.29

Average Number of Change Orders per Contract by Project Type.........

Figure 6.30

Average Number of Change Orders per Contract and Percentage of

Contracts with Change Orders, by Bid Amount Category........

80

Figure 6.31

Average Number of Change Orders per Contract and Percentage of Contracts with Change Orders, by Year ..............

Figure 7.1

Cost Overrun Variation with Proportion of Inclement Days...............

81

Figure 7.2

Cost Overruns Variation with the Level of Competition...

Figure 7.3

Cost Overruns Variation with the Proportion between the Winning and the Second Bid

Figure 7.4

Cost Overruns Variation with the Proportion between the Bid and the Engineer's Estimate.

Figure 7.5

Cost Overrun Variation with the Bid Amount....

Figure 7.6

Time Delay Variation with the Proportion of Inclement Days............

Time Delay Variation with the Bid Amount.......................... 87

Figure 7.7

Time Delay Variation with Contract Duration in Days

88

Figure 7.9

Time Delay Variation with the Level of Competition.

88

Figure 7.10

Time Delay Variation with the Difference between the Winning and Second Bids....

Figure 7.11 Time Delay Variation with the Difference between the Engineers' Estimate and the Bid

Figure 7.12

Variation of the Number of Change Orders with the Proportion of Inclement Days.

Figure 7.13

Variation of the Number of Change Orders with the Level of Competition....

Variation of the Number of Change Orders with the Proportion of the

Difference between the Winning and Second Bid.

Figure 7.15

Variation of the Number of Change Orders with the Proportion of the

Difference between the Bid and Engineer's Estimate.

Figure 7.16

Variation of the Number of Change Orders with the Bid Amount........

Organization of the Modeling Process.

Figure

Distribution of the Average Time Delay per Contract by District.........

144

Distribution of the Average Time Delay per Contract by Project Type...

144

Figure E.2

Distribution of Average Time Delay per Contract by Bid Amount

Category and by District.

145

Figure E.4

Distribution of Average Time Delay per Contract by Project Type and

Bid Amount Category...

145

Distribution of Cost Overrun Amounts (\$1,000’s) by Project Type and by Bid Amount Category........................

Figure E.6

Distribution of Cost Overrun Amounts (\$1,000’s) by Project Type and by District.

Figure E.7

Distribution of Cost Overrun Amounts ( $\$ 1,000$ 's) by District and by

Bid Amount Category............................

Reasons for Change Orders in Bridge Projects....................... 149

Figure E.8

Reasons for Change Orders in Road Construction Projects.

150 
Figure E.10 Reasons for Change Orders in Maintenance Projects................

Figure E.11

Figure E.12

Figure E.13

Figure E.14

Figure E.15

Figure E.16

Figure E.17

Figure E.19

Figure E.20

Figure E.21

Figure E.22

Figure G.1

Figure G.2
Reasons for Change Orders in Traffic Projects

Reasons for Change Orders in Resurfacing Projects.................

Reasons for Change Orders in Traffic Maintenance Projects.........

Reasons for Change Orders in Crawfordsville District...............

Reasons for Change Orders in Fort Wayne District...................

Reasons for Change Orders in Greenfield District...................

Reasons for Change Orders in La Porte District......................

Reasons for Change Orders in Vincennes District...................

Distribution of the Average Number of Change Orders by Project

Type and by District.............................

Distribution of the Average Number of Change Orders by District and by Reason Category...........................

Distribution of the Average Number of Change Orders by Project

Type and by Reason Category.....................

Arizona Time Overrun Management..............................

Arizona Cost Overrun Management............................... 


\section{CHAPTER 1: INTRODUCTION}

\subsection{Background and Problem Statement}

A commonality among state departments of transportation is the inability to complete transportation projects on time and within budget. This is a chronic problem for the Indiana Department of Transportation (INDOT). Time delay, cost overruns and change orders are generally due to factors such as design errors, unexpected site conditions, increases in project scope, weather conditions, and other project changes. A cost overrun may be generally expressed as a percent difference between the final cost of the project and the contract award amount. When this value is negative, it is called a cost underrun. A time delay is simply the difference between a project's original contract period at the time of bidding and its overall actual contract period at the end of construction. In 2001, INDOT incurred approximately $\$ 17,028,000$ in cost overruns, representing approximately 9\% of the total amount for all contracts in 2001. Time delays may or may not resulting liquidated damages. Contractors are liable for liquidated damages to the agency when their contracts incur time delays for which they are responsible. In this regard, a total of approximately $\$ 59,000$ was incurred by INDOT's contractors in 2001 for liquidated damages, which represent part of the consequences of construction delays. It does not reflect unrealized benefits due to construction delays.

\subsection{Objectives of the Present Study}

The aim of the present study was to investigate the increasing frequency of cost overruns and time delays on INDOT projects, and to provide recommendations for addressing the situation. In the course of such investigations, it is expected that the following specific objectives will be addressed:

- Identification of the distribution and trends of the cost overruns and time delays of INDOT contracts. (For instance, what kinds of contracts are more susceptible to cost overruns or time delays? In which year? Do cost overruns depend on project size?)

- Investigation of the reasons and the responsibilities for cost overruns and time delays by collecting, reviewing, processing and analyzing change order and contract information data.

- Comparison of the extent and causes of the cost overrun and time delay problem of INDOT projects with those of other highway agencies. 
- Statistical analyses for identifying the factors that significantly influence cost overruns and time delays.

- Development of a set of recommendations to help INDOT manage the problem of cost overruns, time delays, and change orders.

\subsection{Scope of the Study}

The scope of the study included the following.

Project Type: Major INDOT contract types that were considered for the study are as follows:

- $\quad$ Road and bridge construction and rehabilitation projects.

- Maintenance projects, with road maintenance and resurfacing contracts.

- Traffic and traffic maintenance contracts.

Analysis Period: A contract was selected for the present study if its last day of work fell between January 1, 1996 and December 31, 2001.

Geographical Extent: The study considered all contracted projects from the six highway administration districts in Indiana.

Geo-climatic Region: In utilizing data for facilities located in the six highway districts, the study implicitly considered the climatic variations across the entire state. Detailed weather data, such as daily precipitation, snowfall, temperature, and ground snow thickness, were available on a county basis.

\subsection{Overview of Study Approach}

The overall approach of the study followed the steps shown in Figure 1.1. After establishing the objectives, the study carries out a literature review and agency survey, and follows a study framework that includes data collection and analysis. The data analysis is carried out using an array of statistical methods that include descriptive statistics, correlation analysis, analysis of variance, pairwise tests, and statistical modeling. The study concludes with a set of recommendations for reducing the problem of cost overruns, time delay and change orders associated with INDOT construction projects. 


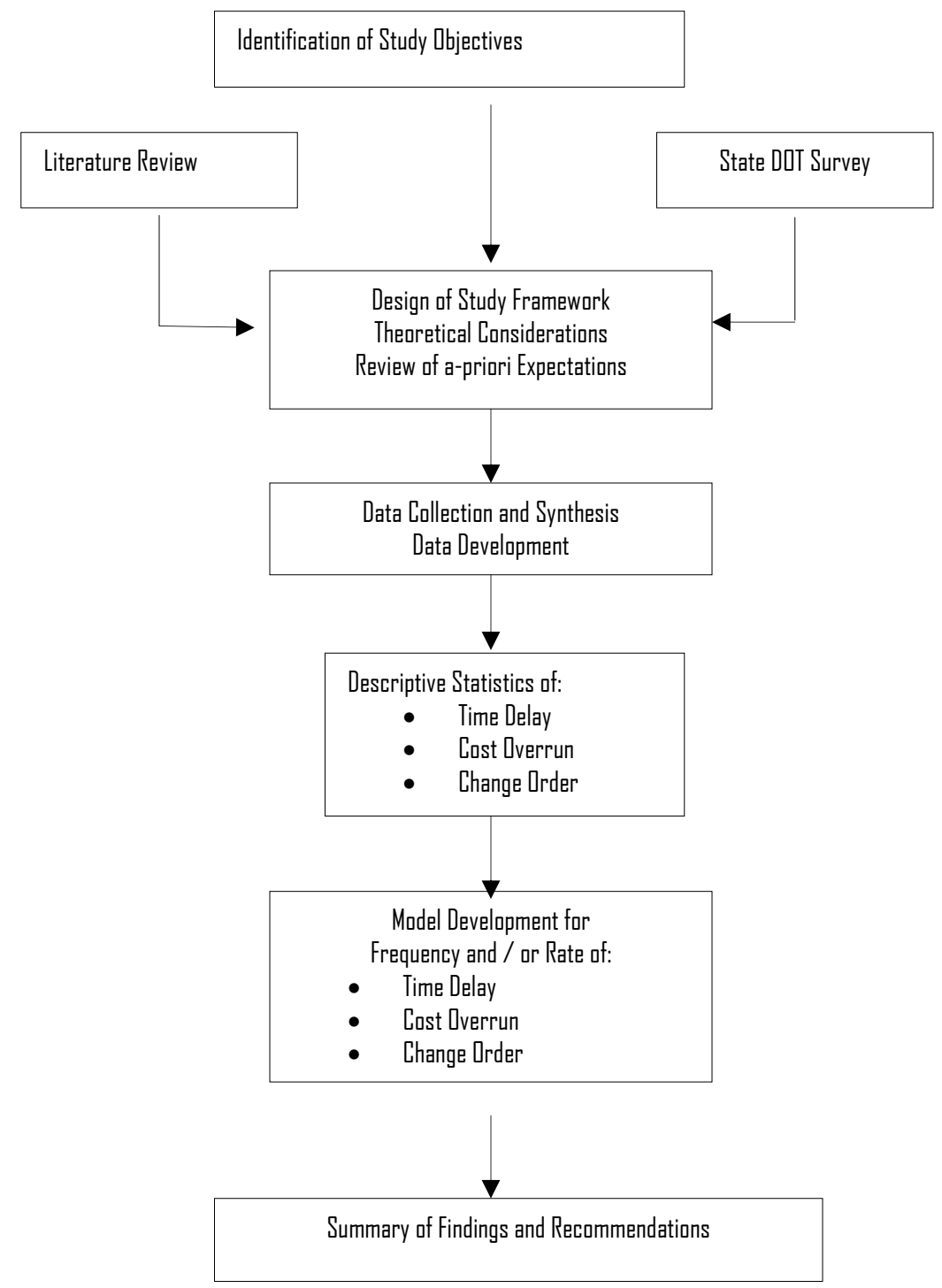

Figure 1.1: Overall Study Approach 
Chapter 1 of this report provides a general overview of the situation in Indiana concerning cost overruns and time delays for INDOT projects. This section also highlights the objectives and scope of the present study and provides a brief overview of the approach used in realizing the study objectives. The literature review in Chapter 2 presents and discusses past findings and experience of previous researchers in the areas related to the present study, such as change orders and root causes for time delays. Chapter 3, which complements Chapter 2, presents and discusses the results of a survey of state DOTs and provides a review of their contract management performances in terms of management of cost overruns and time delays. Chapter 4 presents a framework for the analyses, discusses the various methodologies used, and provides a theoretical basis to concepts used in the analysis for the present study. In Chapter 5, the details of data collection are briefly described, as well as how the raw data was processed and organized into a dataset using a format appropriate for the present (and possible future) analysis of cost overruns and time delays in Indiana. Chapter 6 gives a preliminary overview of the extent of the cost overruns and time delays problem in Indiana, using descriptive statistics. Chapter 7 provides a preliminary statistical analysis of the dataset with, for example, the analysis of variance and other statistical tools that enable an investigation of the trends that will appear in the models. Chapter 8 presents the final results of the modeling process for cost overruns, time delays, and change order prediction. Chapter 9 concludes the study with a summary of the findings. This chapter also discusses the challenges faced during the study, implementation issues, and areas for future investigation. In Chapter 10, recommendations are made for the reduction in the number of cost overruns and time delays and to improve efficiency of project management and contract administration. Implementation issues are discussed in Chapter 11. 


\section{CHAPTER 2: LITERATURE REVIEW}

\section{$2.1 \quad$ Introduction}

This chapter identifies previous literature on the subject of cost overruns and time delays, and provides a brief discussion of past findings. Also, the chapter reviews "standard taxonomy" that has been used in this area. The reasons for cost overruns, time delays, and change orders as found in previous studies are discussed, and examples of audit reports that analyze the problem of cost overruns in past studies are provided.

\subsection{Standard Taxonomy}

Delay occurs when the progress of a contract falls behind its scheduled program. It may be caused by any party to the contract and may be a direct result of one or more circumstances. A contract delay has adverse effects on both the owner and contractor (either in the form of lost revenues or extra expenses), often raises the contentious issue of delay responsibility, and may result in conflicts that frequently reach the courts.

With regard to remedial measures, there are three types of delay (Rowland, 1981):

Excusable delay: the contractor is given a time extension but no additional money.

Concurrent delay: neither party recovers any damages.

Compensable delay: the contractor recovers monetary damages.

Majid and McCaffer [1998] provided similar categories of delay, on the basis of identified responsible parties:

Compensable delays: responsibility borne by the client.

Non-excusable delays: responsibility borne by the contractor.

Excusable party delays: acts of God or a third party.

Cost overruns in construction contracts involve change orders and claims. Defining a "claim" as the proposed changes to the contract that are being negotiated or litigated, Jahren and Ashe [1990] identified two kinds of rates:

- The cost overrun rate, which is the percent difference in cost, (positive or negative) between the final contract cost and the contract award amount, 
- The change order rate, which is the ratio between the dollar amount of change orders and the award amount.

The "final amount" was defined as the cost of the contract including change orders, and outstanding claims and the dollar award amount is the dollar value at which the contract was awarded.

Change orders are "an indication that something on a construction project has not gone as planned” (Rowland, 1981), and are associated with contract alterations such as additions, deletions, or modifications to the contract. The consequences of change orders are additional cost, additional time or both. Contract change orders can be requested by the owner, the contractor or third parties such as local governments (O’Brien, 1998). Change orders are described as "unilateral” when signed only by the contractor, owner or the party authorized by the changes clause in the conditions of the contract. Change orders are referred to as "bilateral" when it is a mutual agreement or supplemental agreement. The price of a change order can be expressed as a lump sum, a unit price, or the cost plus a fee, which needs to be documented, estimated in terms of price and delay, and approved by both parties. A change order is just as legally binding as the original construction contract. Few construction projects are built without changes being made by the owner or by being necessary due to some unforeseen circumstance (Rowland, 1981). Therefore, it may not be possible for any transportation agency to completely eliminate change orders. Rather, efforts should be made to reduce their occurrence. According to contract law, parties to a contract may modify the contract at any time by mutual agreement. The owner's right to order changes is offset by the contractor's right to an equitable adjustment in the contract price and time, to cover the cost of the work as changed. A change order can imply extra or additional work, which are essentially two different concepts: extra work may not be necessary for project completion and can be independent of the contract. Additional work may be necessary because of errors or a change of plans and specifications.

Generally, the primary reasons for actual costs varying from a contractor's original bid price are changes in the scope of the work to be done and incorrect estimates of the work quantities included in the original bid specifications. Contractor errors include unnecessary work, work that is not according to design plans, and work or materials that do not meet contract specifications. On the other hand, contracting agency errors include planning and design deficiencies such as revisions in the scope of the work, added work, and revisions in quantities in the project design. Unforeseen circumstances include site conditions that differ from those described in the contract documents. 


\subsection{Causes of Time Delays}

Non-excusable delays are generally the responsibility of the contractor, and the agency may be entitled to claim damages. In studying non-excusable delays, Majid and McCaffer [1998] discussed methods to document the factors of non-excusable delays using a fishbone diagram and ranking methodology, the steps for which are explained below. The fish bone diagram, shown in Figure 1, enables the identification of contract problems at a micro level and consequently helps to search for the root causes. Majid and McCaffer defined 12 main causes:

1. Materials-related delays

2. Labor-related delays

3. Equipment-related delays

4. Financial delays

5. Improper planning

6. Lack of control

7. Subcontractor delays

8. Poor coordination

9. Inadequate supervision

10. Improper construction methods

11. Technical personnel shortages

12. Poor communication

Materials-related delays include late delivery, damage, or poor quality of materials. Laborrelated delays can be due to low motivation, poor communication or absenteeism. Equipment-related delays can be due to poor equipment planning. Improper planning can be due to a lack of experience. Financial-related delays concern financial planning or delayed payment to suppliers. Lack of control, poor coordination, technical personnel shortage and poor communication are representative of poor management of personnel and the whole agency. Improper construction method is related to items such as a wrong method statement. Subcontractor-related delays include not only items that are the fault of the subcontractor but also of the agency's employees because of absenteeism or slow mobilization. The problem of inadequate supervision concerns managers who, for instance, have too many responsibilities or few management skills. Each main cause of non-excusable delays comprises several contributing factors. Some factors, such as poor monitoring and control, poor planning, and lack of experience, are common to more than one main cause. A total of 25 factors were identified by Majid and McCaffer [1998] as shown in Table 2.1. 


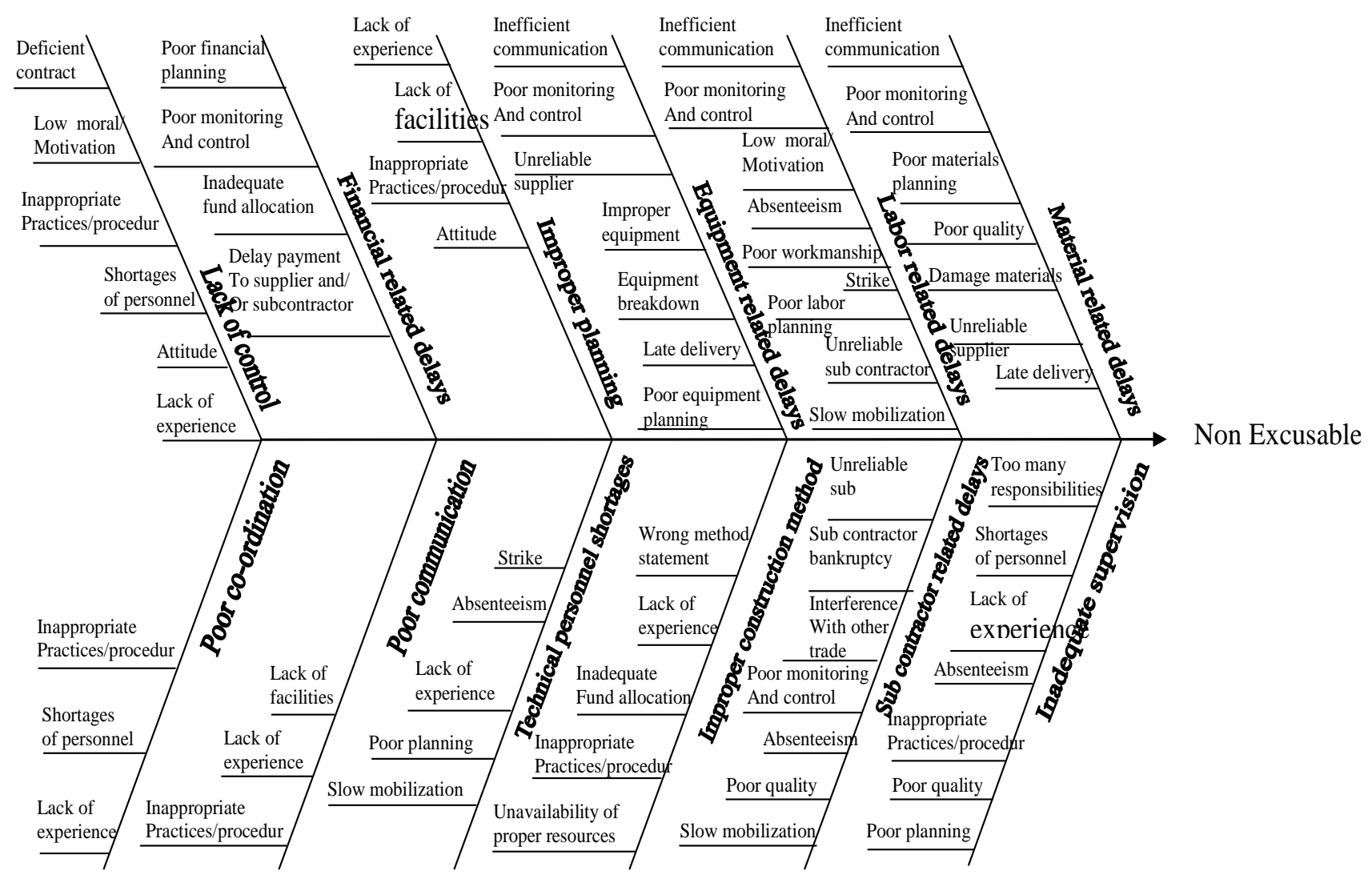

Figure 2.1: Contributory Factors of Non-Excusable Delay [Majid and McCaffer, 1998]

To assign rankings to the 25 factors, Majid and McCaffer utilized findings from eight studies related to construction delays. This involved 900 construction contracting organizations from both developed and developing countries between 1964 and 1995. The study results included the information showed in Table 2.1 which provides the main reasons for non excusable delays sorted by frequency. Table 2.1 shows that "late delivery or slow mobilization" is the main factor that leads to contractors' poor performance as it was ranked first in the eight studies. Majid and McCaffer recommended that construction managers adopt a systematic approach to identify the factors contributing to non-excusable delays in order to increase awareness of the perennially persistent factors and take the necessary proactive measures. 
Table 2.1: Ranking of Contributory Factors of Non-Excusable Delay

\begin{tabular}{lcc}
\hline \multicolumn{1}{c}{ Factor } & $\begin{array}{c}\text { Aggregate Rating } \\
\text { Based on Previous } \\
\text { Studies }\end{array}$ & Final Ranking \\
\hline Late delivery or slow mobilization & 8 & 1 \\
\hline Damaged materials & 22 & 2 \\
\hline Poor planning & 27 & 3 \\
\hline Equipment breakdown & 31 & 4 \\
\hline Improper equipment & 34 & 5 \\
\hline Unreliable supplier/subcontractor & 34 & 5 \\
\hline Inadequate fund allocation & 35 & 7 \\
\hline Poor quality & 36 & 8 \\
\hline Absenteeism & 44 & 9 \\
\hline Lack of facilities & 44 & 9 \\
\hline Inappropriate practices/procedures & 46 & 11 \\
\hline Lack of experience & 47 & 12 \\
\hline Attitude & 47 & 12 \\
\hline Poor monitoring and control & 48 & 14 \\
\hline Strike & 48 & 14 \\
\hline Shortages of personnel & 53 & 16 \\
\hline Delay payment to supplier/subcontractor & 53 & 16 \\
\hline Inefficient communication & 57 & 18 \\
\hline Wrong method statement & 59 & 19 \\
\hline Unavailability of proper resources & 59 & 23 \\
\hline Deficient contract & 61 & 21 \\
\hline Interference with other trades & 62 & 22 \\
\hline Too many responsibilities & 63 & 25 \\
\hline Subcontractor bankruptcy & 64 & 66 \\
\hline & & 29 \\
\hline
\end{tabular}

Source: Majid and McCaffer [1998]

Ellis and Thomas [2002] conducted a study to investigate the root causes of delays in highway construction. In their study, both excusable and non-excusable delays are considered. It was found that $31 \%$ to $55 \%$ of all highway projects experience an average time delay of $44 \%$ in excess of their original contract periods. It was observed that time delays occur more frequently for contracts in urban areas. The focus of that study was to identify the root causes of delays (not only for the apparent causes). A root cause is distinguished from an apparent cause by determining if the cause violated a fundamental principle and if the cause is known or developed in sufficient detail to allow corrective action to be taken (Ellis and Thomas, 2002). For example, an apparent cause may be plan errors; however, an in-depth investigation may ultimately determine that the root cause was a violation of the "time-cost” principle leading to easily recognizable mistakes. Generally, apparent causes are relatively many while root causes are relatively few in number. According to the authors, the main root causes of delays include business practices, procedures, utilities, unforeseen site conditions, contractor and State Highway Agencies management of scheduling and planning, maintenance of traffic work zones, and design errors and omissions. Table 2 summarizes the root causes identified by the Ellis and Thomas study [2002]. 


\subsection{Factors Affecting Cost-Overruns}

As defined in Section 2.2, the concepts of cost overrun rate and change order rate were used by Jahren and Ashe [1990] to analyze the problem of cost overruns. They considered that both cost overrun and change order rates are influenced by the same kinds of factors as listed below:

- $\quad$ project size

- difference between the selected bid and the government estimate

- type of construction

- level of competition

It was found that other non-quantifiable factors, such as the quality of the contract document, the nature of interpersonal relations on the project and the policies of the contractor, could have a significant impact on cost overruns. Jahren and Ashe's study [1990] also found that a cost overrun rate of $1-11 \%$ was more likely to occur on larger projects than smaller ones. The mode for the cost overrun rate for projects over $\$ 1,000,000$ is approximately $2 \%$ rather than near $0 \%$, which is typical for most categories, and the median cost overrun rate increases as the project size increases. A possible explanation for these results is that projects become more complex as they become larger so more cost overruns occur. However, on large projects, managers may make special efforts to keep cost overrun rates from becoming excessively large. Furthermore, Jahren and Ashe [1990] found that contracts with award amounts less than the government estimate were more likely to have cost overrun rates above $5 \%$ and that the risk of high cost overrun rates is greater when the amount is less than the government estimate. Finally, the study recommended that data for computation of the percent difference between award amounts and government estimates should be included in construction contract databases since it appears to influence the cost overrun rate. The design of the dataset of the present study was guided by such findings, but other directions were also followed in order to discover new factors that could influence cost overruns and change orders. 
Table 2.2: Root Causes of Highway Construction Delays

\begin{tabular}{|c|c|}
\hline Major Category & Root Causes \\
\hline \multirow{5}{*}{ Business Practices } & Business as usual \\
\hline & Most projects are treated alike \\
\hline & $\begin{array}{l}\text { For political and funding reasons, projects often need to be awarded based on an accelerated } \\
\text { schedule }\end{array}$ \\
\hline & Various team members have different objectives \\
\hline & Budgets restrict the expenditure of project fund across functional boundaries \\
\hline \multirow{2}{*}{ Procedures } & $\begin{array}{l}\text { There lacks team accountability for timely project completion: the decision maker weigh cost } \\
\text { benefits more heavily than time benefits; and SHA personnel and consultants called to the } \\
\text { project to solve technical problems sometimes do not have an adequate appreciation for the } \\
\text { need for a timely decision }\end{array}$ \\
\hline & $\begin{array}{l}\text { Construction expertise is not incorporated into the design: A shortage of experienced personnel } \\
\text { exist within the design industry; and because of time pressure, designers often leave problems } \\
\text { to be solved during construction }\end{array}$ \\
\hline \multirow{3}{*}{ Utilities } & $\begin{array}{l}\text { Utilities are unidentified or incorrectly located: Many smaller utilities have no as-built } \\
\text { drawings; often, the as-built drawings are incorrect; as-built location information may not } \\
\text { include vertical location; utility location information provided on drawings is not clear } \\
\text { particularly for complex intersections; and the standard of practice for designers with regard to } \\
\text { communicating utility information on drawings is not clearly defined }\end{array}$ \\
\hline & $\begin{array}{l}\text { Slow response by utilities to improve their processes: smaller utilities are restrained by funding } \\
\text { limitations }\end{array}$ \\
\hline & $\begin{array}{l}\text { Delays in the relocation of utilities: utilities companies may not see SHA work as a priority; } \\
\text { and SHA right of way agreements with utilities may not provide adequate terms and conditions } \\
\text { to obtain timely response from the utilities }\end{array}$ \\
\hline \multirow{3}{*}{$\begin{array}{l}\text { Differing or } \\
\text { Unforeseen Site } \\
\text { Conditions }\end{array}$} & $\begin{array}{l}\text { The information provided is inaccurate: conditions are known but not incorporated into the } \\
\text { design because of funding or time pressure issues; and the view point that site investigation is } \\
\text { done for design rather than for construction }\end{array}$ \\
\hline & $\begin{array}{l}\text { Conditions change after the design is complete: project pre-bid visits not done or ineffective; } \\
\text { conditions are unknown and SHA response time is slow; and pressure to get the project bid }\end{array}$ \\
\hline & $\begin{array}{l}\text { Conditions are unknown but are easily discoverable: constructability reviews are ineffective; } \\
\text { and site investigation data is used for design purposes and not for construction planning. }\end{array}$ \\
\hline \multirow{3}{*}{$\begin{array}{l}\text { Contractor and SHA } \\
\text { Management of } \\
\text { Scheduling and } \\
\text { Planning }\end{array}$} & $\begin{array}{l}\text { Inadequate planning by contractor: planning horizon is too short; and unit price contract forms } \\
\text { encourage work on high pay items that are not critical }\end{array}$ \\
\hline & $\begin{array}{l}\text { Inadequate scheduling by contractor: project schedules often do not match the way the work is } \\
\text { to be done; contractor planning management schedules are often overly complex and not } \\
\text { representative of the work plan; and schedule updating is either not done or not done correclty }\end{array}$ \\
\hline & $\begin{array}{l}\text { Inadequate review and administration by SHA: chosen scheduling format is not an appropriate } \\
\text { match for the project; initial review of the contractor's proposed schedule is inadequate; and } \\
\text { schedule update provisions are not enforced }\end{array}$ \\
\hline $\begin{array}{l}\text { Maintenance of } \\
\text { Traffic }\end{array}$ & $\begin{array}{l}\text { Maintenance of traffic focus on traffic management and often are lacking with regard to } \\
\text { constructability: MOT plans often do not represent the required construction process; MOT } \\
\text { plans often do not address worker safety issues; MOT plans often omit critical construction } \\
\text { steps }\end{array}$ \\
\hline $\begin{array}{l}\text { Design Errors and } \\
\text { Omissions }\end{array}$ & $\begin{array}{l}\text { Designers are not given sufficient time to produce quality designs; they are not accountable for } \\
\text { project performance during construction and there is a shortage of experience personnel within } \\
\text { the design industry particularly with regard to construction experience. }\end{array}$ \\
\hline
\end{tabular}




\subsection{Reasons for Change Orders.}

Rowland [1981] found that the change order rate increases with the contract size (in terms of the dollar value of a construction project). Both results can be explained: larger projects are generally more complex, and the complexity may increase the cost overrun rate. Upon analyzing data from 18 contracts, Rowland [1981] found that for large projects, communication channels become significantly longer and information feedback becomes distorted, possibly increasing the likelihood of a high number of change orders. The author contends that these factors could have an impact on project performance: the larger the absolute value of the difference between the owner's fair cost estimate and the low bid on a project, the greater the likelihood that a job will experience more change orders. Also, the greater the difference between the low bid and the next low bid, the greater the number of change orders. According to Rowland, this is logical in a competitive economy where there is an error in a low bid that is significantly lower than the next low bid whether or not the error is intentional. The low bidder who finally gets the job needs to attempt to recover his losses using change orders, and the number of change orders may increase with job complexity. Contracts involving heavy construction experience the greatest number of change orders per job, which is largely attributed to unforeseen conditions. Rowland [1981] found that the change order rate increased when the winning bid was below the government estimate.

From another perspective, it has been hypothesized that because the stakes are higher on larger projects, more care is probably exercised in the building and planning process, leading to a lower likelihood of cost overruns and time delays.

Jacoby (2001) with FHWA carried out a study on construction contract change orders. The study was completed in April 2001 and was based on 74 projects with a minimum cost of $\$ 10$ million and cost overruns of more than $25 \%$. The reasons cited for the change orders are indicated in Table 3. 
Table 2.3: Reasons for Change Orders Identified by FHWA

\begin{tabular}{|c|c|c|}
\hline Reason & $\begin{array}{l}\text { Number of } \\
\text { Projects }\end{array}$ & Remarks \\
\hline Packaging of project & 1 & Project bundled with another \\
\hline $\begin{array}{l}\text { Design revisions between FHWA approval and } \\
\text { actual advertisement. }\end{array}$ & 6 & 3 projects in one state \\
\hline Engineer's estimate was low/bids high. & 27 & $\begin{array}{l}\text { Some fuel price adjustments, } 1 \text { project cited } \\
\text { market conditions, some citations that size of } \\
\text { project or uniqueness of work affected bid } \\
\text { prices or state’s ability to estimate project. }\end{array}$ \\
\hline $\begin{array}{l}\text { Differing site conditions - geotechnical issues } \\
\text { (hazardous waste, muck excavation, additional } \\
\text { shoulder rehab required, additional pavement } \\
\text { patching) }\end{array}$ & 20 & - \\
\hline $\begin{array}{l}\text { Environmental and legal injunction with } \\
\text { construction delay costs }\end{array}$ & 1 & - \\
\hline Low design-build estimates & 3 & _- \\
\hline $\begin{array}{l}\text { Delays/accelerated roadway openings or work in } \\
\text { general }\end{array}$ & 10 & - \\
\hline $\begin{array}{l}\text { Design issues corresponds to construction } \\
\text { changes }\end{array}$ & 5 & $\begin{array}{l}\text { Omissions, issues that carried over to } \\
\text { construction }\end{array}$ \\
\hline Payment of incentives & 2 & \\
\hline $\begin{array}{l}\text { Construction Changes and miscellaneous } \\
\text { or no reasons cited }\end{array}$ & 13 & Minor scope changes or additional work orders \\
\hline Work zone traffic control & 1 & - \\
\hline
\end{tabular}

\subsection{Audit Reports}

An audit of construction contracts in the State of Washington established that the average cost overruns of $10 \%$ for 1998 highway projects were similar to other states (Korman and Daniel, 1998). However, 33\% of the total number of change orders (which represents $\$ 35.4$ million) could have been avoided. The cited causes were inadequate field investigation, unclear specifications, plan errors, design changes, or mistakes by a construction engineer. This audit revealed "modest areas of potential savings” (Korman and Daniel, 1998). It was found that the costs of larger projects tended to run over frequently, compared to smaller ones. Furthermore, about \$3 million a year could have been saved by cutting back on "no added value" change orders. Early project redesign was found to yield significant savings of money and time and was therefore advocated by the researchers.

In a study by the Office of Program Policy Analysis and Government Accountability that investigated the problem of cost overruns in the State of Florida, it was found that that state suffered from cost overruns of 9.5\% between July 1, 1995 and December 31, 1995, within 102 contracts and a total original bid amount of $\$ 302,700,000$ (Turcotte, 1996). However, the report did not indicate whether these contracts represented all contracts within that period or whether they were a random or representative sample. \$15.6 million of the \$28.6 million of cost overruns were considered 
“avoidable” costs. Furthermore, approximately $\$ 4.2$ million of the avoidable costs were considered wasted money because they did not add value for citizens. The Florida study sought to identify the responsibility for such "wasted money," which was supposedly shared among consultants (32\%), third parties (utility companies, permitting agencies, and local governments (55\%), and the highway agency staff (13\%). The report stated that cost overruns are perceived as being avoidable when they occur due to design plan or project management problems that were reasonably foreseeable and preventable. The reported further asserted that cost overruns may add value to projects by producing a better product, but duly noted that in many cases, cost overruns do not add value and are therefore considered as "wasted money." It was found that consultants and third parties in the Florida study were responsible for more avoidable cost overruns (38\% for both) than agency staff (24\%), but the part of cost overruns that do not add value to the project was less for consultants than for agency staff. Finally, in a bid to minimize cost overruns from occurring and to hold responsible parties accountable, Turcotte (1996) made the following recommendations for the Office for Program Policy Analysis and Government Accountability:

- Develop statewide criteria to assess the effectiveness of pursuing recovery of cost overruns that are attributable to consultants that do not add value to projects.

- Develop criteria for including avoidable cost overruns that do not add value in the selection process for awarding future contracts to consultants.

- Develop criteria for including avoidable cost overruns that do not add value in determining the constructability grades for design work.

- Provide an interim constructability grade during the construction process in addition to a final grade.

- Monitor responses to the monthly report of consultant performance grades.

- Modify DOT personnel policies and procedures to include evaluating DOT design staff for the impact of avoidable cost overruns that do not add value.

- Continue implementing strategies to improve the quality of construction plans to resolve plan problems prior to letting contracts for bid and monitor progress toward reducing cost overruns.

- Continue improving coordination with third parties to incorporate design changes and to identify utility lines as plans are developed to minimize cost overruns due to delays in making design changes during construction.

In Delaware (Wagner, 1998), the state DOT (DelDOT) experienced 13.9\% cost overruns between 1994 and 1996 with a total bid amount of \$114,200,000 for 148 contracts. From an economic and efficiency audit study commissioned by the state, Wagner [1998] found that the main causes were 
changes in the work scope and incorrect estimates of the work quantities in the original bid specifications. According to the author, these reasons are probably due to contractor error (unnecessary work, design plans, poor contract specifications), contracting agency error (planning and design deficiencies: scope of work, added work, and revisions in quantities) and unforeseen circumstances (archeological discovery). The report for that study concluded with a set of recommendations (Table 4) covering issues such as considering alternative options for higher costeffectiveness, developing bid a analysis system and a tracking system for project payment revisions, evaluating contractors, developing other performance measures, and updating the procedure manuals.

Table 2.4: Recommendations for Addressing Cost Overruns at DelDOT [Wagner, 1998].

\begin{tabular}{|c|c|}
\hline Number & Recommendations \\
\hline 1 & $\begin{array}{l}\text { Evaluation of the need for alternative contracting options to ensure that statutory and other regulatory } \\
\text { restrictions do not significantly impact the efficient use of taxpayers funds. For example, DelDOT could } \\
\text { consider a policy that would allow re-negotiation of unit prices in certain instances even though the } \\
\text { threshold for a Supplement Agreement is not reached. }\end{array}$ \\
\hline 2 & Completion of the development of the bid analysis system. \\
\hline 3 & $\begin{array}{l}\text { Completion of all aspects of the Project Payment Tracking System so that management has } \\
\text { comprehensive, reliable information regarding change orders. }\end{array}$ \\
\hline 4 & $\begin{array}{l}\text { Revision of contracts to allow the State to recover additional costs incurred as a result of errors and } \\
\text { omissions of consultants. }\end{array}$ \\
\hline 5 & $\begin{array}{l}\text { Continued establishment procedures that will ensure more accurate contract design quantities which will } \\
\text { provide better engineer estimates of costs before the project goes out to bid. }\end{array}$ \\
\hline 6 & $\begin{array}{l}\text { Continued formal tracking both preliminary design requests and input from plan reviewers. The plan } \\
\text { reviewers should be held accountable for non-compliance review deadlines. }\end{array}$ \\
\hline 7 & $\begin{array}{l}\text { Continued implementation of a formal budgetary control process which ensures that each change order } \\
\text { is afforded an appropriate level of management review. }\end{array}$ \\
\hline 8 & $\begin{array}{l}\text { Review of post construction contract review process to insure that its stated objective of decreasing plan } \\
\text { revisions, change orders, and construction claims is attained and resulting improvements to contract } \\
\text { economy and efficiency are documented. }\end{array}$ \\
\hline 9 & Completion of contractor evaluations and use as part of the pre-award evaluation process. \\
\hline 10 & $\begin{array}{l}\text { Implementation of a plan to ensure that highway construction contracts are afforded sufficient audit } \\
\text { coverage. }\end{array}$ \\
\hline 11 & $\begin{array}{l}\text { Development of additional performance measures to provide management with more comprehensive } \\
\text { data to assess performance. }\end{array}$ \\
\hline 12 & $\begin{array}{l}\text { Ensuring that DelDOT processes provide for appropriate reporting of performance measurement, such } \\
\text { as, consistent reporting periods. }\end{array}$ \\
\hline 13 & $\begin{array}{l}\text { Update of DelDOT’s Highway Construction Manual and the Contract Administration Procedures } \\
\text { Manual. }\end{array}$ \\
\hline
\end{tabular}


In response to the above recommendations, DelDOT indicated agreement with only some of them, adding that some were already being implemented and needed time for their effectiveness to be manifest. For instance, Recommendation \#7 would be addressed with Recommendation \#3 by completing the Project Payment Tracking System. Regarding Recommendation \#9, DelDOT stated that a decision had been made several years ago to carry out contractor evaluation. In Recommendation \#11 DelDOT considered that there was no "correct" number of performance measures and the fact that other states used more performance measures did not mean that the DelDOT system was deficient. Finally, for Recommendation \#13 DelDOT agreed with the need for regular updating of performance measures.

\subsection{Discussion of the Literature Review}

2.7

Figure 2.2 summarizes the main elements of the literature review and indicates how the findings of the review relate to the framework of the present study. First, the literature review enabled definition of key terms for the present study. Rowland's study [1981], for example, provided some terms and identified some influential factors affecting change orders. The discussions in Sections 2.3, 2.4, and 2.5 are the basis for comparing the results of the present study to the previous ones. The information in the present chapter provides an indication of issues faced by transportation agencies in managing cost overruns and time delays. While preparing the recommendations for INDOT, it may be helpful to make the distinction between root causes and apparent causes as defined in the Ellis and Thomas’ study [2002].

\subsection{Chapter Summary}

The literature review identified the problems of cost overruns and time delay with some new and external points of view and provided definitions of the key concepts. Previous studies identified some factors that influence cost overruns or time delays and developed tools that help address such problems. 
MAIN ELEMENTS OF THE LITERATURE REVIEW

\section{Taxonomy:}

Delay and its causes (excusable or not)

Cost overrun

Cost overrun rate

Change order

Change order rate

Responsibility for overruns

Apparent and root cause
STUDY METHODOLOGY

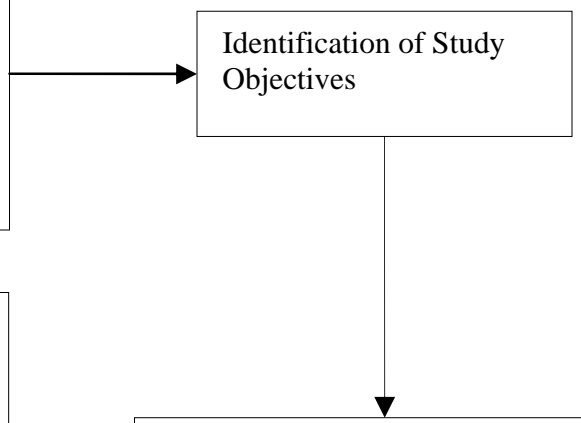

Project size

Difference between the selected bid and the agency estimate

Difference between the low bid and the next low bid Job complexity

Type of construction

Level of competition
Time Delay Issues

(Majid and McCaffer 1998; Ellis and Thomas, 2002)

Development of efficient system to keep track of the reasons for overruns

Improvement of bid, design and construction methods

Evaluation and awarding of performance

Improvement of coordination

Control of the changing budget and change orders

Follow-up
Design of Study Framework and Model Development

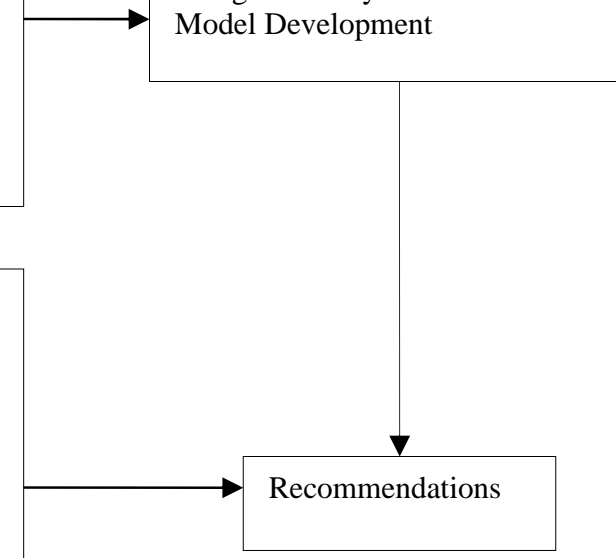

Figure 2.2: Relationship between Literature Review and Other Aspects of the Study 


\section{CHAPTER 3: $\quad$ AGENCY SURVEY}

\subsection{Introduction}

An agency survey was carried out to complement the findings from the literature review and to acquire current state of practice perspectives on the problem of cost overruns, time delay and change orders. The agency survey was also motivated by the success of a fairly recent similar effort by Jacoby (2001) who conducted an AASHTO-FHWA sponsored nationwide survey to ask DOTs about the various methods they use to manage cost overruns and time delays through their change order classifications. The experience of other states would therefore be helpful in establishing appropriate recommendations for INDOT. Two aspects of overruns were compared: the frequency and amount of cost overruns and time delays, and how such problems are addressed. An email solicitation (Appendix B) was distributed through the Research Division of INDOT and posted on a national DOT research list requesting information on cost overruns and time delays. This solicitation yielded 11 responses from other state DOTs in the form of either direct responses to email questions or provision of attached electronic documents. This chapter presents and discusses the responses to the agency survey conducted as part of the present study. The cost overrun amounts herein presented constitute an average of several contracts in any single year and therefore may not reveal variations of cost overruns and underruns across individual contracts. In subsequent chapters, both cost underruns and overruns, rather than their combined average, are presented separately using Indiana data.

\subsection{Cost Overruns and Time Delays: Results of the Agency Survey}

Eleven state transportation agencies responded to the e-mail request: Arkansas, Idaho, Illinois, Iowa, Maryland, Missouri, New Mexico, Ohio, Oregon, Tennessee, and Texas. The respondent from Arkansas indicated that his state is increasingly experiencing cost overruns, with a record cost overrun rate of over $10 \%$ occurring in 2001 . Table 3.1 shows the trends in cost overruns and time delays for Arkansas DOT projects from 1997 to 2002. 
Table 3.1: Cost Overruns and Time Delay in Arkansas

\begin{tabular}{lcccccc}
\hline Year & 1997 & 1998 & 1999 & 2000 & 2001 & 2002 \\
\hline $\begin{array}{l}\text { Total Number of } \\
\text { Contracts }\end{array}$ & 281 & 271 & 289 & 229 & 213 & 94 \\
\hline $\begin{array}{l}\text { Number of Time } \\
\text { Overrun Contracts }\end{array}$ & 83 & 94 & 81 & 98 & 50 & 11 \\
\hline $\begin{array}{l}\text { Percentage of Time } \\
\text { Overrun Contracts }\end{array}$ & $29.54 \%$ & $34.69 \%$ & $28.03 \%$ & $42.79 \%$ & $23.47 \%$ & $11.70 \%$ \\
\hline $\begin{array}{l}\text { Number of Cost } \\
\text { Overrun Contracts }\end{array}$ & 155 & 165 & 178 & 114 & 118 & 56 \\
\hline $\begin{array}{l}\text { Percentage of Cost } \\
\text { Overrun Contracts }\end{array}$ & $55.16 \%$ & $60.89 \%$ & $61.59 \%$ & $49.78 \%$ & $55.40 \%$ & $59.57 \%$ \\
\hline Cost Overrun & $\$ 13,271,341$ & $\$ 27,316,195$ & $\$ 17,624,444$ & $\$ 3,277,792$ & $\$ 23,024,593$ & $\$ 1,671,183$ \\
\hline Bid Amount & $\$ 292,472,031$ & $\$ 406,309,328$ & $\$ 344,829,578$ & $\$ 241,155,482$ & $\$ 219,641,022$ & $\$ 40,940,105$ \\
\hline Cost Overrun Rate & $4.54 \%$ & $6.72 \%$ & $5.11 \%$ & $1.36 \%$ & $10.48 \%$ & $4.08 \%$ \\
\hline Source: Arkansas DOT (2002), email correspondence & & & & &
\end{tabular}

Table 3.1 shows that within the time period under consideration, the percentage of Arkansas DOT contracts with time overruns was between 11.7 and $42.8 \%$, while $49.8 \%$ to $61.1 \%$ of contracts had cost overruns. Generally, over $50 \%$ of all contracts experienced cost overruns in that state. The situation at the state of Idaho is similar: 9.19\% of contracts had overruns in the year 2001 . Table 3.2 shows that 54.7 to $67.5 \%$ of Idaho DOT contracts had cost overruns between 1997 and 2001 and state highway contracts at that state experienced increasing problems with cost overruns.

Table 3.2: Cost Overruns in Idaho between Fiscal Years 1997 and 2001

\begin{tabular}{lccccc}
\hline \multicolumn{1}{c}{ Year } & 1997 & 1998 & 1999 & 2000 & 2001 \\
\hline Bid Amount & $\$ 95,922,292$ & $\$ 115,486,029$ & $\$ 138,517,432$ & $\$ 64,304,580$ & $\$ 90,222,751$ \\
\hline Final Cost & $\$ 100,566,782$ & $\$ 121,428,479$ & $\$ 147,168,090$ & $\$ 71,315,274$ & $\$ 98,515,323$ \\
\hline Cost Overrun Rate & $4.84 \%$ & $5.15 \%$ & $6.25 \%$ & $10.90 \%$ & $9.19 \%$ \\
\hline Average Overrun & $\$ 67,311$ & $\$ 57,139$ & $\$ 113,824$ & $\$ 107,587$ & $\$ 113,597$ \\
\hline Total Annual Overrun & $\$ 4,644,490$ & $\$ 5,942,450$ & $\$ 8,650,659$ & $\$ 7,010,694$ & $\$ 8,292,572$ \\
\hline $\begin{array}{c}\text { Percentage of Contracts } \\
\text { with Cost Overruns }\end{array}$ & $54.70 \%$ & $67.53 \%$ & $62.30 \%$ & $67.70 \%$ & $64.60 \%$ \\
\hline
\end{tabular}

Source: Idaho DOT (2002), email correspondence

In the state of Illinois, 42 closed-out projects in 2001 had liquidated damages (which are associated with time delays) that amounted to approximately $\$ 400,000$. No information was given about cost overruns. 
The Iowa Department of Transportation estimated that $75 \%$ of their contracts have cost overruns and/or time delays. The respondent for that agency stated that the average cost overrun is approximately 5\%, and that the annual amount of cost overruns depends on the amount of work accomplished, and typically ranges between \$16 million and \$25 million. Cost overruns and time delays were largely attributed to inaccurate plan quantities, plan changes, and site conditions.

Cost overruns on Maryland projects typically range from $4 \%$ to $6 \%$. At that state, a large percentage of time overruns are resolved through “justified” time extensions.

For the State of Missouri, the survey respondent stated that, between 1999 and 2002, cost overruns fluctuated over the period, ranging from a low of $1.33 \%$ to a high of 5.22\%. The 2001 fiscal year had only $1.33 \%$ cost overruns (Table 3.3).

Table 3.3: Cost Overruns at Missouri DOT between Fiscal Years 1999 and 2002

\begin{tabular}{lccccc}
\hline & $\begin{array}{c}\text { Fiscal Year } \\
1999\end{array}$ & $\begin{array}{c}\text { Fiscal Year } \\
2000\end{array}$ & $\begin{array}{c}\text { Fiscal Year } \\
2001\end{array}$ & $\begin{array}{c}\text { Fiscal Year } \\
2002\end{array}$ & Total \\
\hline Number of Contracts & 220 & 227 & 152 & 71 & 670 \\
\hline Beginning Date & $7 / 1 / 1999$ & $7 / 1 / 2000$ & $7 / 1 / 2001$ & $7 / 1 / 2002$ & $7 / 1 / 1999$ \\
\hline Ending Date & $6 / 30 / 2000$ & $6 / 30 / 2001$ & $6 / 30 / 2002$ & $11 / 14 / 2002$ & $11 / 14 / 2002$ \\
\hline $\begin{array}{l}\text { Total original } \\
\text { contract amount }\end{array}$ & $\$ 380,447,304$ & $\$ 406,692,618$ & $\$ 217,039,579$ & $\$ 154,961,759$ & $\$ 1,159,141,260$ \\
\hline $\begin{array}{l}\text { Total current } \\
\text { contract amount }\end{array}$ & $\$ 396,508,590$ & $\$ 427,928,541$ & $\$ 219,930,439$ & $\$ 157,218,314$ & $\$ 1,201,585,883$ \\
\hline $\begin{array}{l}\text { Total difference } \\
\text { for all contracts }\end{array}$ & $\$ 16,061,285$ & $\$ 21,235,923$ & $\$ 2,890,860$ & $\$ 2,256,555$ & $\$ 42,444,623$ \\
\hline $\begin{array}{l}\text { Total Percentage of change, } \\
\text { all contracts }\end{array}$ & $4.22 \%$ & $5.22 \%$ & $1.33 \%$ & $1.46 \%$ & $3.66 \%$ \\
\hline $\begin{array}{l}\text { Number of Contracts } \\
\text { with Cost Overruns }\end{array}$ & 131 & 142 & 98 & 44 & 415 \\
\hline $\begin{array}{c}\text { Percentage of Contracts } \\
\text { with Cost Overruns }\end{array}$ & $59.55 \%$ & $62.56 \%$ & $64.47 \%$ & $61.97 \%$ & $61.94 \%$ \\
\hline \begin{tabular}{l} 
Source: Missouri DOT (2002), \\
\hline
\end{tabular}
\end{tabular}

Source: Missouri DOT (2002), email correspondence

Table 3.3 shows that about sixty percent of Missouri DOT contracts experienced cost overruns. While the cost overrun rate seems rather high, the amount of cost overruns at Missouri DOT is generally lower than for other states because Missouri probably incurs relatively lower expenditure on transportation projects.

At New Mexico DOT, 73 projects were completed in 2002 fiscal year. The total original bid amount was approximately \$304 million and the total final contract amount was about \$316 million. Consequently, the difference was approximately \$12 million, representing an overall average overrun of 3.9\%. Forty-five contracts (61.1\%) experienced cost overruns; seven contracts (9.6\%) experienced time overruns (those for which liquidated damages were applied); and 33 contracts (45.2\%) experienced time extensions. The average cost overrun was about $\$ 162,000$ per project. The New 
Mexico Department of Transportation incurred approximately $\$ 16,493,000$ on overruns and "saved" $\$ 4,607,578$ on underruns. The net annual overrun amount in 2002 was therefore approximately \$12 million. The major causes of overruns in percentage of annual net overrun amount were identified as follows:

Extra work (40\%)

Traffic control modifications (6\%)

Design oversight (16\%)

Miscellaneous adjustment to bid quantities (6\%)

Incentive/disincentive payments (21\%)

Claim settlements (6\%)

At Ohio DOT, cost overrun and time delay projects ranged between $80 \%$ to $92 \%$ and $45 \%$ to $55 \%$, respectively, for all projects. The annual cost averages range from a low of approximately $\$ 76$ million in 1995 to a high of over \$196 million in 1999. Not only do these numbers seem rather high compared to other states, but they also indicate an increasing trend of average cost overruns. According to the respondent, the cost overruns are attributed to the difference between planned and actual construction quantities (approximately \$2.6 billion over eight years) and work changes that were deemed unpreventable (approximately $\$ 1$ billion over eight years).

Table 3.4: Ohio DOT Cost Overruns, 1994 - 1997

\begin{tabular}{lcccc}
\hline \multicolumn{1}{c}{ Year } & 1994 & 1995 & 1996 & 1997 \\
\hline Total Number of Projects & 793 & 665 & 783 & 778 \\
\hline Number of Projects with Cost Overruns & 719 & 610 & 720 & 716 \\
\hline Proportion of Projects with Cost Overruns & $90.67 \%$ & $91.73 \%$ & $91.95 \%$ & $92.03 \%$ \\
\hline Number of Projects with Time Extensions & 355 & 361 & 435 & 373 \\
\hline Proportion of Projects with Time Delays & $44.77 \%$ & $54.29 \%$ & $55.56 \%$ & $47.94 \%$ \\
\hline Annual Cost Overruns & $\$ 96,383,928.04$ & $\$ 76,335,671.89$ & $\$ 94,600,976.99$ & $\$ 136,787,513.53$ \\
\hline Average Cost Overrun per Contract & $\$ 121,543.41$ & $\$ 114,790.48$ & $\$ 120,818.62$ & $\$ 175,819.43$ \\
\hline
\end{tabular}

Source: Ohio DOT(2002), email correspondence

Table 3.5: Ohio DOT Cost Overruns 1998 - 2001

\begin{tabular}{lcccc}
\hline \multicolumn{1}{c}{ Year } & 1998 & 1999 & 2000 & 2001 \\
\hline Total Number of Projects & 758 & 796 & 604 & 574 \\
\hline Number of Projects with Cost Overruns & 685 & 720 & 535 & 456 \\
\hline Proportion of Projects with Cost Overruns & $90.37 \%$ & $90.45 \%$ & $88.58 \%$ & $79.44 \%$ \\
\hline Number of Projects with Time Extensions & 372 & 385 & 309 & 302 \\
\hline Proportion of Projects with Time Delays & $49.08 \%$ & $48.37 \%$ & $51.16 \%$ & $52.61 \%$ \\
\hline Annual Cost Overruns & $\$ 118,682,969.33$ & $\$ 196,520,134.89$ & $\$ 154,992,070.17$ & $\$ 136,187,887.81$ \\
\hline \multicolumn{1}{c}{ Average Cost Overrun per Contract } & $\$ 156,573.84$ & $\$ 246,884.59$ & $\$ 256,609.39$ & $\$ 237,261.13$ \\
\hline
\end{tabular}


The management of cost overruns at Oregon is quite sophisticated. After a project is awarded, an authorized spending limit is set. This limit is called the original authorization, and includes bid item amounts, estimated engineering, anticipated items, and a small amount of contingency funds. As the project progresses, the estimated project cost is tracked, which includes change orders and overrun of bid items. Authorization is delegated to various levels to approve overruns of the project. When it is imminent that a project would overrun its authorization by $\$ 500,000$ or more, ODOT staff are required to make a request to the Oregon Transportation Commission to have the authorization increased. If the authorization is increased, then they have a "new authorization level." If there no request to increase the authorization, then the original (or previously approved) authorization level remains. Because the current authorization is greater than or equal to the original authorization, the total project cost can only exceed the current authorization by an amount less than or equal to the amount over original authorization. For example, if the original authorization is $\$ 1,500,500$, the current authorization is $\$ 2,000,000$, and the total project cost is $\$ 2,320,000$, then the amount over original authorization would be $\$ 2,320,000$ less $\$ 1,500,500$ or $\$ 819,500$ and the amount over current authorization becomes $\$ 2,320,000$ less $\$ 2,000,000$ or $\$ 320,000$. Among the surveyed state agencies, Oregon DOT appears to be the only state that processes a corrective action on project cost when major additional investments are needed.

Table 3.6: Cost Overruns at Oregon DOT, 1998 - 2002

\begin{tabular}{lcccccc}
\hline & & 1998 & 1999 & 2000 & 2001 & 2002 \\
\hline \multirow{2}{*}{$\begin{array}{c}\text { Percentage } \\
\text { of } \\
\begin{array}{c}\text { Projects } \\
\text { Exceeding }\end{array}\end{array}$} & Original Completion Date & $65.00 \%$ & $54.80 \%$ & $51.40 \%$ & $42.00 \%$ & $14.80 \%$ \\
\cline { 2 - 6 } & Original Authorized Amount & $32.60 \%$ & $31.30 \%$ & $34.30 \%$ & $36.20 \%$ & $18.50 \%$ \\
\hline & New Authorized Amount & $26.30 \%$ & $26.70 \%$ & $28.60 \%$ & $33.30 \%$ & $18.50 \%$ \\
\hline $\begin{array}{l}\text { Average } \\
\text { Amount } \\
\text { Over }\end{array}$ & Original Authorization & $\$ 200,445$ & $\$ 249,822$ & $\$ 111,146$ & $\$ 54,547$ & $\$ 82,636$ \\
\hline $\begin{array}{l}\text { Total } \\
\text { Amount } \\
\text { Over }\end{array}$ & New Authorization & $\$ 124,680$ & $\$ 75,035$ & $\$ 52,066$ & $\$ 54,645$ & $\$ 82,636$ \\
\cline { 2 - 7 } & Original Authorization & $\$ 11,425,382$ & $\$ 10,242,701$ & $\$ 4,001,246$ & $\$ 1,363,667$ & $\$ 413,178$ \\
\hline Source: Oreg Authorization & $\$ 5,735,277$ & $\$ 2,626,236$ & $\$ 1,561,981$ & $\$ 1,256,843$ & $\$ 413,178$ \\
\hline
\end{tabular}

Source: Oregon DOT (2002), email correspondence

For contracts at Tennessee DOT, cost overrun rates have averaged approximately $6 \%$ over the years 1998-2002, and approximately $14 \%$ of their projects have experienced time delays. This translates to increased contract costs of almost \$40 million a year (Table 3.7). 
Table 3.7: Cost Overruns for Paid-off Tennessee DOT Projects, 7/01/98 to 9/13/02

\begin{tabular}{lc}
\hline \multicolumn{1}{c}{ Category } & Amount or Percentage \\
\hline Original Contract Amount & $\$ 2,642,879,835.72$ \\
\hline Contract Expenditure & $\$ 2,857,739,999.82$ \\
\hline Supplemental & $\$ 58,282,515.63$ \\
\hline Supplemental Rate & $2.21 \%$ \\
\hline Cost Overrun & $\$ 156,577,648.47$ \\
\hline Cost Overrun Rate & $5.92 \%$ \\
\hline Total Average & $\$ 214,860,164.10$ \\
\hline Rate for Total & $8.13 \%$ \\
\hline Total Number of Contracts & 2196 \\
\hline Number of Contracts with Liquidated Damages & 306 \\
\hline \%Percentage of Contracts Not Completed on Time & $13.93 \%$ \\
\hline Source: Tennessee (2002), email correspondence &
\end{tabular}

The Texas data indicate a consistency in cost and time overruns over the years. Tables 3.8 and 3.9 show that between 1998 and 2002 the percentage of cost overruns at Texas varied between $4.5 \%$ to approximately $7 \%$. The percentage of contracts with cost overruns varied between $66 \%$ and $75 \%$. The percentage of contracts with time delays indicated a steady trend, ranging from $52 \%$ to $56 \%$.

Table 3.8: Cost and Time Overruns at Texas DOT, 1998 - 2000

\begin{tabular}{lccc}
\hline & Year 1998 & Year 1999 & Year 2000 \\
\hline Number of Contracts & 938 & 1006 & 973 \\
\hline Total Original Contract Amount & $\$ 1,794,584,651.23$ & $\$ 2,027,903,107.51$ & $\$ 2,293,376,095.56$ \\
\hline Total Final Contract Amount & $\$ 1,874,255,325.59$ & $\$ 2,128,140,882.90$ & $\$ 2,395,615,416.08$ \\
\hline Total Difference for all Contracts & $\$ 79,670,674.36$ & $\$ 100,237,775.39$ & $\$ 102,239,320.52$ \\
\hline Total Percentage of Change, all Contracts & $4.44 \%$ & $4.94 \%$ & $4.46 \%$ \\
\hline Percentage of Contracts with Time Overruns & $51.81 \%$ & $51.89 \%$ & $52.72 \%$ \\
\hline Percentage of Contracts with Cost Overruns & $66.52 \%$ & $66.90 \%$ & $72.15 \%$ \\
\hline
\end{tabular}

Source: Texas DOT(2002), email correspondence

Table 9: Cost and Time Overruns at Texas DOT, 2001, 2002 and 1998 - 2002

\begin{tabular}{lccc}
\hline & Year 2001 & Year 2002 & $1998-2002$ (Total) \\
\hline Number of Contracts & 939 & 474 & 2917 \\
\hline Total Original Contract Amount & $\$ 1,961,075,393.58$ & $\$ 1,084,532,144.86$ & $\$ 6,115,863,854.30$ \\
\hline Total Current Contract Amount & $\$ 2,096,861,510.82$ & $\$ 1,153,147,241.27$ & $\$ 6,398,011,624.57$ \\
\hline Total Difference for all Contracts & $\$ 135,786,117.24$ & $\$ 68,615,096.41$ & $\$ 282,147,770.27$ \\
\hline Total Percentage of Change, all Contracts & $6.92 \%$ & $6.33 \%$ & $4.61 \%$ \\
\hline Percentage of Contracts with Time Overruns & $53.57 \%$ & $56.54 \%$ & $52.93 \%$ \\
\hline Percentage of Contracts with Cost Overruns & $75.19 \%$ & $72.57 \%$ & $70.42 \%$ \\
\hline
\end{tabular}

Source: Texas DOT(2002), email correspondence 


\subsection{Cost and Time Overruns: Comparison among States}

A comparative analysis of cost and time overruns between the responding states was carried out (Table 3.10), and revealed interesting trends. The majority of DOT contracts experience cost overruns and the cost overrun amounts vary between states and are dependent on the volume of contract. Causes are described in general terms. The distribution of time delays exhibits a wider range of variation - this may be attributed to a lack of precision in the definition (and consequently, estimation) of time delays. For instance, INDOT time delays are computed on the basis of liquidated damages which may not representative of all kinds of time delays. However, INDOT is at the lower end of the range for both cost overruns and time delays.

Table 3.10: Comparison of Cost Overruns at Selected States

\begin{tabular}{|c|c|c|c|c|}
\hline State & Period & $\begin{array}{l}\text { Percentage of } \\
\text { Projects with } \\
\text { Cost Overruns } \\
\end{array}$ & $\begin{array}{c}\text { Annual Amount } \\
\text { Spent on Cost } \\
\text { Overruns }\end{array}$ & $\begin{array}{c}\text { Percentage of Projects } \\
\text { with Time Overruns }\end{array}$ \\
\hline Arkansas & 1997 to 2002 & $\mathrm{NI}$ & NI & $\mathrm{NI}$ \\
\hline Idaho & 1997 to 2001 & $55 \%-67 \%$ & $\$ 5$ - 9 million & NA \\
\hline Illinois & $\mathrm{NI}$ & NI & $\mathrm{NI}$ & $\mathrm{NI}$ \\
\hline Indiana & 1996 to 2002 & $55 \%$ & $\$ 26$ - 45 million & $12 \%$ \\
\hline Iowa & NA & NA & \$16 - 25 million & NA \\
\hline Maryland & NA & NA & NA & NA \\
\hline Missouri & 1999 to 2002 & $60 \%-64 \%$ & $\$ 2$ - 42 million & $\mathrm{NI}$ \\
\hline New Mexico & 2002 & $62 \%$ & $\$ 11.9$ million & $10 \%$ \\
\hline Ohio & 1994 to 2001 & $80 \%-92 \%$ & $\$ 76$ - 196 million & $44 \%-56 \%$ \\
\hline Oregon & 1998 to 2002 & $18 \%-33 \%$ & $\$ 0.4-5.7$ million & $15 \%-65 \%$ \\
\hline Tennessee & 1998 to 2002 & $61 \%$ & $\$ 40$ million & $14 \%$ \\
\hline Texas & 1998 to 2002 & $66 \%-75 \%$ & $\$ 68$ - 282 million & $52 \%-55 \%$ \\
\hline
\end{tabular}

The following four figures summarize the findings concerning performance in terms of cost overruns (amounts and rates) of the survey respondents. Few states are represented because the responding states did not provide information in a consistent format. 


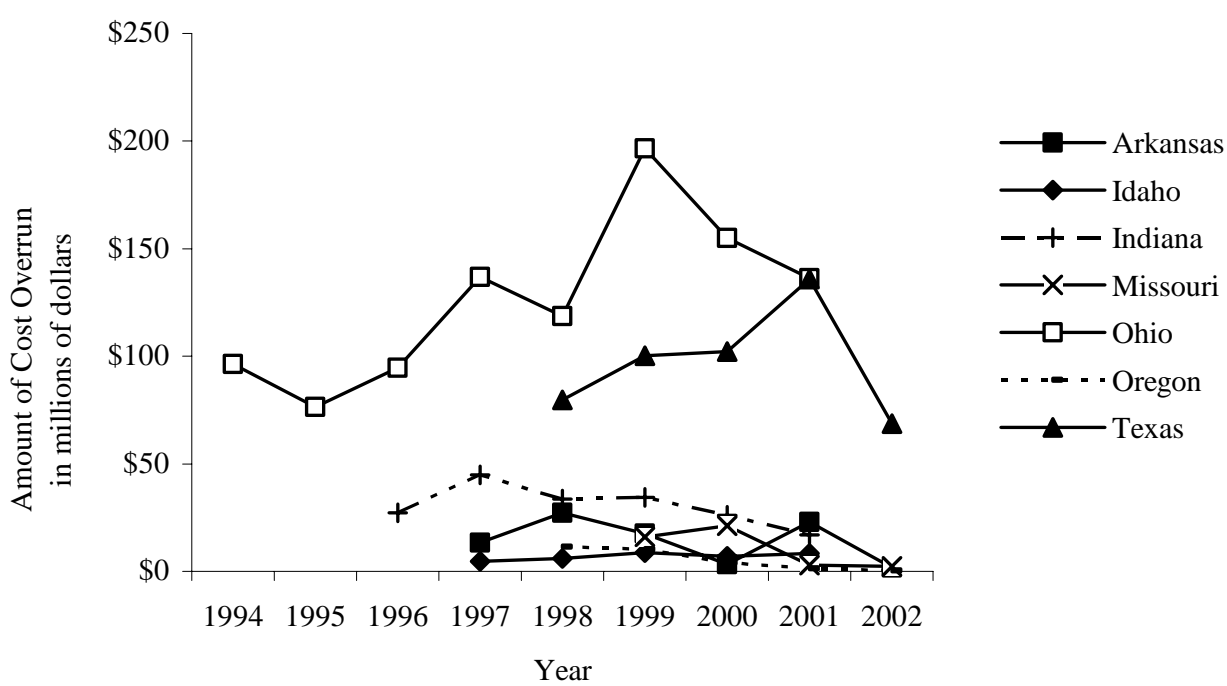

Figure 3.1: Amount of Cost Overruns at Selected States

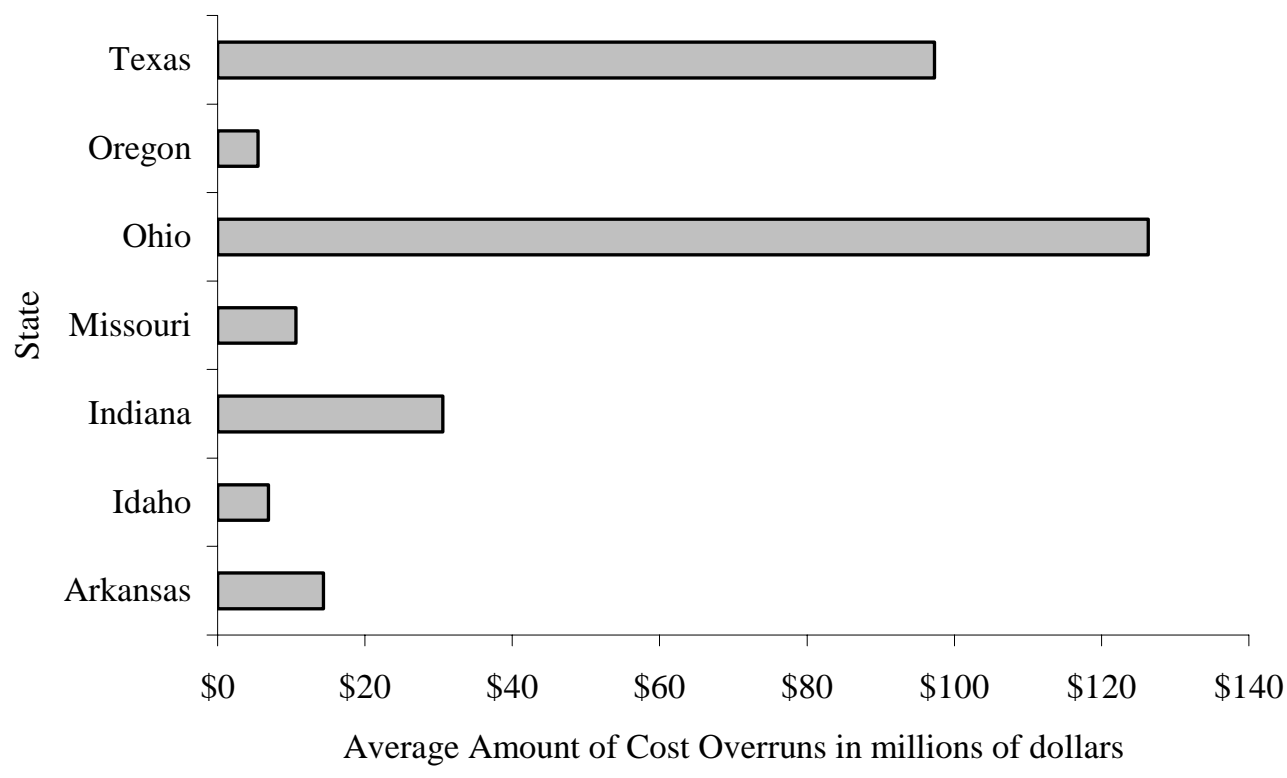

Figure 3.2: Average Annual Amount of Cost Overruns at Selected States 
Figure 3.1 shows that Texas and Ohio DOTs experience the most significant amount of cost overruns each year, but the figure also shows that since 1999 (for Ohio) and since 2001 (for Texas), this annual amount of cost overruns has decreased. Indiana is actually in a relatively "good" position in terms of cost overruns. Figure 33 presents the relative average rate of cost overruns, taken over the years 1997 to 2001.

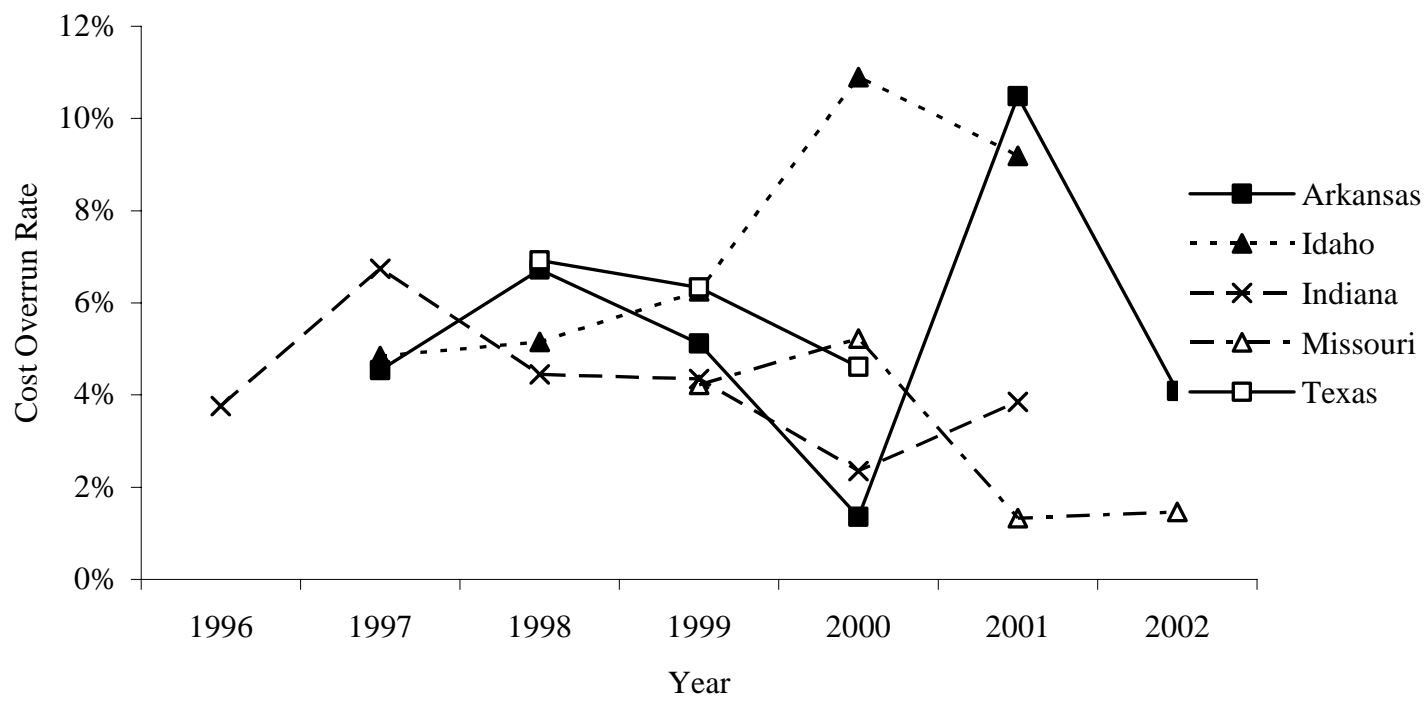

Figure 3.3: Cost Overrun Rates at Selected States

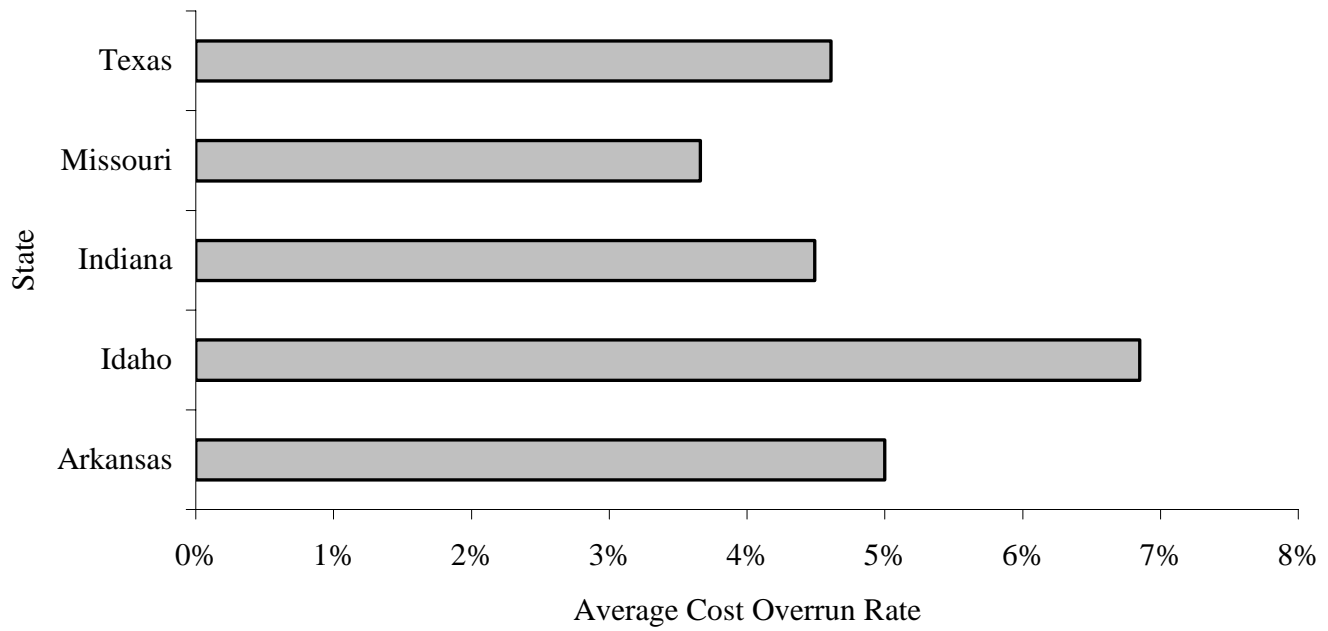

Figure 3.4: Average Annual Cost Overrun Rates at Selected States 
Figures 3.3 and 3.4 represent fewer states than Figures 3.1 and 3.2 because information concerning cost overruns rates was not made available by some respondents. The average cost overrun rate varies between approximately 3.4 and $6.8 \%$. It is seen from the figures that Idaho has the least total cost overrun amount but has the highest cost overrun rate (cost overrun amount per bid amount). With regard to cost overrun rates, it is seen that Indiana is in a relatively good position ranking, fourth out of the five states in order of cost overrun rate (or severity).

\subsection{Tracking Change Orders: Comparison among States}

Some states have developed a precise method to classify their change orders. For such states, change orders constitute vital clues in the identification of reasons for cost and time over/under runs. At the time of reporting, twenty-four states had in place a process for classifying change orders (Alaska, Arizona, Arkansas, California, Connecticut, Florida, Indiana, Iowa, Kentucky, Louisiana, Michigan, Minnesota, New Hampshire, New Jersey, New Mexico, New York, North Dakota, Ohio, Pennsylvania, South Dakota, Texas, Utah, Washington and Wisconsin). The FHWA (Jacoby, 2001) has developed a model which could be used to classify change orders, the basic structure as follows:

1. Physical Work Categories (Additional or extra work out of scope, Contract document revisions and oversights, Contract term adjustments, Changed and unforeseen condition).

\section{Administrative Category}

INDOT follows the above basic structure suggested by FHWA. The specific method developed by INDOT to classify and track its change orders is given in Appendix A. Methods for other states are shown in Appendix C. The relative degree of simplicity of each state's approach is shown in Table 3.11.

Table 3.11: Relative Simplicity of Change Order Classification at Selected State DOTs

\begin{tabular}{ccc}
\hline Very Detailed & Simple but Effective & Simplest \\
Classification & Classification & Classification \\
\hline California & Arizona & \\
Indiana & Arkansas & Alaska \\
Minnesota & Connecticut & Iowa \\
New Jersey & Florida & Louisiana \\
Ohio & Kentucky & Michigan \\
South Dakota & New Mexico & New Hampshire \\
Utah & New York & North Dakota \\
Texas & Pennsylvania & \\
Washington & Wisconsin & \\
\hline Source: Jacoby, 2001, email correspondence &
\end{tabular}


DOTs of states such as Washington, Ohio, and Texas have developed very detailed classification systems for tracking change orders. It would be useful to ascertain how such agencies use their classifications to improve project management. It can be assumed, therefore, that states with fewer problems in terms of cost and time overruns typically do not have detailed classification system as is available at Washington and Texas.

\subsection{Chapter Summary}

$100 \%$ of all respondents indicated concern about the issue of cost overruns, time delays and change orders. It may be argued that such concern is reflective of state DOTs nationwide. Indiana seems to be in an "average" position in terms of the percentage of projects with cost overruns and time delays, even though the state incurs significant amounts (\$26-45 million per year) due to these problems. The relatively good performance at INDOT can be attributed to the existence of an effective classification and tracking system for the change orders. However, it is obvious that there is still room for improvement, and in a subsequent chapter, the present study identify avenues for such further enhancements to the existing system. 


\section{CHAPTER 4: STUDY METHODOLOGY}

\subsection{Introduction}

This chapter explains the overall framework, methods, and underlying assumptions for analyzing the problem of cost overruns, time delays and change orders in Indiana. Figure 4.1 presents an overview of the steps. The methodology includes preliminary descriptive statistics that examines the general temporal and spatial trends in the data. It also includes correlation matrix analysis, pairwise tests, analysis of variance, and statistical modeling. The methodologies include definitions of dependent variables (cost overrun amounts and rates, time delay and change orders) and potential influential factors (independent variables), and selection of model categories and appropriate mathematical forms. Also, techniques used for model calibration and validation are discussed in the present chapter. The methodology was designed to yield statistical models with a view to predict cost overruns and time delays, but more importantly, to identify significant factors that influence cost overruns, time delays and the frequency of change orders.

\subsection{Descriptive Statistics}

The present study seeks to identify the main reasons and responsibilities for change orders, among others, and it is expected that a descriptive statistical analysis would throw more light on this issue. For cost overruns and time delays, descriptive statistical analysis in terms of their frequency and amounts was carried out. Simple descriptive graphs (histograms) may show any variations in such attributes by geographical location, type of project or year of implementation. Moreover, descriptive figures such as pie charts easily and readily show the relative significance of various categories of cost overruns. A description of the distribution and frequency of each type of change order can help understanding the extents and root causes of the problem. 


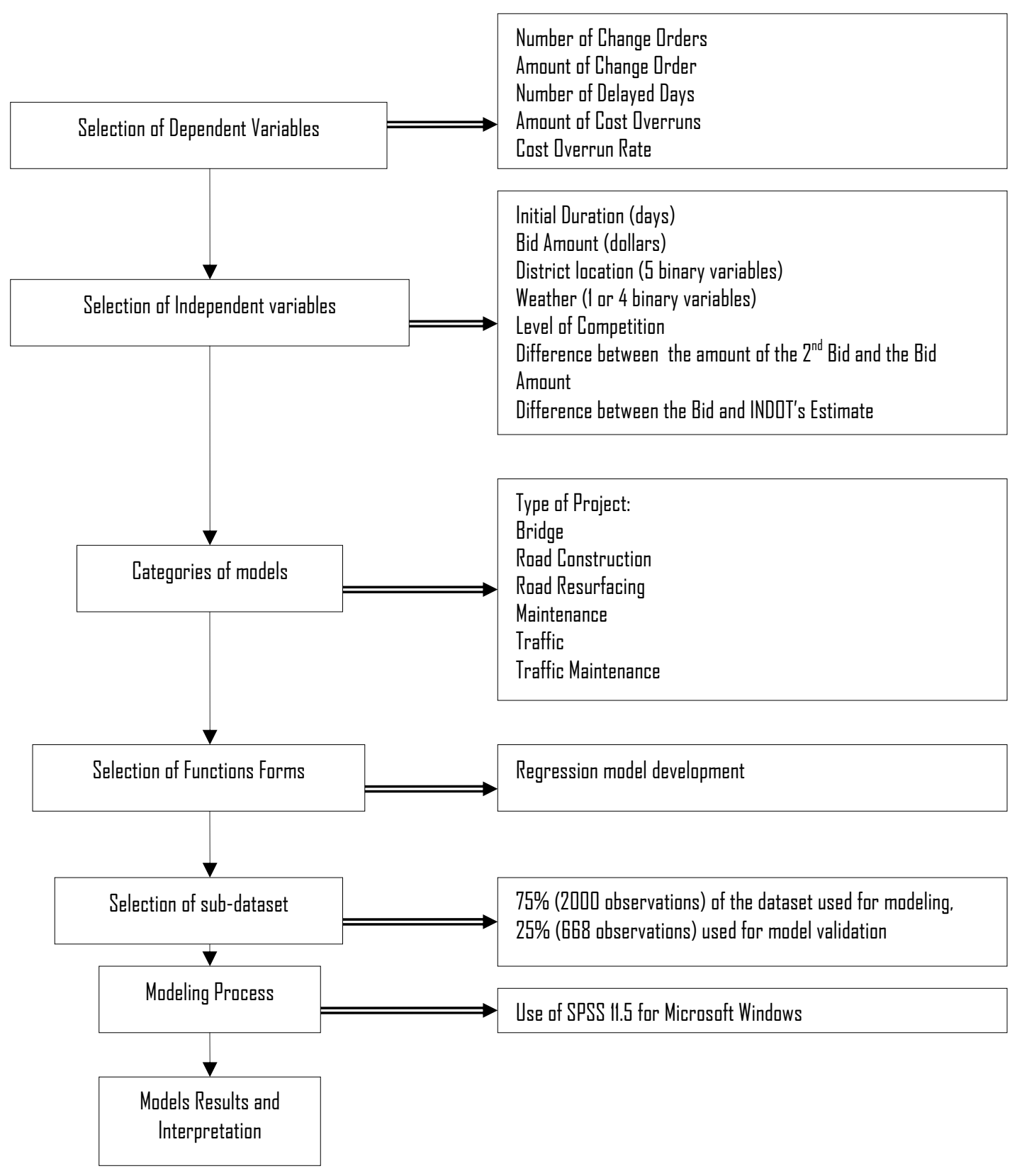

Figure 4.1: Approaches Used in the Statistical Analyses. 


\subsection{Statistical Analysis}

\subsubsection{Correlation Matrix Analysis}

A correlation matrix analysis of the data was carried out using SPSS 11.5 for Microsoft Windows, in order to identify any possible linear correlations between the independent variables that influence cost overruns, time delay, and change orders. The equation to compute correlation coefficient, $r$, is shown:

$r=\frac{\sum_{i=1}^{n}\left(x_{i}-\bar{x}\right)\left(y_{i}-\bar{y}\right)}{(n-1) S_{x} S_{y}}$

Where:

$x$ and $y$ are any pair of variables whose level of correlation is being sought

$\bar{x}$ and $\bar{y}$ are the means of $x$ and $y$, respectively

$S_{\mathrm{X}}$ and $S_{\mathrm{Y}}$ are the standard deviations of $x$ and $y$, respectively.

The correlation coefficient lies between -1 and +1 . If the coefficient is close to -1 or +1 , the two variables are close to a perfect linear relationship, and when the coefficient is close to 0 , there is little or no correlation.

\subsubsection{Analysis of Variance (ANOVA)}

The analysis of variance is conducted to show the overall significance of the independent variables. Two levels were considered for each independent variable, as shown in Table 4.1.

Table 4.1: Selected Levels for Each Independent Variable

\begin{tabular}{lcc}
\hline \multicolumn{1}{c}{ Variable } & Low Value (1) & High Value (2) \\
\hline Bid Amount & $<\$ 350,000$ & $>\$ 350,000$ \\
\hline Proportion of Inclement Weather Days & $<0.25$ & $>0.25$ \\
\hline Level of Competition & $\leq 3$ & $>3$ \\
\hline $\begin{array}{l}\text { Proportion of the Difference between } \\
\text { the First and Second Bids }\end{array}$ & $<0.07$ & $>0.07$ \\
\hline $\begin{array}{l}\text { Proportion of the Difference between } \\
\text { the Bid and Engineer's Estimate }\end{array}$ & $<0.22$ & $>0.22$ \\
\hline Project Duration & $<110$ & $\geq 110$ \\
\hline
\end{tabular}

Only the first five variables shown in Table 4.1 were used for the analysis of variance of cost overruns, the amount of change orders and the number of change orders. For time delay, only three variables (bid amount, project duration, and proportion of inclement weather days) were considered. The analysis of variance was carried out using SPSS 11.5 for Microsoft Windows [SPSS, 1999].

For each unique combination of the levels of the independent variables, a dummy integer variable was established to facilitate the analysis of variance. For example, as seen in Appendix F, the 
dummy variable takes a value of 1 when the proportion of inclement days is low (level =1), bid amount is low (level =1), level of competition is low (level =1), proportion of the difference between the winning and second bid is low (level =1), proportion of the difference between the engineers estimate and the winning bid is low (level =1). As such, it is possible to calculate the mean, the standard deviation, and the number of observations for each value of the dummy variable. The analysis of variance was then carried out by comparing the means of cost overruns, time delay, and change orders for each value of the dummy variable. ANOVA yields an F-ratio and a corresponding $\mathrm{P}$-value. The higher the F-ratio, the lower the P-value, and consequently the more significant the difference between the group means.

\subsubsection{Pair-wise Tests}

A pair-wise t-test analysis was conducted to determine further significance of the independent variables. A more detailed explanation of the method is provided by Harnett [1975]. For each test, it was assumed that the two populations are normally distributed and that the samples are independent random samples. A t-test for the difference between the two samples can be constructed on the basis of the difference for each matched pairs. The matched pairs are a pair of observations that differ from each other for only one variable, and the difference between the other variables must not exceed $+/-$ $10 \% . x$ is defined as the difference between $x_{\mathrm{A}}$ and $x_{\mathrm{B}}$ that are matched pairs of the two populations, and is assumed to be normally distributed. The null hypothesis is $\mathrm{H}_{0}: \mu_{\mathrm{A}}-\mu_{\mathrm{B}}=0$ which is equivalent to $\mathrm{H}_{0}: \mu_{\mathrm{x}}=0$ and

$$
s_{x}=\sqrt{\frac{1}{n-1} \sum(x-\bar{x})^{2}}
$$

The test statistic for matched pairs is: $t_{(n-1)}=\frac{\bar{x}-\mu_{0}}{s / \sqrt{n}}$ with $\mu_{0}=0$.

This t-test compares with $\left[-t_{(\alpha / 2, n-1)} ;+t_{(\alpha / 2, n-1)}\right]$. If $t_{(n-1)}$ is in this range, $\mathrm{H}_{0}$ is true and the variable is not significant. $\bar{x}$ is always calculated as the difference between the dependent variable for the high value of the studied variable and for the low value of this variable. In this section, $\alpha$ is defined as $10 \%, \alpha=0.1$.

The following method was followed in the pair-wise testing: first, two categories were established for each independent variable (high and low values). Then, for each level of some independent variables, appropriate pairs of contracts were identified. Then the pairs of contracts were further refined to include only those whose attributes (such as bid amounts) matched closely. The results of such analysis are presented as Tables F.5 - F.15 (Appendix F. For most of the analyses, the 
bid amount is used for this final step of developing the tables for the analysis, as it is obviously the most significant variable. For the analysis of the bid amount, it was necessary to keep another variable at a fixed level so that the matching pairs could be established. The proportion of inclement weather days was selected for practical reasons for cost overruns and change orders. But project duration was selected for time delay. Then the differences in their cost overruns, time delays or change orders were determined.

\subsubsection{Graphical Trend Investigations}

In order to discern general trends in the data, each potentially influential factor (independent variable) was categorized into three levels: low, medium, and high. Then the variation of the dependent variable (cost overrun, time delay or change orders) with respect to a selected independent variable was investigated while keeping the other independent variables at a constant level. The medium level was chosen as the level to which the other independent variables were held constant. The range values for each category are defined in Table 4.2.

Table 4.2: Definition of the Proportions for each Variable

\begin{tabular}{l|ccc}
\hline \multirow{2}{*}{ Variable } & \multicolumn{3}{c}{ Level } \\
\cline { 2 - 4 } & None or Low & Medium & High \\
\hline Proportion of Inclement Days & $<0.15$ & $0.15-0.5$ & $>0.5$ \\
\hline Bid Amount & $<300000$ & $300000-1000000$ & $>1000000$ \\
\hline $\begin{array}{l}\text { Percentage of Difference between the First } \\
\text { and Second Bids }\end{array}$ & $<10$ & $10-20$ & $>20$ \\
\hline $\begin{array}{l}\text { Percentage of Difference between the Bid } \\
\text { Amount and the Engineers Estimate }\end{array}$ & $<20$ & $20-40$ & $>40$ \\
\hline Original Duration & $<100$ & $100-200$ & $>200$ \\
\hline \multicolumn{1}{c}{ Level of Competition } & $\leq 4$ & $=5$ or 6 & $>6$ \\
\hline
\end{tabular}

\subsection{Description of the Modeling Process}

The next step after examining statistical characteristics was to develop models to confirm the magnitude and direction of the influence of potential factors and to predict the severity cost overruns, time delay, or change order frequency of any future projects. Interestingly, all three dependent variables are potentially influenced by the same set of independent variables which are discussed in Section 4.4.2.

\subsubsection{Response Variables}

The first step was to identify the response (or dependent variables) to be used in the statistical models. These were as follows:

- Cost overrun amount 
- Cost overrun rate (cost overrun amount divided by the bid amount)

- Time delay (in days)

- Number of change orders

- Amount of change orders

\subsubsection{Cost Overrun}

The total amount of cost overrun was calculated by the difference between the final contract cost and the bid amount. In another set of models the response variables was the cost overrun rate, which is the percent difference in cost (positive or negative) between the final contract cost and the contract award amount (Jahren and Ashe, 1990).

\subsubsection{Time Delay}

The response variable for the time delay models was the number of days of time overrun, which is defined as the difference between the actual duration of the project and the original duration (decided in the contract). The dataset provided the following dates: the notice to proceed date, the last day of work, and the estimated date of project completion, which enabled calculation of the time delay.

\subsubsection{Change Orders}

There were two types of change order information: the daily change order that contains all the change orders in a day and the second type is the member of individual change orders. In the present study, the number of individual change orders, as well as the total amount of money involved in change order, was modeled as a function of various independent variables.

\subsubsection{Independent Variables}

The second step was to identify the factors that potentially influence the amount of change orders, cost overruns and time delays. This step was guided by the findings from the literature review and agency survey (Chapter 2 and 3). The results of the descriptive statistics, pair-wise $t$ test and analysis of variance were instrumental in developing a tentative list of independent variables for use in the statistical models.

An important independent variable is project duration, or the initial length (days) of the project, computed as the difference between the estimated last day of work and the notice to proceed date. An initial expectation for this variable would be that longer projects would result in longer delays. Indeed, Rowland [1981] found that the size of the project is a significant variable. Size can be 
understood as the total cost or duration of the project. It is intuitive that a high-cost project will likely involve a long contract duration. Conversely, a project of long duration is likely to have a high cost. So, these two potential influential variables are obviously related to each other. Rowland [1981] states that a bigger project would have a greater change order amount rate. In the present study, the initial project length was used only for time delay models because this is the most relevant variable for these models.

The bid amount (in dollars) may also be a significant variable for all three model types. It is quite possible that correlation may exist between the bid amount variable and the initial length (days). The project size in terms of cost and the size in terms of length may exhibit different levels of influence on the dependent variables. On one hand, it can be hypothesized that an expensive project is often managed more efficiently, resulting in less delay. On the other hand, it may be argued that the involvement of more contractors and subcontractors may result in increased delay certainly because of inevitable lapses in communication between them. The same comment can be made about the impact of project size on cost overrun.

To examine the influence of project type, six binary variables were created (bridge, road construction, resurfacing, maintenance, traffic, and traffic maintenance). Each of these variables takes a value of 1 if the information pertains to the project type, 0 otherwise. Bridge and road construction projects may not suffer from traffic management as much as the other projects, so there may be less risk in terms of safety and delay. However, actual bridge construction is much more unpredictable than the other project types, and unforeseen site conditions or delays in obtaining right-of-way could cause delays and cost overruns. Maintenance and traffic projects are significantly affected by passing traffic, but overall, a lower level of construction delays and cost overruns may be expected for such projects because of their typical small size and short duration. Jahren and Ashe [1990] found that the size of a project is significant in time delays. For models that included the "project type" variable, five binary variables were used (excluding the traffic maintenance variable). As such, a project that shows a zero value for all the binary variables is a traffic maintenance project.

The district at which a project is located may be a significant variable because of variations in weather and administrative practices/culture. Contract locations by districts were represented using binary variables. It is possible that some interaction may exist between the variables representing contract location and those representing weather conditions. The district variables are expected to reveal differences in the effectiveness of supervision practices. If these variables are found to be strongly related to the weather variables, they may only represent a climatic and geological variation among the state. However, if this is not the case, other disparities may be revealed among the districts, 
such as INDOT staff's management efficiency, the performance of the main contractors in the district, etc.

Weather variation was not considered in previous studies. In the present study, four different continuous variables were used to describe the weather conditions during the duration of each project.

- Temperature (in number of days with a temperature less than 0 degree Celsius)

- Rain precipitation (in number of days with rain precipitation)

- Snow precipitation (in number of days with snow precipitation)

- Ground snow conditions (in number of days with snow on the ground)

These variables are expected to reveal the impact of inclement weather conditions on the construction process. It is expected that the coefficients for these variables will have a positive sign for all models. In order to prevent correlation between the four weather variables, another independent variable was considered: inclement weather (in terms of the number of days of the contract duration that experienced either low temperature (less than zero degree Celsius), precipitation, snow, or snow on the ground). This new variable incorporates the four weather variables. It helps avoid the problems of correlation because when the temperature is under zero degree Celsius, any precipitation will be in the form of snow, not rain. The same comment can be made for the variable "ground snow conditions," because it is obviously strongly related to the variable "snow precipitation." These weather variables (expressed in the number of days) are finally reduced to a rate by dividing the number of inclement days by the total number of days worked on the project.

The level of competition for each contract is the number of contractors who submitted a bid to INDOT for that contract. The level of competition was found relevant in the Jahren and Ashe [1990] study. Obviously, it is expected that the higher the level of competition, the more competitive the bidding, and consequently the higher the number of change orders, cost overruns and time delays likely to be experienced by the contract.

The difference between the bid amount and the INDOT engineer's estimate was also taken into account in the present study to ascertain the validity of Rowland's assertion [1981] that the larger the absolute value of the difference between the owner's fair cost estimate and the low bid on a project, the greater the likelihood that a job will experience more change orders, and by extension, more cost overruns.

The difference between the bid amount and the next low bid might have an influence on the number of change orders as found by Rowland [1981]. It is expected that when such difference is larger, the number of change orders or cost overrun amounts is greater.

For these variables (i.e., the difference between the first and second bids and between the bid and the engineer's estimate) a rate is defined by dividing these amounts by the original bid amount. 


\subsubsection{Project Types}

The project type variable was deemed appropriate for categorizing the statistical analyses. The categories consisting of bridge, road construction, resurfacing, maintenance, traffic and traffic maintenance are characterized by significant differences in management practices due to the nature of the categories. Separate models were developed for each category. Also, a general model for all contracts that utilized project type independent variables (rather than having model families based on project type) was developed to further investigate any differences between the impacts of each project type.

\subsubsection{Investigation and Selection of Mathematical Forms}

All the variables were modeled with the linear regression form, and some typical Box Cox transformations were tried for each dependent variable, depending on the range of these variables.

\subsubsection{Model Calibration and Validation}

Influential variables were selected on the basis of their relatively high statistical significance, which was ascertained using their t-statistics and P-values given with the model results. The best models were obtained through progressive inclusion and exclusion of various variables in the models. The variables were selected or inclusion if their t-statistics were approximately greater than 1.6. The statistical package SPSS 11.5 for Windows [SPSS, 1999] was used to run the regressions.

Approximately $25 \%$ of the data was set aside to validate the models. As such, of the 2,668 projects, a randomly selected set of 2,000 projects were used for the modeling process. The other set of 668 projects were used to determine whether the predictions given by the calibrated model matched the observed values. The following parameters were estimated to evaluate the effectiveness of each model:

$$
\begin{aligned}
& \text { Root mean square error }=\sqrt{\frac{\sum\left(x_{o b s}-x_{\text {mod }}\right)^{2}}{n}} \\
& \text { Percentage of deviations }=\sum\left|\frac{x_{o b s}-x_{\text {mod }}}{x_{o b s}}\right|
\end{aligned}
$$




\subsection{Chapter Summary}

The present chapter explained the overall framework, methods, and underlying assumptions for analyzing the problem of cost overruns, time delays and change orders in Indiana. The methodology included preliminary descriptive statistics, correlation matrix analysis, pair-wise $\mathrm{t}$ tests, analysis of variance, and statistical modeling. The chapter provided a description of the methodologies used in the statistical analysis. Five models types, based on the form of response variable, were considered for development: number of change orders, change order amount, severity of time overrun, cost overrun, and cost overrun rate. The following independent variables were discussed: duration, bid amount, project type, district, weather conditions, level of competition, engineer's estimate comparison, and first and second bid comparison. Also, appropriate functional forms were discussed. The techniques used for model calibration and validation were also discussed in the present chapter. 


\section{CHAPTER 5: DATA COLLECTION}

\subsection{Introduction}

This chapter describes the data collection and the development of the dataset used for the analysis of cost overruns, time delays and change orders in Indiana DOT. Most of the data were obtained from the INDOT contracts division. The study uses data period of approximately five years: between January 1, 1996 and September 6, 2002. There were a total of 2,668 projects during this period.

\subsection{Data Collection}

\subsubsection{INDOT Information}

The codes used in the datasets provided by INDOT are indicated in Table 5.1.

Table 5.1: Raw Contract Data Provided by INDOT

\begin{tabular}{lc}
\hline Variable Code & Meaning \\
\hline CONT & Contract ID \\
\hline PR & Type of Contract (Bridge, Road, Traffic...) \\
\hline CNFACS & District \\
\hline CNAWDAMT & (Contract Award Amount) Original Bid Amount \\
\hline CNDTNTP & Notice to Proceed Date \\
\hline LASTWRK & Last day of Work \\
\hline FNLAMT & Final Amount \\
\hline LIQ/DAM & Liquidated Damages \\
\hline OCNUM & Original County Number \\
\hline TOTCO & Total Change Orders Amount \\
\hline CONUM & Number of Change Orders \\
\hline COMPLEV & Competition Level \\
\hline ENGESTIM & Engineer's Estimate \\
\hline SECLOWBID & Second Low Bid \\
PSTIMETH & Type of Contract (Available Days or Date) \\
\hline PSORIGDY & Work Day Completion \\
\hline PSDTORIG & Calendar Completion Date \\
\hline
\end{tabular}

INDOT staff members at the Program Development Division, Special Projects Division, Systems Technology Division, were particularly helpful in providing information. The following information was made available on Paradox files easily transferable to Access format:

- $\quad$ Contract ID

- $\quad$ Project type (bridge, maintenance, etc.)

- $\quad$ Project location (district) 
- $\quad$ Bid amount

- $\quad$ Final amount

- $\quad$ Dates: Notice to proceed, Acceptance date, Final day of work.

- $\quad$ Liquidated damages

Most of this information is also available at the following website:

http://www.in.gov/dot/div/contracts/letting/oldletting.html, which is regularly updated. The data concerning the level of competition, the engineer's estimate, and the second low bid was also obtained from this website. The following information on change orders was made available in Access format:

- Description of each change order

- $\quad$ Reason code

- Amount of change orders in dollars

- $\quad$ Expected final date

The following information was provided in Excel files that were exported from BAM files:

- $\quad$ Project location (counties, in order to introduce the weather data into the dataset)

- Amount of change orders in dollars

- Vendor's reference

- Description of the location

A portion of the data could not be used because of a lack of explanation of the codes used in the dataset supplied by INDOT. In some cases, many columns were empty.

Figure 5.1 indicates the geographical location of the various INDOT districts in Indiana. The present study takes into account data from these six districts: La Porte, Fort Wayne, Crawfordsville, Greenfield, Seymour, and Vincennes. The Toll Road district is not represented because no contract data was provided on this district for this study. 


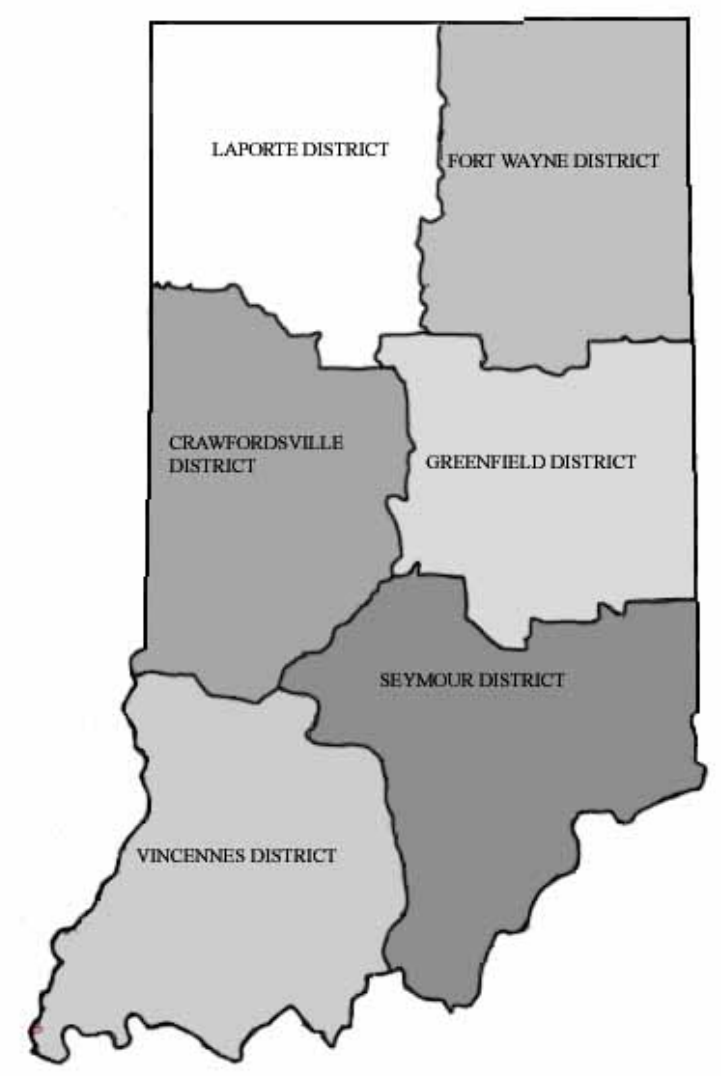

Figure 5.1: Highway Administrative Districts in Indiana

Data regarding change order reasons were not incorporated into the main dataset because they had to be organized differently. The available data provided for each contract a description of each change order: contract number, unit price, quantity, and reason for the change order (code). The final cost of the change order (obtained by multiplying the quantity by the unit price) and the reason for the change order are the most important pieces of information. For this database, six major datasets were created for each project type (bridge, maintenance, etc) and seven different descriptions were done in order to compare the different categories of work in terms of responsibility for change orders. For the analysis, the number of change orders and the amounts of the change orders for a given contract were incorporated in the main dataset. 


\subsubsection{Weather Data}

The weather data were available on the web site: http://shadow.agry.purdue.edu/sc.index.html. The county-specific data covered the period between January 1, 1995 and November 1, 2002. The following data were collected:

- Maximum temperature

- Minimum temperature

- Amount of rainfall in inches

- Amount of snowfall in inches only between November and March

- Amount of snow on the ground in inches

\subsection{Database Development}

\subsubsection{Refinement of the Dataset}

Contracts with incomplete information because of errors or missing data were deleted from the modeling dataset. Consequently, the dataset used for the three types of models (cost overruns, time delays, and change orders) were slightly different. Moreover, there were a few potentially influential factors (independent variables) for which available data did not cover the entire dataset. As such, it was found prudent to develop two sets of models: one with the entire dataset but with few variables, and the another with a reduced dataset but with many variables. Also, a few outliers were excluded form the modeling dataset,

\subsubsection{Weather Database}

The present study placed more emphasis on the number of inclement weather days compared to the actual amount of daily precipitation. Therefore, for the duration of each contract, the number of days (with rain, snow, or cold days) was counted. It considered that snow and rain not only preclude a day of work, but also cause the entire process of construction to slow down. The data collection was subsequently simplified In the dataset, weather conditions are presented as the number of days with the following attributes:

- cold temperatures. Cold days were defined with maximum temperature under zero degree

Celsius, i.e., 32 degrees Fahrenheit

- rain precipitation

- snow precipitation

- snow on the ground

Information from Figure 5.2 was used in inputting missing weather data by utilizing data from the closest county that had weather data (Appendix D). For a few counties with missing data, the 
nearest county that had data were used to impute data. A complete dataset of weather conditions for each county was thus established drawn. In order to incorporate the information into the database, the software Microsoft Access was used with Microsoft Visual Studio.NET to develop a program with Visual Basic that counts the number of days in each category given by the county and the beginning and final date of the project. The proportion of inclement days was calculated on the basis of the actual number of working days.

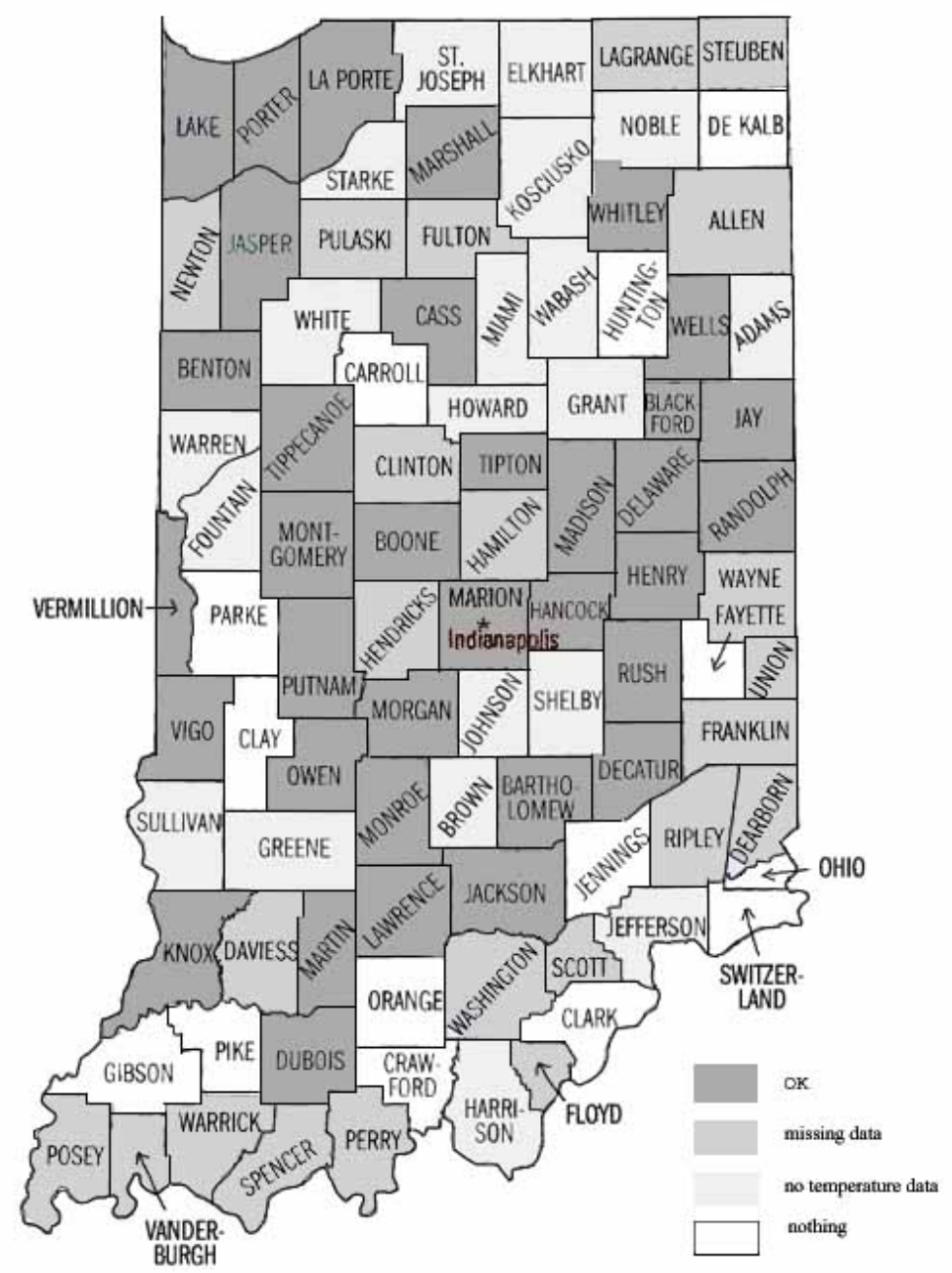

Figure 5.2: Weather Data Availability by County 


\subsubsection{Construction of the Database}

Data items in the database are listed in Table 5.2 and discussed below:

COSOVER: Cost Overrun = Final Amount - Original Bid Amount .

COSRATE: Cost Overrun Rate $=$ Cost Overrun / Original Amount.

TIMEDELAY = Time Delay = Last Day of Work - Expected Last Days of Work.

CONLENGTH: Contract Duration = Last Day of Work - Notice to Proceed Date (in days).

PDIFFIRSECBID: Difference between the First and Second Bid = (Second Low Bid - Original Bid Amount) / Original Bid Amount.

PDIFENGBID: Difference between the Engineer's Estimate and the Bid = (Engineer's Estimate Original Bid Amount) / Original Bid Amount.

PNINCL $=$ Proportion of Inclement Days $=$ Number of Inclement Days/Total Project Duration in Days

Six binary variables were defined: B, M, R, RS, T and TM corresponding to the project type. Year corresponds to the year of the final day of work.

Table 5.2: Items in the Database

\begin{tabular}{|c|c|}
\hline Variable Code & Meaning \\
\hline$B$ & Bridge Project \\
\hline$M$ & Maintenance Project \\
\hline$R$ & Road Construction Project \\
\hline$T$ & Traffic Project \\
\hline$R S$ & Resurfacing Project \\
\hline$T M$ & Traffic Maintenance Project \\
\hline CRAWF & Crawfordsville District \\
\hline FORTW & Fort Wayne District \\
\hline GREEN & Greenfield District \\
\hline LAPOR & La Porte District \\
\hline SEYMO & Seymour District \\
\hline VINCE & Vincennes District \\
\hline PNCOLD & Proportion of Cold Days \\
\hline PNRAIN & Proportion of Rainy Days \\
\hline PNSNOW & Proportion of Snow Days \\
\hline PNSNOWG & Proportion of Days with Snow on the Ground \\
\hline PNINCL & Proportion of Inclement Days \\
\hline CNAWDAMT & Contract Award Amount (Original Bid Amount) \\
\hline COSOVER & Cost Overrun \\
\hline COSRATE & Cost Overrun Rate \\
\hline COMPLEV & Competition Level \\
\hline PDIFFIRSECBID & $\begin{array}{l}\text { Proportion of the Difference between } \\
\text { the First and Second Bids }\end{array}$ \\
\hline PDIFENGBID & $\begin{array}{l}\text { Proportion of the Difference between the } \\
\text { Engineer's Estimate and the Bid Amount }\end{array}$ \\
\hline CONDUR & Contract Duration \\
\hline LIQDAM & Liquidated Damages \\
\hline TIMEDEL & Total Time Delay \\
\hline CHONUM & Number of Change Orders \\
\hline TOTCO & Total Change Orders Amount \\
\hline YEAR & Year \\
\hline
\end{tabular}


As the data came from various sources, consistent sets of data was not available for all necessary items, such as the case of the reasons for change orders or year. Table 5.3 summarizes the number of observations that were found for the variables considered in statistical analysis.

Table 5.3: Number of Observations for Variable

\begin{tabular}{lc}
\hline \multicolumn{1}{c}{ Variable } & Number of Observations \\
\hline Change Order Amount & 2650 \\
\hline Time Delay & 1975 \\
\hline Number of Change Order & 822 \\
\hline Level of Competition & 730 \\
\hline $\begin{array}{l}\text { Proportion of the Difference between the } \\
\text { First and Second Bid }\end{array}$ & 714 \\
\hline $\begin{array}{l}\text { Proportion of the Difference between the } \\
\text { Bid and the Engineer's Estimate }\end{array}$ & 674 \\
\hline Other data & 2668 \\
\hline
\end{tabular}

\subsection{Chapter Summary}

This chapter described the methods used to collect and develop the database for the statistical analysis of the cost overrun, time delay and change order data. Most of the data were obtained from the INDOT contracts division. A total of 29 data items were established. 


\section{CHAPTER 6: DESCRIPTIVE STATISTICS}

\subsection{Introduction}

This chapter describes trends in the dependent variables used in the various models based on the data obtained from 2,668 projects. It describes time delays both in terms of liquidated damages and in time delays in days. A detailed description of the cost overrun trends classified by categories gives an explicit overview of cost overruns. The chapter also provides a detailed description of the trends in change orders.

In order to describe the dataset, two factors are defined that describe the importance of overruns (time or cost) and the number of change orders:

- When a large percentage of contracts have overruns, it indicates the extent (or frequency) of the problem.

- When the total overrun is high (in percentage), it indicates the severity of the problem.

In any given year, the problem can be extensive but not severe, severe but not extensive, both extensive and severe, or neither extensive nor severe.

All dollar amounts are in current dollars, and no inflation factor was considered because the duration of most projects were small, and the analysis period is rather small.

\subsection{General Description}

\subsubsection{Distribution of Contracts by District}

Table 6.1 presents the distribution of the studied projects among districts. There are between 390 and 589 contracts in each category. There are enough contracts in each district for the description statistics and to justify regression analysis. The district with the most contracts was Greenfield, probably because the city of Indianapolis is included in this district. Moreover, there is a correlation between the number of contracts and the population; the most populated district is the one where more contracts were completed. It is interesting to note, however, that there was no relationship between the number of projects in a district and the total road mileage in the district. 
Table 6.1: Distribution of Contracts by District

\begin{tabular}{cccc}
\hline Districts & Number of Projects & $\begin{array}{c}\text { Estimated Population } \\
\text { in July 2002 }\end{array}$ & $\begin{array}{c}\text { Approximate } \\
\text { Total Mileage }\end{array}$ \\
\hline Crawfordsville & 391 & 646,339 & 1,936 \\
\hline Fort Wayne & 422 & $1,029,265$ & 1,822 \\
\hline Greenfield & 589 & $1,754,456$ & 1,677 \\
\hline LaPorte & 438 & $1,249,087$ & 2,065 \\
\hline Seymour & 438 & 892,532 & 1,753 \\
\hline Vincennes & 390 & 587,389 & 1,947 \\
\hline
\end{tabular}

Source: US. Census Bureau and INDOT

\subsubsection{Distribution of Contracts by Project Type}

In Table 6.2, it can be noticed that there is a fairly even distribution of contracts across the various project types, each with a large number of observations, with the exception of the category "Traffic Maintenance." As the number of projects in this category was 36, only 27 (75\%) could be used for modeling leaving only 9 (25\%) for validation. Therefore, this category was not considered for modeling purpose, although descriptive statistics for traffic maintenance were computed.

Table 6.2: Distribution of Contracts by Project Type

\begin{tabular}{cc}
\hline Project Type & Number of Contracts \\
\hline Bridge & 621 \\
\hline Road Construction & 599 \\
\hline Road Resurfacing & 419 \\
\hline Maintenance & 607 \\
\hline Traffic & 386 \\
\hline Traffic Maintenance & 36 \\
\hline
\end{tabular}

\subsection{Time Overruns}

\subsubsection{Analysis of Liquidated Damages}

From the 2,668 contracts, 187 were determined to have liquidated damages. Projects that incurred liquidated damages are associated with time overrun, and specific information on the causes of the time delays was sought. Figure 6.1 shows the trend in liquidated damages due to time delays during the analysis period. The year 1997 experienced a relatively high amount of liquidated damages. The causes for this anomaly need to be investigated. Since 1998, these damages have leveled to below $\$ 100,000$. This level is surprisingly low considering the total number of contracts involved. The same trend was observed for the number of contracts with liquidated damages. 


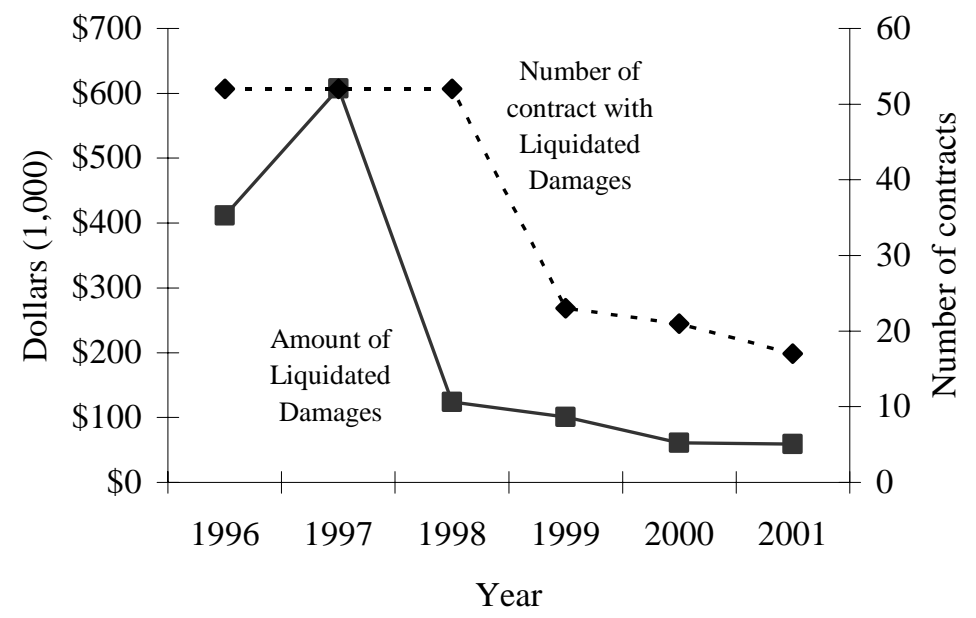

Figure 6.1: Annual Frequency of Contracts with Liquidated Damages and Amount of Liquidated Damages, 1996 - 2001.

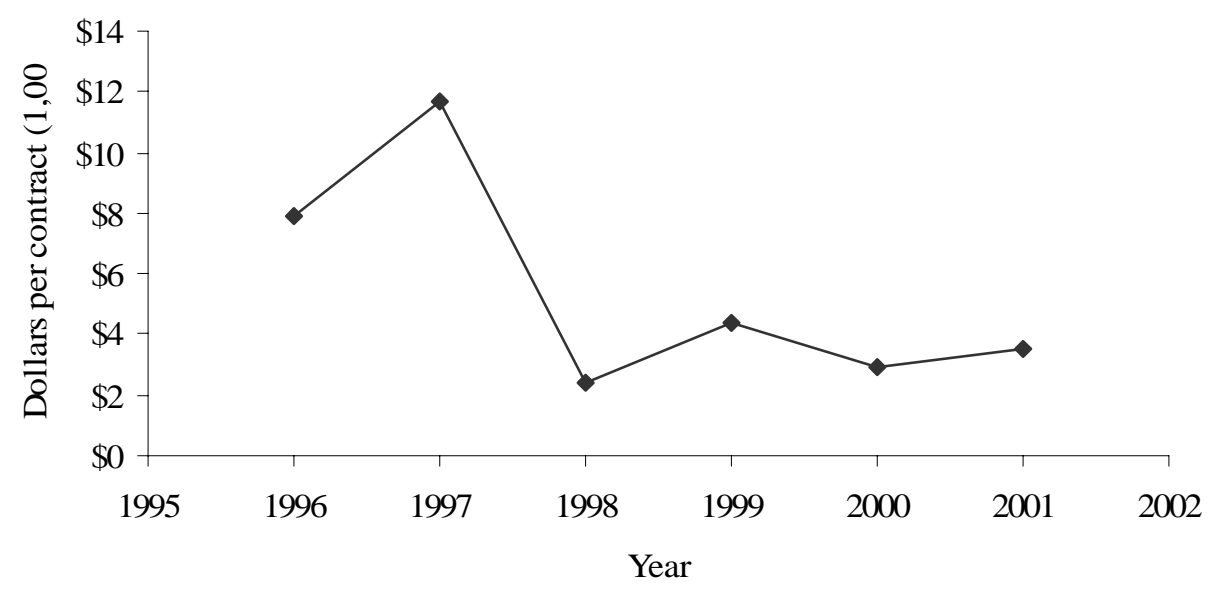

Figure 6.2: Annual Average Liquidated Damage Amounts per Contract, 1996 - 2001.

Figure 6.2 presents the average liquidated damage amounts per contract per year. The year 1997 had the highest level of per contract liquidated damages due to time delay. The problem of liquidated damaged was both extensive and severe in 1997. 


\subsubsection{Analysis of Time Delays}

The analysis of the time delay included only 1,987 contracts of the database because time delay information was not provided for the remaining contracts. Time delay is defined as the difference between the estimated final date and the actual one. It is worth noting that most of these delayed days were actually time extensions that were authorized or requested by INDOT.

Figure 6.3 presents the distribution of time delay in increments of 10 days. The mean time delay is about 120 days and the standard deviation is approximately 153 days. It can be noticed that the distribution is not symmetric. Indeed, there were few projects that were completed before the estimated final date, and for such projects, the time delay was negative.

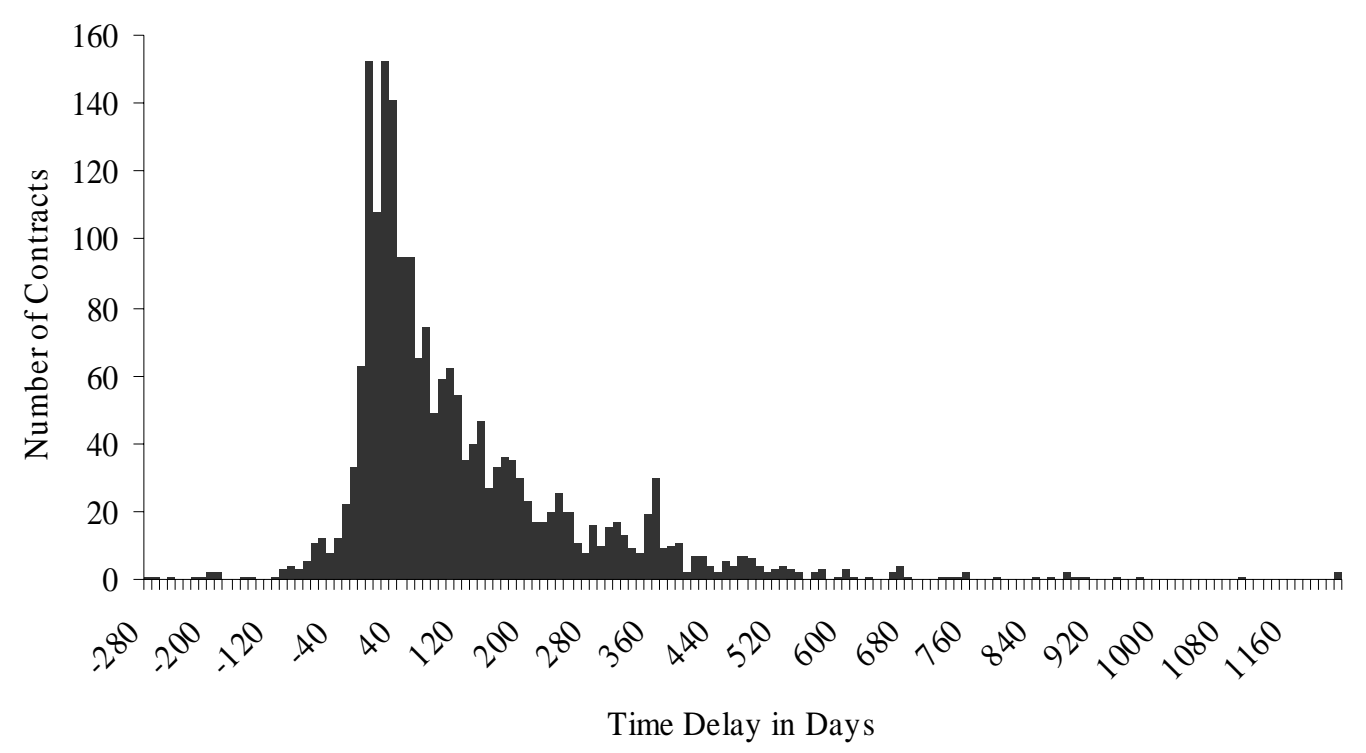

Figure 6.3: Distribution of Time Delays

Table 6.3 presents a summary of average contracts delays by district, project type and project size during the time period, 1996-2001. The values given for the traffic maintenance projects were not taken into account because of the small number of contracts in that category (only three). 
Table 6.3: Average Contract Time Delays (in Days)

\begin{tabular}{|c|c|c|c|c|c|c|c|c|}
\hline \multirow[b]{2}{*}{ 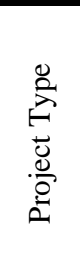 } & \multirow[b]{2}{*}{$\begin{array}{l}\text { Bid Amount } \\
\text { Category }\end{array}$} & \multicolumn{7}{|c|}{ District } \\
\hline & & 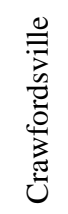 & 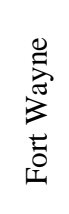 & 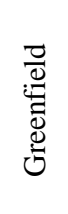 & $\begin{array}{l}\stackrel{\Xi}{0} \\
0 \\
\stackrel{0}{0} \\
.\end{array}$ & 录 & $\begin{array}{l}\stackrel{\Xi}{\Xi} \\
\stackrel{\Xi}{\Xi} \\
\vdots\end{array}$ & 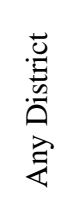 \\
\hline \multirow{5}{*}{ 总 } & $\$ 0-100,000$ & 132 & 28 & 70 & 57 & 63 & 21 & 73 \\
\hline & $\$ 100,000-500,000$ & 92 & 90 & 54 & 73 & 86 & 61 & 72 \\
\hline & $\$ 500,000-1,000,000$ & 95 & 170 & 91 & 111 & 137 & 90 & 110 \\
\hline & $>\$ 1,000,000$ & 164 & 124 & 100 & 129 & 175 & 186 & 141 \\
\hline & Any Bid Amount & 124 & 104 & 74 & 89 & 108 & 75 & 94 \\
\hline \multirow{5}{*}{ 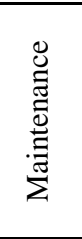 } & $\$ 0-100,000$ & 80 & 112 & 75 & 143 & 163 & 150 & 122 \\
\hline & $\$ 100,000-500,000$ & 89 & 90 & 98 & 88 & 123 & 114 & 101 \\
\hline & $\$ 500,000-1,000,000$ & 184 & 197 & 162 & 174 & 168 & 158 & 174 \\
\hline & $>\$ 1,000,000$ & 346 & 214 & 187 & 166 & 230 & 266 & 225 \\
\hline & Total & 174 & 140 & 135 & 135 & 170 & 166 & 153 \\
\hline \multirow{5}{*}{ 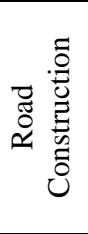 } & $\$ 0-100,000$ & 32 & 123 & 131 & 122 & 77 & 103 & 106 \\
\hline & $\$ 100,000-500,000$ & 53 & 91 & 68 & 102 & 68 & 93 & 80 \\
\hline & $\$ 500,000-1,000,000$ & 101 & 103 & 104 & 100 & 100 & 122 & 104 \\
\hline & $>\$ 1,000,000$ & 119 & 106 & 118 & 196 & 225 & 226 & 172 \\
\hline & Any Bid Amount & 78 & 104 & 102 & 129 & 119 & 152 & 114 \\
\hline \multirow{5}{*}{ 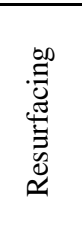 } & $\$ 0-100,000$ & 144 & 40 & 66 & 14 & 74 & 6 & 64 \\
\hline & $\$ 100,000-500,000$ & 63 & 62 & 83 & 58 & 77 & 103 & 74 \\
\hline & $\$ 500,000-1,000,000$ & 159 & 120 & 65 & 104 & 171 & 214 & 132 \\
\hline & $>\$ 1,000,000$ & 133 & 62 & 253 & 165 & 164 & 120 & 144 \\
\hline & Any Bid Amount & 114 & 67 & 110 & 77 & 121 & 110 & 101 \\
\hline \multirow{5}{*}{ 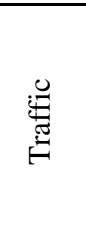 } & $\$ 0-100,000$ & 79 & 99 & 88 & 126 & 152 & 35 & 101 \\
\hline & $\$ 100,000-500,000$ & 58 & 98 & 42 & 39 & 97 & 86 & 71 \\
\hline & $\$ 500,000-1,000,000$ & 84 & 135 & 78 & 69 & 299 & 117 & 118 \\
\hline & $>\$ 1,000,000$ & 170 & 212 & 193 & 222 & 146 & 185 & 188 \\
\hline & Any Bid Amount & 84 & 131 & 90 & 103 & 138 & 107 & 110 \\
\hline \multirow{5}{*}{ 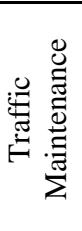 } & $\$ 0-100,000$ & & & 89 & & & & 89 \\
\hline & $\$ 100,000-500,000$ & & 53 & & & & & 53 \\
\hline & $\$ 500,000-1,000,000$ & & & & & & & \\
\hline & $>\$ 1,000,000$ & & 237 & & & & & 237 \\
\hline & Any Bid Amount & & 145 & 89 & & & & 126 \\
\hline \multirow{5}{*}{ 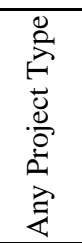 } & $\$ 0-100,000$ & 107 & 88 & 88 & 86 & 104 & 76 & 92 \\
\hline & $\$ 100,000-500,000$ & 74 & 86 & 67 & 74 & 91 & 91 & 80 \\
\hline & $\$ 500,000-1,000,000$ & 133 & 137 & 100 & 114 & 161 & 136 & 127 \\
\hline & $>\$ 1,000,000$ & 195 & 140 & 164 & 170 & 189 & 206 & 177 \\
\hline & Any Bid Amount & 119 & 109 & 101 & 107 & 132 & 125 & 115 \\
\hline
\end{tabular}


If the difference between districts in terms of time delay is considered, Seymour experienced most time delays, with an average of 132 days, while Greenfield experienced the least time delay, with 101 days. With regard to project type, maintenance projects experienced the most time delays (an average of 153 days per contract), while bridge and resurfacing projects had the least time delay (averages of 94 and 101 days per contract, respectively,). Also, more expensive projects, on average, generally incurred greater magnitudes of time delay, the only exception being the higher level of delay observed for $\$ 0-100,000$ contracts compared to 100,000-500,000 contracts. A complete set of figures that illustrate these results are available in Appendix E, while a few selected figures are presented as part of the present chapter. The values given in the following graphs should be interpreted with caution, especially for the years 2000 and 2001. Out of 1,987 contracts, there was information for only 71 contracts in the year 2000 and 13 in the year 2001. For each of the other years, information was available only for $414-533$ contracts.

Figure 6.5 presents the trends in average time delay per contract, and shows relatively low severity of average time delay until after the year 1999. It is important to note that the high severity of time delays in 2000 and 2001 were based on a small number of observations therefore the relatively high severity of time delays observed for contracts in that period may not be representative of all contracts in those years.

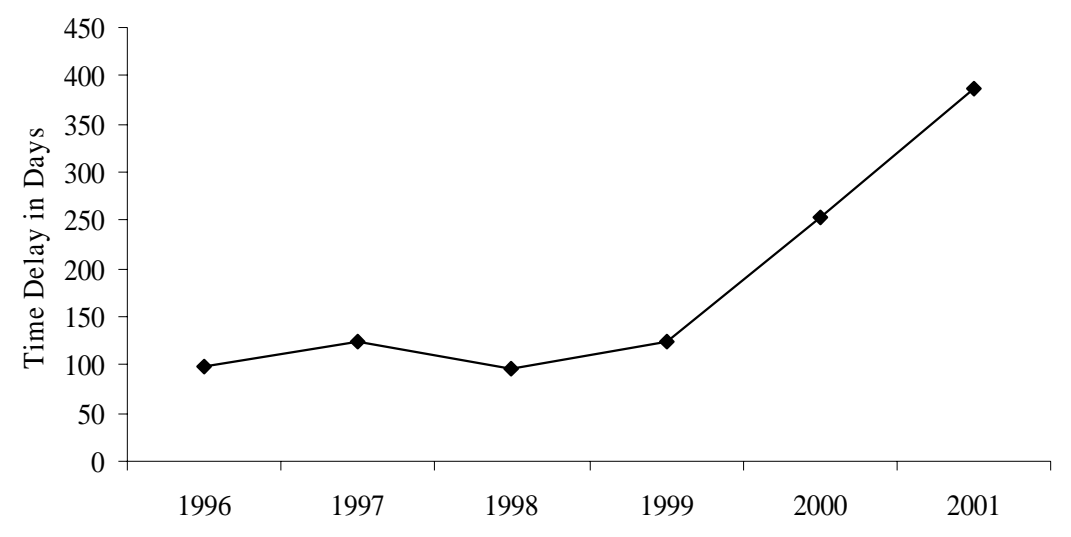

Figure 6.5: Variation of Average Time Delay, 1996 - 2001

Figure 6.6 presents average time delays per contract, by project type. Maintenance projects experienced the most severe time delays. In 1999, time delay for maintenance projects had a sharp increase to approximately 3,244 days. The zero delay value for traffic projects in 2001 was because there was only one project in that category during that year, that project did not experience any time delay. 
Figure 6.7 presents trends in the average time delay per contract, for each district, between 1996 and 2001. The figure shows that concerning the average time delay, there are only small disparities among districts between 1996 and 1998. It can be noticed that in 1999, Crawfordsville District experienced more time delays than the other districts, with about 220 days on average per contact. For years 2000 and 2001, it is difficult to reach any conclusions due to lack of adequate data for those years.

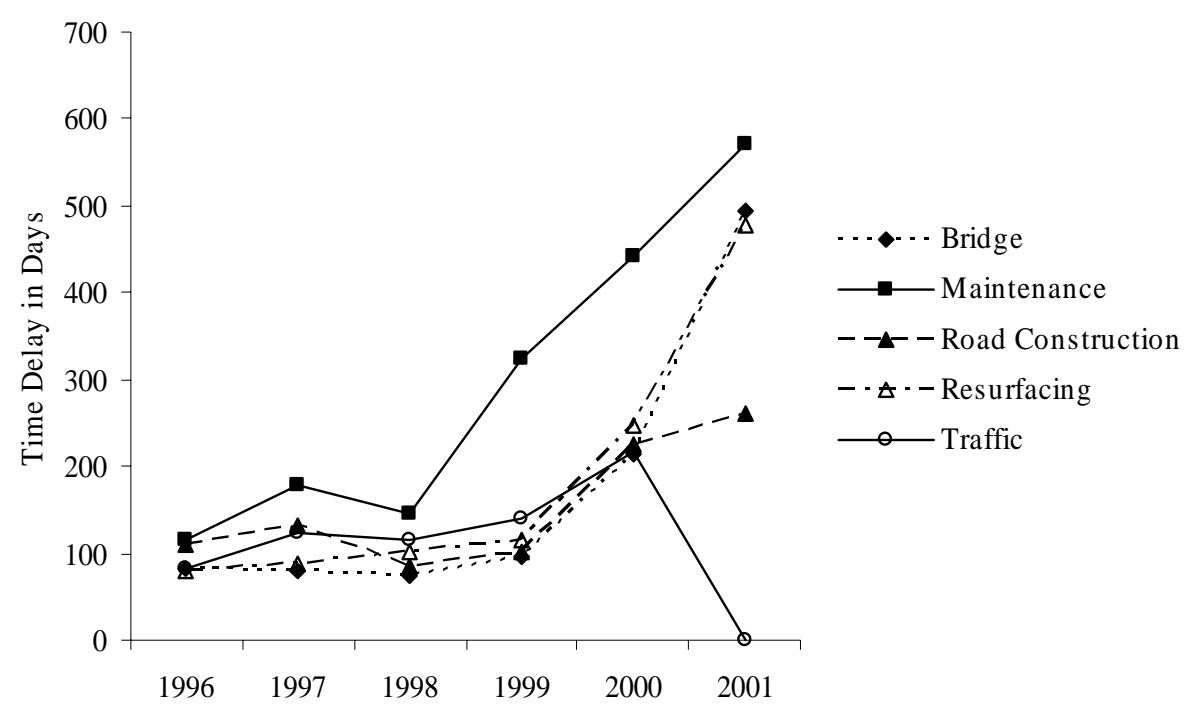

Figure 6.6: Variation of Average Time Delay by Project Type, 1996 - 2001

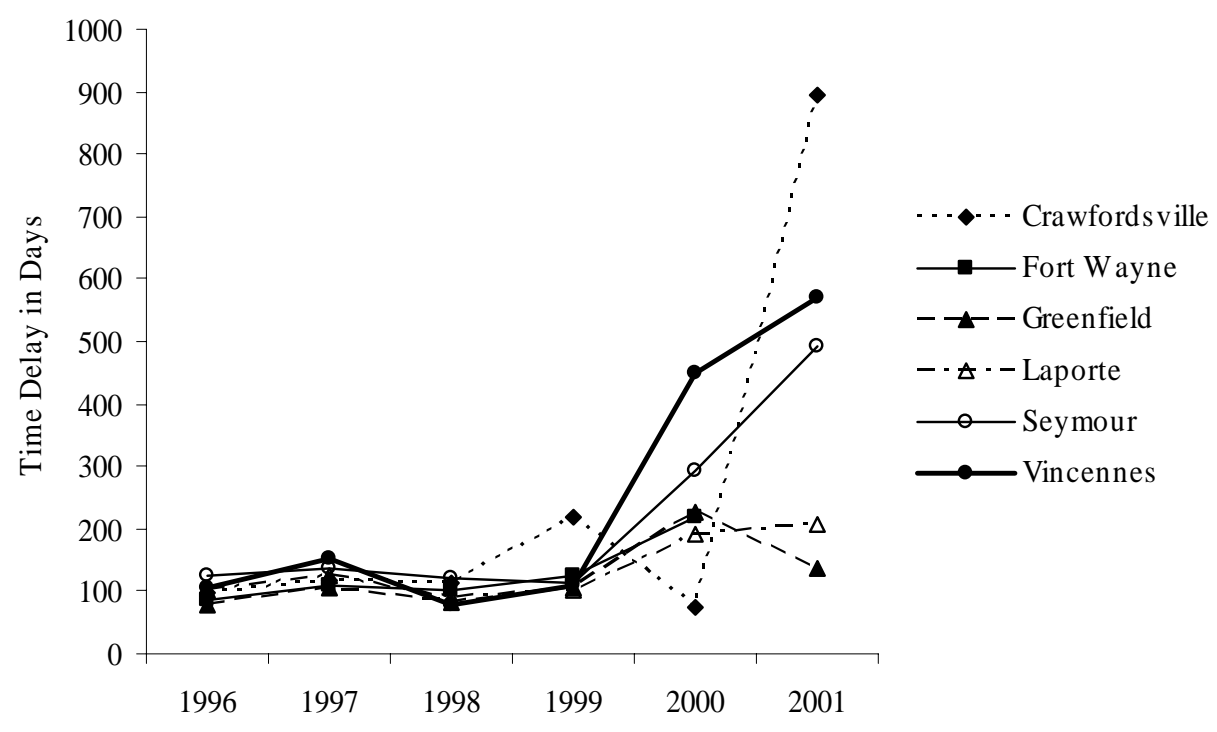

Figure 6.7: Trends in Average Time Delay per Contract by District, 1996 - 2001 


\subsection{Cost Overruns and Underruns}

Figure 6.8 represents the distribution of the cost overrun rates for the 2,668 projects. It shows that most contracts either had a small percentage of cost under or overruns. However, there were several contracts with large overruns. Most contracts (1,889 contracts, i.e., 70.8\% of the total number of contracts) had a cost deviation between $-10 \%$ and $+10 \%$.

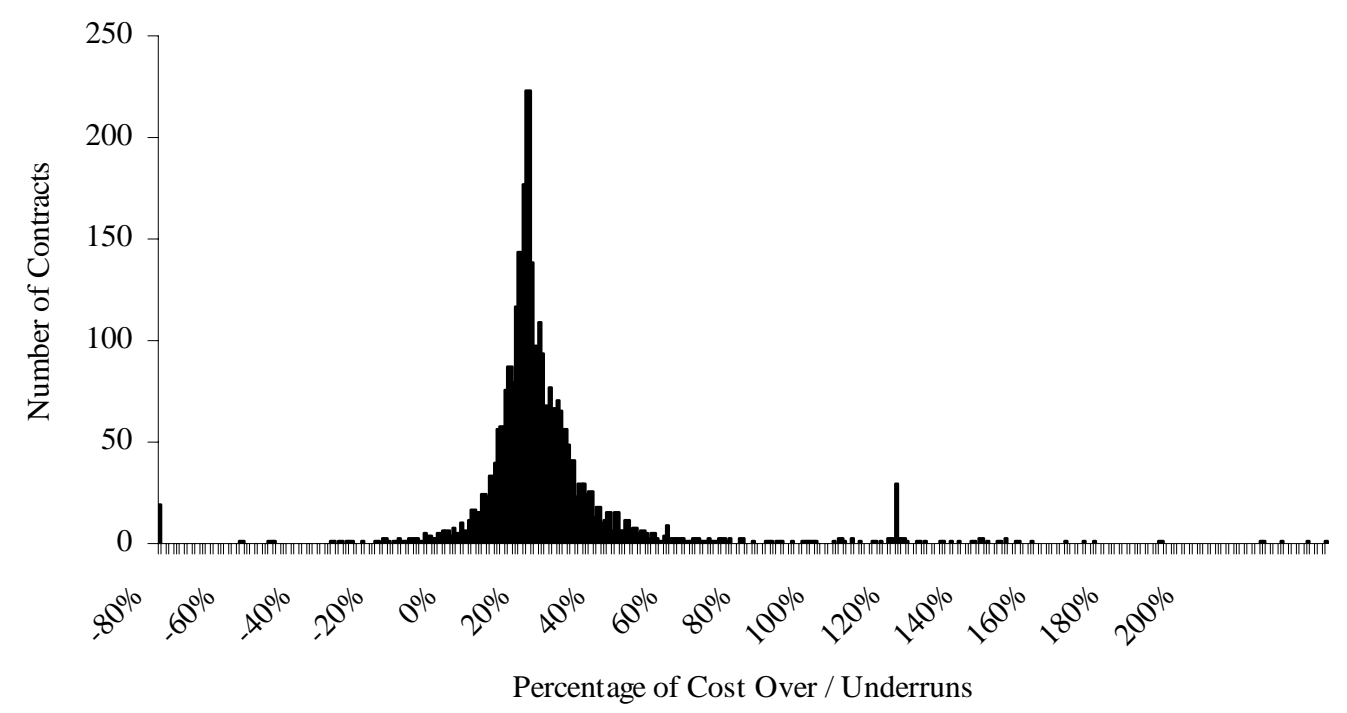

Figure 6.8: Distribution of Contracts with Cost Overruns or Underruns

There were 18 contracts in the database for which no final amount was provided. Therefore, cost under and overrun data were available for 2,650 projects. As seen in Figure 6.8, the data generally appears to be normally distributed, and a chi-squared test was carried out to ascertain the normality assumption for this dataset. The standard value for $95 \%$ confidence interval and degree of freedom of 40 is 55.76. The basic statistics of the cost overrun rate are shown in Table 6.4.

Table 6.4: Basic Statistics of the Cost Overrun Rate

\begin{tabular}{lc}
\hline \multicolumn{1}{c}{ Statistics } & Value \\
\hline Valid Observations & 2,589 \\
\hline Mean & $3.02 \%$ \\
\hline Standard Deviation & $14.91 \%$ \\
\hline Range & $199.39 \%$ \\
\hline Minimum & $-99.54 \%$ \\
\hline Maximum & $99.85 \%$ \\
\hline
\end{tabular}


Two tests were done using log-normal distributions. The value for the log-normal was very large (55.76) indicating that the data did not follow a log-normal distribution. The value for the normal distribution was computed as 2.52 . As this value was lower than 55.76, the data could be assumed to follow a normal distribution. Figure 6.9 presents the fitted distribution along with the observed data.

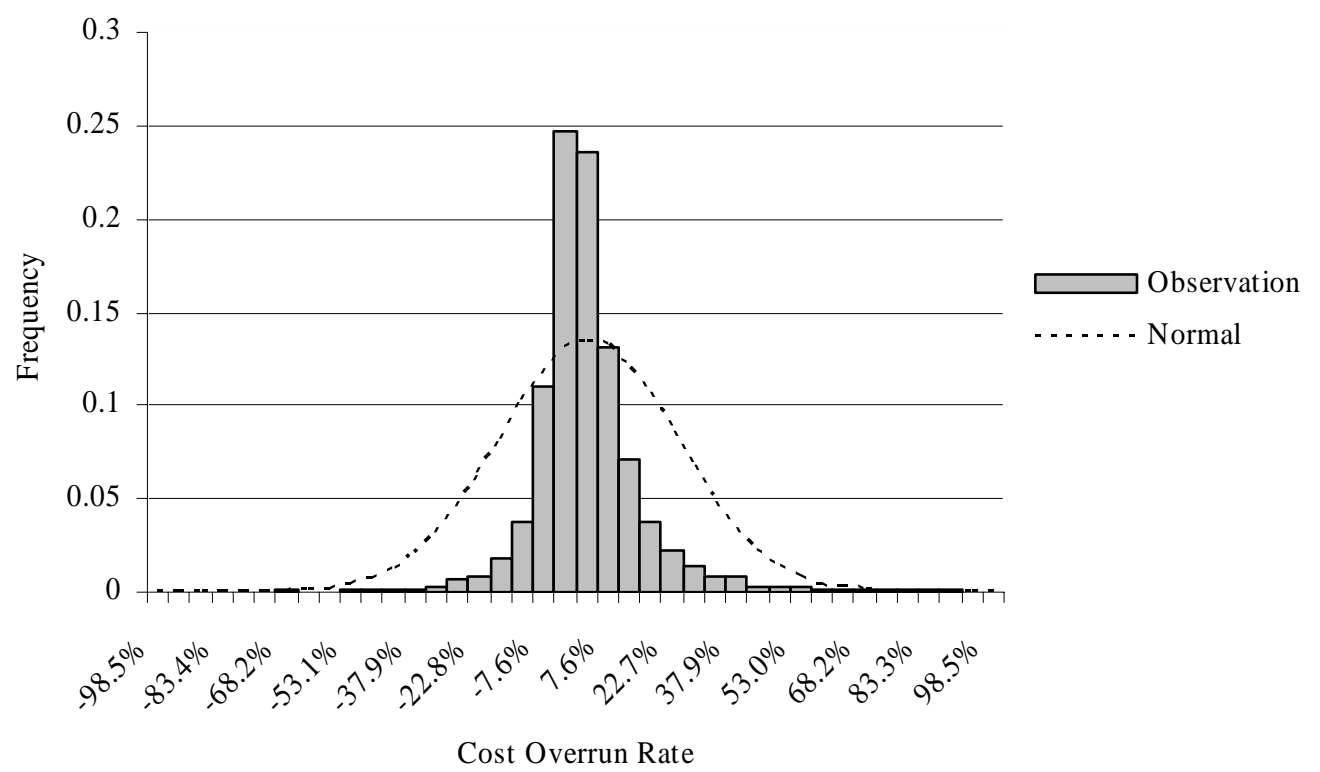

Figure 6.9: Frequency Distribution of Cost Overrun Rates

It is important to note that there were more cost overruns than cost underruns in term of frequency (positive mean) and that the dispersion around this mean of 3.02\% was quite large (14.91\%). During the analysis period, 1,947 contracts experienced cost overruns and 1,166 contracts had cost underruns. Only 435 contract final costs were the same as the original bid amount. Since 1997, the total amount of cost overruns has decreased. In 2001, the total cost of overruns was $\$ 17,028,137$. Figures 6.10 and 6.11 show the extensiveness and severity of cost overruns in Indiana between 1996 and 2001.

In a situation similar to that of liquidated damages, cost overruns were both extensive and severe in 1997. Moreover, it can be noticed that after 1997, the average cost overruns per cost overrun contract per year decreased to a level close to that of 1996.

A detailed statistical description of the average cost overrun amount was carried out for each project type and bid amount category, and is presented in the following section. Bid amounts were categorized into four groups as shown in Table 6.5. 


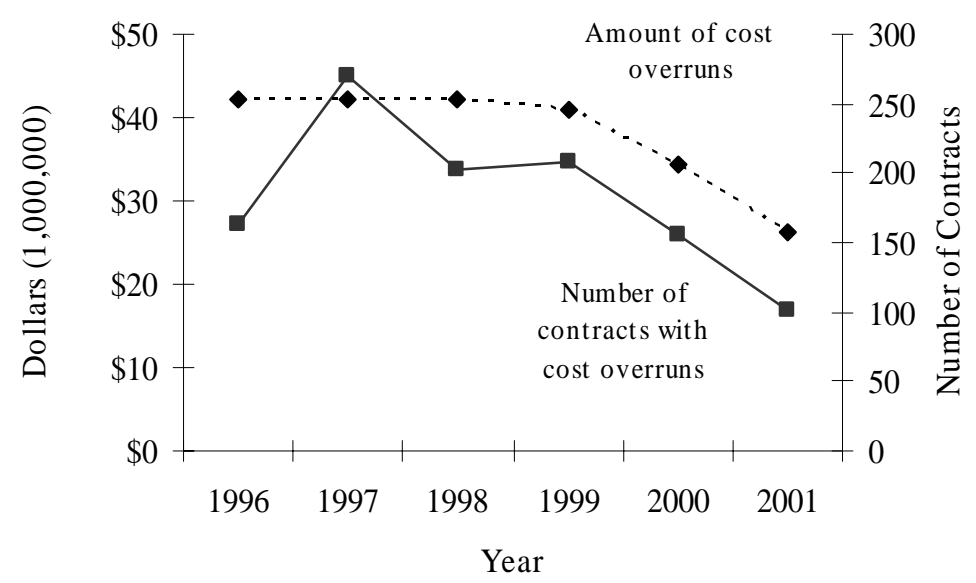

Figure 6.9: Annual Frequency and Amounts of Cost Overruns, 1996 - 2001

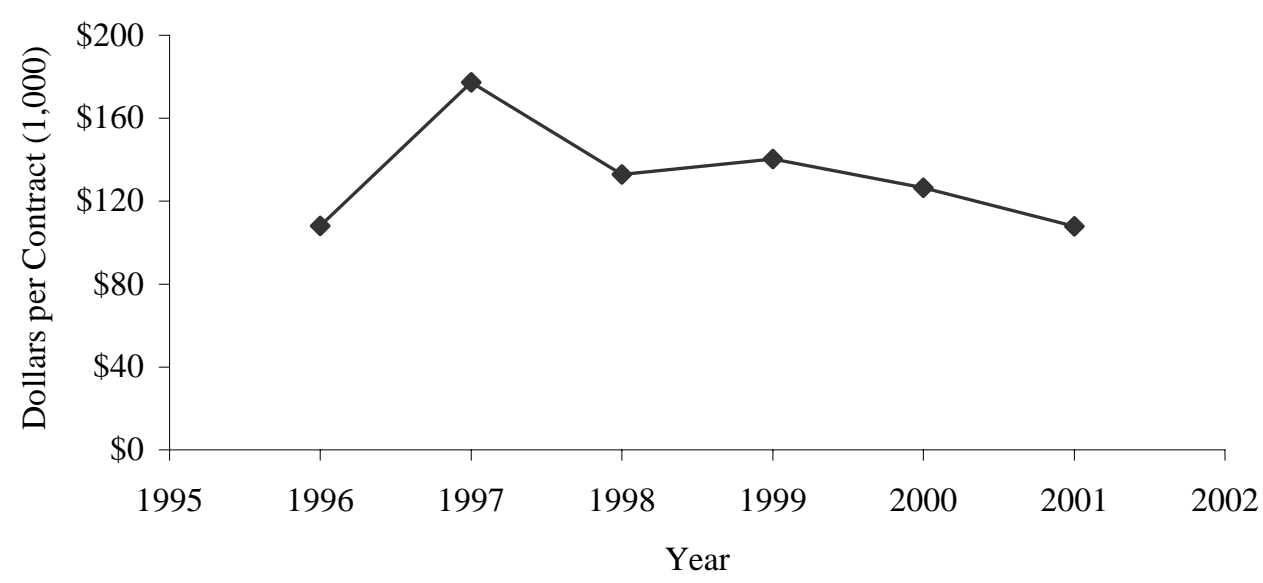

Figure 6.10: Average Cost Overrun per Contract, per Year

Table 6.5: Bid Amount Categories

\begin{tabular}{lccc}
\hline \multicolumn{1}{c}{ Bid Amount Category } & More than & and less than & Number of Contracts \\
\hline Low Bid Amount & $\$ 0$ & $\$ 100,000$ & 551 \\
\hline Medium Bid Amount & $\$ 100,000$ & $\$ 500,000$ & 1,054 \\
\hline High Bid Amount & $\$ 500,000$ & $\$ 1,000,000$ & 436 \\
\hline Very High Bid Amount & $\$ 1,000,000$ & & 627 \\
\hline
\end{tabular}


Table 6.6 presents the average cost overrun amounts for a given project characterized by district, project type, and bid amount category. It is seen that the average amount of cost overrun for a contract was $\$ 43,661$. Also, Fort Wayne had the highest average amount among all districts, and the resurfacing project experienced the highest average cost overrun amount among all project types.

Table 6.6: Average Cost Overrun Amounts

\begin{tabular}{|c|c|c|c|c|c|c|c|c|}
\hline \multirow[b]{2}{*}{ Project } & \multirow{2}{*}{$\begin{array}{l}\text { Category of } \\
\text { Bid Amount } \\
\text { in Thousand }\end{array}$} & \multicolumn{7}{|c|}{ District } \\
\hline & & $\begin{array}{l}\text { Crawford- } \\
\text { sville }\end{array}$ & $\begin{array}{c}\text { Fort } \\
\text { Wayne }\end{array}$ & Greenfield & LaPorte & Seymour & Vincennes & $\begin{array}{c}\text { Average } \\
\text { for any } \\
\text { District }\end{array}$ \\
\hline \multirow{5}{*}{ Bridge } & $\$ 0-100$ & 15,956 & 163 & 2,364 & $-2,096$ & 7,616 & -920 & 5,046 \\
\hline & $\$ 100-500$ & 5,544 & 9,637 & $-7,518$ & 81,658 & 15,570 & 11,050 & 18,000 \\
\hline & $\$ 500-1,000$ & 21,559 & 48,270 & 12,799 & 24,643 & $-22,278$ & 10,282 & 15,531 \\
\hline & $>\$ 1,000$ & 146,334 & 180,450 & 182,902 & 59,450 & 130,664 & 266,952 & 146,926 \\
\hline & Total & 47,510 & 51,708 & 35,296 & 48,172 & 34,407 & 39,850 & 41,778 \\
\hline \multirow{5}{*}{ Maintenance } & $\$ 0-100$ & 38,923 & 8,426 & 5,037 & 14,190 & 17,795 & 5,394 & 13,577 \\
\hline & $\$ 100-500$ & -994 & 13,841 & 9,410 & $-10,806$ & 9,917 & 14,964 & 6,221 \\
\hline & $\$ 500-1,000$ & 8,003 & 18,871 & $-2,857$ & 67,817 & 9,073 & $-19,525$ & 12,971 \\
\hline & $>\$ 1,000$ & 310,710 & 373,885 & 129,171 & 75,046 & 186,532 & $-16,813$ & 162,746 \\
\hline & Total & 80,476 & 90,409 & 45,861 & 30,859 & 58,661 & 1,113 & 49,851 \\
\hline \multirow{5}{*}{$\begin{array}{l}\text { Road } \\
\text { Construction }\end{array}$} & $\$ 0-100$ & 9,412 & 10,521 & 9,882 & 8,591 & 5,621 & 3,543 & 8,416 \\
\hline & $\$ 100-500$ & 12,204 & 8,455 & 7,885 & 12,989 & 6,297 & 3,125 & 8,356 \\
\hline & $\$ 500-1,000$ & $-12,419$ & $-6,087$ & 73,198 & $-20,026$ & $-43,239$ & 16,452 & 5,861 \\
\hline & $>\$ 1,000$ & $-178,643$ & 326,902 & $-21,063$ & 135,216 & $-27,959$ & 145,561 & 58,179 \\
\hline & Total & $-38,976$ & 54,655 & 13,736 & 27,177 & $-9,709$ & 46,915 & 18,964 \\
\hline \multirow{5}{*}{ Resurfacing } & $\$ 0-100$ & 5,747 & 6,761 & -75 & 20,621 & 7,213 & -749 & 6,240 \\
\hline & $\$ 100-500$ & 9,114 & $-3,392$ & 5,304 & $-2,902$ & 8,246 & 6,054 & 3,949 \\
\hline & $\$ 500-1,000$ & 30,525 & $-8,691$ & 6,913 & 70,938 & 126,080 & 60,511 & 40,233 \\
\hline & $>\$ 1,000$ & 405,952 & 147,459 & 501,329 & 111,212 & 263,886 & 152,209 & 264,214 \\
\hline & Total & 66,724 & 43,883 & 126,847 & 38,367 & 120,218 & 50,699 & 78,931 \\
\hline \multirow{5}{*}{ Traffic } & $\$ 0-100$ & $-1,664$ & 4,787 & 9,194 & 2,506 & 13,192 & $-4,022$ & 4,753 \\
\hline & $\$ 100-500$ & 9,525 & 43,474 & 7,061 & $-2,373$ & 6,457 & -840 & 9,886 \\
\hline & $\$ 500-1,000$ & 64,399 & 62,883 & 66,793 & 34,618 & 148,206 & $-12,992$ & 59,836 \\
\hline & $>\$ 1,000$ & 33,489 & 468,285 & $-195,361$ & 53,727 & 78,621 & $-13,170$ & 93,705 \\
\hline & Total & 20,140 & 140,525 & $-26,399$ & 16,367 & 43,492 & $-5,127$ & 33,678 \\
\hline \multirow{5}{*}{$\begin{array}{l}\text { Traffic } \\
\text { Maintenance }\end{array}$} & $\$ 0-100$ & -44 & $-6,836$ & 116,668 & $-1,618$ & -303 & & 27,456 \\
\hline & $\$ 100-500$ & $-4,300$ & 42,222 & $-25,410$ & $-41,487$ & 16,240 & & 5,024 \\
\hline & $\$ 500-1,000$ & 147,464 & & & 46,743 & $-93,638$ & & 36,828 \\
\hline & $>\$ 1,000$ & 38,483 & 269,469 & & 515,589 & 807,217 & & 380,045 \\
\hline & Total & 36,312 & 86,769 & 45,629 & 57,736 & 111,177 & & 69,924 \\
\hline \multirow{5}{*}{ Total } & $\$ 0-100$ & 13,546 & 6,468 & 8,243 & 6,453 & 10,200 & 1,715 & 8,117 \\
\hline & $\$ 100-500$ & 6,064 & 14,185 & 2,743 & 19,923 & 9,821 & 7,143 & 9,688 \\
\hline & $\$ 500-1,000$ & 22,713 & 12,912 & 28,160 & 27,581 & 24,380 & 7,875 & 21,781 \\
\hline & $>\$ 1,000$ & 143,626 & 297,685 & 125,660 & 88,716 & 146,400 & 94,023 & 147,922 \\
\hline & Total & 39,584 & 75,666 & 37,365 & 34,057 & 50,808 & 25,560 & 43,661 \\
\hline
\end{tabular}


If the distribution of cost overrun amounts is examined by project type and by bid amount category, it is seen that the average amount of cost overrun is the highest for an original bid amount greater than $\$ 1$ million. It can be noticed that for bid amounts less than $\$ 1$ million, the average cost overrun is of the same magnitude and is much lower than for those bid amounts greater than $\$ 1$ million. For road construction, traffic, and resurfacing, the districts experienced very different types of cost under and overruns. If cost overrun amounts were examined by district and bid amount category, it is seen (Table 6.3) that for every district there are more cost overruns for expensive (over \$1 million) projects. Graphical illustrations of these results are presented in Appendix E.

Figure 6.5 shows the variation of the average cost overrun amount by project and by district. For bridge projects, no district consistently had the highest average cost overrun amount over the analysis period: Fort Wayne was highest in 1996, LaPorte in 1997, Crawfordsville in 1998, Vincennes in 1999, Greenfield in 2000, and Seymour in 2001. In 2000, highest average cost overruns for road construction, resurfacing, and traffic projects occurred in Crawfordsville, Fort Wayne, and Greenfield Districts, respectively.

Figure 6.6 shows the distribution of cost overruns by project type. The shape was the same for each type. Moreover, the trend at the extremes was the same although the number of contracts with low cost under or overruns differed by project type. Bridge projects had the highest curve, then maintenance, road construction, resurfacing, and traffic. The traffic maintenance curve was very low because of the very small amount of contracts in this category.

Figure 6.11 presents cost overrun rates by dividing all of the data points Figure 6.6 by the total number of contracts in each project type category. It appears that the five major project types exhibited similar distributions. 
Bridge Project

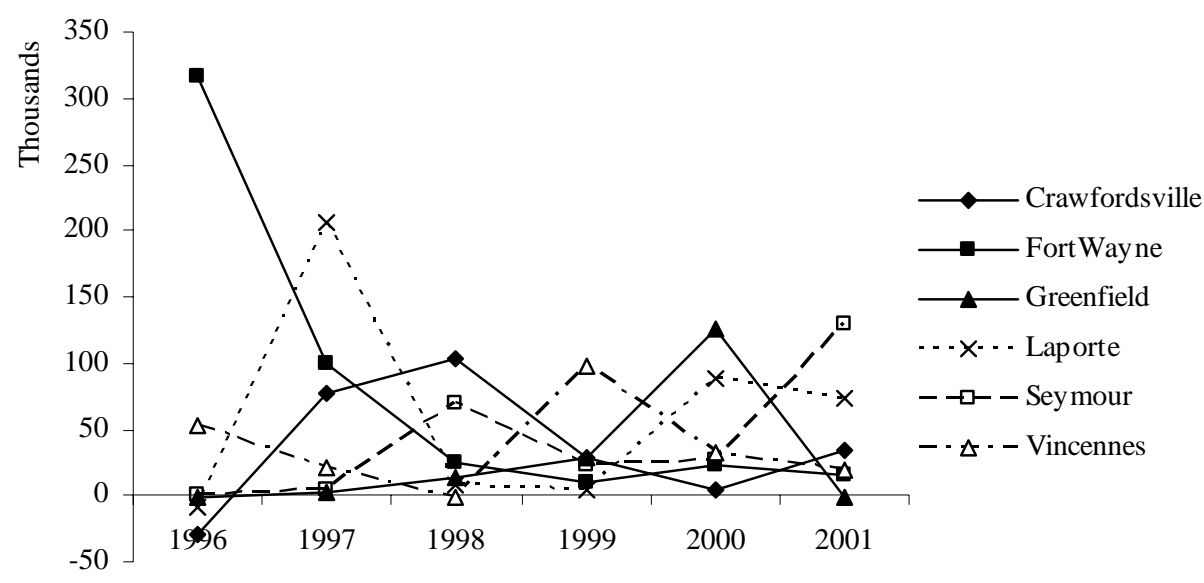

Road Construction Project

M aintenance Project
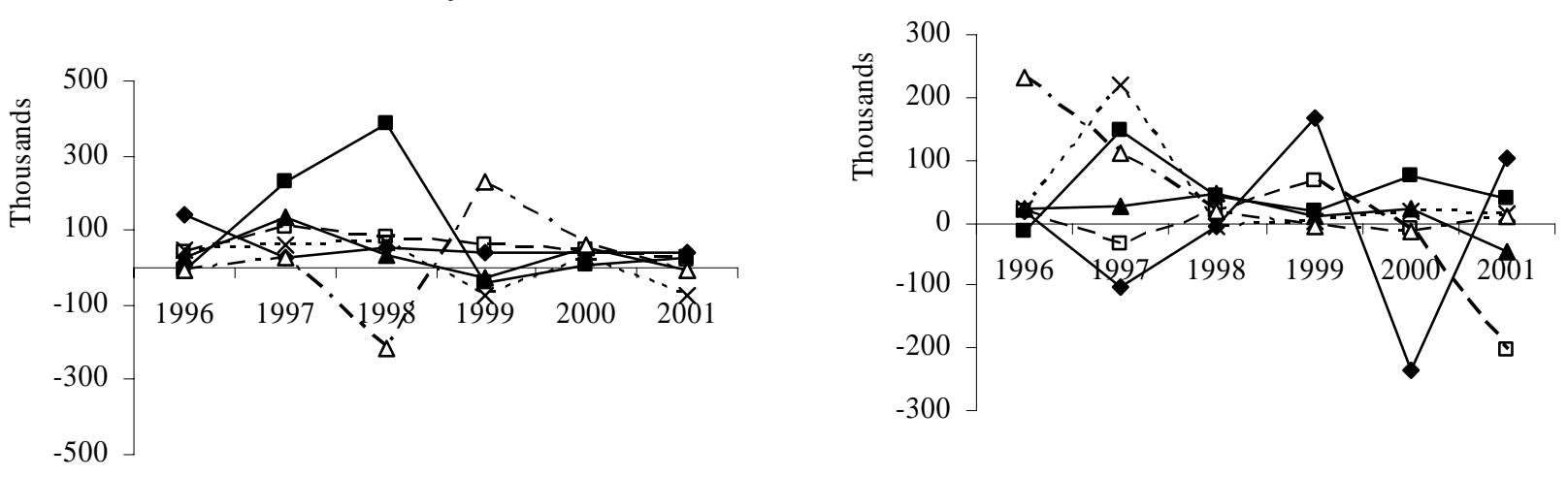

Resurfacing Project

Traffic Project
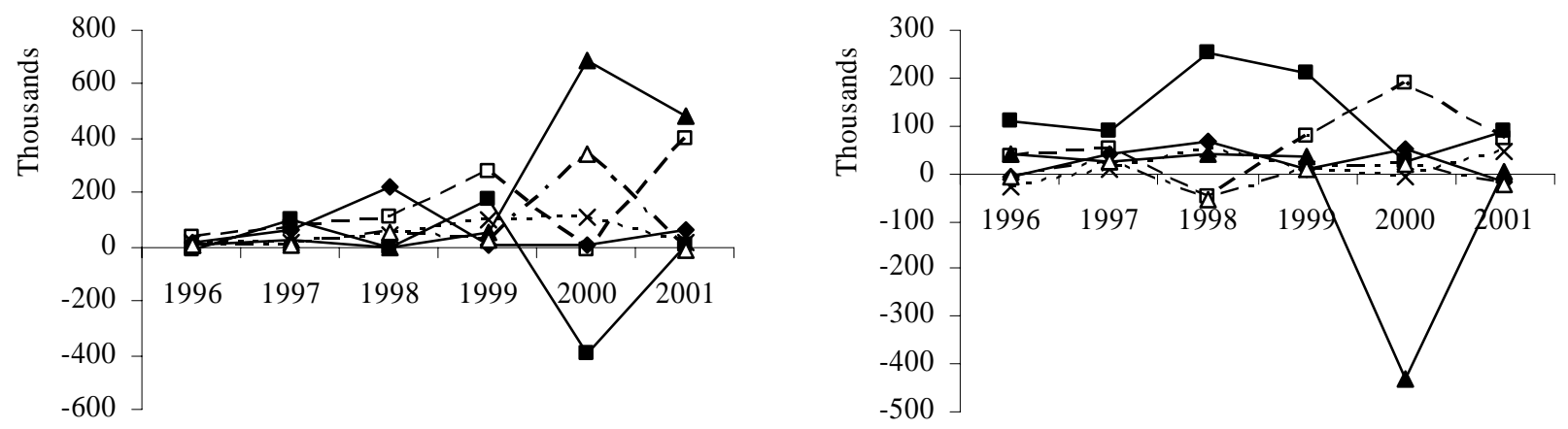

Figure 6.11: Variation of the Average Cost Overrun Amount by Project Type and by District 


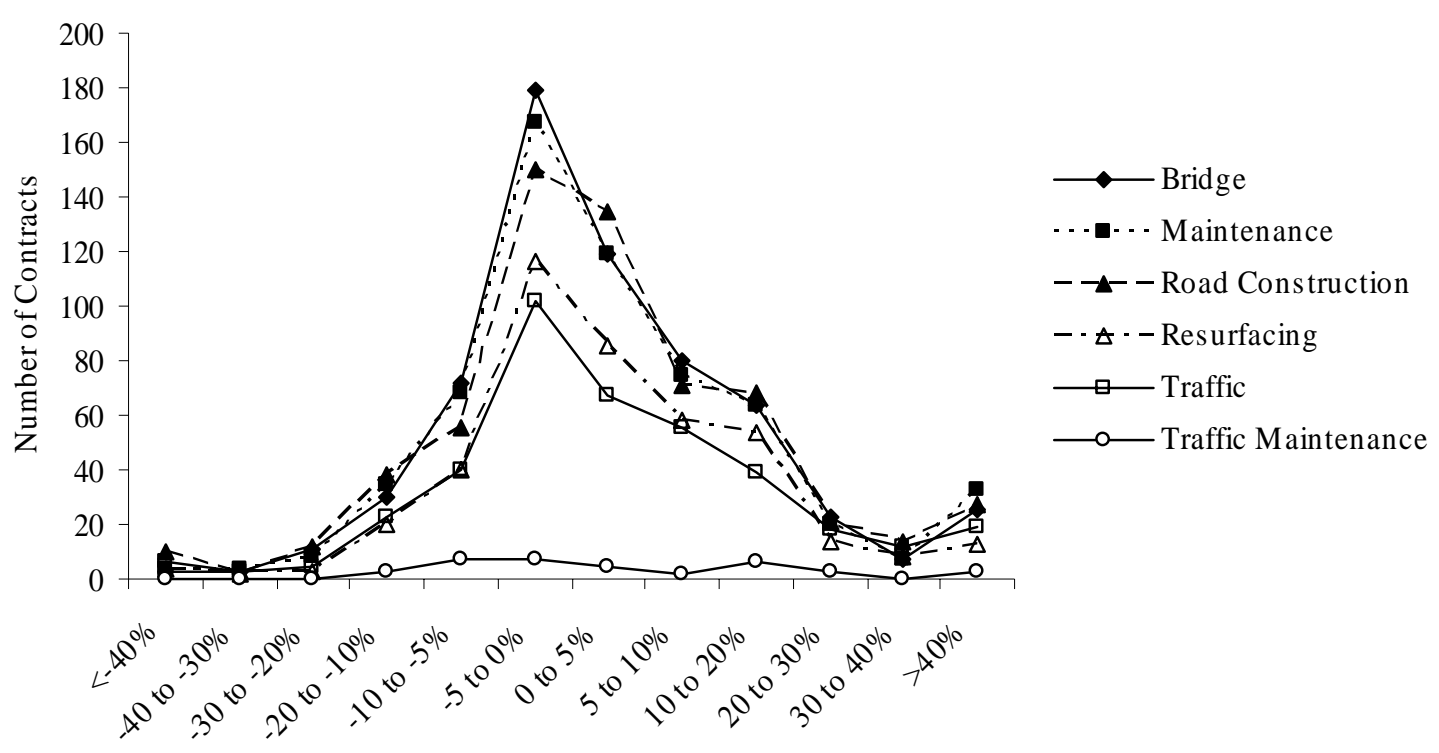

Figure 6.12: Frequency of Cost Overrun Rates by Project Type

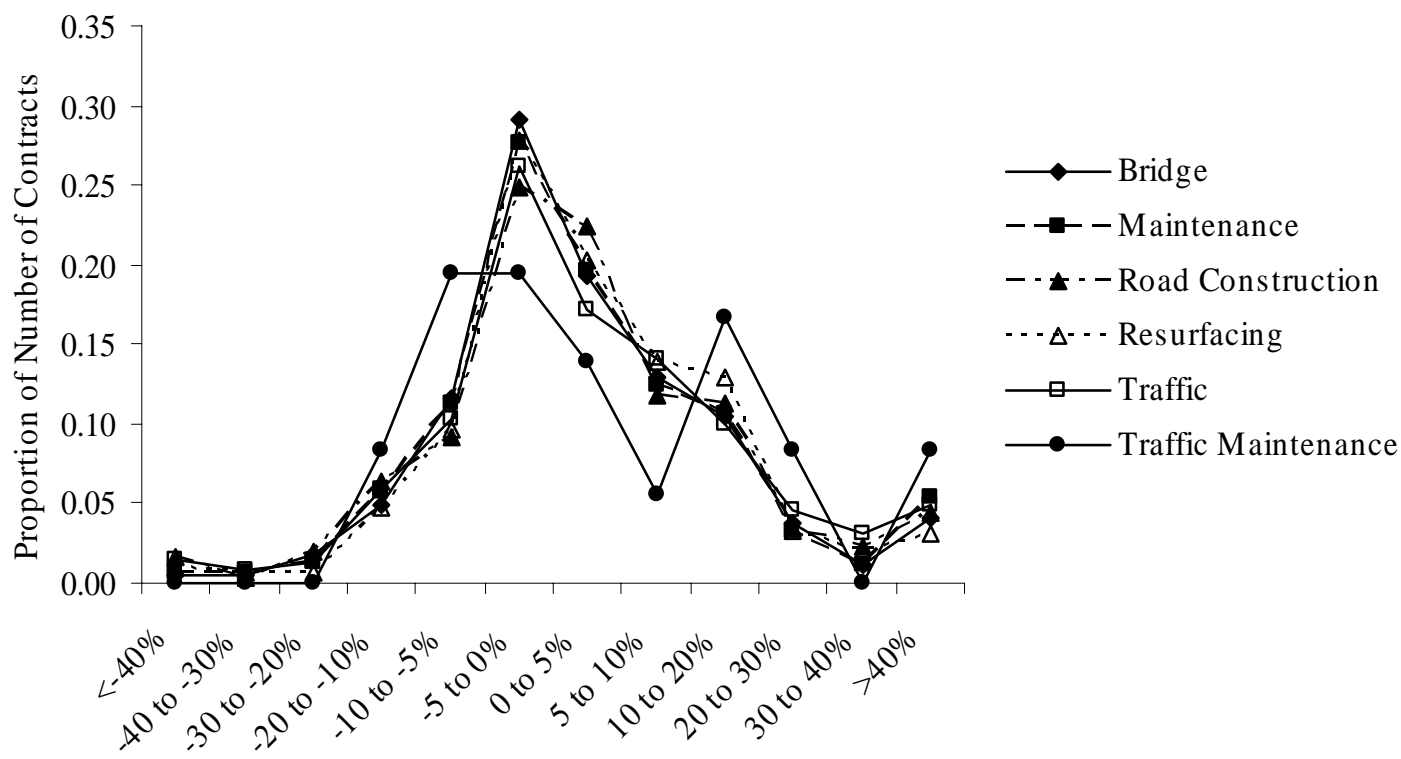

Figure 6.13: Relative Frequency of Cost Overrun Rates by Project Type 


\subsubsection{Cost Underruns}

Figure 6.14 shows the number of cost underrun contracts in various percentage ranges. For example, the majority of the contracts (645 out of the 1,166 contracts) had cost underruns in the 5\% range. However, Figure 6.9 shows that the cost underruns ranges of $-10 \%$ to $-5 \%$ and $-20 \%$ to $-10 \%$ were dominant in terms of dollars associated with each cost underrun rate category. These two figures show that the category of underrun " $<-40 \%$," for instance, was not extensive but rather was severe. This concerned only ten contracts but represented over $\$ 6,300,000$. These underrun amounts were taken into account in the bid amount although they were actually not spent.

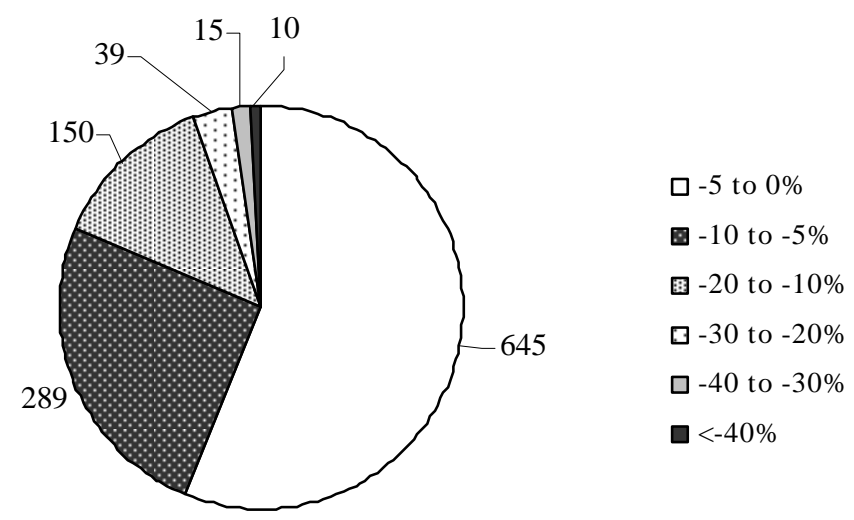

Figure 6.14: Number of Contracts by Cost Underrun Category

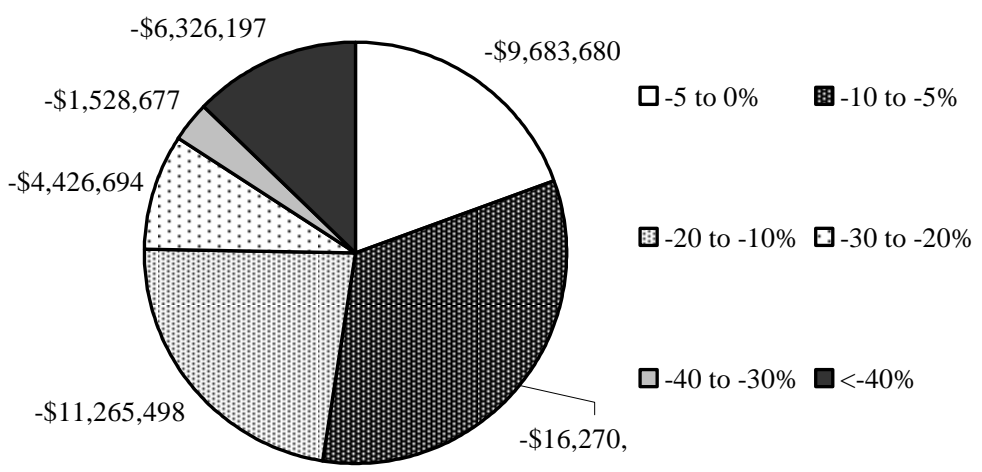

Figure 6.15: Value of Underrun Amounts by Underrun Category 


\subsubsection{Cost Overruns}

Figure 6.16 shows the percentage of cost overrun contracts in various ranges. The highest number of overruns was in the $0-5 \%$ range. The next highest was the $5-10 \%$ range, and the third highest was the 10-20\% range. Approximately one in every four contracts had cost overruns within the range of 5-20\%. Figure 6.17 shows that approximately half of the expenditure incurred on cost overruns was in the $5-20 \%$ range.

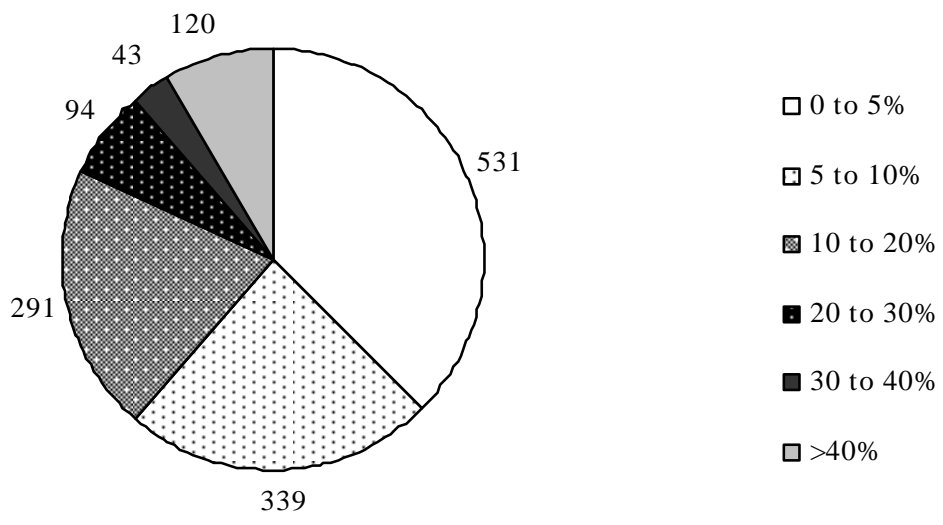

Figure 6.16: Number of Contracts by Cost Overrun Category

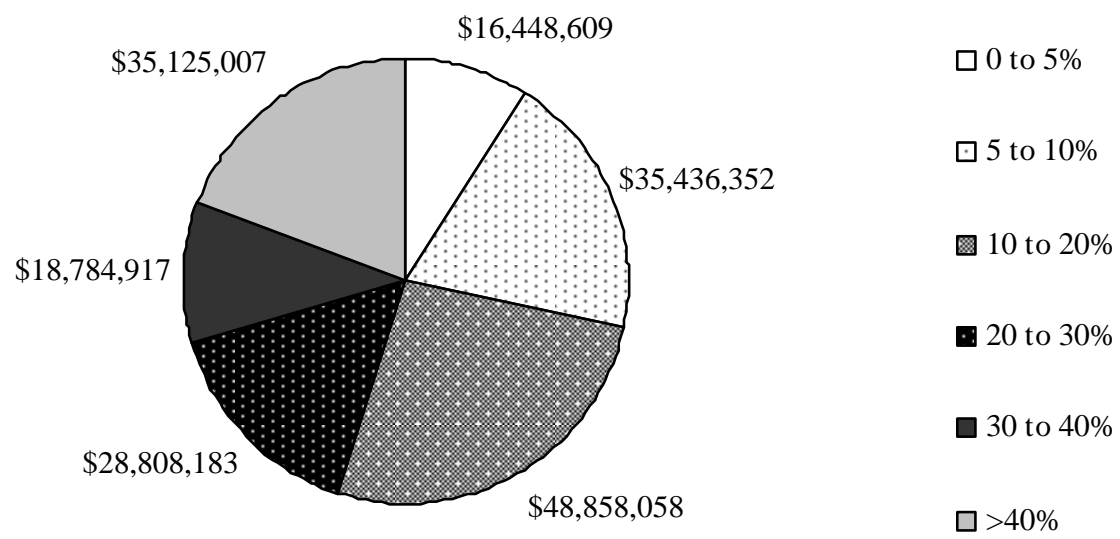

Figure 6.17: Cost Overrun Amounts by Overrun Category 
In the case of cost overruns, it is important to consider the severity and the extensiveness of the trend, particularly in the categories " 0 to 5\%" and "30 to 40\%." The first category represented 531 projects with less than $\$ 16,500,000$, and the second category had only 43 projects and represented more than $\$ 18,700,000$ of cost overruns. Figure 6.18 provides an alternative representation of the categorization of cost over/under runs in Indiana within the analysis period. As the figure shows, the money saved due to cost underruns in that period did not compensate for that incurred due to cost overruns.

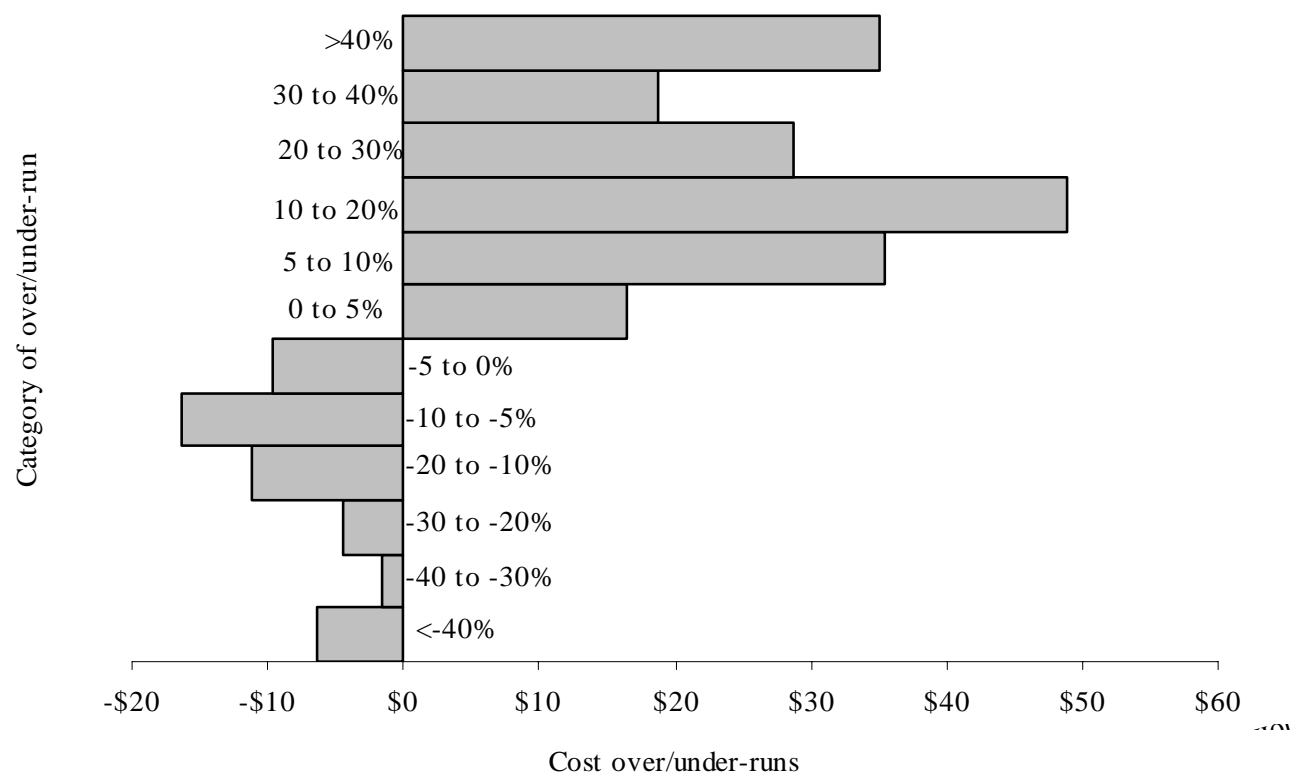

Figure 6.18: Cost Over/Underrun Amount by Over/Underrun Category 


\subsection{Change Orders}

\subsubsection{General Description of the Change Orders}

A total of 2,668 contracts was available to study daily change orders. Table 6.7 shows that an average contract had between four and five daily change orders. Figure 6.19 shows the distribution of the number of change orders. Most contracts had fewer than nine change orders.

Table 6.7: Descriptive Statistics of Change Order Frequency.

\begin{tabular}{lc}
\hline \multicolumn{1}{c}{ Statistics } & Number of contracts \\
\hline Number of observations & 2,668 \\
\hline Mean & 5 \\
\hline Standard Deviation & 6 \\
\hline Variance & 34 \\
\hline Range & 55 \\
\hline Minimum & 0 \\
\hline Maximum & 55 \\
\hline
\end{tabular}

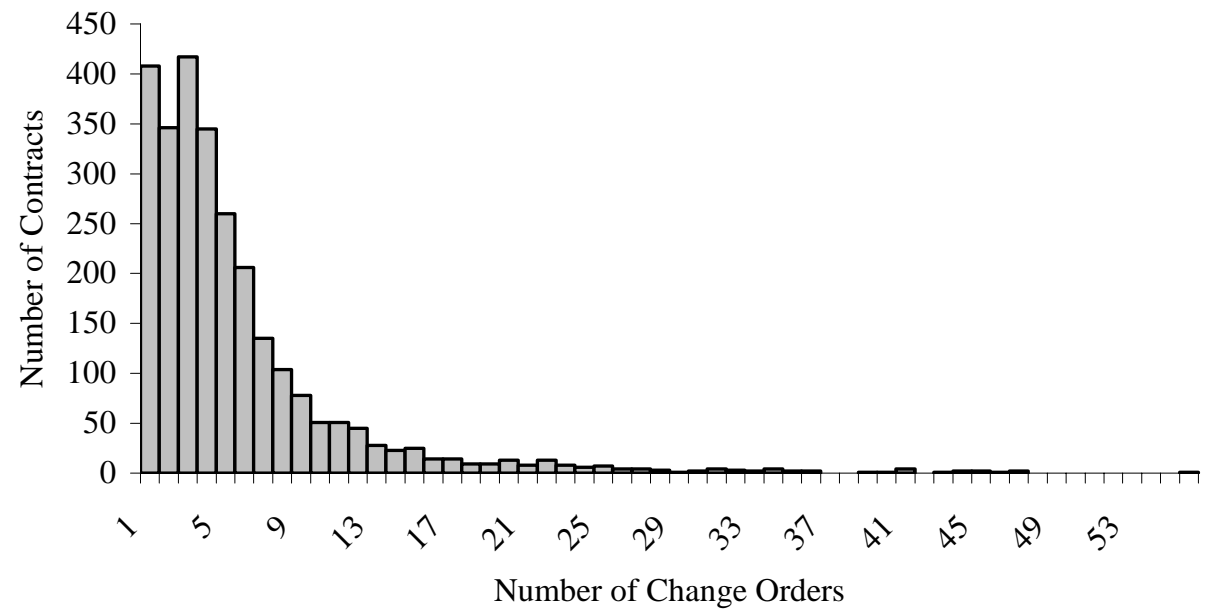

Figure 6.19: Distribution of the Number of Daily Change Orders per Contract

In a bid to investigate whether the distribution of the number of daily change orders per contract followed any standard distribution, three tests were carried out: normal, log normal, and Poisson distributions. Figure 6.20 shows plots of such distributions with their respective means and standard deviations. Good fits were obtained for the normal and lognormal distributions (0.72 and 
2.45, respectively) compared to the maximum expected (74.47 with a 95\% confidence). The Poisson distribution did not give good results although it seems to fairly fit the observed distribution.

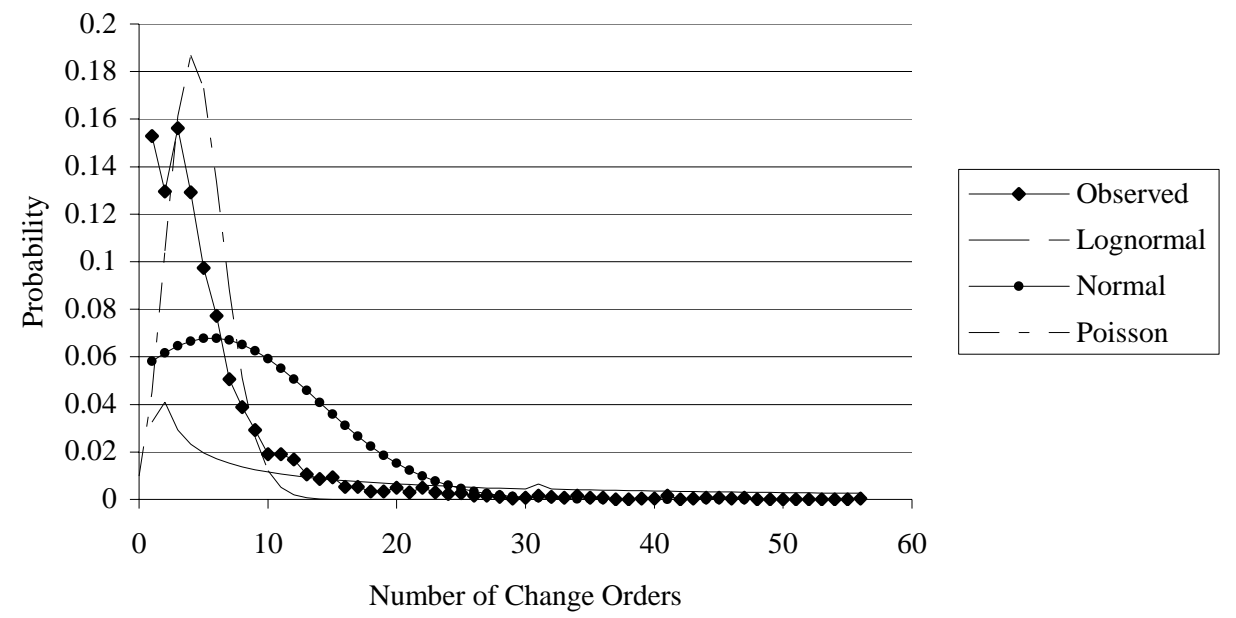

Figure 6.20: Plot of the Observed Values, Normal, and Log Normal Distributions for the Number of Daily Change Orders

Table 6.8 describes the total amount of change orders (in dollars) for each contract. It shows that out of 2,668 contracts, 413 contracts did not require change orders and for 340 projects, the final contract amount after the change orders was reduced. However, Table 6.2 also shows that the main part of the change orders increases the project cost.

Table 6.8: Distribution of Daily Change Order Frequency

\begin{tabular}{ccc}
\hline \multicolumn{2}{c}{ Total Amount of Change Orders } & Number of contracts \\
\hline More than & Less than \\
\hline \multicolumn{3}{c}{0} \\
\hline 0 & 0 & 340 \\
\hline 0 & 10,000 & 413 \\
\hline 10,000 & 20,000 & 466 \\
\hline 20,000 & 30,000 & 205 \\
\hline 30,000 & 40,000 & 149 \\
\hline 40,000 & 50,000 & 118 \\
\hline 50,000 & 100,000 & 63 \\
\hline 100,000 & 500,000 & 276 \\
\hline 500,000 & $1,000,000$ & 470 \\
\hline $1,000,000$ & & 94 \\
\hline
\end{tabular}




\subsubsection{Reasons for Change Orders}

The change orders described in the previous section contained various small-amount change orders issued daily for various reasons. Detailed information relating to such change orders could not be obtained. As such available data pertain to change orders of only 822 contracts between 1996 and 1999. This involved a total of 17,992 change orders. Figure 6.21 provides the distribution of the average number of change orders per contract, for these contracts.

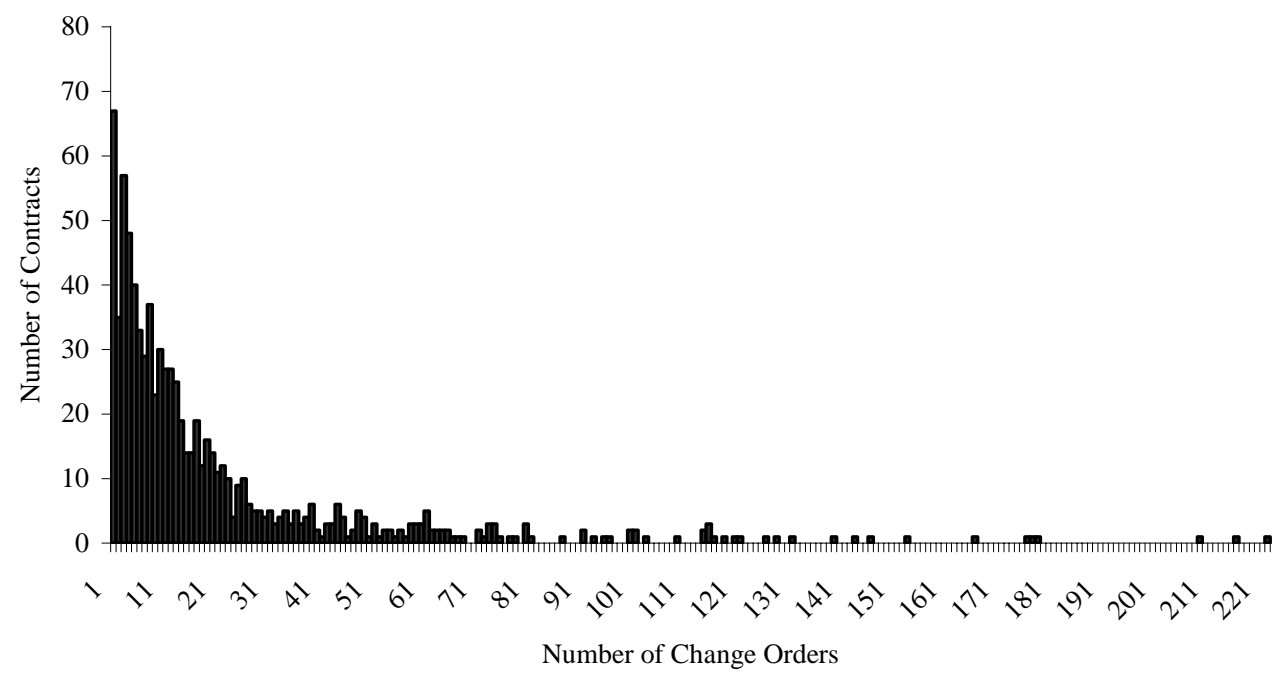

Figure 6.21: Distribution of the Number of Contract Change Orders

Table 6.9 provides a general overview of the change order reasons. The "amount" column shows the amount spent for the 822 contracts for a particular change order reason. The next column gives the number of change orders corresponding to the change order reason, and the "rate" column gives the importance in terms of dollars of each change order reason. The "no recorded reason" category represents approximately $\$ 29$ million for 6,024 change orders and 224 contracts. The "errors and omissions” category (100) represents approximately \$12 million for 3,937 change orders and 476 contracts. The “constructability” category (200) represents approximately \$10 million for 3,227 change orders and 410 contracts. The “scope changes” category (300) represents approximately \$7 million for 2,093 change orders and 278 contracts. The "changed field conditions" category (400) represents approximately \$2 million for 1,813 change orders and 324 contracts. The "failed materials" category (500) represents approximately $-\$ 1$ million for 392 change orders and 251 contracts. The “incentive/disincentive” category (600) represents $\$ 4$ million for 116 change orders and 22 contracts. The “standard specifications update or changes” category (700) represents $\$ 700,000$ for 390 change 
orders and 94 contracts. The total number of 2,079 contracts is much higher than the original 822 contracts because there are many different types of reason category in a same contract.

Table 6.9: Reasons for Change Orders

\begin{tabular}{|c|c|c|c|c|}
\hline $\begin{array}{c}\text { Reason } \\
\text { Code }\end{array}$ & Reason for Change Order & Amount & Number & Rate \\
\hline 000 & No Recorded Reason & $\$ 29,288,445.35$ & 6,024 & $45.28 \%$ \\
\hline$\overline{101}$ & ERRORS \& OMISSIONS, Contract Related & $\$ 1,100,928.48$ & 378 & $1.70 \%$ \\
\hline 102 & ERRORS \& OMISSIONS, Design Related & $\$ 9,416,964.21$ & 1,743 & $14.56 \%$ \\
\hline 103 & ERRORS \& OMISSIONS, Environmental & $\$ 70,567.28$ & 42 & $0.11 \%$ \\
\hline 104 & ERRORS \& OMISSIONS, Materials Related & $\$ 5,574.99$ & 97 & $0.01 \%$ \\
\hline 105 & ERRORS \& OMISSIONS, Permits & $\$ 2,727.50$ & 4 & $0.00 \%$ \\
\hline 106 & ERRORS \& OMISSIONS, Quantity Related & $\$ 1,142,288.56$ & 1,358 & $1.77 \%$ \\
\hline 107 & ERRORS \& OMISSIONS, R/W Related & $\$ 15,450.89$ & 14 & $0.02 \%$ \\
\hline 108 & ERRORS \& OMISSIONS, Soils Related & $-\$ 41,469.41$ & 14 & $-0.06 \%$ \\
\hline 109 & ERRORS \& OMISSIONS, Staging Related & $-\$ 110,666.64$ & 14 & $-0.17 \%$ \\
\hline 110 & ERRORS \& OMISSIONS, Traffic Control & $\$ 723,059.88$ & 260 & $1.12 \%$ \\
\hline 111 & ERRORS \& OMISSIONS, Utilities Related & $\$ 50,060.88$ & 13 & $0.08 \%$ \\
\hline 201 & CONSTRUCTABILITY, Construction Related & $\$ 3,661,076.21$ & 1,792 & $5.66 \%$ \\
\hline 202 & CONSTRUCTABILITY, Design Related & $\$ 3,396,308.49$ & 580 & $5.25 \%$ \\
\hline 203 & CONSTRUCTABILITY, Environmental Related & $\$ 192,384.05$ & 57 & $0.30 \%$ \\
\hline 204 & CONSTRUCTABILITY, Materials Related & $\$ 707,927.02$ & 258 & $1.09 \%$ \\
\hline 205 & CONSTRUCTABILITY, R/W Related & $\$ 71,599.73$ & 19 & $0.11 \%$ \\
\hline 206 & CONSTRUCTABILITY, Soils Related & $\$ 950,976.50$ & 104 & $1.47 \%$ \\
\hline 207 & CONSTRUCTABILITY, Staging Related & $-\$ 42,970.52$ & 43 & $-0.07 \%$ \\
\hline 208 & CONSTRUCTABILITY, Traffic Control & $\$ 670,108.10$ & 300 & $1.04 \%$ \\
\hline 209 & CONSTRUCTABILITY, Utilities Related & $\$ 99,648.15$ & 74 & $0.15 \%$ \\
\hline 301 & SCOPE CHANGES, FHWA & $\$ 70,921.94$ & 6 & $0.11 \%$ \\
\hline 302 & SCOPE CHANGES, Central Office & $\$ 3,110,165.84$ & 277 & $4.81 \%$ \\
\hline 303 & SCOPE CHANGES, District/Subdistrict & $\$ 1,555,618.77$ & 290 & $2.41 \%$ \\
\hline 304 & SCOPE CHANGES, District Construction Eng & $\$ 519,015.68$ & 125 & $0.80 \%$ \\
\hline 305 & SCOPE CHANGES, Area Engineer & $\$ 305,965.65$ & 288 & $0.47 \%$ \\
\hline 306 & SCOPE CHANGES, Project Engr/Supervisor & $-\$ 118,425.72$ & 340 & $-0.18 \%$ \\
\hline 307 & SCOPE CHANGES, Traffic Engineer & $\$ 396,932.79$ & 253 & $0.61 \%$ \\
\hline 308 & SCOPE CHANGES, Local Agency Request & $\$ 856,812.54$ & 462 & $1.32 \%$ \\
\hline 309 & SCOPE CHANGES, Public/Political Request & $\$ 167,123.14$ & 52 & $0.26 \%$ \\
\hline 401 & CHANGED COND, Construction Related & $\$ 1,317,316.52$ & 1,473 & $2.04 \%$ \\
\hline 402 & CHANGED COND, Environmental Related & $\$ 248,912.51$ & 48 & $0.38 \%$ \\
\hline 403 & CHANGED COND, Materials Related & $\$ 124,549.99$ & 107 & $0.19 \%$ \\
\hline 404 & CHANGED COND, R/W Related & $-\$ 26,324.45$ & 20 & $-0.04 \%$ \\
\hline 405 & CHANGED COND, Soils Related & $\$ 808,472.88$ & 94 & $1.25 \%$ \\
\hline 406 & CHANGED COND, Staging Related & $-\$ 149,318.87$ & 35 & $-0.23 \%$ \\
\hline 407 & CHANGED COND, Utilities Related & $\$ 148,829.06$ & 36 & $0.23 \%$ \\
\hline 500 & FAILED MATERIAL & $-\$ 1,062,604.73$ & 392 & $-1.64 \%$ \\
\hline 601 & INCENTIVE/DISINCENT, Contract Compl & $\$ 1,780,056.84$ & 10 & $2.75 \%$ \\
\hline 602 & INCENTIVE/DISINCENT, Contract Payments & $\$ 138,260.17$ & 8 & $0.21 \%$ \\
\hline 603 & INCENTIVE/DISINCENT, Cost Reduction & $-\$ 34,452.97$ & 95 & $-0.05 \%$ \\
\hline 604 & INCENTIVE/DISINCENT, A+B Contract & $\$ 1,700,000.00$ & 2 & $2.63 \%$ \\
\hline 605 & INCENTIVE/DISINCENT, A+B+C Contract & $\$ 700,000.00$ & 1 & $1.08 \%$ \\
\hline 701 & STANDARDS/SPECS CHANGE, Completion Time & $\$ 298,176.36$ & 124 & $0.46 \%$ \\
\hline 702 & STANDARDS/SPECS CHANGE, Contract Payment & $-\$ 32,128.47$ & 15 & $-0.05 \%$ \\
\hline 703 & STANDARDS/SPECS CHANGE, Other & $\$ 481,777.95$ & 251 & $0.74 \%$ \\
\hline Total & TOTAL & $\$ 64,676,643.12$ & 17,992 & \\
\hline
\end{tabular}


Figure 6.22 presents the annual number of change orders for which reasons are provided, between 1996 and 2001. Most change order reason information came from contracts in year 2000, which experienced almost 5,700 change orders with given reasons. Figure 6.23 shows that most of the change orders concerned road construction contracts, with 9,402 change order reasons. Only 96 change orders were recorded for traffic maintenance projects between 1996 and 1999.

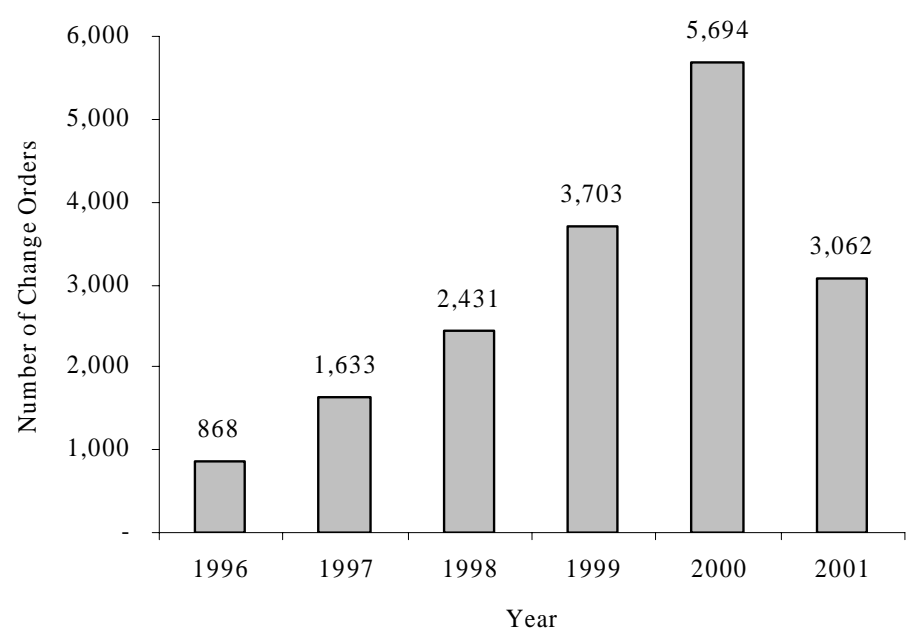

Figure 6.22: Annual Number of Change Orders for which Reasons were Provided

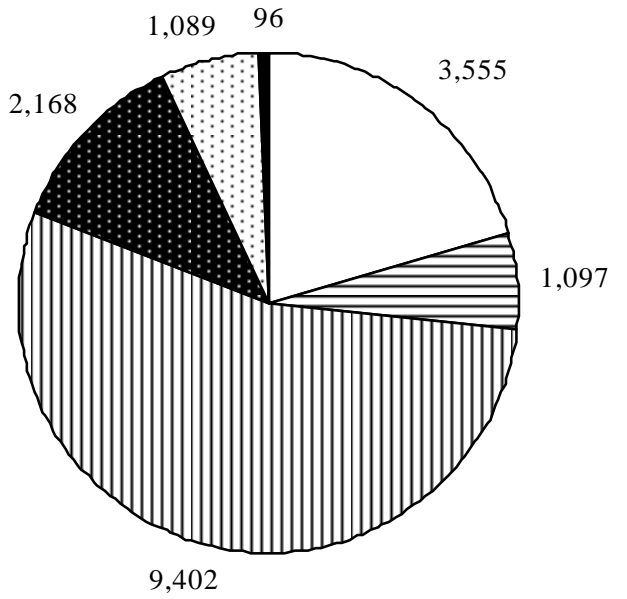

$\square$ Bridge (3,555)

曰 Maintenance $(1,097)$

ㅁ Road Construction $(9,402)$

Resurfacing $(2,168)$

$\square$ Traffic $(1,089)$

- Traffic Maintenance (96)

Figure 6.23: Available Change Order Reason Data per Project Type 
Figure 6.24 presents the number of available change orders per district. The Greenfield District experienced more change orders than the other districts, with 4,599 change orders. Also, Vincennes District experienced the least number of change orders.

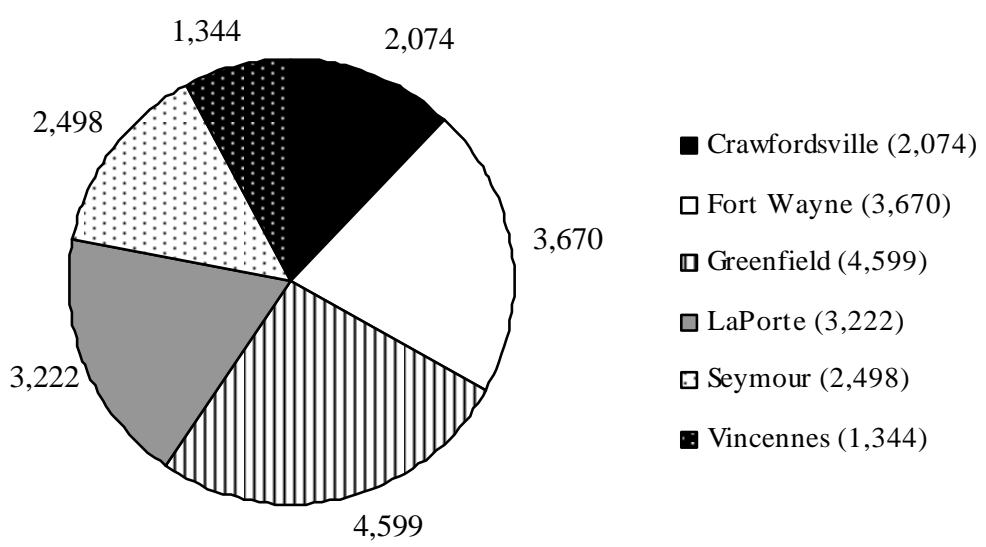

Figure 6.24: Availability of Change Order Reason Data per District

Figure 6.25 shows that the most frequent reasons for change order were "construction-related constructability”, “design-related error and omissions”, “construction-related changed conditions”, and quantity-related error and omissions”. Figure 6.26 presents the total amount involved in each type of change orders. Figure 6.27 provides an indication of the average dollar amount involved per change order. "No recorded reason" as used in this section of the report actually means no reason was indicated for the change order as seen in the records, even though it is likely that there actually was a reason. There were 6,024 change orders in the "no reason," while 8,612 change orders were assigned a reason. The bar charts shown on Figure 6.25 does not include reason types for change orders associated with very high amounts. These are: “A+B", “ $A+B+C$ ", and contract completion incentive/disincentive” change orders which represented approximately $\$ 850,000, \$ 700,000$, and $\$ 178,000$, respectively. The overall average change order amount was $\$ 1,245$.

The responsibility for these change orders was defined in the available dataset and is presented as Table 6.10. It is seen that most change orders are the responsibility of INDOT and its consultants. One category is the responsibility of FHWA, and seven others are the responsibility of the contractors. 


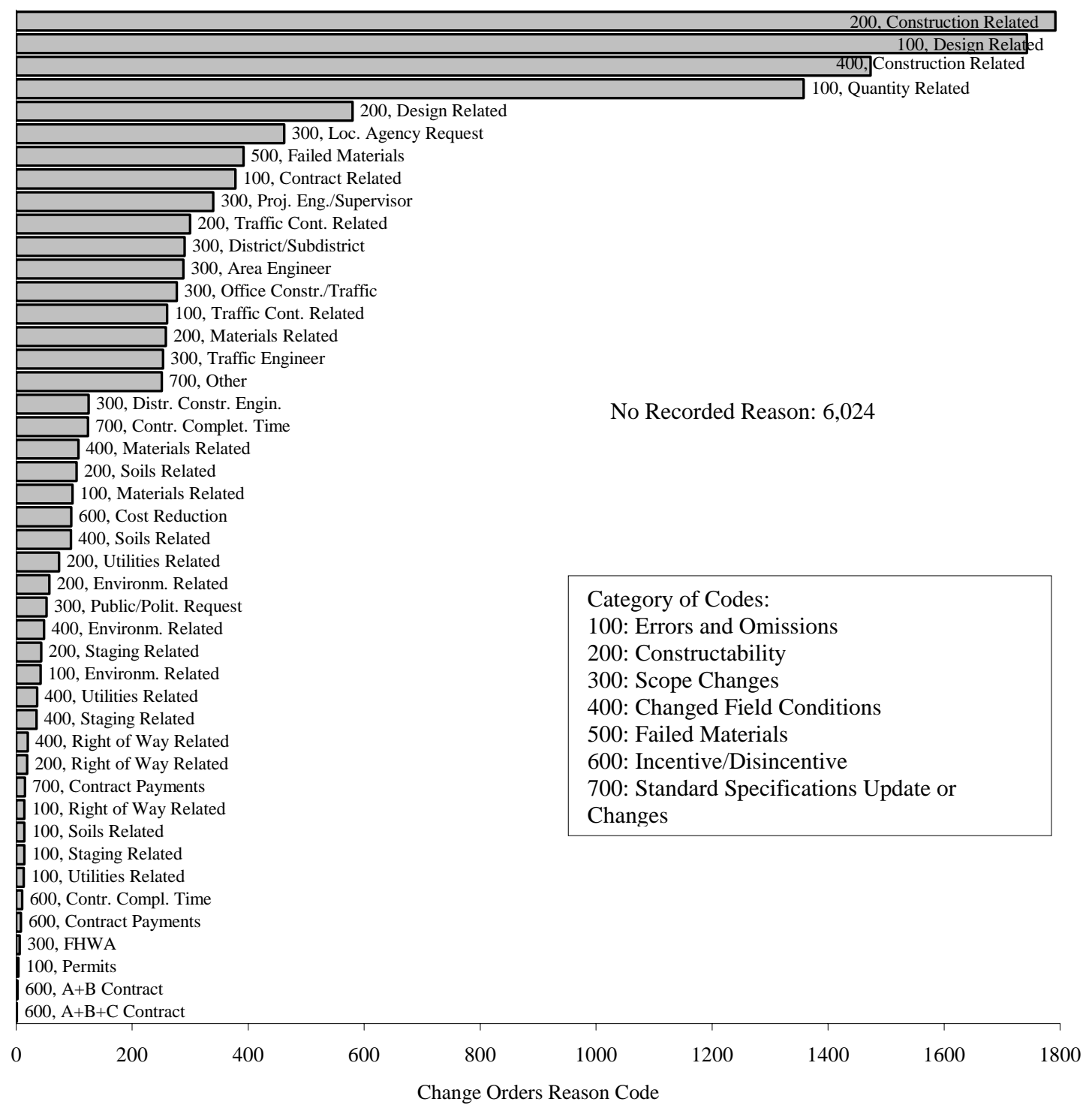

Figure 6.25: Distribution of the Number of Change Orders by Reason Type for all Types of Projects 


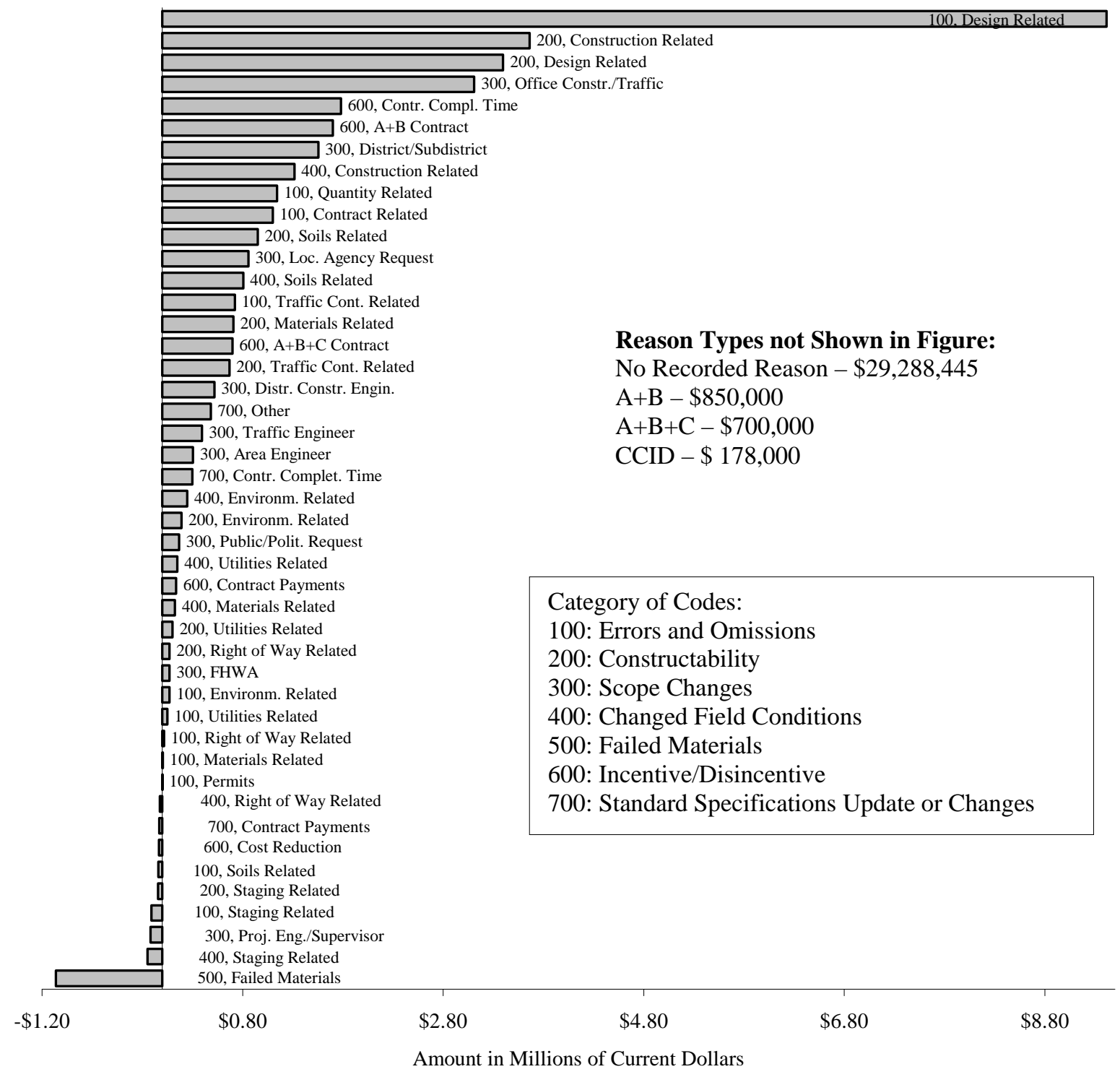

Figure 6.26: Distribution of Total Change Order Amounts by Change Order Type 


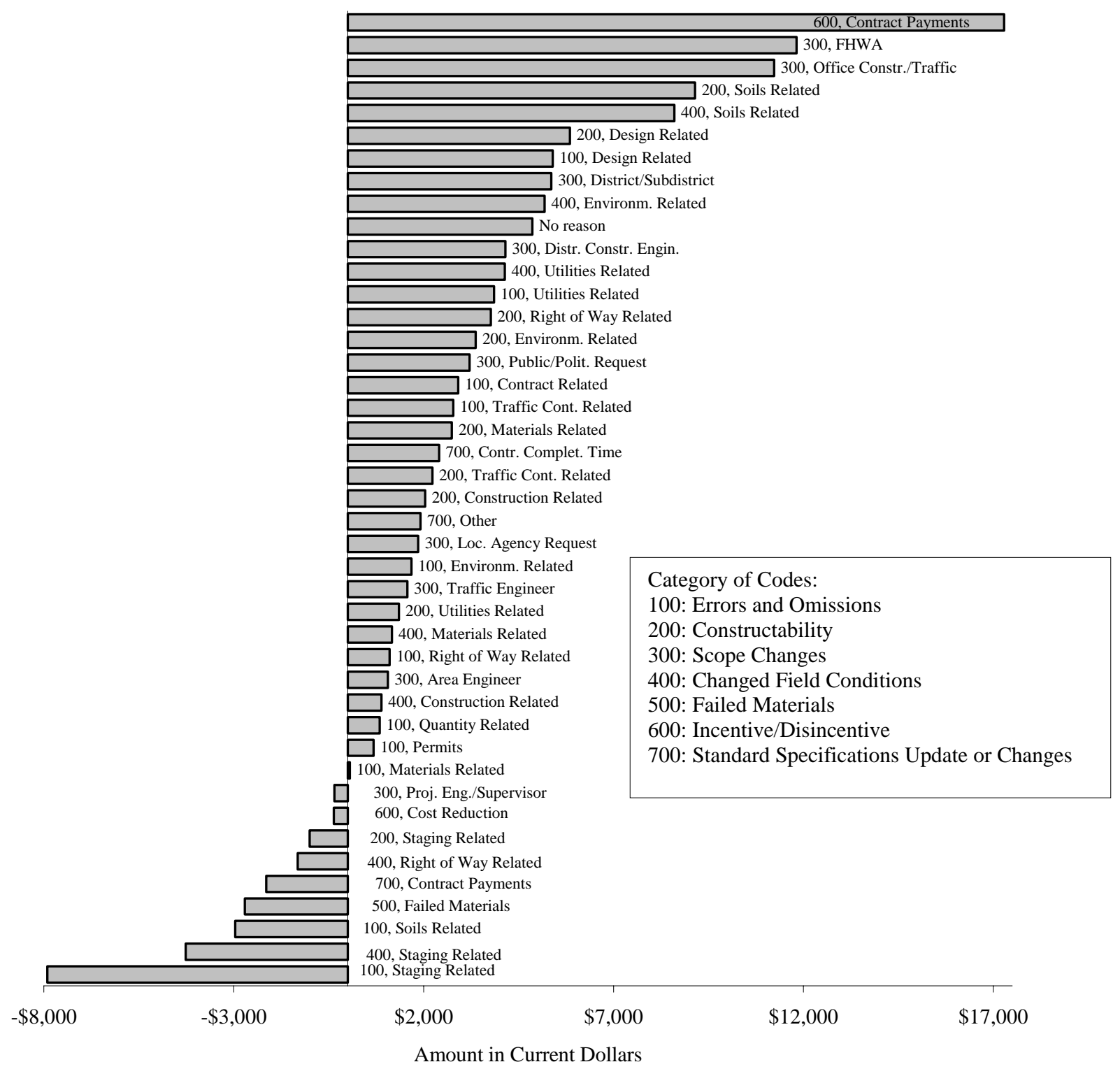

Figure 6.27: Distribution of the Average Amount per Change Order by Reason Type

for all Types of Projects 
Table 6.10: Responsibility of Change Orders

\begin{tabular}{|c|c|c|}
\hline Code & Reason & Responsibility \\
\hline 101 & Errors \& Omissions, Contract Related & INDOT \\
\hline 102 & Errors \& Omissions, Design Related & INDOT \\
\hline 103 & Errors \& Omissions, Environmental Related & INDOT \\
\hline 104 & Errors \& Omissions, Materials Related & INDOT \\
\hline 105 & Errors \& Omissions, Permits & INDOT \\
\hline 106 & Errors \& Omissions, Quantity Related & INDOT \\
\hline 107 & Errors \& Omissions, Right of Way Related & INDOT \\
\hline 108 & Errors \& Omissions, Soils Related & INDOT \\
\hline 109 & Errors \& Omissions, Staging Related & INDOT \\
\hline 110 & Errors \& Omissions, Traffic Control Related & INDOT \\
\hline 111 & Errors \& Omissions, Utilities Related & INDOT \\
\hline 201 & Constructability, Construction Related & Contractors \\
\hline 202 & Constructability, Design Related & INDOT \\
\hline 203 & Constructability, Environmental Related & INDOT \\
\hline 204 & Constructability, Materials Related & Contractors \\
\hline 205 & Constructability, Right of Way Related & INDOT \\
\hline 206 & Constructability, Soils Related & INDOT \\
\hline 207 & Constructability, Staging Related & Contractors \\
\hline 208 & Constructability, Traffic Control Related & INDOT \\
\hline 209 & Constructability, Utilities Related & INDOT \\
\hline 301 & Scope Changes, FHWA & FHWA \\
\hline 302 & Scope Changes, Central Office Construction/Traffic & INDOT \\
\hline 303 & Scope Changes, District/Subdistrict & INDOT \\
\hline 304 & Scope Changes, District Construction Engineer & INDOT \\
\hline 305 & Scope Changes, Area Engineer & INDOT \\
\hline 306 & Scope Changes, Project Engineer/Supervisor & INDOT \\
\hline 307 & Scope Changes, Traffic Engineer & INDOT \\
\hline 308 & Scope Changes, Local Agency Request & INDOT \\
\hline 309 & Scope Changes, Public/Political Request & INDOT \\
\hline 401 & Changed Field conditions, Construction Related & Contractors \\
\hline 402 & Changed Field conditions, Environmental Related & INDOT \\
\hline 403 & Changed Field conditions, Materials Related & Contractors \\
\hline 404 & Changed Field conditions, Right of Way Related & INDOT \\
\hline 405 & Changed Field conditions, Soils Related & INDOT \\
\hline 406 & Changed Field conditions, Staging Related & Contractors \\
\hline 407 & Changed Field conditions, Utilities Related & INDOT \\
\hline 500 & Failed Materials, & Contractors \\
\hline 601 & Incentive/Disincentive, Contract Completion Time & INDOT \\
\hline 602 & Incentive/Disincentive, Contract Payments & INDOT \\
\hline 603 & Incentive/Disincentive, Cost Reduction & INDOT \\
\hline 604 & Incentive/Disincentive, $\mathrm{A}+\mathrm{B}$ Contract & INDOT \\
\hline 605 & Incentive/Disincentive, $\mathrm{A}+\mathrm{B}+\mathrm{C}$ Contract & INDOT \\
\hline 701 & Stand/Spec Update or Changes, Contract Completion Time & INDOT \\
\hline 702 & Stand/Spec Update or Changes, Contract Payments & INDOT \\
\hline 703 & Stand/Spec Update or Changes, Other & INDOT \\
\hline
\end{tabular}


The data shows that over $\$ 30$ million of change orders were the responsibility of INDOT or their consultants; approximately $\$ 70,000$ was due to FHWA, and over $\$ 4.5$ million was due to the contractors. Change orders are classified as preventable or non preventable. In Indiana, there is clear definition of what constitutes a preventable or non preventable change order [INDOT, 2002]. Preventable change orders include those due to errors and omissions in contract documents, constructability problems, and changes in scope of the project. On the other hand, non preventable change orders are those associated with changed field conditions, failed materials, incentive/disincentive provisions, and changes or updates to standards/specifications. Further explanation of each category of preventable and non preventable change orders are provided in Appendices $\mathrm{A}$ and $\mathrm{C}$ of this report. Using these definitions, the present study determined that of the \$30 million due to INDOT or its consultants for change orders incurred on contract between 1996 and 2001, about \$25 million was preventable.

For bridge projects, the reasons associated with the highest change order amount were "design related errors and omissions", and construction related changes field conditions. Again, the "no reason" change orders represented more than $\$ 6.5$ million, which is large compared to the approximately\$10million spent overall in change orders in this category (bridge projects). More than \$2.5 million was related to change orders due to INDOT, with more than \$2.3 million that could have been prevented. FHWA was responsible for no change orders in bridge projects, less than \$1 million was due to the contractors, and more than half of it could have been prevented.

Road construction projects also experienced the highest amount of change orders in the type “design related errors and omission." The "no reason" was approximately \$19.8 million, while the total amount of change orders for bridge projects was approximately \$40 million. More than \$19 million was the responsibility of INDOT, and more than \$14 million could have been prevented. More than $\$ 700,000$ spent on change orders were due to the contractors and actually about \$1 million were preventable (some not preventable change orders were negative amounts).

The most important reasons for change orders in terms of amount spent in maintenance projects were the following: "design related errors and omissions," "construction completion time in constructability," and "construction and environmental related changed filed conditions." In maintenance projects, the "no reason" change orders represented more than $\$ 532,000$. The percentage of the dollar amount of "no reason" change order out of the total change order amount for maintenance projects (22.4\%) was not as high as for other project categories. For maintenance projects, about \$1.5 million of the change orders out of $\$ 2.37$ million was the responsibility, of INDOT, with less than $\$ 900,000$ preventable. Moreover, the contractors were responsible for more than $\$ 380,000$, with half 
of it preventable. The data on this project category did not indicate any FHW A responsibility for change orders.

For traffic projects, the amount of money spent in change orders involved mostly traffic related reasons ("traffic engineer" and "scope changes"). It is also interesting to notice that in this category of projects, "construction related changes field conditions" and district construction engineering scope changes," the change orders resulted in a smaller final amount (were negative amounts). Approximately $\$ 680,000$ was the responsibility of INDOT and most of it was preventable. About $\$ 118,000$ out of $\$ 380,000$ in change orders that were the responsibility of the contractors could have been prevented.

For resurfacing, "design related errors and omissions" and "construction related in constructability" Were the main reasons for change order amounts. For such projects, approximately all of \$5.3 million spent on INDOT responsible change orders could have been prevented. Approximately \$1.3million was the responsibility of the contractors, but most of this amount came from "construction related constructability: and was preventable. In this category of projects, over $\$ 70,000$ was attributed to FHWA change orders.

Among the 96 change orders recorded in the traffic maintenance projects, only 2 had a reason for such change orders, "construction related changed filed conditions" and "district/sub district scope changes".

Concerning the distribution of change order reasons per district location, the "errors and omission, design related" was always at the first or second position for the most expensive reasons for change orders, except in the Crawfordsville District where it was at the fourth position. The "error and omission" reason category was in every district the most expensive one in terms of change order attributable to INDOT.

Figure 6.26 shows that the most influential change order reason was "design related errors and omissions," with almost $\$ 10$ million. It must be added that for approximately $\$ 29,300,000$ (which represents $45 \%$ of the total change orders available for the study) no explicit reason was given for the change order. Figure 6.26 does not take into account such "no-reason" change orders. A second category of reasons for change orders was "construction-related and design-related constructability" and "Central Office scope changes," with approximately \$3.1 to \$3.6 million. Some change order reasons do not represent a large amount, such as, the following "errors and omissions reasons": "environmental-related," "utilities-related," "right-of-way related," "materials-related,” and "permits related.” On the contrary, the failed material reason for change orders generally resulted in a diminution of the contract amount. Indeed, it is obvious that INDOT would not pay for a failed work. 
Tables 1 to 5 present the average number of change orders (per contract) by district, bid amount category and reason category (bridge, maintenance, road construction, resurfacing, traffic and traffic maintenance projects) The change order reason categories corresponded to the following categories: 0: no reason given, 1: errors and omissions, 2: constructability, 3: scope changes, 4: changed field conditions, 5: failed materials, 6: incentive/disincentive, 7: standard specifications update or changes.

Table 6.11: Average Number of Bridge Contract Change Orders

\begin{tabular}{|c|c|c|c|c|c|c|c|c|c|c|}
\hline \multirow{2}{*}{$\begin{array}{c}\text { Category of Bid } \\
\text { Amount }\end{array}$} & \multirow[b]{2}{*}{ District } & \multicolumn{8}{|c|}{ Change Order Reason Category } & \multirow[b]{2}{*}{$\begin{array}{c}\text { Any } \\
\text { Reason }\end{array}$} \\
\hline & & 0 & 1 & 2 & 3 & 4 & 5 & 6 & 7 & \\
\hline \multirow{7}{*}{$\$ 0-100,000$} & Crawfordsville & 3.50 & 21.25 & 5.60 & 1.00 & 3.50 & 1.00 & & 1.00 & 6.64 \\
\hline & FortWayne & & 3.67 & 8.33 & 2.50 & 10.00 & 1.25 & & 1.00 & 4.25 \\
\hline & Greenfield & 56.00 & 16.57 & 13.71 & 8.83 & 6.40 & 2.25 & 1.33 & 2.00 & 10.26 \\
\hline & Laporte & 3.00 & 4.80 & 3.00 & 13.00 & 2.00 & 2.00 & & & 4.07 \\
\hline & Seymour & 9.00 & 5.00 & 7.33 & & 7.00 & 1.00 & & & 6.08 \\
\hline & Vincennes & & 8.00 & 5.00 & 4.67 & 1.67 & 1.50 & & & 4.36 \\
\hline & Average of all Districts & 9.89 & 10.77 & 8.13 & 6.62 & 5.35 & 1.53 & 1.33 & 1.25 & 6.88 \\
\hline \multirow{7}{*}{$\$ 100,000-500,000$} & \begin{tabular}{|l|} 
Crawfordsville \\
\end{tabular} & 16.67 & 2.44 & 6.33 & 2.00 & 2.00 & 1.25 & & 5.00 & 4.48 \\
\hline & FortWayne & 3.00 & 12.29 & 3.57 & 3.75 & 3.67 & 1.00 & & & 4.97 \\
\hline & Greenfield & 14.80 & 6.93 & 13.22 & 5.88 & 1.86 & 1.25 & & & 7.75 \\
\hline & Laporte & 9.75 & 6.27 & 5.70 & 5.00 & 8.00 & 1.17 & 3.00 & 1.00 & 6.02 \\
\hline & Seymour & 13.83 & 4.50 & 4.33 & 4.00 & 3.33 & 1.00 & 1.00 & 1.00 & 4.97 \\
\hline & Vincennes & 2.00 & 4.25 & 3.25 & & 3.00 & 1.00 & & & 3.17 \\
\hline & Average of all Districts & 11.90 & 6.24 & 6.62 & 4.16 & 4.00 & 1.14 & 1.67 & 3.00 & 5.74 \\
\hline \multirow{7}{*}{$\$ 500,000-1,000,000$} & \begin{tabular}{|l|} 
Crawfordsville \\
\end{tabular} & 8.00 & 3.00 & & & 1.00 & 1.00 & & & 4.00 \\
\hline & FortWayne & 28.33 & 6.75 & 6.00 & 7.50 & 5.00 & 1.00 & & & 8.45 \\
\hline & Greenfield & & 5.50 & 4.50 & 5.50 & 3.67 & 1.00 & & & 4.29 \\
\hline & Laporte & 11.75 & 5.00 & 4.00 & 3.33 & 4.00 & 1.83 & & 1.00 & 5.52 \\
\hline & Seymour & 29.67 & 4.67 & 2.60 & 4.00 & 3.00 & 1.00 & & 5.00 & 7.94 \\
\hline & Vincennes & 1.00 & & & 7.00 & 16.00 & & & & 10.00 \\
\hline & Average of all Districts & 16.76 & 5.21 & 4.13 & 5.22 & 5.05 & 1.36 & & 3.00 & 6.42 \\
\hline \multirow{7}{*}{$>\$ 1,000,000$} & Crawfordsville & 20.00 & 5.00 & 3.00 & 4.50 & 5.20 & 1.00 & & 1.00 & 6.42 \\
\hline & FortWayne & & 3.00 & 4.33 & 1.00 & & 1.00 & & & 3.00 \\
\hline & Greenfield & 14.75 & 2.33 & 12.67 & 2.80 & 4.00 & 1.00 & 30.00 & & 7.41 \\
\hline & Laporte & 19.20 & 5.88 & 5.00 & 3.00 & 7.50 & 1.25 & & 3.00 & 6.97 \\
\hline & Seymour & 13.00 & 8.67 & 15.60 & 3.00 & 4.00 & 1.25 & 36.00 & 6.00 & 8.68 \\
\hline & \begin{tabular}{|c|} 
Vincennes \\
\end{tabular} & & 13.00 & 4.00 & 6.00 & 2.00 & 1.00 & & & 5.20 \\
\hline & Average of all Districts & 17.87 & 5.46 & 8.31 & 3.47 & 5.20 & 1.11 & 33.00 & 3.80 & 6.90 \\
\hline \multirow{7}{*}{$\begin{array}{l}\text { Average of all Bid } \\
\text { Amount Category }\end{array}$} & \begin{tabular}{|c|} 
Crawfordsville \\
\end{tabular} & 11.69 & 6.65 & 5.06 & 3.08 & 4.00 & 1.09 & & 3.00 & 5.66 \\
\hline & FortWayne & 18.20 & 7.82 & 5.06 & 3.92 & 5.17 & 1.07 & & 1.00 & 5.51 \\
\hline & Greenfield & 17.53 & 8.64 & 11.36 & 5.95 & 4.36 & 1.35 & 8.50 & 2.00 & 7.96 \\
\hline & Laporte & 12.32 & 5.67 & 4.95 & 4.73 & 5.60 & 1.47 & 3.00 & 2.00 & 5.91 \\
\hline & Seymour & 17.64 & 5.44 & 7.32 & 3.67 & 4.13 & 1.09 & 12.67 & 4.50 & 6.63 \\
\hline & \begin{tabular}{|c|} 
Vincennes \\
\end{tabular} & 1.67 & 6.75 & 4.00 & 5.40 & 6.00 & 1.25 & & & 4.71 \\
\hline & Average of all Districts & 14.04 & 6.88 & 6.99 & 4.56 & 4.82 & 1.25 & 9.38 & 2.80 & 6.36 \\
\hline
\end{tabular}


Table 6.12: Average Number of Maintenance Contract Change Orders

\begin{tabular}{|c|c|c|c|c|c|c|c|c|c|c|}
\hline \multirow{2}{*}{$\begin{array}{l}\text { Category of } \\
\text { Bid Amount }\end{array}$} & \multirow[b]{2}{*}{ District } & \multicolumn{8}{|c|}{ Reason for change order } & \multirow[b]{2}{*}{$\begin{array}{c}\text { Any } \\
\text { Reason }\end{array}$} \\
\hline & & 0 & 1 & 2 & 3 & 4 & 5 & 6 & 7 & \\
\hline \multirow{7}{*}{$\$ 0-100,000$} & Crawfordsville & & & & & & & & & \\
\hline & FortWayne & & 8.00 & & 59.00 & & 1.00 & & 2.00 & 17.50 \\
\hline & Greenfield & 8.00 & 4.00 & 1.00 & 1.00 & 6.00 & 1.00 & & 2.00 & 3.10 \\
\hline & Laporte & & & & & & 1.00 & & & 1.00 \\
\hline & Seymour & 3.00 & 1.00 & & & 2.00 & & & & 2.00 \\
\hline & Vincennes & 1.00 & 3.67 & 3.00 & & 4.00 & & & & 3.17 \\
\hline & Average for all Districts & 4.00 & 4.00 & 1.67 & 30.00 & 4.50 & 1.00 & & 2.00 & 5.29 \\
\hline \multirow{7}{*}{$\begin{array}{l}\$ 100,000- \\
500,000\end{array}$} & Crawfordsville & 42.50 & 5.83 & 4.17 & 5.00 & 5.00 & 1.00 & & 4.50 & 7.18 \\
\hline & FortWayne & 7.00 & 3.00 & 3.83 & 2.67 & & 1.00 & & & 2.90 \\
\hline & Greenfield & 7.00 & 2.20 & 3.00 & 2.33 & 1.00 & 1.00 & & 61.00 & 6.57 \\
\hline & Laporte & 5.50 & 3.30 & 2.13 & 4.00 & 1.71 & 1.00 & & & 2.71 \\
\hline & Seymour & & 3.60 & 2.00 & 6.00 & 1.50 & 1.00 & & 1.00 & 2.62 \\
\hline & Vincennes & 1.00 & 4.33 & & & 1.00 & 4.00 & 1.00 & 2.00 & 2.75 \\
\hline & Average for all Districts & 15.86 & 3.68 & 3.13 & 3.50 & 2.67 & 1.21 & 1.00 & 10.38 & 4.26 \\
\hline \multirow{7}{*}{$\begin{array}{l}\$ 500,000- \\
1,000,000\end{array}$} & Crawfordsville & & 3.00 & 1.00 & & 4.00 & 1.00 & & & 2.25 \\
\hline & FortWayne & & 3.00 & 4.00 & & 6.00 & 1.00 & & & 3.11 \\
\hline & Greenfield & 4.00 & 2.33 & 6.00 & & 2.50 & 1.00 & & & 3.22 \\
\hline & Laporte & & 2.50 & 1.67 & 4.00 & 3.50 & & & & 2.63 \\
\hline & Seymour & 3.00 & 6.33 & & 1.00 & 1.00 & & & & 4.00 \\
\hline & Vincennes & & & & & & & & & \\
\hline & Average for all Districts & 3.50 & 3.70 & 3.40 & 2.50 & 3.29 & 1.00 & & & 3.08 \\
\hline \multirow{7}{*}{$>\$ 1,000,000$} & Crawfordsville & & 3.00 & 6.75 & & 1.00 & 1.00 & & & 5.38 \\
\hline & FortWayne & & 2.00 & 5.00 & 5.00 & 1.00 & 1.00 & & & 2.89 \\
\hline & Greenfield & & 1.00 & 3.25 & 10.00 & 2.00 & 1.00 & & & 2.15 \\
\hline & Laporte & 61.00 & 2.50 & & 1.00 & & 1.00 & & & 9.25 \\
\hline & Seymour & 11.00 & 4.40 & 8.00 & 5.00 & 3.00 & 1.00 & & & 5.53 \\
\hline & Vincennes & & 3.00 & 8.00 & & 1.00 & & 1.00 & & 3.25 \\
\hline & Average for all Districts & 23.50 & 2.60 & 5.64 & 5.17 & 1.75 & 1.00 & 1.00 & & 4.08 \\
\hline \multirow{7}{*}{$\begin{array}{l}\text { Average of all } \\
\text { Bid } \\
\text { Amount } \\
\text { Category }\end{array}$} & Crawfordsville & 42.50 & 4.70 & 4.82 & 5.00 & 4.00 & 1.00 & & 3.00 & 5.56 \\
\hline & FortWayne & 7.00 & 3.50 & 4.15 & 14.40 & 2.67 & 1.00 & & 2.00 & 4.33 \\
\hline & Greenfield & 6.33 & 1.87 & 3.33 & 3.60 & 2.64 & 1.00 & & 31.50 & 3.68 \\
\hline & Laporte & 24.00 & 3.00 & 2.00 & 3.50 & 2.11 & 1.00 & & & 3.69 \\
\hline & Seymour & 7.80 & 4.29 & 5.00 & 4.40 & 2.00 & 1.00 & & 1.00 & 4.05 \\
\hline & Vincennes & 1.00 & 3.86 & 5.50 & & 2.00 & 4.00 & 1.00 & 2.00 & 3.00 \\
\hline & Average for all Districts & 14.00 & 3.40 & 3.80 & 6.27 & 2.68 & 1.09 & 1.00 & 7.25 & 4.14 \\
\hline
\end{tabular}


Table 6.13: Average Number of Road Construction Contract Change Orders

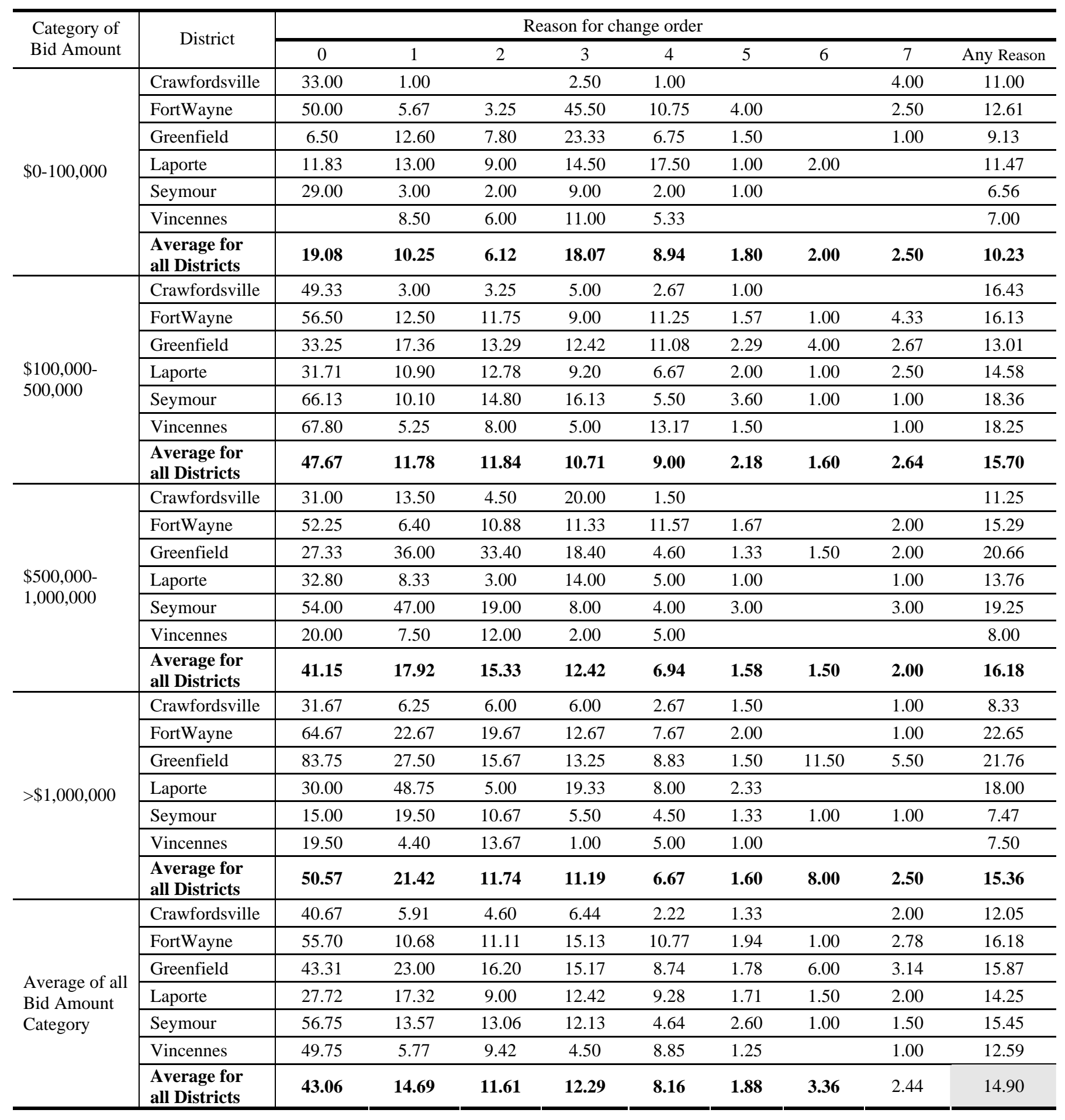


Table 6.14: Average Number of Resurfacing Contract Change Orders

\begin{tabular}{|c|c|c|c|c|c|c|c|c|c|}
\hline \multirow{2}{*}{$\begin{array}{l}\text { Category of } \\
\text { Bid Amount }\end{array}$} & \multirow[b]{2}{*}{ District } & \multicolumn{7}{|c|}{ Reason for change order } & \multirow[b]{2}{*}{$\begin{array}{c}\text { Any } \\
\text { Reason }\end{array}$} \\
\hline & & 0 & 1 & 2 & 3 & 4 & 5 & 7 & \\
\hline \multirow{7}{*}{$\$ 0-100,000$} & Crawfordsville & 12.00 & 5.00 & 2.00 & 1.50 & 8.00 & 1.00 & 1.00 & 3.67 \\
\hline & FortWayne & 11.00 & 4.67 & 3.00 & 5.00 & & 1.25 & 1.50 & 3.47 \\
\hline & Greenfield & 31.00 & 5.00 & 6.33 & 4.33 & 4.50 & 1.67 & & 6.13 \\
\hline & Laporte & 6.00 & 7.00 & 4.50 & 2.00 & 2.00 & 1.00 & & 4.56 \\
\hline & Seymour & & 5.33 & 1.67 & 5.00 & 2.00 & 1.00 & 5.00 & 3.54 \\
\hline & Vincennes & 7.00 & 8.00 & 5.50 & & 25.00 & 2.50 & 1.00 & 7.22 \\
\hline & $\begin{array}{c}\text { Average for all } \\
\text { Districts }\end{array}$ & 13.40 & 5.80 & 3.93 & 3.91 & 6.86 & 1.46 & 2.00 & 4.70 \\
\hline \multirow{7}{*}{$\begin{array}{l}\$ 100,000- \\
500,000\end{array}$} & Crawfordsville & 5.00 & 6.89 & 4.38 & 4.00 & 6.60 & 1.00 & 5.75 & 5.06 \\
\hline & FortWayne & 20.00 & 3.71 & 4.78 & 2.50 & 4.67 & 2.00 & 1.40 & 3.79 \\
\hline & Greenfield & 21.00 & 10.10 & 7.00 & 6.38 & 3.80 & 1.86 & 6.00 & 7.00 \\
\hline & Laporte & 14.25 & 2.33 & 3.80 & 1.50 & 3.25 & 1.50 & 1.00 & 4.58 \\
\hline & Seymour & 8.00 & 3.75 & 3.14 & 2.00 & 3.00 & 1.00 & 3.67 & 3.44 \\
\hline & Vincennes & & 4.00 & 13.33 & 4.00 & 4.00 & 3.00 & 1.00 & 6.67 \\
\hline & $\begin{array}{c}\text { Average for all } \\
\text { Districts } \\
\end{array}$ & 14.00 & 5.95 & 5.38 & 4.11 & 4.31 & 1.70 & 3.44 & 5.03 \\
\hline \multirow{6}{*}{$\begin{array}{l}\$ 500,000- \\
1,000,000\end{array}$} & Crawfordsville & 12.00 & 7.00 & 3.67 & & 4.00 & 1.00 & 4.00 & 5.18 \\
\hline & FortWayne & & 3.00 & 6.00 & & 2.00 & 1.00 & 2.00 & 3.71 \\
\hline & Greenfield & & 6.00 & 5.67 & 4.67 & 11.50 & 2.50 & & 5.47 \\
\hline & Laporte & 2.50 & 3.00 & 3.00 & & 16.00 & 2.00 & 1.00 & 4.00 \\
\hline & Seymour & & 3.50 & 6.00 & 2.67 & 4.00 & 1.50 & 2.00 & 3.69 \\
\hline & $\begin{array}{l}\text { Average for all } \\
\text { Districts }\end{array}$ & 5.67 & 4.77 & 5.07 & 3.67 & 7.13 & 1.89 & 2.25 & 4.48 \\
\hline \multirow{7}{*}{$>\$ 1,000,000$} & Crawfordsville & & 2.00 & 9.67 & 1.00 & 3.33 & & & 4.89 \\
\hline & FortWayne & 5.00 & 5.00 & 16.17 & 7.60 & 3.83 & 2.00 & 1.00 & 6.18 \\
\hline & Greenfield & 44.00 & 14.00 & 4.60 & 5.75 & 4.67 & 1.75 & 2.00 & 7.43 \\
\hline & Laporte & 7.00 & 9.50 & 6.00 & 4.50 & 2.33 & 1.00 & & 5.00 \\
\hline & Seymour & 11.00 & 4.73 & 4.50 & 4.29 & 1.75 & 1.33 & 3.33 & 4.03 \\
\hline & Vincennes & 6.00 & 9.33 & 7.25 & 5.00 & 3.00 & 1.00 & 1.00 & 5.50 \\
\hline & $\begin{array}{l}\text { Average for all } \\
\text { Districts }\end{array}$ & 14.60 & 6.93 & 8.44 & 5.30 & 3.19 & 1.61 & 1.90 & 5.53 \\
\hline \multirow{7}{*}{$\begin{array}{l}\text { Average of all } \\
\text { Bid Amount } \\
\text { Category }\end{array}$} & Crawfordsville & 9.67 & 6.13 & 5.13 & 2.00 & 5.36 & 1.00 & 4.67 & 4.85 \\
\hline & FortWayne & 12.00 & 4.29 & 7.95 & 5.27 & 4.08 & 1.79 & 1.36 & 4.59 \\
\hline & Greenfield & 29.25 & 9.50 & 6.05 & 5.61 & 5.42 & 1.94 & 4.00 & 6.73 \\
\hline & Laporte & 9.38 & 5.27 & 4.00 & 2.80 & 4.22 & 1.29 & 1.00 & 4.59 \\
\hline & Seymour & 9.00 & 4.41 & 3.90 & 3.69 & 2.62 & 1.29 & 3.50 & 3.73 \\
\hline & Vincennes & 6.50 & 7.43 & 8.89 & 4.50 & 8.75 & 2.25 & 1.00 & 6.31 \\
\hline & $\begin{array}{l}\text { Average for all } \\
\text { Districts }\end{array}$ & 12.91 & 6.07 & 5.93 & 4.45 & 4.58 & 1.65 & 2.66 & 5.05 \\
\hline
\end{tabular}


Table 6.15: Average Number of Traffic Contract Change Orders

\begin{tabular}{|c|c|c|c|c|c|c|c|c|c|c|}
\hline \multirow{2}{*}{$\begin{array}{l}\text { Category of } \\
\text { Bid Amount }\end{array}$} & \multirow[b]{2}{*}{ District } & \multicolumn{8}{|c|}{ Reason for change order } & \multirow[b]{2}{*}{$\begin{array}{c}\text { Any } \\
\text { Reason }\end{array}$} \\
\hline & & 0 & 1 & 2 & 3 & 4 & 5 & 6 & 7 & \\
\hline \multirow{7}{*}{$\$ 0-100,000$} & Crawfordsville & & & 1.00 & 2.00 & & & & & 1.50 \\
\hline & FortWayne & 16.50 & 5.67 & 6.00 & 8.20 & 1.00 & 1.67 & & 2.00 & 5.73 \\
\hline & Greenfield & & 3.33 & 3.00 & 5.00 & & & & & 3.60 \\
\hline & Laporte & 11.00 & 5.00 & 2.00 & 4.00 & & 1.00 & & & 6.25 \\
\hline & Seymour & & 2.00 & 1.00 & & & & & & 1.50 \\
\hline & Vincennes & & 8.00 & & 2.00 & 6.00 & & & & 5.33 \\
\hline & $\begin{array}{l}\text { Average of all } \\
\text { Districts }\end{array}$ & 13.20 & 5.06 & 3.17 & 6.00 & 2.25 & 1.50 & & 2.00 & 5.20 \\
\hline \multirow{7}{*}{$\begin{array}{l}\$ 100,000- \\
500,000\end{array}$} & Crawfordsville & 4.00 & 4.80 & 5.33 & 2.00 & 6.00 & & & & 4.71 \\
\hline & FortWayne & & 4.43 & 5.25 & 3.67 & 8.50 & 1.50 & & 2.00 & 4.47 \\
\hline & Greenfield & 6.00 & 2.60 & 2.25 & 1.00 & 3.50 & & & & 2.87 \\
\hline & Laporte & 10.00 & 2.00 & 10.50 & 5.00 & 2.50 & & & & 5.00 \\
\hline & Seymour & 5.00 & 1.33 & 3.00 & 1.00 & & & & & 2.57 \\
\hline & Vincennes & 8.00 & 12.29 & 4.17 & 5.25 & 1.25 & & & & 6.59 \\
\hline & $\begin{array}{l}\text { Average of all } \\
\text { Districts }\end{array}$ & 6.33 & 5.59 & 4.75 & 3.69 & 3.76 & 1.50 & & 2.00 & 4.68 \\
\hline \multirow{4}{*}{$\begin{array}{l}\$ 500,000- \\
1,000,000\end{array}$} & Crawfordsville & 4.00 & 4.67 & 2.00 & 3.00 & 1.00 & 2.00 & & & 2.69 \\
\hline & Greenfield & & 16.50 & 4.50 & 29.00 & 7.00 & 1.00 & 1.00 & 1.00 & 9.00 \\
\hline & Laporte & & 2.00 & 22.00 & 3.00 & 3.00 & 2.00 & & & 5.83 \\
\hline & $\begin{array}{l}\text { Average of all } \\
\text { Districts }\end{array}$ & 4.00 & 8.17 & 6.17 & 8.20 & 2.60 & 1.67 & 1.00 & 1.00 & 5.39 \\
\hline \multirow{7}{*}{$>\$ 1,000,000$} & Crawfordsville & 11.00 & 25.00 & & & 8.00 & & & & 14.67 \\
\hline & FortWayne & 8.00 & 7.83 & 7.33 & 5.60 & 4.33 & 1.00 & & 14.00 & 6.38 \\
\hline & Greenfield & & 2.50 & 4.00 & 3.00 & 1.00 & & & & 3.00 \\
\hline & Laporte & 15.50 & 7.00 & & & & & & & 12.67 \\
\hline & Seymour & 3.00 & 1.00 & 4.67 & 2.50 & 6.00 & & & & 3.63 \\
\hline & Vincennes & 1.00 & 6.50 & 2.00 & & 2.00 & & & & 3.60 \\
\hline & $\begin{array}{l}\text { Average of all } \\
\text { Districts }\end{array}$ & 9.00 & 7.54 & 5.00 & 4.33 & 4.29 & 1.00 & & 14.00 & 5.98 \\
\hline \multirow{7}{*}{$\begin{array}{l}\text { Average of all } \\
\text { Bid Amount } \\
\text { Category }\end{array}$} & Crawfordsville & 6.33 & 7.00 & 3.29 & 2.40 & 4.14 & 2.00 & & & 4.63 \\
\hline & FortWayne & 13.67 & 5.86 & 6.11 & 6.15 & 4.13 & 1.43 & & 5.00 & 5.58 \\
\hline & Greenfield & 6.00 & 5.08 & 3.30 & 8.20 & 3.67 & 1.00 & 1.00 & 1.00 & 4.49 \\
\hline & Laporte & 12.33 & 3.83 & 11.25 & 4.00 & 2.60 & 1.50 & & & 6.36 \\
\hline & Seymour & 4.33 & 1.40 & 3.60 & 2.00 & 6.00 & & & & 2.94 \\
\hline & Vincennes & 4.50 & 10.70 & 3.86 & 4.60 & 2.17 & & & & 5.97 \\
\hline & $\begin{array}{l}\text { Average of all } \\
\text { Districts }\end{array}$ & 9.00 & 6.09 & 4.79 & 5.06 & 3.52 & 1.45 & 1.00 & 4.20 & 5.19 \\
\hline
\end{tabular}

Examination of Tables 1 to 5, particularly the bottom right cells, shows that on the average, all the project types experienced approximately the same number of change orders (approximately 5). The only exception was road construction projects where the average is approximately 15 change orders per contract. 
Figure 6.29 shows that the average number of change orders per contract does not vary greatly among districts. Greenfield experienced the highest average number of change orders, with ten change orders per contract, while Crawfordsville experienced the lowest average number of change orders, with five change orders per contract. Figure 6.30 shows that road construction projects experiences a greater average number of change orders by contract, with 15 change orders, and maintenance projects experienced fewer change orders, with an average of only four change orders per contract.

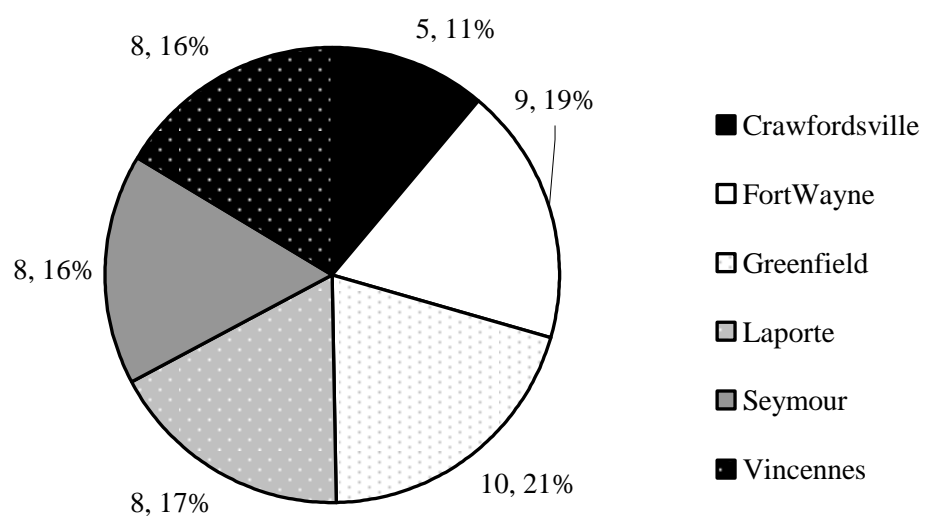

Figure 6.29: Average Number of Change Orders per Contract and Percentage of Contracts with Change Order, by District

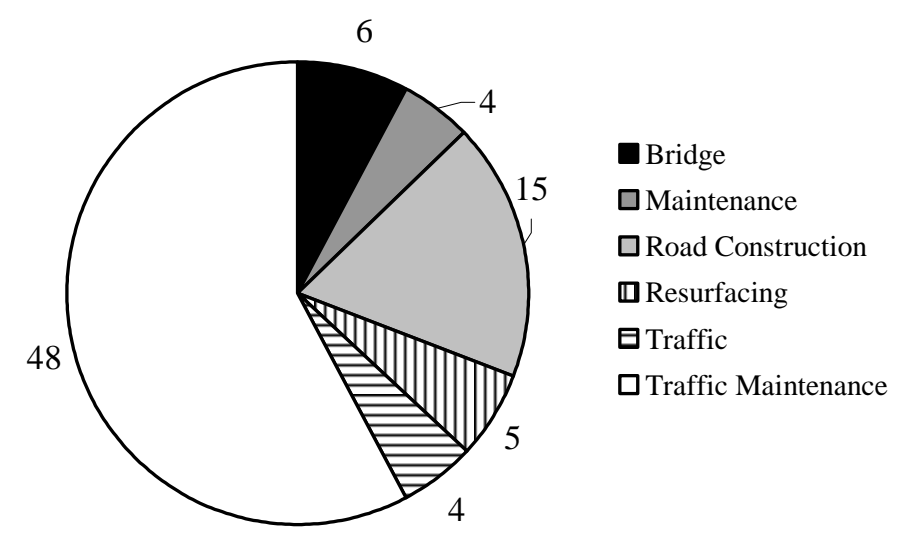

Figure 6.30: Average Number of Change Orders per Contract by Project Type 
Figure 6.31 provides the average number of change orders per contract by bid amount category. Projects in the bid category less than $\$ 100,000$ or more than $\$ 1$ million had less average number of change orders per contract than the projects with bid amounts in the medium range of $\$ 100,000$ - \$1 million. Figure 6.32 shows that the yearly variation of the average number of change orders per contract varied from 4 in 1996 to 13 in 1999.

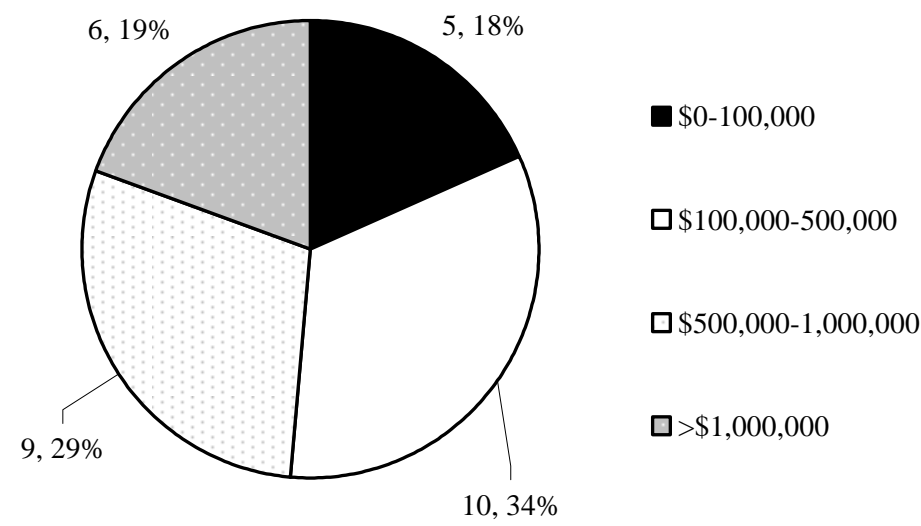

Figure 6.31: Average Number of Change Orders per Contract and Percentage of Contracts with Change Orders, by Bid Amount Category

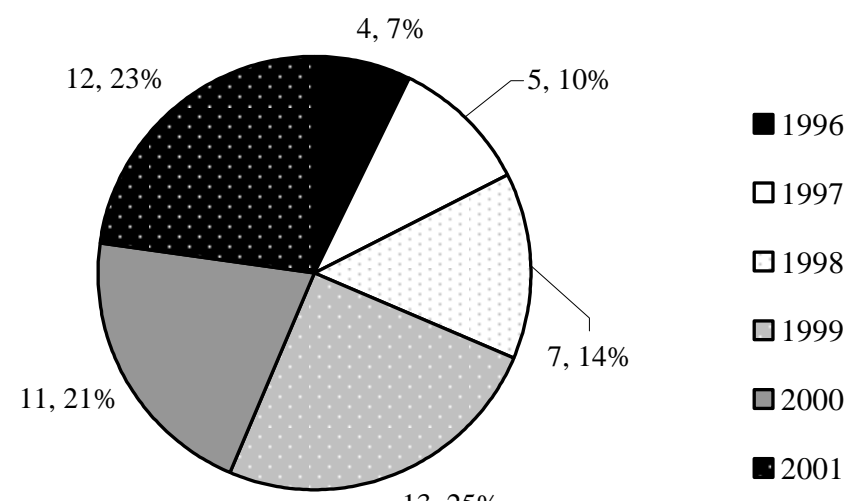

Figure 6.32: Average Number of Change Orders per Contract and Percentage of Contracts with Change Orders, by Year 
Appendix E provides further detailed information on change orders. A comparison of the average frequency of change orders per contract by project type and by district shows that Greenfield bridge projects had the highest average number of change orders. For maintenance projects, Crawfordsville had the highest average. In the six districts, road construction projects experienced more change orders, with a much higher average (approximately 15 change orders), with no particularly dominant district. For resurfacing projects, the Greenfield and Vincennes Districts had more change orders per contract than the other district, and for traffic projects, the Seymour District is had fewer change orders per contract. The "no reason" change order category was dominant in every district, with only exception of Crawfordsville, where the proportion of "no reason" change orders was much less than for the other districts. Concerning the other change order reason categories, the Greenfield District had more "errors and omissions” and "constructability” change orders per contract. Otherwise, there was little disparity among districts for change order reasons. Traffic projects seem to experience less "no reason" change orders in proportion to other project types. Road construction projects had the highest average number of change orders in the "errors and omissions," “constructability," and "scope changes” categories.

\subsection{Chapter Summary}

The present chapter provided a discussion on the incidence of cost overruns, time delays, and change orders in terms of their distribution by district, project type and bid amount category. Almost half of the amount spent on change orders was associated with "no recorded reason." If the "no recorded reason" category is excluded, the "error and omission” category was the overwhelming reason for change orders. Resurfacing projects experienced the most cost overruns, and maintenance projects had the most time delay. The following chapter carries out detailed statistical analysis of cost overruns, time delays, and change orders. 


\section{CHAPTER 7: $\quad$ STATISTICAL ANALYSIS I}

\subsection{Introduction}

In discussing the distribution of cost overruns, time delays, and change order frequency by project type, location, and bid amount category, the previous chapter laid the groundwork upon which further statistical analysis could be carried out. The present chapter carries out preliminary statistical investigations aimed at confirming identified trends between the dependent variables (cost overruns, time delay and change order frequency) on one hand, and the potentially influential factors (independent variables) on the other hand, and also to further establish a-priori expectations of the strength and direction of such relationships. Four statistical tools were used to conduct the preliminary statistical analysis. The correlation matrix was carried out to ascertain the existence of any linear correlation between each pair of independent variables. The analysis of variance was carried out to investigate any differences in the means of each dependent variables for various combinations of levels of the potential influential factors. Then a pair-wise t-test was carried out to study any such differences in a more precise manner. Finally, an analysis of the influence of each potentially influential factor on the dependent variables was carried out.

\subsection{Correlation Matrix}

The correlation matrix between the independent variables provided in Table 7.1 showed the Pearson correlation coefficient for each pair of variables. This statistic helped to identify any correlations so that possible modeling biases from using correlated variables in the same model could be avoided. Table 7.1 (where correlations are at 10\% significance) shows that most of the Pearson correlation coefficients were between -0.3 and 0.3. A notable exception is that for the variables representing the proportion of the difference between the first and second bids and the proportion of the difference between the lowest bid and the engineer's estimate, which had a correlation coefficient of 0.83 and is indicative of a strong positive association. As such, it was necessary to avoid using these two variables in the same model or to exercise due caution where they had to be used in the same model. For the other variables, there seemed to be no problem with correlation as their correlation coefficients were sufficiently low. 
Table 7.1: Correlation Matrix of the Independent Variables

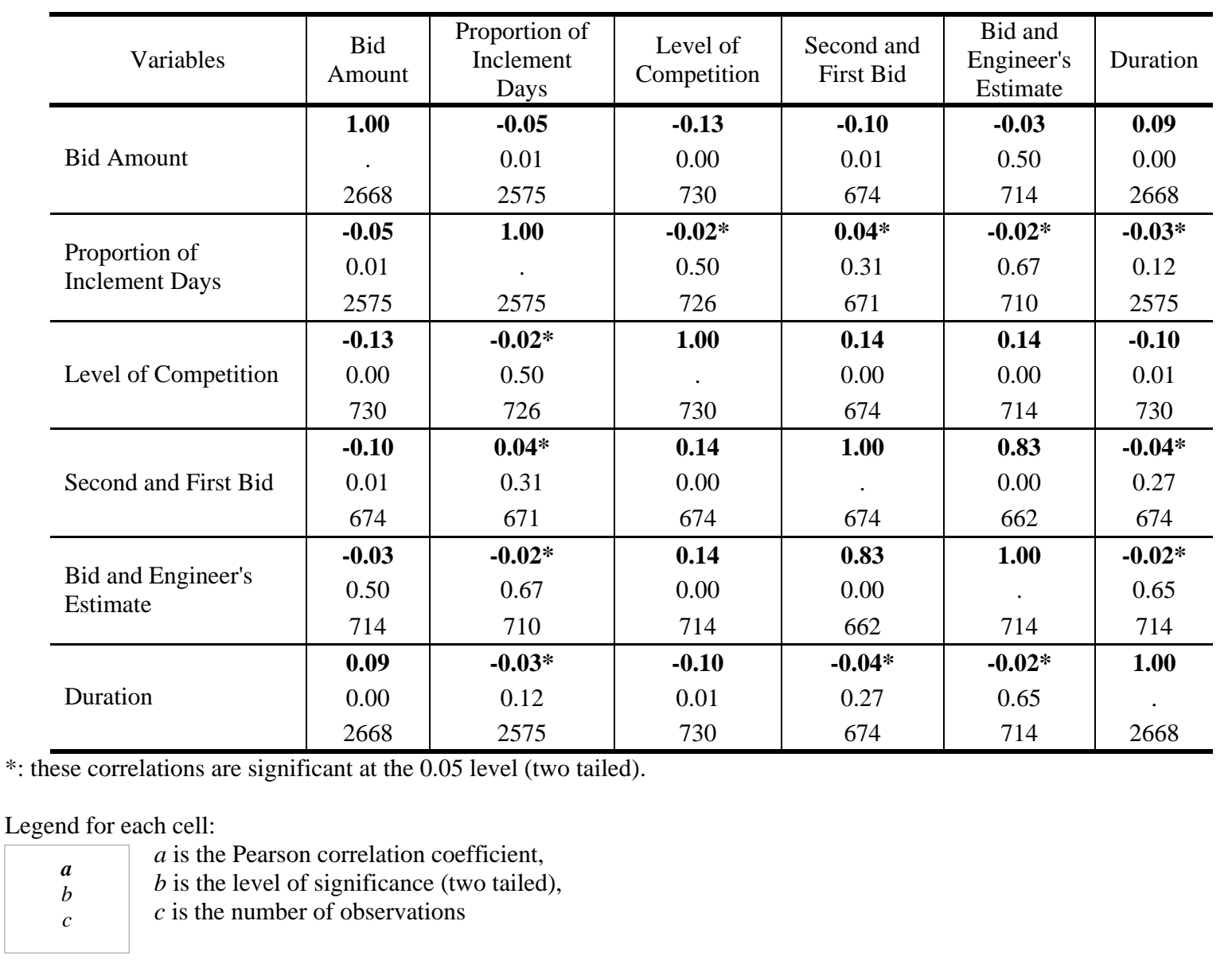

\subsection{Analysis of Variance (ANOVA)}

The analysis provides the mean responses for each combination of levels of the following variables: proportion of inclement days, bid amount, level of competition, proportion of the difference between the first and second bids, and proportion of the difference between the winning bid and engineer's estimate. Details are provided in Appendix F. The mean for time delays could not be provided in the preliminary analysis because there were inadequate data points for estimating some of the means. Moreover, the duration variable that was used for time delay, was not included in this analysis.

The analysis of variance enables simultaneous comparison at all the means, and consequently addresses the following questions:

(i) Are all time delays statistically the same regardless of the combinations of extents of the explanatory factors?

(ii) Are all cost overrun amounts statistically the same regardless of the combinations of extents of the explanatory factors? 
(iii) Are all changer order frequencies the same regardless of the combinations of extents of the explanatory factors?

The hypothesis tests are:

$$
\begin{aligned}
& \mathrm{H}_{0}: \exists(i, j) \in(1 ; 32)^{2}, i \neq j, \mu_{i}=\mu_{j} \\
& \mathrm{H}_{1}: \mu_{1} \neq \mu_{2} \neq \ldots \neq \mu_{32}
\end{aligned}
$$

An affirmative answer to the above questions is evidenced by a high F-value. If the answer to the above questions is not affirmative, then that at least two means do not have a significant differences variable (but the others could be significant). Table 7.2 presents the ANOVA results.

Table 7.2: Analysis of Variance Using Selected Variables

\begin{tabular}{l|c|c|c|c|c|c}
\hline & & Sum of Squares & df & Mean Square & F & P-Value \\
\hline \multirow{3}{*}{ Cost Overrun } & Between Groups & $2.29 \mathrm{E}+12$ & 31 & $7.39 \mathrm{E}+10$ & & \multirow{2}{*}{0.10} \\
& Within Groups & $3.44 \mathrm{E}+13$ & 627 & $5.49 \mathrm{E}+10$ & 1.34 & \\
& Total & $3.67 \mathrm{E}+13$ & 658 & & \\
\hline \multirow{3}{*}{ Amount of Change Order } & Between Groups & $4.21 \mathrm{E}+12$ & 31 & $1.36 \mathrm{E}+11$ & & \multirow{2}{*}{0.59} \\
& Within Groups & $9.22 \mathrm{E}+13$ & 627 & $1.47 \mathrm{E}+11$ & 0.92 & \\
\hline \multirow{3}{*}{ Number of Change Order } & Total & $9.64 \mathrm{E}+13$ & 658 & & \\
& Between Groups & $2.55 \mathrm{E}+04$ & 31 & $8.24 \mathrm{E}+02$ & \multirow{2}{*}{0.34} \\
& Within Groups & $1.57 \mathrm{E}+05$ & 209 & $7.52 \mathrm{E}+02$ & & \\
\hline
\end{tabular}

Table 7.2 shows that there are significant differences in the means of cost overruns between the combinations of variables at the $10 \%$ significance level. However, for average change order amounts or frequencies, such a difference was not found significant.

The analysis provides the means of each combination of various levels of each independent variable as shown in Appendix F. In this case, the intention was to investigate time delays, and the duration variable is included. When the bid comparison variables are added in the analysis, the means for time delays cannot be computed because there were missing observations in the groups defined for the ANOVA. The analysis makes it possible to examine the differences between the means for amount or frequency of change orders and cost overrun without the bid comparison variables.

For the four dependent variables, Table 7.3 shows the effect of the three selected independent variables on any of the dependent variables. This is reflected in the high F-value, indicating the strong statistical significance of such effects. Comparison of the two sets of ANOVA tests shows that bid amount and proportion of inclement days had a strong influence on cost overrun, time delay, amount and frequency of change orders. However, this is not true for bid comparison variables such as level of 
competition and proportion of the difference between first and second bid and proportion of the difference between the winning bid and engineer's estimate.

Table 7.3: Analysis of Variance Using Selected Independent Variables

\begin{tabular}{|c|c|c|c|c|c|c|}
\hline & & Sum of Squares & df & Mean Square & $\mathrm{F}$ & P-Value \\
\hline Cost Overrun & $\begin{array}{c}\text { Between Groups } \\
\text { Within Groups } \\
\text { Total }\end{array}$ & $\begin{array}{l}7.88 \mathrm{E}+12 \\
2.22 \mathrm{E}+14 \\
2.30 \mathrm{E}+14\end{array}$ & $\begin{array}{c}7 \\
1940 \\
1947\end{array}$ & $\begin{array}{l}1.13 \mathrm{E}+12 \\
1.15 \mathrm{E}+11\end{array}$ & 9.82 & 0.00 \\
\hline Time Delay & $\begin{array}{c}\text { Between Groups } \\
\text { Within Groups } \\
\text { Total } \\
\end{array}$ & $\begin{array}{l}1.13 \mathrm{E}+07 \\
3.47 \mathrm{E}+07 \\
4.60 \mathrm{E}+07 \\
\end{array}$ & $\begin{array}{c}7 \\
1940 \\
1947\end{array}$ & $\begin{array}{l}1.61 \mathrm{E}+06 \\
1.79 \mathrm{E}+04\end{array}$ & 90.16 & 0.00 \\
\hline Change Order Amount & $\begin{array}{c}\text { Between Groups } \\
\text { Within Groups } \\
\text { Total }\end{array}$ & $\begin{array}{l}1.52 \mathrm{E}+13 \\
1.28 \mathrm{E}+15 \\
1.30 \mathrm{E}+15\end{array}$ & $\begin{array}{c}7 \\
1940 \\
1947\end{array}$ & $\begin{array}{l}2.17 \mathrm{E}+12 \\
6.61 \mathrm{E}+11\end{array}$ & 3.29 & 0.00 \\
\hline Number of Change Order & $\begin{array}{c}\text { Between Groups } \\
\text { Within Groups } \\
\text { Total }\end{array}$ & $\begin{array}{l}1.92 \mathrm{E}+05 \\
6.44 \mathrm{E}+05 \\
8.36 \mathrm{E}+05\end{array}$ & $\begin{array}{c}7 \\
502 \\
509\end{array}$ & $\begin{array}{l}2.75 \mathrm{E}+04 \\
1.28 \mathrm{E}+03\end{array}$ & 21.42 & 0.00 \\
\hline
\end{tabular}

\subsection{Pairwise t-Tests}

The pairwise t-test was constructed on the basis of the difference score for each matched pairs. The matched pairs were a pair of observation that differed from each other for only one variable, and the difference between the other variables could not exceed $+/-10 \% . x$ was defined as the difference between $\mu_{\mathrm{A}}-\mu_{\mathrm{B}} . x_{\mathrm{A}}$ and $x_{\mathrm{B}}$ that were matched pairs of the two populations, and was assumed to be normally distributed. The null hypothesis was $\mathrm{H}_{0}: \mu_{\mathrm{A}}-\mu_{\mathrm{B}}=0$ which was equivalent to $\mathrm{H}_{0}: \mu_{\mathrm{x}}=0$ $s_{x}=\sqrt{\frac{1}{n-1} \sum(x-\bar{x})^{2}}$

The test statistic for matched pairs was: $t_{(n-1)}=\frac{\bar{x}-\mu_{0}}{s / \sqrt{n}}$ with $\mu_{0}=0$.

This t-test compared with $\left[-t_{(\alpha / 2, n-1)} ;+t_{(\alpha / 2, n-1)}\right]$. If $t_{(n-1)}$ was in this range, $\mathrm{H}_{0}$ could not be rejected and the variable was not significant.

\subsubsection{Bid Amount Pairs}

For the purpose of carrying out the pairwise t-tests, two levels of bid amount were defined: bid amounts greater than $\$ 340,192$, and bid amounts less than $\$ 340,192$, each with 1,374 contracts. 
A preliminary assessment was made for contracts with the following characteristics: bridge project types, Crawfordsville district locations, proportion of inclement weather days less than 0.5, and level of competition less than five. Table F5 and F7 show cost overruns and time delays of the selected contracts that were compared. For contracts in this category, the average time delay of low bid contracts was compared to that of high bid contracts, and any such difference was tested for statistical significance. This procedure was repeated for cost overrun, change order, and time delay. The results indicated that the bid amount was a significant variable for cost overrun and change orders at $95 \%$ level of confidence, but not for time delay.

\subsubsection{Duration Pairs}

Two levels of contract duration were defined: 975 contracts with duration greater than 110 days, and 1,007 contracts with duration less than 111 days. An assessment was made for contracts with the following characteristics: bridge project types, Crawfordsville district locations, proportion of inclement weather days less than 0.5 , and level of competition less than five. Table F8 shows cost overruns and time delays of the selected contracts that were compared. The results suggested that the duration variable was not a significant variable for time delay at $95 \%$ level of confidence.

\subsubsection{Proportion of Inclement Weather Days Pairs}

Two levels of the proportion of inclement weather days variable were defined: 1,275 contracts with a proportion greater than 0.27 , and 1,293 contract with a proportion less than 0.26 . A preliminary assessment was made for contracts with the following characteristics: bridge project types, Crawfordsville district locations, and level of competition less than two. Table F9 and F10 show cost overruns and time delays of the selected contracts that were compared. The results suggested that the

proportion of inclement weather days does not significantly affect cost overruns but could be a significant variable for time delay. For the frequency of change orders, pairs matched on the basis of available levels of the variables were inadequate for such analysis to be carried out.

\subsubsection{Level of Competition Pairs}

Two levels of the level of competition variable were defined: 377 contracts with a level of competition greater than four contractors, and 353 contracts with a level of competition less than three contractors. An assessment was made for contracts with the following characteristics: bridge project type and proportion of inclement weather days less than 0.5. Table F11 and F12 show cost overruns and time delays of the selected contracts that were compared. The results suggested that the level of competition was not a significant variable for cost overrun and for the frequency of change orders at 
95\% level of confidence. For time delay, pairs matched on the basis of available levels of the variables were inadequate for such analysis to be carried out.

\subsubsection{Proportion of the Difference between the First and Second Bid Pairs}

Two levels of the proportion of the difference between the first and second bid variable were defined: 337 contracts with a proportion greater than 0.064 , and 337 contracts with a proportion less than 0.064. A preliminary assessment was made for contracts with the following characteristics: bridge project type, and a level of competition less than four. Table F13 and F14 show cost overruns and time delays of the selected contracts that were compared. From the results, it is seen that the proportion of the difference between the first and second bid was not a significant variable for cost overruns, but was significant for time delay. For frequency of change orders, pairs matched on the basis of available levels of the variables were inadequate for such analysis to be carried out.

\subsubsection{Proportion of the Difference between the Bid and the Engineer's Estimate Pairs}

Two levels of the proportion of the difference between the winning bid and engineer's estimate variable were defined: 357 contracts with a proportion greater than 0.2131 , and 356 contracts with a proportion less than 0.2131. A preliminary assessment was made for contracts with the following characteristics: road construction project type and a level of competition less than three. Table F15 shows cost overruns and time delays of the selected contracts that were compared. The results indicated that the proportion of the difference between the winning bid and engineer's estimate was not a significant variable for cost overruns. For frequency of change orders and time delay, pairs matched on the basis of available levels of the variables were inadequate for such analysis to be carried out.

\subsubsection{Conclusions of the Pair-wise t-Tests}

The results of the pair-wise t-test analysis are summarized in Table 7.4. The results suggest that bid amount is the variable that most significantly influences cost overrun, while the proportion of inclement days variable is most significant for time delay. Both of these variables were significant for the frequency of change orders at 95\% level of confidence.

Table 7.4: Results of the Pairwise t-Tests 


\begin{tabular}{lccc}
\hline \multicolumn{1}{c}{ Independent Variable } & Cost Overrun & Time Delay & Frequency of Change Orders \\
\hline Bid Amount & Significant & Not significant & Significant \\
\hline Project Duration & - & Not Significant & - \\
\hline Proportion of Inclement Days & Not Significant & Significant & - \\
\hline Level of Competition & Not Significant & - & Significant \\
\hline $\begin{array}{l}\text { Proportion of the Difference between } \\
\text { the First and Second Bids }\end{array}$ & Not Significant & Significant & - \\
\hline $\begin{array}{l}\text { Proportion of the Difference between } \\
\text { the Winning Bid and Engineer's } \\
\text { Estimate }\end{array}$ & Not Significant & - & - \\
\hline
\end{tabular}

\subsection{Preliminary Graphical Analysis of the Influence of Potential Explanatory Factors (Independent Variables) on the Dependent Variables}

The preliminary statistical analysis concerned the potential trends of the data. In order to investigate such trends, each variable was classified in three categories: low, medium, and high. The variation of a dependent variable as a function of a particular independent variable was considered, keeping the other variables constant at their "medium” level.

\subsubsection{Cost Overrun}

Figure 7.1 was developed using the following considerations on the other variables: a medium level of bid amount, a medium level of proportion of the difference between the winning bid and the engineer's estimate, and a medium level of proportion of the difference between the first and the second bid. The results suggest that cost overrun increases when the proportion of inclement days increased, which is expected. The next figure (Figure 7.2) was developed using a medium level of bid amount and a medium level of proportion of the difference between the first and second bid, but failed to yield any discernible trends. 


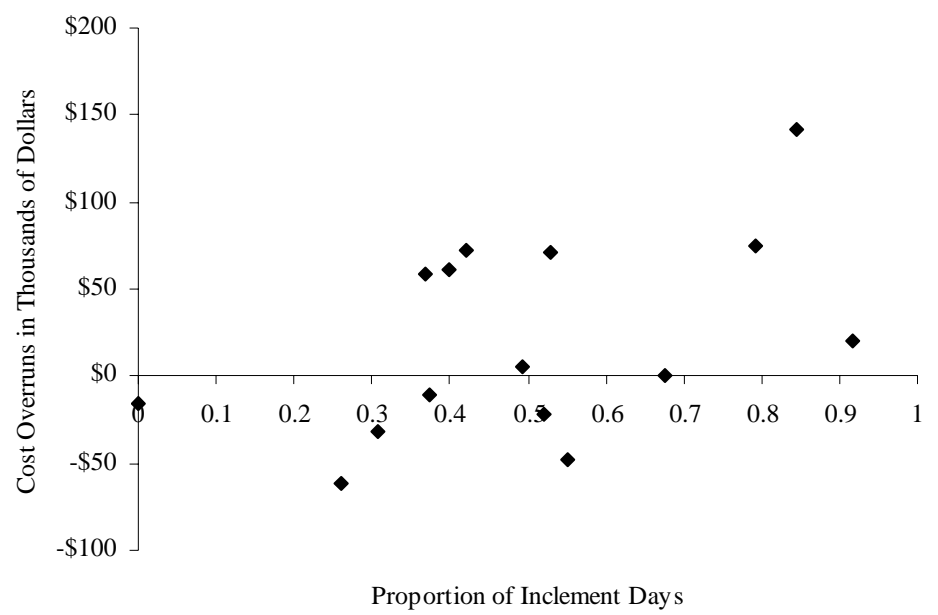

Figure 7.1: Cost Overrun Variation with Proportion of Inclement Days.

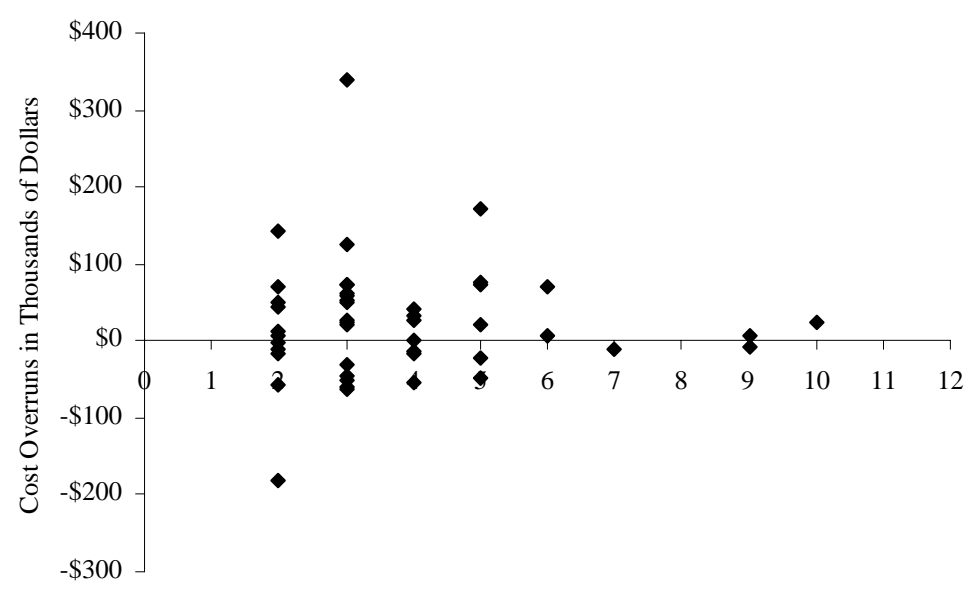

Level of Competition

Figure 7.2: Cost Overruns Variation with the Level of Competition 


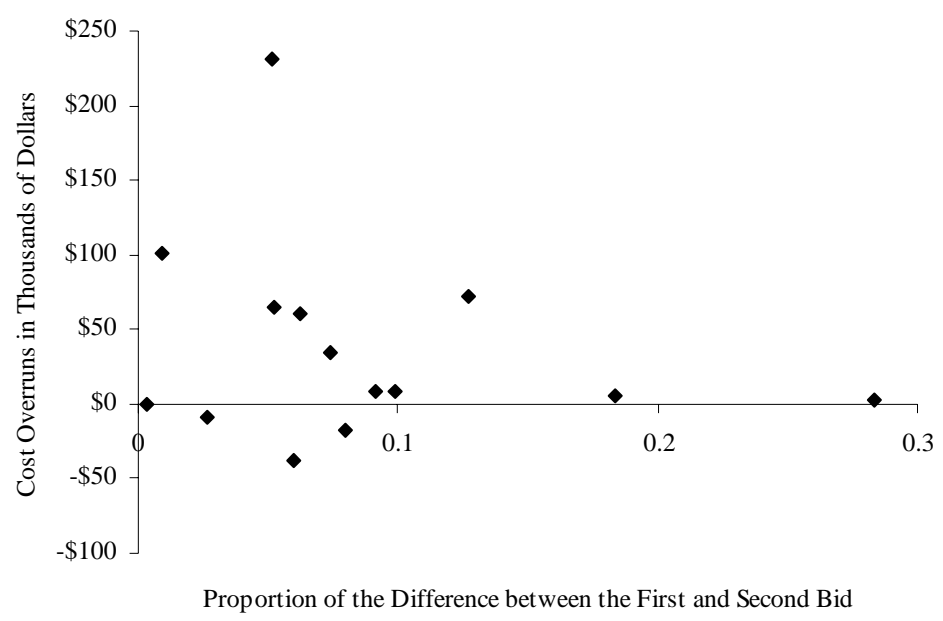

Figure 7.3: Cost Overruns Variation with the Proportion between the First and the Second Bid

Figure 7.3 is associated with medium levels of bid amount, level of competition, and proportion of inclement days. This figure seems to suggest that the larger the difference between the first and second bid, the generally lower the cost overrun amount, even though the trend is not so “clean”. A similar trend is observed when the Proportion between the Bid and the Engineer's Estimate is used as a dependent variable (Figure 7.4)

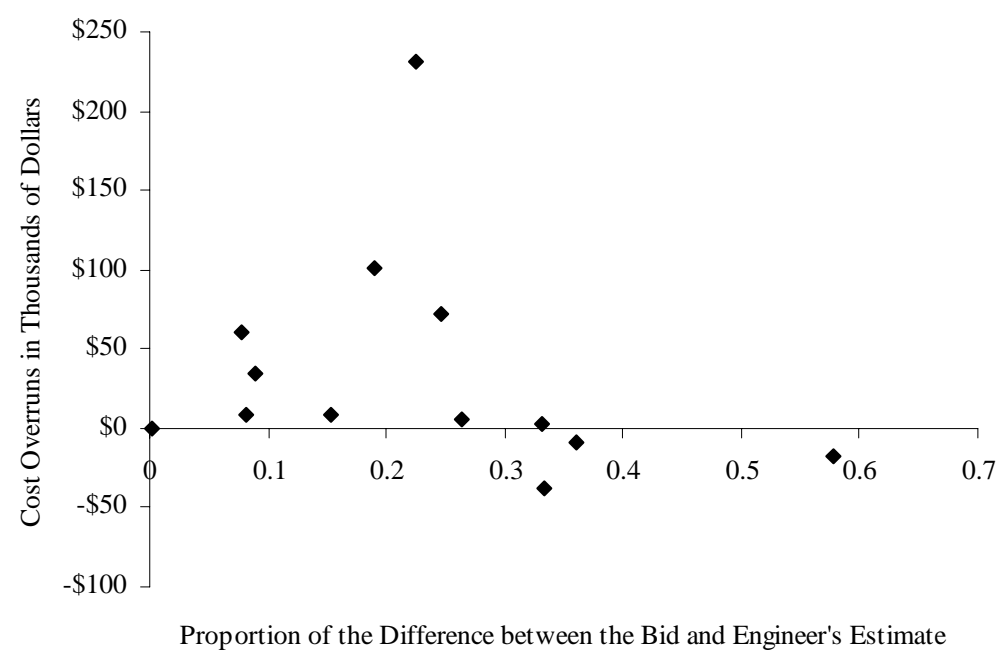

Figure 7.4: Cost Overrun Variation with the Proportion between the Bid and the Engineer's Estimate 
Figure 7.5 was developed using the same levels of factors as was dome for the previous figure. It is seen that the larger the bid amount, the higher the cost overruns. Figure 7.5 was developed using a medium level of the level of competition variable and a medium level of the proportion of inclement days variable. The result is consistent with the finding of Rowland (1981).

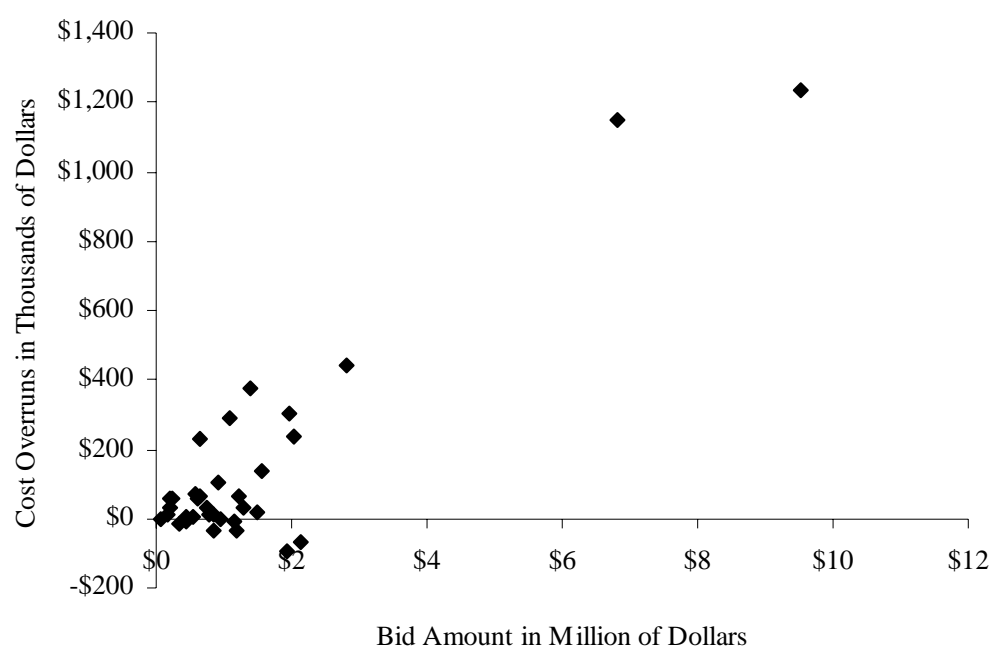

Figure 7.5: Cost Overrun Variation with the Bid Amount

\subsubsection{Time Overrun}

Figure 7.7 was developed using a medium level of the bid amount variable and a medium level of the proportion of difference between the first and the second bid variable. A higher proportion of inclement days in a project seemed to be associated with a fewer delayed days. Figure 7.7 utilized a medium level of the proportion of inclement days variable and a medium level of the proportion of difference between the first and second bids variable. A higher bid amount seemed to be associated with a lower number of delayed days. 


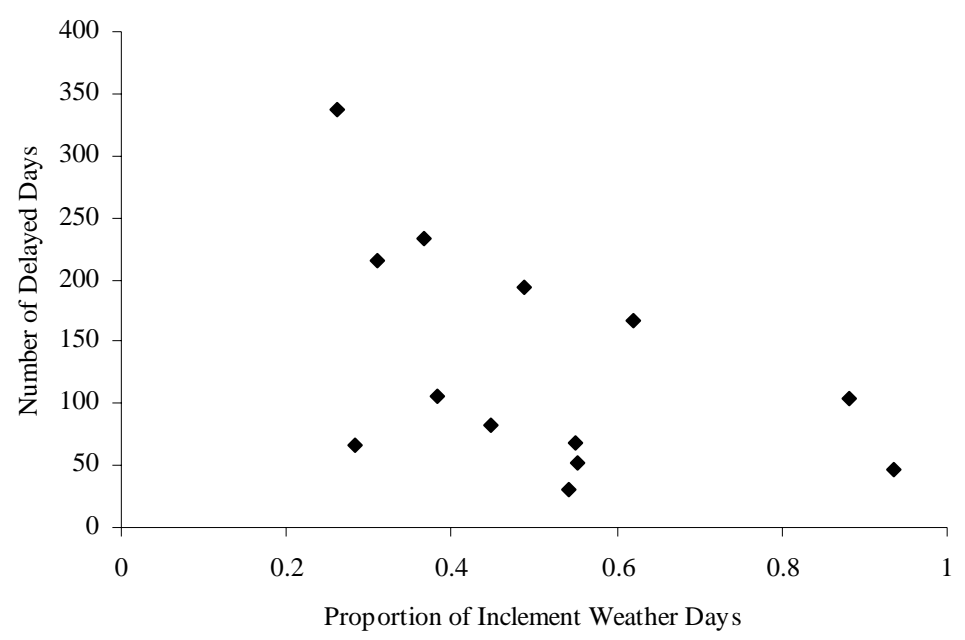

Figure 7.6: Time Delay Variation with the Proportion of Inclement Days

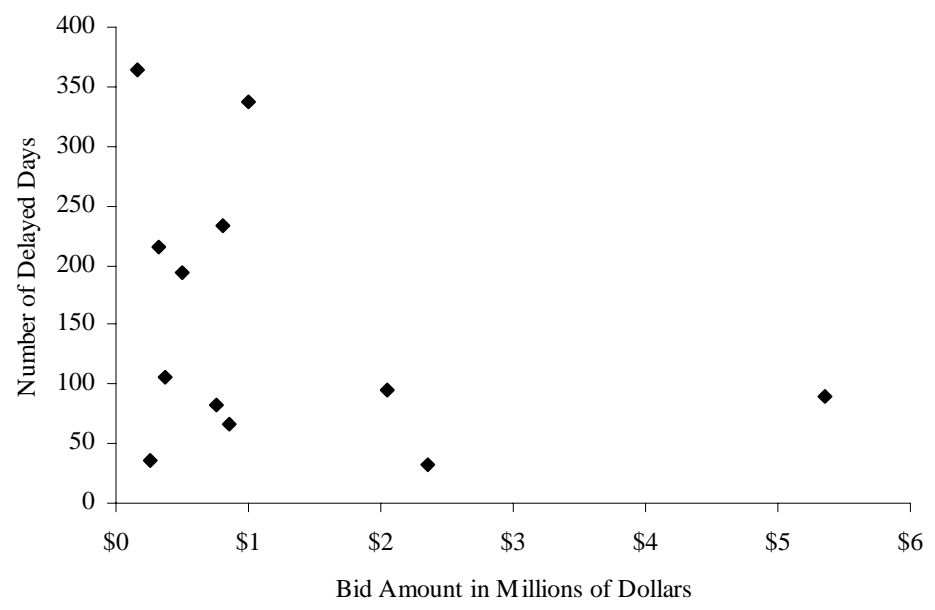

Figure 7.7: Time Delay Variation with the Bid Amount

Figure 7.9 was developed using a medium level of the bid amount variable, a medium level of the proportion of inclement weather days variable and a medium level of the proportion of difference between the engineer's estimate and bid variable. A higher original duration implied a lower number of delayed days. Figure 7.10 shows that the level of competition seemed to have a little influence on time delays. The conditions were a medium level of the (original) duration variable and a medium proportion of difference between the first and second bid variable. 


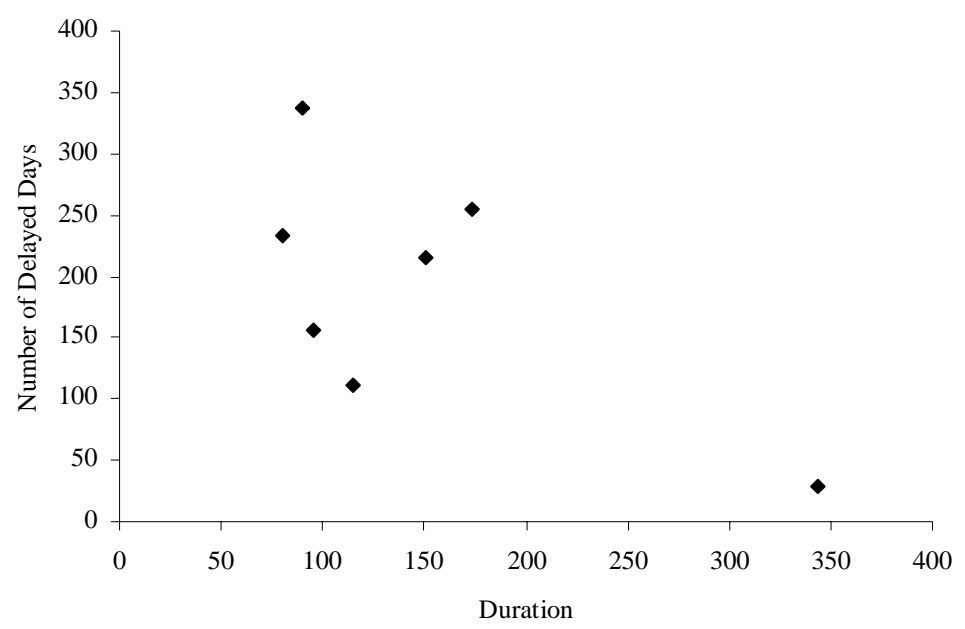

Figure 7.9: Time Delay Variation with Contract Duration in Days

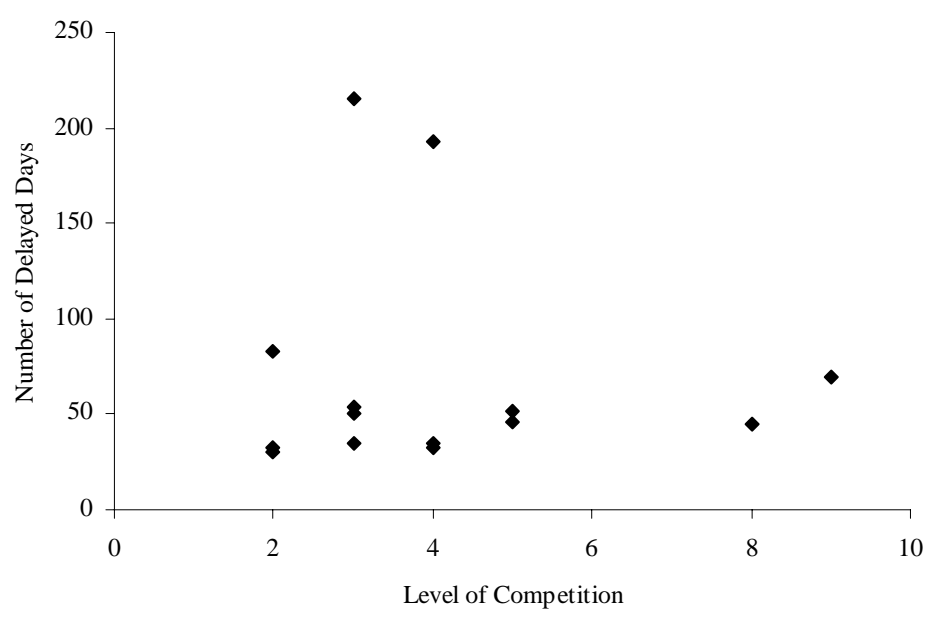

Figure 7.10: Time Delay Variation with the Level of Competition

Figure 7.11 suggests that if the difference between the first and second bids was large, the time delay was also large. The figure was developed using a medium level of the level of competition variable. Although there were only a few data points, Figure 7.12 shows that the number of delayed days decreased with the variation of the difference between the winning bid and engineer's estimate. This graph followed the same conditions as for the previous figure. 


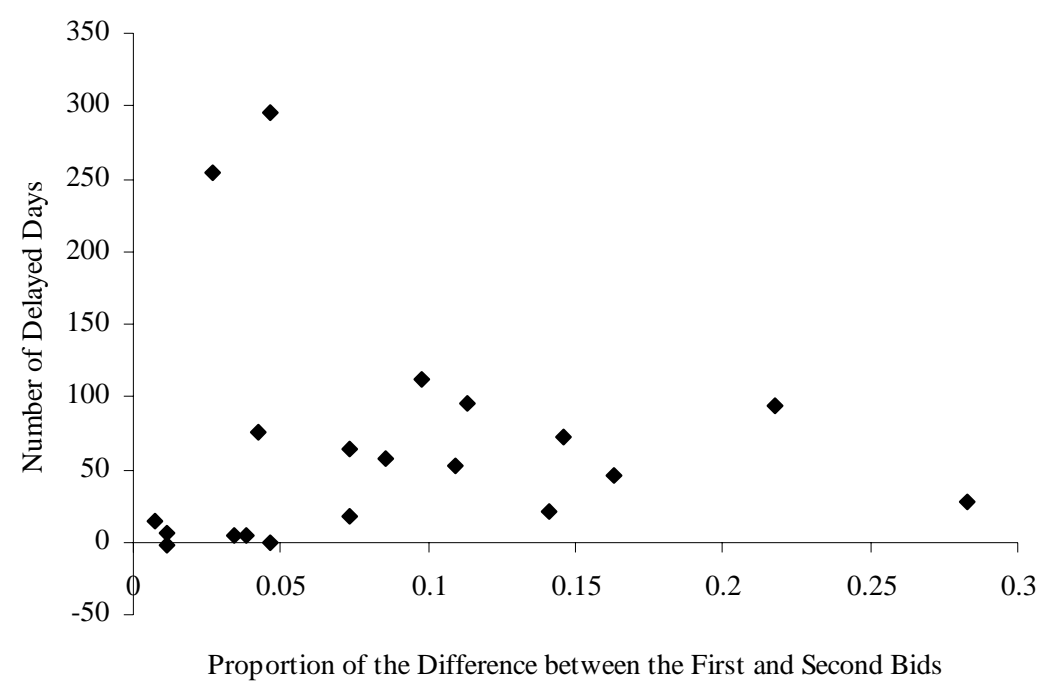

Figure 7.11: Time Delay Variation with the Difference between the First and Second Bids

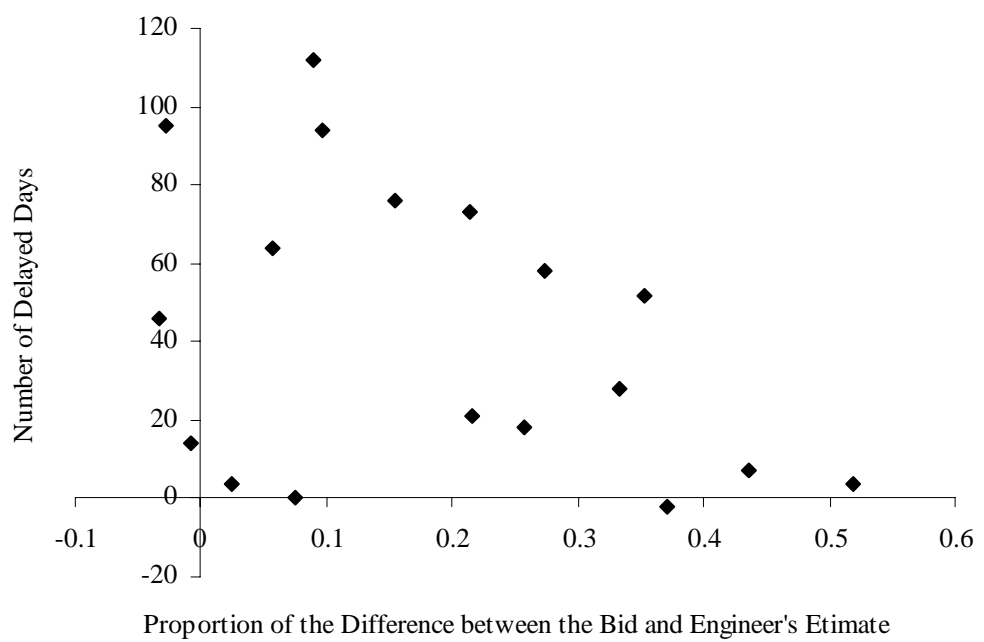

Figure 7.12: Time Delay Variation with the Difference between the Engineers' Estimate and the Bid

\subsubsection{Frequency of Change Orders}

Figure 7.13 shows that the frequency of change orders increased when the proportion of inclement days increased. This figure was developed using the following conditions: a medium level of the level of competition variable and a medium level of the bid amount variable. Figure 7.14 shows that the level of competition had a slight decreasing effect on the frequency of change orders. The 
condition was a medium level of the proportion of difference between the first and second bids variable.

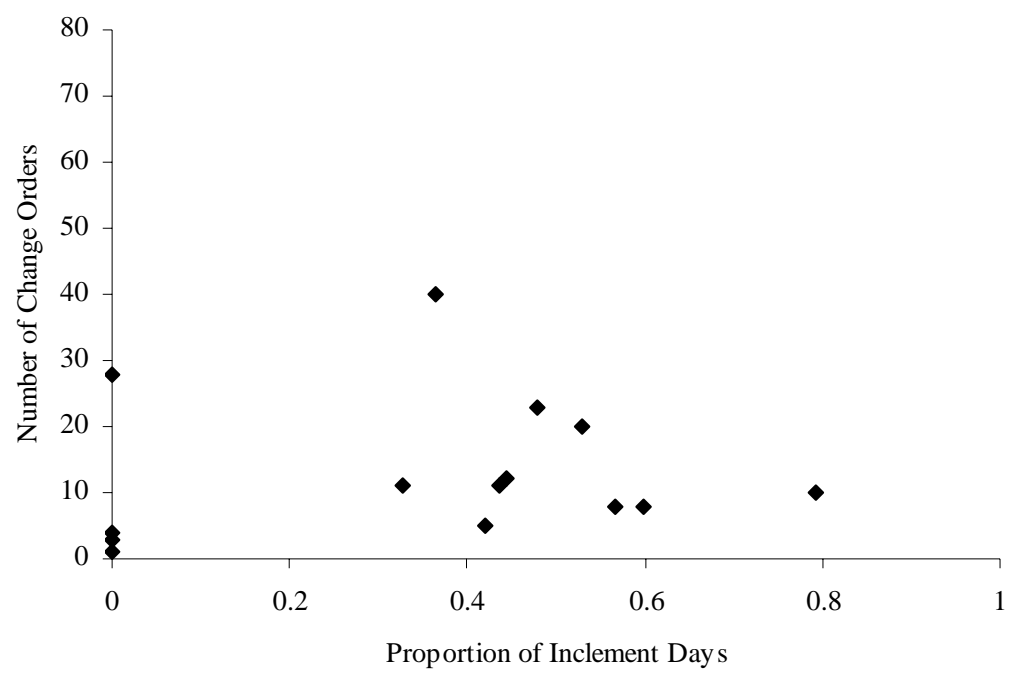

Figure 7.13: Variation of the Frequency of Change Orders with the Proportion of Inclement Days

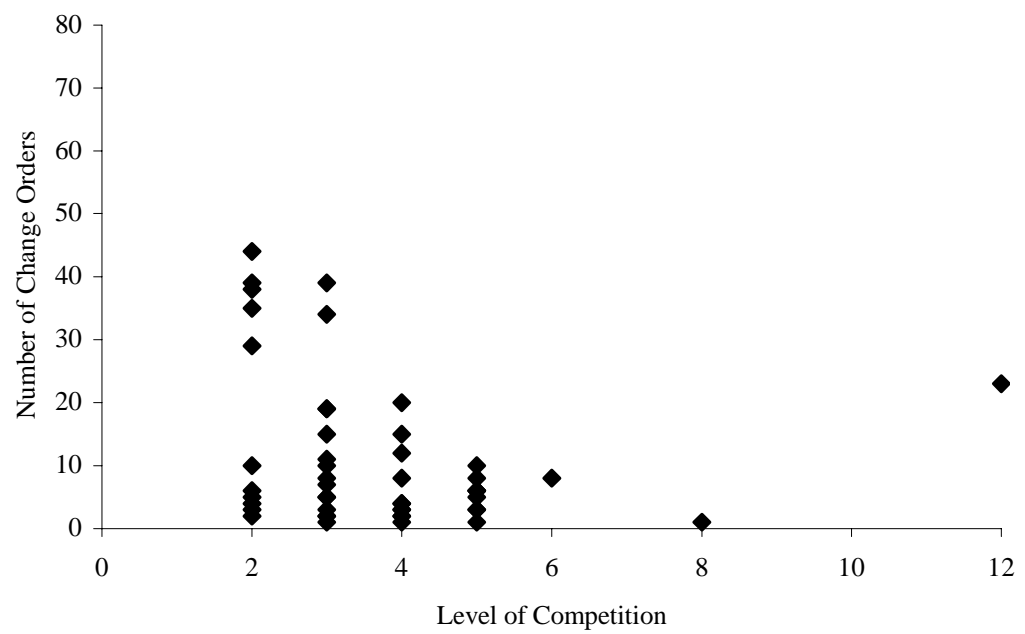

Figure 7.14: Variation of the Frequency of Change Orders with the Level of Competition

Figure 7.15 shows that increasing proportion of difference between the first and second bid is associated with decreased frequency of change orders. The condition was a medium level of the level of competition variable. The condition for Figure 7.16 is a medium level of the level of competition variable. It shows that if this proportion of difference was high, the frequency of change orders is lower than for small proportions. 


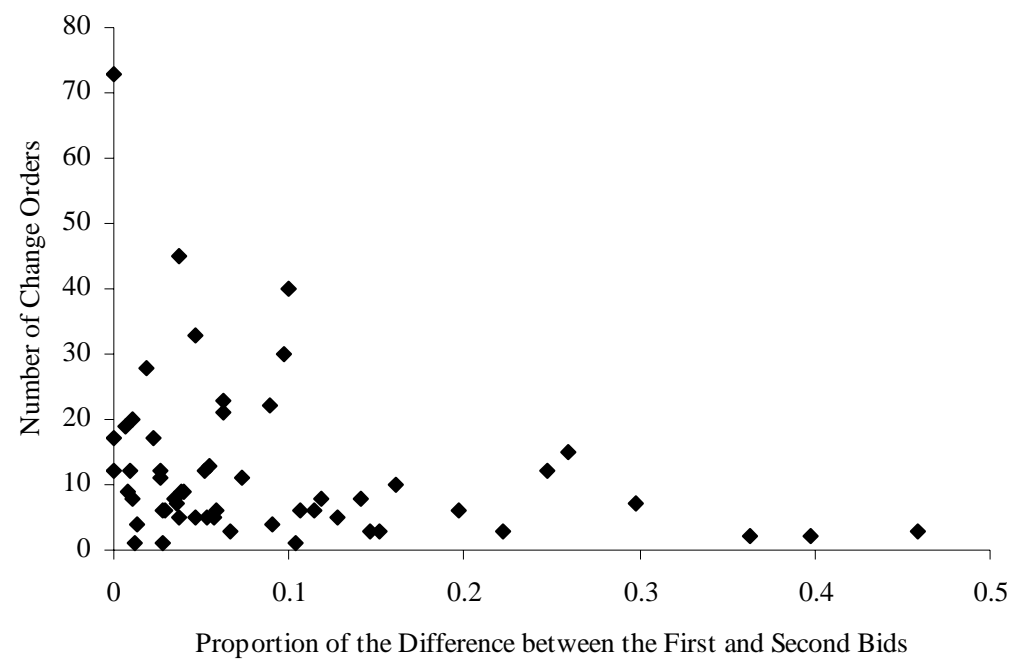

Figure 7.15: Variation of the Frequency of Change Orders with the Proportion of the Difference between the First and Second Bid

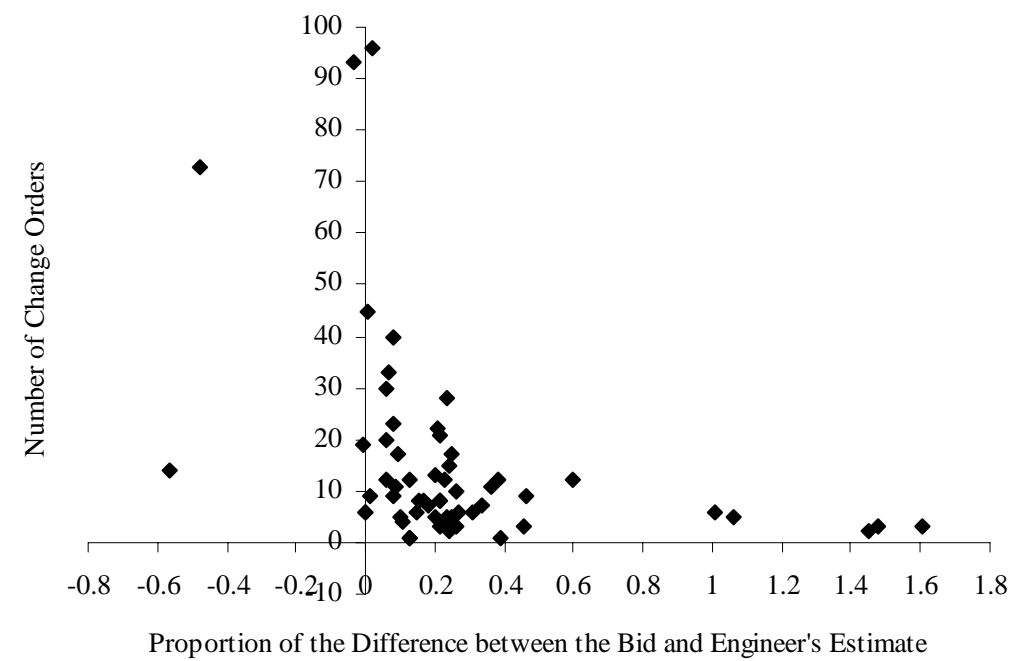

Figure 7.16: Variation of the Frequency of Change Orders with the Proportion of the Difference between the Winning Bid and Engineer's Estimate

In Figure 7.17, the following conditions on the variables were used: a medium level of the proportion of inclement days variable and a medium level of the level of competition variable. The figure shows that as the bid amount increased, the frequency of change orders also increased. 


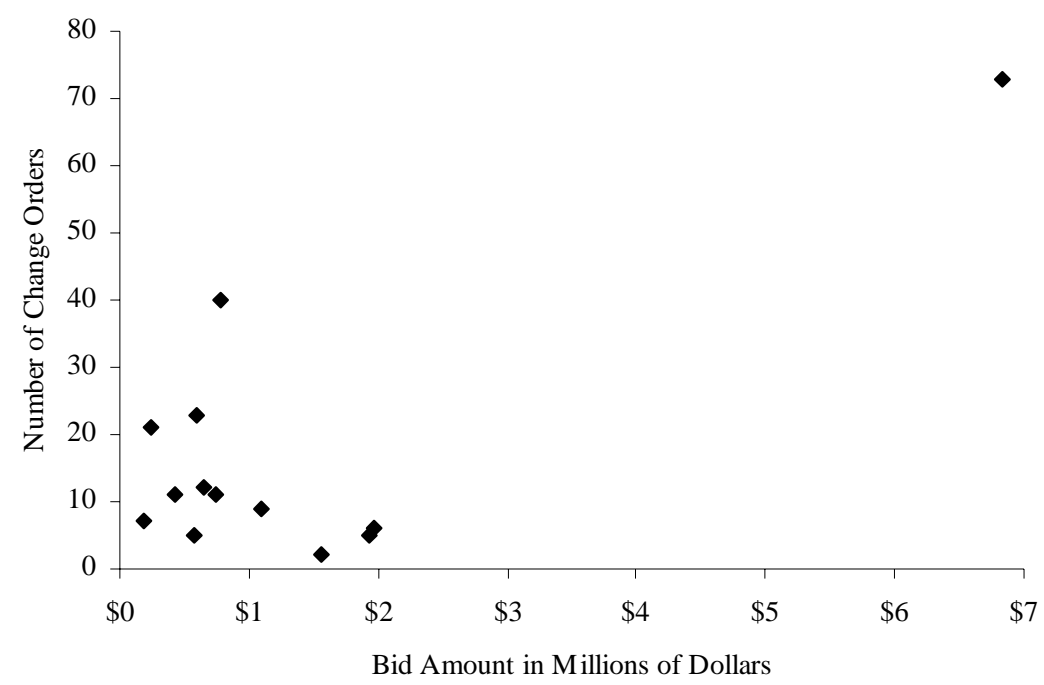

Figure 7.17: Variation of the Frequency of Change Orders with the Bid Amount

\subsubsection{Conclusions for the Graphical Analysis}

Table 7.14 summarizes the findings of the graphical analysis that sought to discern any clear trends in the relationships between the potentially influential factors (independent variables) on cost overruns, time delay, and change order frequency.

Table 7.5: Effects of each Independent Variable on the Dependent Variables

\begin{tabular}{lccc}
\hline Independent Variable & $\begin{array}{c}\text { Effect of Increasing Independent Variable on the following Dependent Variables } \\
\text { while Keeping Other Independent Variables at a Fixed Level }\end{array}$ \\
\hline & Cost Overrun & Time Overrun & Frequency of Change Orders \\
\hline Bid Amount & Increasing effect & Decreasing effect & Increasing effect \\
\hline Length & & Decreasing effect & Increasing effect \\
\hline Proportion of Inclement Days & Increasing effect & Decreasing effect & No influence \\
\hline Level of Competition & No influence & Slightly decreasing effect & Decreasing effect \\
\hline $\begin{array}{l}\text { Proportion of the Difference } \\
\text { between the First and Second Bid }\end{array}$ & $\begin{array}{c}\text { Decreasing } \\
\text { effect }\end{array}$ & Slightly decreasing effect & Decreasing effect \\
\hline $\begin{array}{l}\text { Proportion of the Difference } \\
\text { between the Winning Bid and the } \\
\text { Engineer's Estimate }\end{array}$ & $\begin{array}{c}\text { Decreasing } \\
\text { effect }\end{array}$ & Decreasing effect & \\
\hline
\end{tabular}

This analysis provided somewhat contradicting results. The bid amount had a decreasing effect on time delays, although it was expected that the influence would be always increasing. The bid 
comparison variable had either no influence or a decreasing influence. The proportion of inclement weather days had an increasing effect, except on time delays.

\subsection{Chapter Summary}

The preliminary statistical investigations in the present chapter helped identify trends between cost overruns, time delay and change order frequency on one hand and the potentially influential factors on the other hand, and also to establish a-priori expectations of the strength and direction of such relationships. The correlation matrix analysis indicated no significant linear correlation between the independent variables, except for the two variables: proportion of the difference between the first and second bids and proportion of difference between the winning bid and engineer's estimate. The analysis of variance showed that the variables, bid amount, proportion of inclement weather days and duration had significant differences among cost overruns, time delays, and frequency of change orders.

The results of the pair-wise test and the graphical analysis did not yield results that were always consistent with the analysis of variance. For example, the proportion of inclement days seemed to have a significant impact on cost overruns using graphical analysis, but the ANOVA test indicated otherwise. However, it is not unexpected to obtain such seemingly contradictory results from such analyses. The pair-wise t-test analysis or the influence analysis was conducted with very precise data characteristics and may have occluded some general trends that were revealed in the ANOVA tests. The results in this chapter provide only general hints for a-priori expectations for further investigations and results that are discussed in Chapter 8. 


\section{CHAPTER 8: STATISTICAL MODELS}

\subsection{Introduction}

The present chapter investigates the influence of variables found significant from analyses presented in the previous chapter. This is done for cost overrun, time delay, and change orders. It is worth mentioning that the primary goal of the modeling process was to identify or confirm the magnitude and direction of the impacts of the variables, while the use of the developed models for prediction was considered only a secondary goal.

For each of the three response variables, two models were developed: one that included "bid comparison" variables, and one that excluded such variables. Models that included the "bid comparison" variables were developed using only those observations for which such data was available, and therefore the dataset for such models was only a subset of the full dataset. Such models are applicable in cases where bid have been received for a contract, and INDOT seeks to estimate the expected cost overruns, time delay or change orders for the contract. Models that excluded the "bid comparison" variables were developed using the entire dataset. Such models are applicable in cases where no bids are yet available for a contract, and are therefore useful for long term planning and estimation of expected cost overruns, time delay or change orders for contracts. The " bid comparison" variables are the proportion of the difference between the amounts for the winning bid and the second bid, the proportion of the difference between the winning bid and the engineer's estimate, and the level of competition. Each model was validated using $25 \%$ of data points set aside for that purpose.

Figure 8.1 presents a schematic framework of the modeling process.

The strength and magnitude of factors affecting change order frequency and amounts, time delay, and cost overrun amounts and rates, models were investigated using regression modeling. Recognizing that efforts by INDOT to predict these parameters for future projects may be constrained by lack of bidding information, separate models were attempted for cases where bid comparison variables are available and where such variables are not available. The regression modeling was carried out for each project type. 

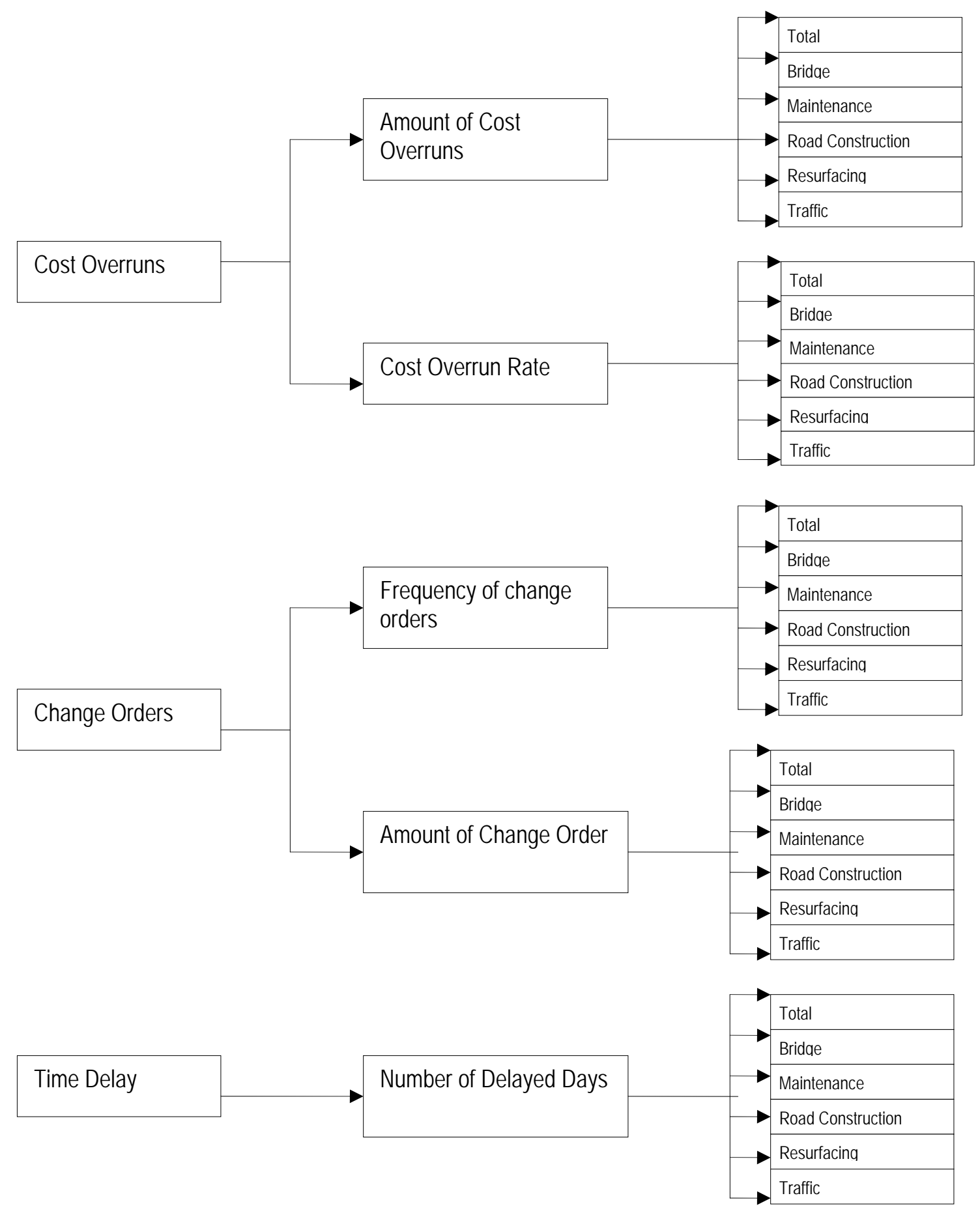

Figure 8.1: Organization of the Modeling Process 


\subsection{Models for Change Orders}

Models were developed was attempted to identify the strength and magnitude of factors affecting change order frequency and also to estimate the amount involved in change orders. The first phase of the modeling exercise involved exclusion of the "bid comparison" variables, and the second phase involved inclusion of such variables. Models were developed first for all project types combined, and then separately for each project type.

\subsubsection{Models for Change Order Frequency}

\subsubsection{Estimating the Frequency of Change Orders for All Project Types Combined}

Several functional forms were investigated for developing the model for frequency of change orders. It was found that the linear model provided the best results. Table 8.1 below presents the model results for the estimated frequency of change orders given independent variables such as the project type, location by district, bid amount and proportion of inclement days.

Table 8.1: Linear Change Order Model Excluding the "Bid Comparison” Variables

\begin{tabular}{lccccc}
\hline \multicolumn{1}{c}{ Variable } & & Coefficient & Std. Error & t-stat & P-value \\
\hline Bridge Project & $B$ & 21.94 & 2.78 & 7.89 & 0.00 \\
\hline Maintenance Project & $M$ & 19.63 & 2.61 & 7.51 & 0.00 \\
\hline Road Construction Project & $R$ & 19.44 & 2.82 & 6.89 & 0.00 \\
\hline Traffic Project & $T$ & 20.19 & 3.50 & 5.77 & 0.00 \\
\hline Resurfacing Project & $R S$ & 19.56 & 3.20 & 6.12 & 0.00 \\
\hline Fort Wayne District & FortW & 7.75 & 3.34 & 2.32 & 0.02 \\
\hline Proportion of Inclement Days & PNINCL & -3.13 & 1.69 & -1.85 & 0.07 \\
\hline \multicolumn{1}{c}{ Bid Amount/1,000,000 } & bidamount & 1.43 & 0.58 & 2.46 & 0.01 \\
\hline $\begin{array}{l}\text { Adjusted R }{ }^{2}=0.368 \\
\text { Number of Observations }=555 \\
\text { Response Variable }(N C O) \text { is the Number of Change Orders Associated with a Contract }\end{array}$
\end{tabular}

$N C O=21.94 * B+19.63 * M+19.44 * R+20.19 * T+19.56 * R S+7.75 *$ Fortw $-3.13 *$ Pnincl $+1.43 * \frac{\text { bidamount }}{1,000,000}$

The influence of each of the five project types on the frequency of change orders was found significant. Bridge projects were found to be associated with the highest frequency of change orders compared to the other project types. This is probably due to uncertainties regarding the quantities of bridge related work. Such uncertainties, which may include bridge structure and foundation defects that were probably not seen at time of inspection, but were subsequently uncovered during the 
construction work. On the other hand, traffic maintenance (which was assigned a value of zero for each of the above project type variables) was associated with the least frequency of change orders. This finding suggests that parties responsible for estimating the quantities required for traffic maintenance are providing better estimates which are in turn due to the fact that traffic maintenance work is less vulnerable to uncertainties at the site. The modeling results also showed that there are differences in the frequency of change orders across districts. It was seen that compared to projects at all other districts, projects in the Fort Wayne District were associated with a larger frequency of change orders, all other factors being equal. This finding can be attributed to the highly variable nature of ground conditions in the Fort Wayne district (Labi, 2001). Glacial depositional features in the region include moraines, outwash plains, kames, and lake plains, and surface geology in this area consist of a diverse mix of sediments with highly variable hydrogeologic properties and lithographic discontinuities [Fenelon et al., 1994]. Postglacial landforms in this region include a multiplicity of lakes found in northeastern Indiana, and the frequent pockets of muck and peat bogs that arise from the damming of drainage areas. The highly variable nature of the soils in the Fort Wayne District may therefore be responsible for the relatively high frequency of change orders in that district compared to the other districts.

The model results also showed that all else being the same, the higher the bid amount, the higher the frequency of change orders, a finding that is consistent with expectation. Finally, the model showed a decreasing effect of the proportion of inclement days on the frequency of change orders. This finding is counter intuitive, but it can be noted that the significant is only marginal, as seen from the t-statistic. The final model may be used by INDOT to estimate the expected number of change orders for a future project of any type where the "bid comparison” variables are not known.

Another model was developed that included the "bid comparison" variables, i.e., the level of competition, the proportion of the difference between the winning and second bids and the proportion of the difference between the winning bid and the engineer's estimate. Again, several functional forms were tried for that model, but even the best model had an adjusted $\mathrm{R}^{2}$ of only 0.135 .

\subsubsection{Frequency of Change Orders for Bridge Projects}

In a similar manner done for all project types combined, a model was developed for estimating the frequency of change orders associated with bridge projects. Again, several functional forms were tried, and the form that gave the best results was the linear form as shown below: 
Table 8.2: Model for Frequency of change orders

for Bridge Projects, Excluding “Bid Comparison” Variables

\begin{tabular}{lccccc}
\hline \multicolumn{1}{c}{ Variable } & Coefficient & Std. Error & t-stat & P-value \\
\hline Proportion of Inclement Days & PNINCL & -7.18 & 4.54 & -1.58 & 0.12 \\
\hline Natural Logarithm of Bid Amount & Ln(bidamount) & 2.11 & 0.29 & 7.15 & 0.00 \\
\hline $\begin{array}{l}\text { Adjusted R }{ }^{2}=0.369 \\
\text { Number of Observations }=126 \\
\text { Response Variable }(N C O) \text { is the Number of Change Orders Associated with a Contract }\end{array}$ & &
\end{tabular}

The proportion of inclement weather days was found to be only marginally significant in the model. Also, the model results showed that a higher bid amount is associated with a greater frequency of change orders, all else being equal. Validation of the model yielded a root mean square error of 25 units. INDOT may use this model to estimate the expected number of change orders for future contracts where the "bid comparison" variables are not known.

For estimating the expected frequency of change orders for bridge projects, another model was developed to include the "bid comparison" variables. Again, several functional forms were tried for that model, and the best model had an adjusted $\mathrm{R}^{2}$ of 0.407 . The significant variables were the proportion of inclement weather days (decreasing effect), the bid amount (increasing effect), and the proportion of the difference between the bid and engineer's estimate (decreasing effect). This model is appropriate for use by INDOT to predict the expected number of change orders for future contracts where the "bid comparison” variables are known.

\subsubsection{Frequency of Change Orders for Maintenance Projects}

For maintenance projects, the linear functional form yielded the most encouraging results, even though the adjusted $\mathrm{R}^{2}$ of 0.232 may be considered relatively low. Three variables representing the project location were found significant: Crawfordsville, Fort Wayne and Seymour Districts. The results showed that maintenance projects in these districts had more change orders than the other districts, all else being equal. This finding may be attributed to natural variations in the project environment or management culture and practices. The model results also showed that the higher the proportion of inclement days, the greater the frequency of change orders. Also, the results showed that all else being the same, a higher bid amount significantly and directly influences the frequency of change orders.

In order to estimate the expected frequency of change orders for maintenance projects where "bid comparison” variables are known, another model was developed. After investigating the linear, quadratic and logarithmic functional forms, the logarithmic form was selected because it had the 
highest $\mathrm{R}^{2}$. For all the functional forms that were tried, the bid amount had a (counter-intuitive) inverse relationship with the frequency of change orders for maintenance projects, and this may be attributed to the small number of observations (34) for which data were available. The models also showed that the location of projects at Crawfordsville and Laporte Districts had diametrically opposite effects on the frequency of change orders, while the location at the other districts do not seem to influence the frequency of change orders. The models also showed that the higher the proportion of inclement days, the higher the frequency of change orders, all else being equal, which is quite intuitive. Finally, it was seen that a higher frequency of change orders are obtained for a lower proportion of the difference between the winning bid amount and the engineer's estimate (which is intuitive), and for a lower proportion of the difference between the winning and second bid (which is counter-intuitive). The $\mathrm{R}^{2}$ was 0.414 . The logarithmic and linear models used the same variables, yielded the same coefficient signs of the variables except for the bid amount, and had comparable $\mathrm{R}^{2}$ values. The logarithmic model validation yielded a percentage deviation of 6.3 and a root mean square error of 26.8 units. This model may be used by INDOT to predict the expected frequency of change orders for maintenance projects where the "bid comparison" variables are known.

Table 8.3: Model for Frequency of Change Orders for Maintenance Projects, Including the "Bid Comparison” Variables

\begin{tabular}{|c|c|c|c|c|c|}
\hline Variable & & Coefficient & Std. Error & t-stat & P-value \\
\hline Constant Term & (Constant) & 1.65 & 0.30 & 5.46 & 0.00 \\
\hline Crawfordsville District & CRAWF & 0.15 & 0.06 & 2.53 & 0.02 \\
\hline La Porte District / 100 & LAPOR & -8.36 & 0.05 & -1.58 & 0.13 \\
\hline Proportion of Inclement Days / 100 & PNINCL2 & 4.32 & 0.02 & 1.86 & 0.07 \\
\hline $\begin{array}{l}\text { Proportion of the Difference between the } \\
\text { First and Second Bid }\end{array}$ & PDIFSEC & -0.23 & 0.10 & -2.29 & 0.03 \\
\hline $\begin{array}{l}\text { Proportion of the Difference between the } \\
\text { Bid Amount and the Engineer's Estimate }\end{array}$ & PDIFENG & -0.28 & 0.08 & -3.63 & 0.00 \\
\hline Natural Logarithmic of the Bid Amount / 100 & Ln(bidamount) & -3.39 & 0.02 & -1.48 & 0.15 \\
\hline
\end{tabular}

\subsubsection{Frequency of Change Orders for Road Construction Projects}

To investigate the factors affecting the frequency of change orders associated with road construction projects and to predict the expected number of change orders for a future road construction project, various regression models were investigated. The initial models excluded the "bid comparison” variables, and a linear model was adjudged the most appropriate form for such models. The results are shown in Table 8.4. 
Table 8.4: Change Order Frequency Model for Road Construction Projects Excluding the "Bid Comparison” Variables

\begin{tabular}{lccccc}
\hline \multicolumn{1}{c}{ Variable } & Coefficient & Std. Error & t-stat & P-value \\
\hline Constant Term & (Constant) & 11.54 & 4.29 & 2.69 & 0.01 \\
\hline Fort Wayne District & FORTW & 14.11 & 5.62 & 2.51 & 0.01 \\
\hline Square Root of Bid Amount, in 1,000’s & SQRT(bidamount) & 7.82 & 0.00 & 1.60 & 0.11 \\
\hline $\begin{array}{l}\text { Adjusted R } \\
\text { Number of Observations }=142 \\
\text { Response Variable }(\text { NCO) is the Number of Change Orders Associated with a Contract }\end{array}$ \\
\\
$\quad N C O=11.54+14.11 *$ Fortw $+7.82 * \frac{\sqrt{\text { bidamount }}}{1,000}$
\end{tabular}

The model shown above had a $\mathrm{R}^{2}$ of 0.45 and contained two variables: the Fort Wayne District, and a transformed variable representing the bid amount. The model results showed that all else being the same, road construction projects in Fort Wayne District had a greater frequency of change orders compared to similar projects in other districts. This finding is similar to that for the all projects combined, and may be attributed to the highly variable nature of the Fort Wayne subsoils. Also, the model showed that a higher bid amount translates directly to a higher frequency of change orders, all other factors remaining the same. This result is consistent with expectation. Validation of the model was carried out using the reserved dataset for that purpose, and it yielded a percentage deviation of $113 \%$ and a root mean square error of 21 units. INDOT may use this model to predict the expected frequency of change orders for road construction projects where the "bid comparison" variables are not known.

For estimating the frequency of change orders for road construction projects, another model was developed to include the "bid comparison" variables. Regardless of functional form, the models obtained had relatively poor validation statistics. The significant variables were the proportion of the difference between the winning bid and engineer's estimate, the proportion of the difference between the winning and second bid, and the bid amount.

\subsubsection{Frequency of Change Orders for Traffic Projects}

For the traffic projects and excluding the "bid comparison" variables, the modeling process indicated generally poor fits regardless of functional form used. Compared to the other functional forms, the linear form had the highest adjusted $\mathrm{R}^{2}$ of 0.122 and only the bid amount variable was found to be significant. 
When the "bid comparison" variables were included, the linear and logarithmic forms gave similar results, but the latter gave a better $\mathrm{R}^{2}$. The model results showed that projects located at the Crawfordsville District seemed to experience more change orders for traffic projects. It may be noted that unlike road construction projects, traffic project scopes are relatively less influenced by variations in the project environment; therefore district such as Fort Wayne did not have a larger frequency of change orders for this project type. As such, the higher frequencies of change orders in Crawfordsville District may be attributed to its administrative/management practices or other peculiar environment. Finally, it was seen that a higher frequency of change orders are obtained for a lower proportion of the difference between the winning bid amount and the engineer's estimate (which is intuitive), and for a higher proportion of the difference between the winning and second bid (which is intuitive). It is worth noting that even though the number of observations was rather small (17), the adjusted $\mathrm{R}^{2}$ was quite high (0.724). Validation of the model yielded a percentage deviation of 5.63 and a root mean square error of 11.2. Even though the quadratic form had similar results as the linear and logarithmic forms, and even had a better $\mathrm{R}^{2}(0.788)$, it had relatively poor validation statistics. INDOT may use this model to predict the expected frequency of change orders for traffic projects where the "bid comparison” variables are known.

Table 8.5: Model for Estimating Frequency of Change Orders for Traffic Projects Including the "Bid Comparison” Variables

\begin{tabular}{lccccc}
\hline \multicolumn{1}{c}{ Variable } & & Coefficient & Std. Error & t-stat & P-value \\
\hline Constant Term & (Constant) & 1.38 & 0.10 & 13.35 & 0.00 \\
\hline Crawfordsville District & CRAWF & 0.17 & 0.11 & 1.51 & 0.16 \\
\hline $\begin{array}{l}\text { Proportion of the Difference between the } \\
\text { First and Second Bid }\end{array}$ & PDIFSEC & 2.40 & 0.49 & 4.85 & 0.00 \\
\hline $\begin{array}{l}\text { Proportion of the Difference between the } \\
\text { Bid Amount and the Engineer's Estimate }\end{array}$ & PDIFENG & -1.42 & 0.29 & -4.84 & 0.00 \\
\hline \multicolumn{1}{c}{ Bid Amount / 1,000,000 } & Amoun6 & -0.16 & 0.08 & -2.08 & 0.06 \\
\hline
\end{tabular}

Response Variable is the exponent of the Frequency of change orders

Adjusted $\mathrm{R}^{2}=0.724$

Number of Observations $=17$

Response Variable (NCO) is the Number of Change Orders Associated with a Contract

$$
N C O=\ln \left(1.38+0.17 * \text { Crawf }+2.4 * \text { Pdifse }-1.42 * \text { Pdifeng }-0.16 * \frac{\text { bidamount }}{1,000,000}\right)
$$




\subsubsection{Frequency of Change Orders for Resurfacing Projects}

Model development for estimating the frequency of change orders for road resurfacing projects was attempted using various functional forms, but the results showed that only the bid amount seems to be significant: A higher bid amount translates to a higher frequency of change orders, all else being equal. The logarithmic form provided the best fit, compared to the other forms. The model was validated using a dataset reserved for such purpose, and a percentage deviation and root mean square error of 29 and 50.5, respectively, were obtained. This model may be used by INDOT to estimate the frequency of change orders for future resurfacing projects where the "bid comparison" variables are not known.

Table 8.6: Model for Frequency of Change Orders for Resurfacing Projects Excluding the "Bid Comparison” Variables

\begin{tabular}{llcccc}
\hline \multicolumn{1}{c}{ Variable } & & Coefficient & Std. Error & t-stat & P-value \\
\hline Seymour District / 10 & SEYMO1 & 1.44 & 0.11 & 1.31 & 0.19 \\
\hline $\begin{array}{l}\text { Natural Logarithmic of the Bid } \\
\text { Amount, in 100's }\end{array}$ & Lnamou2 & 9.79 & 0.00 & 24.72 & 0.00 \\
\hline
\end{tabular}

Response Variable is the exponent of the Frequency of change orders

Adjusted $\mathrm{R}^{2}=0.895$

Number of Observations $=95$

Response Variable (NCO) is the Number of Change Orders Associated with a Contract

$$
N C O=\ln \left(1.44 * \frac{\text { Seymo }}{10}+9.79 * \frac{\ln (\text { bidamount })}{100}\right)
$$

\subsubsection{Change Order Amount}

Model development was attempted to estimate the amount spent on all change orders in a given contract. However, the resulting models were not encouraging and such modeling efforts were abandoned. As such, the present study provides only average values of change order amounts by project type and by district (Table 8.7). It is seen that bridge projects are associated with the highest amount spent on change orders per contract. On the other hand, traffic maintenance projects have the least amount spent on change orders per contract. The results seem to be similar to those obtained for the frequency of change orders. It is seen that bridge projects in Crawfordsville and Seymour have the highest amount of change orders. Also, the table shows that maintenance and road construction projects located at Fort Wayne District have higher amounts spent on change orders, compared to such projects at other districts. Resurfacing and traffic projects at Seymour, and traffic maintenance projects 
at Laporte have the highest amount spent on change orders, compared to similar projects at the other districts. It may be interesting to examine the variations of average amount spent per change order given other attributes such as project type, district location, bid amount, and other factors.

Table 8.7: Average Change Order Amounts by Project Type and by District

\begin{tabular}{|c|c|c|c|}
\hline Project Type & District & $\begin{array}{l}\text { Average Amount for Change } \\
\text { Orders Per Contract }\end{array}$ & $\begin{array}{c}\text { Average per Project Type, for all } \\
\text { Districts }\end{array}$ \\
\hline \multirow{6}{*}{ Bridge } & Crawfordsville & $\$ 245,409$ & \multirow{6}{*}{$\$ 179,997$} \\
\hline & Fort Wayne & $\$ 138,819$ & \\
\hline & Greenfield & $\$ 174,451$ & \\
\hline & La Porte & $\$ 161,581$ & \\
\hline & Seymour & $\$ 234,006$ & \\
\hline & Vincennes & $\$ 102,010$ & \\
\hline \multirow{6}{*}{ Maintenance } & Crawfordsville & $\$ 129,056$ & \multirow{6}{*}{$\$ 164,082$} \\
\hline & Fort Wayne & $\$ 431,666$ & \\
\hline & Greenfield & $\$ 97,115$ & \\
\hline & La Porte & $\$ 154,079$ & \\
\hline & Seymour & $\$ 136,803$ & \\
\hline & Vincennes & $\$ 86,312$ & \\
\hline \multirow{6}{*}{$\begin{array}{l}\text { Road } \\
\text { Construction }\end{array}$} & Crawfordsville & $\$ 210,919$ & \multirow{6}{*}{$\$ 164,569$} \\
\hline & Fort Wayne & $\$ 308,341$ & \\
\hline & Greenfield & $\$ 115,616$ & \\
\hline & La Porte & $\$ 115,531$ & \\
\hline & Seymour & $\$ 181,504$ & \\
\hline & Vincennes & $\$ 72,595$ & \\
\hline \multirow{7}{*}{ Resurfacing } & Crawfordsville & $\$ 109,371$ & \multirow{7}{*}{$\$ 117,365$} \\
\hline & Fort Wayne & $\$ 143,620$ & \\
\hline & Greenfield & $\$ 57,369$ & \\
\hline & La Porte & $\$ 41,635$ & \\
\hline & Seymour & $\$ 189,894$ & \\
\hline & Vincennes & $\$ 128,550$ & \\
\hline & Fort Wayne & $\$ 28,583$ & \\
\hline \multirow{6}{*}{ Traffic } & Crawfordsville & $\$ 218,514$ & \multirow{6}{*}{$\$ 162,776$} \\
\hline & Fort Wayne & $\$ 79,912$ & \\
\hline & Greenfield & $\$ 151,436$ & \\
\hline & La Porte & $\$ 100,274$ & \\
\hline & Seymour & $\$ 273,810$ & \\
\hline & Vincennes & $\$ 181,156$ & \\
\hline \multirow{6}{*}{$\begin{array}{l}\text { Traffic } \\
\text { Maintenance }\end{array}$} & Crawfordsville & $\$ 51,824$ & \multirow{6}{*}{$\$ 55,669$} \\
\hline & Fort Wayne & $\$ 28,583$ & \\
\hline & Greenfield & $\$ 42,215$ & \\
\hline & La Porte & $\$ 100,965$ & \\
\hline & Seymour & $\$ 46,534$ & \\
\hline & Vincennes & not available & \\
\hline
\end{tabular}




\subsection{Models for Estimating Time Delay and to Identify Influential Variables}

The dataset for developing time delay models consisted of 1,452 contracts. In the present section of this report, the response variable was denoted by "TD", an estimate of the number of delayed days. A variable representing contract duration, computed as the time difference between the expected and actual last days of work, was added to the time delay dataset. The contract duration variable was not used in the cost overrun and change order models in order to avoid statistical bias that could arise from correlation between the bid amount and contract duration variables.

Models were developed was attempted to identify the strength and magnitude of factors affecting the extent of time delay. The first phase of the modeling exercise involved exclusion of the "bid comparison" variables, and the second phase involved inclusion of such variables. Models were developed first for all project types combined, and then separately for each project type.

\subsubsection{Time Delay for All Project Types Combined}

The modeling process started with the development of time delay models using a dataset that excluded the "bid comparison" variables. After deleting approximately $10 \%$ of outliers from the dataset, various functional forms were tried, and the linear model yielded the best results as shown below.

Table 8.8: Model for Time Delay for All Project Types Combined, Excluding the “Bid Comparison” Variables

\begin{tabular}{|c|c|c|c|c|c|}
\hline \multicolumn{2}{|l|}{ Variable } & Coefficient & Std. Error & t-stat & P-value \\
\hline Constant Term & (Constant) & 284.91 & 7.77 & 36.67 & 0.00 \\
\hline Bridge Project & $B$ & 14.29 & 7.88 & 1.81 & 0.07 \\
\hline Road Construction Project & $R$ & 27.70 & 8.22 & 3.37 & 0.00 \\
\hline Proportion of Inclement Weather Days & PNINCL & -351.45 & 14.61 & -24.05 & 0.00 \\
\hline Project Duration & LENGTH & -0.50 & 0.03 & -16.23 & 0.00 \\
\hline Bid Amount / 1,000,000 & amoun6 & 9.29 & 1.40 & 6.61 & 0.00 \\
\hline $\begin{array}{l}\text { Response variable is time delay (TD) in day } \\
\text { Adjusted } \mathrm{R}^{2}=0.345 \\
\text { Number of Observations }=1305\end{array}$ & & & & & \\
\hline
\end{tabular}

The model results showed that all other factors being the same, bridge and road construction projects experienced more time delays than the other project types. This may be due to the higher levels of uncertainty of field conditions, and design errors and omissions that are associated with road and bridge projects. The results also showed that a higher bid amount, all else being the same, resulted 
in a greater time delay. An interesting result was that a longer contract duration is associated with a smaller time delay. This finding seems rather surprising as a longer contract duration would typically be expected to have a greater time delay. It is possible that such unexpected finding was caused by correlation between the project duration and bid amount. However, the correlation matrix for these two variables did not reveal existence of any linear correlation. It may be interesting to carry out further investigation of these trends such as examining any existence of non-linear correlation between these two variables. Validation of the model showed rather high percentage deviation and root mean square error.

The model development was repeated with the consideration of the "bid comparison" variables. The linear and logarithmic functional forms gave good results, $\mathrm{R}^{2}$ of 0.241 and 0.225 , respectively. In this case, maintenance and resurfacing projects were found to be associated with less time delay compared to other project types, which is not inconsistent with the findings of the model that excluded the "bid comparison" variables. The proportion of inclement weather days was found to have an inverse effect on time delays, a finding which is contrary to expectation. The bid amount and duration variables had the same influence as found for the models that excluded the "bid comparison" variables. The variable representing the proportion of the difference between the first and second bid had a direct influence on contract time delay, which is consistent with expectation. INDOT may use this model to predict the expected time delay any project type where the "bid comparison" variables are not known.

\subsubsection{Time Delay for Bridge Projects}

For bridge projects, the best model was the linear model, with an $\mathrm{R}^{2}$ of 0.355 . Using this functional form, the following variables were significant: the proportion of inclement days (which had a decreasing effect on the response variable), the contract duration (which had a decreasing effect), and the bid amount (which had an increasing effect).

For time delay on bridge projects, the modeling process was repeated using "bid comparison” variables among other variables, and yielded a linear model with $\mathrm{R}^{2}$ of 0.566 . The following variables were found significant: Seymour District location, where projects were found to experience more time delays than at the other districts, the proportion of inclement weather days (which was seen to have an inverse relationship with time delay), the "bid comparison" variables (which were seen to have inconsistent effects on time delay), the project duration variable (which was seen to have an inverse relationship with time delay), and the bid amount (which had an increasing effect on time delay).

The logarithmic model yielded very similar results as that using the linear form. The influence of each variable on time delay remained the same, but the obtained $\mathrm{R}^{2}$ was much smaller than for the 
linear model. The linear model was validated using 36 observations, and yielded a percentage deviation and root mean square error of 34.5 and 96.5, respectively. INDOT may use the linear model to predict the expected time delay for bridge projects where the "bid comparison" variables are known.

Table 8.9: Logarithmic Time Delay Model Including the “Bid Comparison” Variables for Bridge Projects

\begin{tabular}{lccccc}
\hline \multicolumn{1}{c}{ Variable } & & Coefficient & Std. Error & t-stat & P-value \\
\hline Constant Term & (Constant) & 1.20 & 0.05 & 24.45 & 0.00 \\
\hline Seymour District / 100 & SEYMO2 & 8.3 & 0.04 & 2.15 & 0.04 \\
\hline Proportion of Inclement Days / 100 & PNINCL2 & -9.5 & 0.02 & -4.36 & 0.00 \\
\hline Project Duration / 10,000 & LENGTH4 & -8.34 & 0.00 & -3.72 & 0.00 \\
\hline Bid Amount / 100,000,000 & Amoun8 & 8.24 & 0.02 & 3.45 & 0.00 \\
\hline $\begin{array}{l}\text { Proportion of the Difference between the } \\
\text { First and Second Bid / 10 }\end{array}$ & PDIFSEC1 & 5.28 & 0.23 & 2.31 & 0.03 \\
\hline \multicolumn{1}{c}{$\begin{array}{l}\text { Proportion of the Difference between the } \\
\text { Bid Amount and the Engineer's Estimate / 10 }\end{array}$} & PDIFENG1 & -1.78 & 0.09 & -2.01 & 0.06 \\
\hline
\end{tabular}

Response Variable: Exponent of time delay, where time delay is in days

Adjusted $\mathrm{R}^{2}=0.548$

Number of Observations $=28$

$T D=\ln \left(1.2+8.3 * \frac{\text { Seymo }}{100}-9.5 * \frac{\text { Pnincl }}{100}-8.34 * \frac{\text { Length }}{10,000}+8.24 * \frac{\text { bidamount }}{100,000,000}+5.28 * \frac{\text { Pdifse }}{10}-1.78 * \frac{\text { Pdifeng }}{10}\right)$

\subsubsection{Time Delay for Maintenance Projects}

For time delay on maintenance projects, excluding the "bid comparison" variables, the following linear model shown in the Table 8.10 below was adjudged the best. Like the model for bridge projects, it was again found that the proportion of inclement weather days had a negative effect on time delay. Also, the bid amount was found to have a positive and expected effect on tie delay. The validation statistics showed rather poor prediction of the observed values. The percentage deviation was 3303 and the root mean square error was 204. INDOT may use this model to predict the expected time delay for maintenance projects where the "bid comparison” variables are not known.

The modeling process for estimating time delay of maintenance projects was repeated, this time with the inclusion of the "bid comparison" variables. However, such models did not provide any significant results possibly due to the paucity of observations. 
Table 8.10: Time Delay Model Excluding the "Bid Comparison” Variables for Maintenance Projects

\begin{tabular}{|c|c|c|c|c|c|}
\hline Variable & & Coefficient & Std. Error & t-stat & P-value \\
\hline Constant Term & (Constant) & 285.95 & 15.39 & 18.58 & 0.00 \\
\hline Proportion of Inclement Weather Days & PNINCL & -398.51 & 38.75 & -10.28 & 0.00 \\
\hline Bid Amount / 1,000,000 & amoun6 & 10.63 & 3.08 & 3.45 & 0.00 \\
\hline Project Duration & LENGTH & -0.48 & 0.07 & -7.26 & 0.00 \\
\hline
\end{tabular}

$$
T D=285.95-398.51 * \text { Pnincl }-0.48 * \text { Length }+10.63 * \frac{\text { bidamount }}{1,000,000}
$$

\subsubsection{Time Delay for Road Construction Projects}

For the 257 road construction projects, a model was developed for the estimation of time delay. It was found that the linear form produced the best results, which are shown in the table below. The model calibration and validation results were similar to those for bridge and maintenance projects.

Table 8.11: Time Delay Model Excluding the "Bid Comparison” Variables for Road Construction Projects

\begin{tabular}{lccccc}
\hline \multicolumn{1}{c}{ Variable } & & Coefficient & Std. Error & t-stat & P-value \\
\hline Constant Term & (Constant) & 304.83 & 20.12 & 15.15 & 0.00 \\
\hline Proportion of Inclement Weather Days & PNINCL & -347.40 & 33.26 & -10.45 & 0.00 \\
\hline Bid Amount in millions & amoun6 & 5.67 & 2.96 & 1.92 & 0.06 \\
\hline Project Duration & LENGTH & -0.43 & 0.08 & -5.60 & 0.00 \\
\hline $\begin{array}{l}\text { Response Variable is the Time Delay (TD) in days } \\
\text { Adjusted R } \mathrm{R}^{2}=0.319 \\
\text { Number of Observations }=257\end{array}$
\end{tabular}

$$
T D=304.83-347.40 * \text { Pnincl }+5.67 * \frac{\text { bidamount }}{1,000,000}-0.43 * \text { Length }
$$

INDOT may use the developed model to predict the expected time delay for road construction projects where the "bid comparison" variables are not known.

The modeling process for estimating time delay on road construction projects was repeated with the "bid comparison" variables included. The linear functional form produced the best results, with an adjusted $\mathrm{R}^{2}$ of 0.309 . The two variables representing the proportions for "bid comparison" had an increasing effect on the response variable and the proportion of inclement weather days still had a decreasing effect on the number of delayed days. The results obtained using the logarithmic form were comparable to those obtained using the linear form, with a similar $\mathrm{R}^{2}$ value and the same significant variables of similar magnitude and direction. 


\subsubsection{Time Delay for Traffic Projects}

The time delay experienced on traffic projects were modeled using 183 contracts for which such data were available. At the initial phase of the modeling process, "bid comparison" variables were excluded. Again, it was found that the linear model seemed to provide the best explanations for the trends in the data. The model calibration and validation results were similar to those for bridge and maintenance projects.

Table 8.12: Time Delay Model Excluding the "Bid Comparison” Variables for Traffic Projects

\begin{tabular}{lccccc}
\hline \multicolumn{1}{c}{ Variable } & & Coefficient & Std. Error & t-stat & P-value \\
\hline Constant Term & (Constant) & 320.84 & 20.79 & 15.43 & 0.00 \\
\hline Proportion of Inclement Weather Days & PNINCL & -377.75 & 37.39 & -10.10 & 0.00 \\
\hline Bid Amount in millions & amoun6 & 21.83 & 5.01 & 4.36 & 0.00 \\
\hline Project Duration & LENGTH & -0.76 & 0.10 & -7.82 & 0.00 \\
\hline
\end{tabular}

Response Variable is the Time Delay $(T D)$ in days

Adjusted $\mathrm{R}^{2}=0.430$

Number of Observations $=183$

$$
T D=320.84-377.75 * \text { Pnincl }-0.76 * \text { Length }+21.83 * \frac{\text { Bidamount }}{1,000,000}
$$

INDOT may use this model to predict the expected time delay for bridge projects where the “bid comparison” variables are not known.

Model development was then attempted for estimating the time delay associated with traffic projects, this time with the inclusion of the "bid comparison" variables. However, such efforts did not produce any significant results because the observations were inadequate.

\subsubsection{Time Delay for Resurfacing Projects}

Data from 247 contracts were used to develop a model for estimating the time delay associated with resurfacing projects. After exhaustive investigation of various functional forms, the linear model was found to provide the best explanation, and had an $\mathrm{R}^{2}$ of 0.394 . Similar results were obtained as in the models for the time delay on other project types. However, in this case, the location of a project in Fort Wayne District seemed to be associated with less time delay than similar projects located at other districts all else being the same. This may be attributable to differences in management practices. 
Table 8.13: Time Delay Model Excluding the "Bid Comparison” Variables for Resurfacing Projects

\begin{tabular}{lccccc}
\hline \multicolumn{1}{c}{ Variable } & & Coefficient & Std. Error & t-stat & P-value \\
\hline Constant Term & (Constant) & 306.98 & 17.00 & 18.05 & 0.00 \\
\hline Fort Wayne District location & FORTW & -38.97 & 16.22 & -2.40 & 0.02 \\
\hline Proportion of Inclement Weather Days & PNINCL & -378.84 & 33.42 & -11.33 & 0.00 \\
\hline Bid Amount / 1,000,000 & amoun6 & 6.55 & 2.69 & 2.43 & 0.02 \\
\hline \multicolumn{1}{c}{ Project Duration } & LENGTH & -0.53 & 0.06 & -8.39 & 0.00 \\
\hline
\end{tabular}

Response Variable is the Time Delay (TD) in days

Adjusted $\mathrm{R}^{2}=0.394$

Number of Observations $=247$

$$
T D=306.98-38.97 * \text { Fortw }-378.84 * \text { Pnincl }-0.53 * \text { Length }+6.55 * \frac{\text { Bidamount }}{1,000,000}
$$

INDOT may use this model to predict the expected time delay for resurfacing projects where the "bid comparison" variables are not known.

The modeling process for estimating time delay on resurfacing projects was repeated taking into the consideration the "bid comparison" variables, but various efforts in this regard did not yield any significant results largely because of lack of adequate observations.

\subsubsection{Discussion for Time Delay Models}

It can be noticed that for all the time delay models, the proportion of inclement days was not only consistently the most significant variable, but also had a negative sign, implying the higher the proportion of inclement weather, the lower the time delay. This seems to be contrary to expectation, and the reason for this finding requires further investigation. Also, the higher the project duration the lower the time delays. This also seems counter intuitive but probably suggests that contract periods are made more realistic for larger contracts. The bid amount variable was always significant and had an increasing effect on the dependent variable. The differences in the direction of the impacts of these two contract size variables shows that there could be some correlation between the two variables that could be investigated in a future study. 


\subsection{Models for Estimating Cost Overruns and Identifying Influential Factors}

Models were developed was attempted to identify the strength and magnitude of factors affecting cost overrun amounts and cost overrun rates, and also to estimate the amount of cost overruns. The first phase of the modeling exercise involved exclusion of the "bid comparison" variables, and the second phase involved inclusion of such variables. Models were developed first for all project types combined, and then separately for each project type.

\subsubsection{Estimation of Cost Overrun Amounts}

\subsubsection{Cost Overrun Amounts All Project Types Combined}

In the present section, the dependent variable, $C O$, denotes the amount incurred in cost overruns for a contract. The first phase of the modeling process did not include the "bid comparison" variables. Various functional forms and transformations were attempted and the linear functional form yielded the most intuitive results (Table 8.14).

Table 8.14: Model for Cost Overrun Amount Excluding the “Bid Comparison” Variables

\begin{tabular}{|c|c|c|c|c|c|}
\hline \multicolumn{2}{|l|}{ Variable } & \multirow{2}{*}{$\frac{\text { Coefficient }}{-3.16}$} & \multirow{2}{*}{$\frac{\text { Std. Error }}{1.10}$} & \multirow{2}{*}{$\frac{\text { t-stat }}{-2.86}$} & \multirow{2}{*}{$\frac{\text { P-value }}{0.00}$} \\
\hline Maintenance Project & $M$ & & & & \\
\hline Road Construction Project & $R$ & -2.47 & 1.19 & -2.07 & 0.04 \\
\hline Traffic Project & $T$ & -3.08 & 1.43 & -2.16 & 0.03 \\
\hline Fort Wayne District & FORTW & 2.98 & 1.36 & 2.19 & 0.03 \\
\hline Laporte District & LAPOR & -2.34 & 1.37 & -1.71 & 0.09 \\
\hline Bid Amount in millions & amoun6 & 6.45 & 0.25 & 26.17 & 0.00 \\
\hline \multicolumn{6}{|c|}{$\begin{array}{l}\text { Response Variable is the Cost Overrun (CO) in \$10,000’s } \\
\text { Adjusted } \mathrm{R}^{2}=0.303 \\
\text { Number of Observations }=1664\end{array}$} \\
\hline$\frac{C O}{10,000}=-3.16 * M$ & $3.08 *$ & 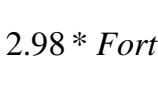 & $-2.34 * 1$ & & $\frac{\text { bidamount }}{1,000,000}$ \\
\hline
\end{tabular}

The model results show that maintenance, road construction, and traffic projects generally had fewer cost overruns compared to other project types, all other factors being the same. For maintenance and traffic projects, this finding can be explained by the relatively low amounts involved in each contract of such project types. For road construction projects, quantities are estimated at design stage and final amount of work done depends more on established quantities rather than from inspection data. It may be argued that such projects may be vulnerable to unexpected or variable site conditions, 
thus making such projects have high overruns. The sign obtained therefore appears to be a net effect of these two contrasting justifications. Besides, the variable representing district which was found significant, may account partly for the relationship between high cost overruns and site variability. The model showed that a project located at Fort Wayne District is associated with more cost overruns compared to other districts, all else being equal. Also, the model showed that projects located at Laporte District is associated with lower cost overruns compared to other districts, all other factors being the same. It was found that the bid amount variable was the most significant, and that a higher bid amount translates to a higher amount of cost overruns, all else being equal. The proportion of inclement weather days was not found to be significant. Validation of the models yielded rather high values of percentage deviation (5814) and root mean square error (\$309,000). INDOT may use the developed model to predict the expected cost overrun for any project type where the "bid comparison" variables are not known.

The model development was also carried out to include the "bid comparison" variables. Of the several forms investigated, only the logarithmic form produced encouraging results, with an $\mathrm{R}^{2}$ of 0.23. The model showed that traffic maintenance projects generally had more cost overruns than other project types, all else being the same. Also, it was found that a higher level of competition was associated with a greater amount of cost overruns. This may be attributed to the fact that in a competitive environment, contractors try to reduce their prices as much as possible, but such reductions may result in unrealistic bid prices. Finally, the model with the "bid comparison" variables showed that a higher bid amount had an increasing effect on cost overruns. INDOT may use this model to predict the expected cost overrun amount for any project type where the "bid comparison" variables are known.

\subsubsection{Cost Overrun Amounts for Bridge Projects}

Using the 449 bridge contracts, models were developed to estimate the amount of cost overruns for bridge projects. The first step was to exclude the "bid comparison" variables. The linear model was found to be the most intuitive and gave the best results. From the model results, it is suggested that bridge projects located at Laporte District experienced fewer cost overruns than those located at other districts, all other factors being the same. Also, the bid amount had an increasing effect on cost overrun amount. This model may be used by INDOT to predict the expected cost overrun for bridge projects where the "bid comparison" variables are unknown. 
Table 8.15: Cost Overrun Amount Model Excluding the "Bid Comparison” Variables for Bridge Projects

\begin{tabular}{|c|c|c|c|c|c|}
\hline \multicolumn{2}{|l|}{ Variable } & \multirow{2}{*}{$\frac{\text { Coefficient }}{-2.29}$} & \multirow{2}{*}{$\frac{\text { Std. Error }}{0.89}$} & \multirow{2}{*}{$\frac{\text { t-stat }}{-2.58}$} & \multirow{2}{*}{$\frac{\text { P-value }}{0.01}$} \\
\hline Constant Term & (Constant) & & & & \\
\hline Laporte District & LAPOR & -3.17 & 1.85 & -1.72 & 0.09 \\
\hline Bid Amount in millions & amoun6 & 8.11 & 0.38 & 21.28 & 0.00 \\
\hline \multicolumn{6}{|c|}{$\begin{array}{l}\text { Response Variable is the Cost Overrun (CO) in \$millions } \\
\text { Adjusted } \mathrm{R}^{2}=0.505 \\
\text { Number of Observations }=449\end{array}$} \\
\hline$\frac{C O}{1,000,000}=-2.29-$ & $7 *$ Lapor + & $11 * \frac{\text { bidam }}{1,000}$ & & & \\
\hline
\end{tabular}

The modeling process was repeated using the "bid comparison” variables, and again the linear model was found to be most explanatory of the observations, with an adjusted $\mathrm{R}^{2}$ of 0.212 . It was seen that bridge projects located at Greenfield and Seymour Districts experienced smaller cost overruns amounts than those at other districts, all else being the same. It was also seen that when there are more bidders for a contract, the cost overrun amount increases, which is intuitive. Also, for a higher proportion of the difference between the bid and the engineer's estimate, the model suggests that there is a smaller cost overrun amount. The final model may be used by INDOT to estimate the expected cost overrun amount for future bridge projects where the "bid comparison” variables are known.

\subsubsection{Cost Overrun Amounts for Maintenance Projects}

Attempts to develop models that explain the variability of cost overrun amounts of maintenance projects did not yield any encouraging results, regardless of functional form and inclusion (or otherwise) of "bid comparison” variables.

\subsubsection{Cost Overrun Amounts for Road Construction Projects}

Data on a total of 449 road construction projects served as the basis for developing a model to estimate the cost overrun amount for road construction projects. The first phase of model development involved exclusion of the "bid comparison" variables. The linear functional form provided the best results, as shown in the Table 8.16 below.

Table 8.16: Cost Overrun Amount Model Excluding “Bid Comparison” Variables, Road Construction Projects

\begin{tabular}{cccccc}
\hline \multicolumn{1}{c}{ Variable } & & Coefficient & Std. Error & t-stat & P-value \\
\hline Seymour District & SEYMO & -3.92 & 2.40 & -1.63 & 0.10 \\
\hline Bid Amount / 1,000,000 & amoun6 & 5.55 & 0.36 & 15.59 & 0.00 \\
\hline Response Variable is the Cost Overrun (CO) in \$10,000’s & & & \\
Adjusted R ${ }^{2}=0.351$ & & & & \\
Number of Observations $=449$ &
\end{tabular}




$$
\frac{C O}{1,000,000}=-3.92 * \text { seymo }+5.55 * \frac{\text { bidamount }}{1,000,000}
$$

It was found that road construction projects located at Seymour District generally had smaller cost overruns amounts compared to projects at other districts. This may be attributed to differences in management practices. 137 observations were used to validate the model, and the validation statistics obtained were rather high. An attempt was made to find a significant model for the "amount of cost overrun model with the "bid comparison” variables for road construction projects,” but the resulting models were consistently poor, with few relevant variables and very low $\mathrm{R}^{2}$ values (about $1 \%$ ). Further investigation using a logarithmic model did not provide a better result. The final model may be used by INDOT to estimate the expected cost overrun amount for future road construction projects where the "bid comparison" variables are not known.

\subsubsection{Cost Overrun Amounts for Traffic Projects}

Attempts to develop models that explain the variability of cost overrun amounts of traffic projects did not yield any encouraging results, regardless of functional form and inclusion (or otherwise) of "bid comparison” variables.

\subsubsection{Cost Overrun Amounts for Resurfacing Projects}

Models were developed was carried out to identify the strength and magnitude of factors affecting cost overruns, and also to estimate the amount of cost overruns for resurfacing projects. The first phase of the modeling exercise was to exclude the "bid comparison" variables, and both linear and logarithmic regressions provided good results. For the linear model (adjusted $\mathrm{R}^{2}$ of 0.565 ), resurfacing projects located in Vincennes District seemed to experience a greater cost overrun amount compared to projects located in other districts, all other factors being equal. Also, the results suggest that the bid amount variable is significant and has an increasing effect on cost overrun amount. Logarithmic forms were also investigated but yielded an $\mathrm{R}^{2}$ of 0.308 and suggested that the only significant variable was the bid amount. The final model may be used by INDOT to estimate the expected cost overrun amount for future resurfacing projects where the "bid comparison" variables are not known.

In the second phase of the modeling, the "bid comparison" variables were included. Again, both functional forms provided good results. The linear form produced a high $\mathrm{R}^{2}$ of 0.804 , and the three "bid comparison" variables were found significant. The level of competition had a decreasing effect, suggesting that higher competition is associated with lower cost overruns, but this finding may 
be considered counter intuitive. The results also suggest that for resurfacing projects, when the difference between the winning bid and second bid was high, greater cost overrun amounts are encountered, and when the difference between the winning bid and the engineer's estimate was high, there were lower cost overruns. Both results are consistent with expectation. Resurfacing projects located in Seymour District seemed to experience a smaller amount of cost overruns compared to similar projects at other districts, all else being the same, a finding that is similar to that found for road construction projects, and may be attributed to management practices at the highway administrative district of Seymour. The results also indicate that for resurfacing projects, the bid amount had an increasing effect on the dependent variable, which is quite intuitive. The logarithmic model produced similar results as those obtained using the linear model with a few differences in the variables that were found significant. Specifically, the variable representing the level of competition was not found significant. Also, the results suggest that projects located in both Laporte and Crawfordsville Districts generally experienced more cost overruns compared to those located in other districts. The other two "bid comparison" variables were found significant and had the same influence on the dependent variable as in the case of the linear model. Furthermore, the bid amount was found significant with an increasing effect on cost overruns, which is intuitive. With 12 observations, the validation yielded rather high values for the percentage deviation and the root mean square error $(2,180$ and $\$ 1,121,752$, respectively). INDOT may use the final model to estimate the expected cost overrun amount for future resurfacing projects where the "bid comparison” variables are known.

Table 8.17: Logarithmic Cost Overrun Amount Model Including the “Bid Comparison” Variables for Resurfacing Projects

\begin{tabular}{|c|c|c|c|c|c|}
\hline Variable & & Coefficient & Std. Error & t-stat & P-value \\
\hline Constant Term & (Constant) & 0.86 & 0.07 & 11.93 & 0.00 \\
\hline Crawfordsville District / 10 & CRAWF1 & 1.63 & 0.10 & 1.69 & 0.10 \\
\hline Bid Amount / 10,000,000 & Amoun7 & 2.6 & 0.03 & 8.82 & 0.00 \\
\hline $\begin{array}{l}\text { Proportion of the Difference between the } \\
\text { First and Second Bid / } 10\end{array}$ & PDIFSEC1 & 7.89 & 0.38 & 2.07 & 0.05 \\
\hline $\begin{array}{l}\text { Proportion of the Difference between the } \\
\text { Bid Amount and the Engineer's Estimate / } 10\end{array}$ & PDIFENG1 & -3.88 & 0.17 & -2.32 & 0.03 \\
\hline Laporte District / 10 & LAPOR1 & 1.79 & 0.13 & 1.36 & 0.19 \\
\hline
\end{tabular}

Response Variable is the Exponent of Cost Overrun (CO) in \$10,000's

Adjusted $\mathrm{R}^{2}=0.804$

Number of Observations $=31$

$$
\frac{C O}{1,000,000}=\ln \left(0.86+1.63 * \frac{\text { Crawf }}{10}+2.6 * \frac{\text { bidamount }}{10,000,000}+7.89 * \frac{\text { Pdifse }}{10}-3.88 * \frac{\text { Pdifeng }}{10}+1.79 * \frac{\text { Lapor }}{10}\right)
$$




\subsubsection{Cost Overrun Rate}

The modeling investigation for the dependent variable "cost overrun rate" did not produce any satisfactory results compared to those concerning cost overrun amounts as discussed in the preceding section. Attempts to develop cost overrun rate models yielded poor $\mathrm{R}^{2}$ and no statistically significant variables.

\subsection{Chapter Discussion}

For models that estimate the time delay for a project, the $\mathrm{R}^{2}$ varied between 0.27 and 0.55 , depending on the project type, whether the model included "bid comparison" variables, and functional form. Also, for models that were developed to estimate the amount of cost overrun likely to be experienced on a project, the $\mathrm{R}^{2}$ varied between 0.30 and 0.80 , depending on the above attributes. Furthermore, for models that estimated the Frequency of change orders for a project, the $\mathrm{R}^{2}$ varied between 0.37 and 0.89 . Among the several models developed in each category, the best model was selected based on the $\mathrm{R}^{2}$ and the results of the validation tests. Table 8.18 summarizes these categorizations, while Table 8.19 provides the significant variables in each model.

Table 8.18: Categories of Calibrated Models and Their Coefficients of Determination

\begin{tabular}{l|c|c|c|c|c|c}
\hline \multirow{2}{*}{$\begin{array}{c}\text { Model } \\
\text { Type }\end{array}$} & \multicolumn{2}{c|}{ Change Order } & \multicolumn{2}{c|}{ Time Delay } & \multicolumn{2}{c}{ Cost Overrun } \\
\cline { 2 - 7 } & Model Form & $\mathrm{R}^{2}$ & Model Form & $\mathrm{R}^{2}$ & \multicolumn{2}{c}{ Model Form } \\
\hline $\begin{array}{l}\text { Any Project } \\
\text { Type }\end{array}$ & Linear Excluding BCV & 0.37 & Linear Excluding BCV & 0.34 & Linear Excluding BCV & 0.30 \\
\hline $\begin{array}{l}\text { Bridge } \\
\text { Project }\end{array}$ & Linear Excluding BCV & 0.37 & Logarithmic Including BCV & 0.55 & Linear Excluding BCV & 0.51 \\
\hline $\begin{array}{l}\text { Maintenance } \\
\text { Project }\end{array}$ & Logarithmic Including BCV & 0.43 & Linear Excluding BCV & 0.27 & No Significant Model & - \\
\hline $\begin{array}{l}\text { Road } \\
\text { Construction } \\
\text { Project }\end{array}$ & Linear Excluding BCV & 0.45 & Linear Excluding BCV & 0.32 & Linear Excluding BCV & 0.35 \\
\hline $\begin{array}{l}\text { Resurfacing } \\
\text { Project }\end{array}$ & Logarithmic Including BCV & 0.89 & Linear Excluding BCV & 0.40 & Logarithmic Including BCV & 0.80 \\
\hline $\begin{array}{l}\text { Traffic } \\
\text { Project }\end{array}$ & Logarithmic Including BCV & 0.72 & Linear Excluding BCV & 0.43 & No Significant Model & - \\
\hline
\end{tabular}

BCV = "bid comparison" variables (level of competition, proportion of the difference between the first and second bid, or proportion of the difference between the bid and engineer's estimate) 
Table 8.19: Significant Variables of the Models

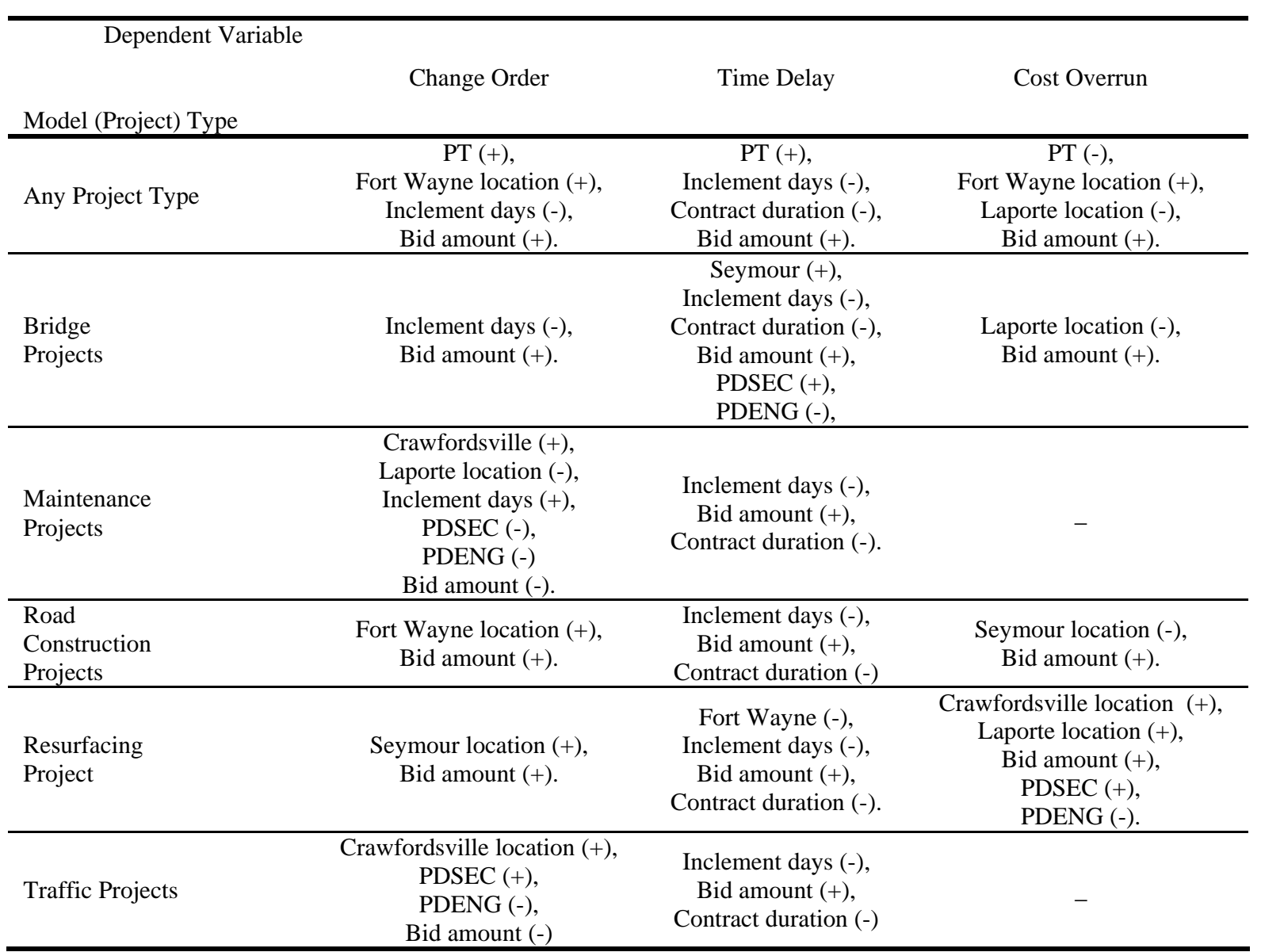

PT- Project Type (in comparison to Traffic Maintenance Projects)

PDSEC: Proportion of the difference between the winning and second bids

PDENG: Proportion of the difference between the winning bid and engineer's estimate

The modeling process showed that with respect to the response variables (frequency of change orders, time delay, or cost overrun amount), the most influential variables were as follows:

- Bid amount, with a dominant increasing effect on the response variables (in 14 out of 16 models, the bid amount had an increasing effect on the response variables),

- Project duration, with a decreasing effect,

- Proportion of the difference between the winning bid and the second bid, with a dominant increasing effect,

- Proportion of the difference between the winning bid and engineer's estimate, with a decreasing effect,

- Duration of inclement weather, with a dominant decreasing (surprisingly) effect. 


\subsection{Chapter Summary}

This chapter provided the results of the modeling process and attempted to explain the results found therein. A few models had satisfactory $\mathrm{R}^{2}$ and validation statistics. The results obtained were generally consistent with expectation. However, there were a few cases where the variable signs were counter intuitive and may need further investigation. Using the model results it may be possible to obtain estimates of the Frequency of change orders, time delay or cost overruns associated with any future INDOT project, given basic characteristics such as bid amount, project type, location by district, nature of weather, and "bid comparison” variables if available. 


\section{CHAPTER 9 - CONCLUSIONS}

This study analyzed the problem of cost overruns, time delays, and change orders associated with INDOT projects. This was carried out using a variety of methods including an agency survey, literature review, and statistical analyses.

The agency survey revealed that INDOT's contract management performance in terms of cost overruns and time delays is generally similar to that of other state DOTs. Nevertheless, cost overruns and time delays in Indiana represent a sizeable portion of agency costs, and even a marginal reduction can lead to substantial savings.

The study showed that between the years 1996 and 2001, 55\% of all Indiana DOT contracts experienced cost overruns, and the overall cost overrun rate was $4.5 \%$ of the bid amount. With regard to cost overruns, it was determined that the average cost overrun amount and rate differ by project type. Also, the strength of influential factors differ by project type The average cost overrun rates were as follows: bridge projects -- $8.1 \%$, road construction -- $5.6 \%$, road resurfacing -- $2.6 \%$, traffic projects -- 5.6\%, maintenance projects -- 7.5\%. It was also determined that influential factors of cost overrun of highway contracts include the contract bid amount, difference between the winning bid and second bid, difference between the winning bid and the engineer's estimate, project type and location by district. The developed models may be used to estimate the extent of future cost overruns on the basis of contract and project characteristics, and are therefore useful in long term budgeting and needs assessment studies. With regard to time delay, it was also found that $12 \%$ of all INDOT contracts experience time delays, and the average delay per contract was 115 days. The study also determined average time delay for each type of contract. From the various statistical analyses, it was determined that factors influential to time delays are contract bid amount, difference between the winning bid and second bid, difference between the winning bid and the engineer's estimate, project type and location by district. Based on the results of the analysis, recommendations can be made for improving the management of projects and the administration of contracts in order to reduce time delays.

Using an array of statistical methods, the present research project explored the problem statement further. The magnitude of cost overrun, time delay and change order problems associated INDOT's construction projects were explored by investigating the relationships between these parameters and key characteristics of the bidding process, project, and environment. The descriptive 
statistics showed that the following change order types were the most critical in terms of frequency and cost: "errors and omissions, design related," “errors and omissions, quantity related," “constructability, construction related," “constructability, design related," and "changed field conditions, construction related.” It was found that most of such change order reason categories were the responsibility of INDOT or its consultants, and therefore is within INDOT's capability to reduce the incidence of such change orders by improving its contract management system. The descriptive statistics also indicated that cost overruns and time delays have been on the decrease since 1997. It was indicated that more time delays were experienced for maintenance projects compared to other project types, and for projects in the Seymour District compared to those located at other districts. The results of such preliminary analyses also suggested that higher cost overrun amounts were experienced for resurfacing projects compared to other project types, and also for projects located in the Fort Wayne District compared to other districts. Furthermore, the descriptive statistics suggested that a higher number of change orders is associated with road construction projects compared to other project types, and also for projects in the Greenfield District compared to other districts. The correlation matrix analysis showed that the selected independent variables were not affected by the problem of linear correlation, with the exception of the variables representing the "proportion of the difference between the winning and second bids" and the "proportion of the difference between the winning bid and the engineer's estimate.” From the analysis of variance, it was observed that there generally exists a statistical difference between the mean responses (cost overruns, time delays, and change orders) of any two categories of the independent variables. The pairwise t-tests provided confirmation of the ANOVA findings.

The last statistical method used was regression modeling to confirm the influence of the independent variables, and to estimate values of cost overruns, time delay and change orders for future projects. Given the inconsistent performance of a few of the developed models in terms of $\mathrm{R}^{2}$ and validation statistics, it may be stated that some of models may be used for prediction only with caution. The developed models provided interesting information about the factors that affect cost overruns, time delays, and change orders. It was found that significant variables included bid amount, project type, location by district, weather, and bid comparison variables. The level of competition was generally found not influential. Specifically, the proportion of the difference between the winning and second bid had a dominant increasing effect. The proportion of the difference between the winning bid and the engineer's estimates had a decreasing effect. These conclusions are similar to those found from the literature review. The advantage of the present study compared to the studies found in the literature is the greater dataset size so the resulting analysis is expected to yield results that are more consistent. 
A major problem encountered during the course of the present study was existence of several change orders for which no reason was assigned to change orders. For approximately a third of all change orders (representing one-half of amounts incurred on change orders), no reason was assigned in the dataset. This suggests that there are a few lapses in the current management of change orders at INDOT. The constructability reviews report from the Constructability Process Review Committee shows that a key need was the development of a process to determine the causes of change orders. Therefore, the tracking for change orders and their causes may be expected to improve after implementation of such a mechanism. This recommendation was implemented on April 11, 1997. However, examination of the change order reason database even after that date showed that most of the "no-reason" change orders were for years subsequent to such implementation (i.e., 1999, 2000, and 2001). It is conceivable that because the year indicated in the dataset represented the final year of work, such contracts may have started several years earlier, at which time the Constructability Process Review Committee recommendations had not yet been implemented. Upon further investigation of archival data, it was determined that some change orders currently categorized as having "no recorded reason" in the dataset were actually categorized as "errors and omissions" change orders in the archives. However, it could not be ascertained why such reasons were not transferred from the archives to the dataset. It is obvious that further work needs to be done to identify the source and nature of this problem.

The implementation of SiteManager will provide a more effective way to classify and code change order information. This should reduce the occurrence of "no recorded reason" change orders and thereby improve the accessibility and evaluation of this type of data. Since the completion of data analysis, System Technology has deployed BAMS Decision Support System (DSS). DSS provides an easier way to retrieve project data.

The results of the present study provided a framework for subsequent recommendations made with a view to reducing the frequency and amounts involved in change orders, cost overruns, and time delays at INDOT. 


\section{CHAPTER 10 - RECOMENDATIONS}

The present study revealed some areas where it is possible to improve, and the following recommendations are offered for consideration.

Improvements could be made to the current design review process of a project, particularly for large, high-value projects. The study found that “design errors and omissions” was the most frequent change order category that created the most cost. This was discussed at a November 20, 2003 meeting attended by INDOT personnel from Budget, Operations Support, and Design. Several options were floated such as: hiring additional design personnel to review contract documents; establishing a review of consultant's performance in regards to number and type of change orders occurring on projects; and, adding additional review requirements for consultants. After much discussion the following recommendations were made. First, a Change Order Management process needs to be developed and implemented. This will consist of:

1. Developing a Change Order mindset in the Department.

2. Developing procedures and instructions for recording change order information in SiteManager.

3. Developing a system of controls that routes change order information to the appropriate personnel in Operations Support and Design Divisions.

The change order mindset would raise the necessary awareness of the problem, help develop an agency-wide attitude geared towards the reduction of change orders, and help identify improvements needed at various stages of the project life-cycle for mitigating the problem.

In the past, change orders have not been recorded until the end of the contract. SiteManager allows for the recording of change order information as the project progresses. Also, with the current INDOT change order classification code, it is often not possible to determine the appropriate code that is applicable to all situations. The presence of so many "no indicated reason” change orders suggests that there may be some lapses in the recording of appropriate reasons for change orders. The code may therefore need review and modification. A system of instructions and more definitive definitions can improve documentation and eliminate the assignment of "no indicated reason" to change orders.

The problem of change orders needs to be addressed at source. Most bidding documents (with the exception of those for resurfacing projects) are prepared by consultants A standard report for each consultant and for each contract could be prepared and provided to such consultants to point out errors 
committed and how such errors may be avoided in future. Moreover, "real time" recording of change orders would probably accelerate the process of feedback to designers and field personnel. If data about change orders is collected on a daily basis, it is possible to create a "weekly change order report" and route it to the appropriate personnel.

It is recommended that INDOT should design an annual report that reviews the performance of consultants. Such a report would assign "grades" to each consultant, taking into account the number and dollar amount of preventable change orders that are attributable to the consultant. If grades are to be assigned in such manner, INDOT's change order classification may be adapted to this new objective in order to better distinguish the responsibilities of each change order type.

INDOT personnel should be given ample opportunity to carry out a detailed review of change orders reports and their implications. Also, such personnel should be encouraged to continually improve their methods. Obviously, implementing additional requirements will be a challenge, given the current staffing levels and work loads at INDOT. However, an electronic routing system that collects and distributes change order information would reduce the resources needed to implement this recommendation.

Finally, it is recommended to develop a system that would facilitate communication of updated information concerning cost overruns, time delays, and change orders, to the general public. As has been done in some states (ADOT, 2003) and illustrated in Appendix G, this could be implemented using an electronic tool that could be made available on the internet. 


\section{CHAPTER 11 - IMPLEMENTATION}

The project constitutes an evaluation of the problem of cost overruns, time delays, and change orders at INDOT. This research effort is consistent with INDOT's strategic objectives for resource management (INDOT, 2003) which include reduction in INDOT overhead costs and increase in the efficiency of the capital program expenditures. The present study provided some initial answers to address problems in the present system. Using the results herein as a starting point, it is possible to carry out future work such as the implementation of a methodology to enhance contract management at INDOT. Another activity is to develop an evaluation method or system to manage the collection, analysis, and presentation of change orders, cost overruns, and time delays information in an efficient manner. At the present time, there are indications that INDOT is considering establishing a new system to record change orders online directly from the construction site. The next step would be to develop or enhance the organization of a change order database to facilitate analysis of change order information and preparation of periodic consultant performance reports. Furthermore, with such enhanced information system, it will be possible to carry out future work geared towards improving the predictive ability of models relating to change orders, time delays, and cost overruns. Finally, conducting a meticulous review of construction management techniques used can help identify any weaknesses in the design and construction process, thus making it possible to make more precise recommendations for improvements in contract management at INDOT. 


\title{
Appendix A:
}

\section{Copy of E-Mail Message Soliciting Cost Overrun, Time Delay and Change Order Information form State Highway Agencies}

\begin{abstract}
The Indiana Department of Transportation (INDOT) is conducting an analysis about cost overruns and time delays of its projects for the last 5 years. The analysis will look at the causes by investigating final contract information. We would like to know the extent of this problem in other DOTs. We are looking for the following information: \% of contracts with time and cost overruns, average cost overrun, annual amount spent on overruns, and causes of these overruns. If you posses this information and are willing to share it with us, please forward it to (Bob McCullouch, the study supervisor) at Purdue University at bgm@ecn.purdue.edu. T would be appreciated if you could please respond by December 1 . Thank you in advance for your assistance.
\end{abstract}




\section{Appendix B: Indiana Change Order Organization}

\section{B.1: Change Order Reasons}

Table B.1: INDOT Classification of Reasons for Change Orders (INDOT, 2002)

\begin{tabular}{|c|c|c|c|}
\hline Code & Type & Reason Type & Change Order \\
\hline 000 & 000 & & Uncoded \\
\hline 101 & 100 & Errors \& Omissions Contract Document & Contract Related \\
\hline 102 & 100 & Errors \& Omissions Contract Document & Design Related \\
\hline 103 & 100 & Errors \& Omissions Contract Document & Environmental Related \\
\hline 104 & 100 & Errors \& Omissions Contract Document & Materials Related \\
\hline 105 & 100 & Errors \& Omissions Contract Document & Permits \\
\hline 106 & 100 & Errors \& Omissions Contract Document & Quantity Related \\
\hline 107 & 100 & Errors \& Omissions Contract Document & Right of Way Related \\
\hline 108 & 100 & Errors \& Omissions Contract Document & Soils Related \\
\hline 109 & 100 & Errors \& Omissions Contract Document & Staging Related \\
\hline 110 & 100 & Errors \& Omissions Contract Document & Traffic Control Related \\
\hline 111 & 100 & Errors \& Omissions Contract Document & Utilities Related \\
\hline 201 & 200 & Constructability & Construction Related \\
\hline 202 & 200 & Constructability & Design Related \\
\hline 203 & 200 & Constructability & Environmental Related \\
\hline 204 & 200 & Constructability & Materials Related \\
\hline 205 & 200 & Constructability & Right of Way Related \\
\hline 206 & 200 & Constructability & Soils Related \\
\hline 207 & 200 & Constructability & Staging Related \\
\hline 208 & 200 & Constructability & Traffic Control Related \\
\hline 209 & 200 & Constructability & Utilities Related \\
\hline 301 & 300 & Scope Changes & FHWA \\
\hline 302 & 300 & Scope Changes & Central Office Construction/Traffic \\
\hline 303 & 300 & Scope Changes & District/Subdistrict \\
\hline 304 & 300 & Scope Changes & District Construction Engineer \\
\hline 305 & 300 & Scope Changes & Area Engineer \\
\hline 306 & 300 & Scope Changes & Project Engineer/Supervisor \\
\hline 307 & 300 & Scope Changes & Traffic Engineer \\
\hline 308 & 300 & Scope Changes & Local Agency Request \\
\hline 309 & 300 & Scope Changes & Public/Political Request \\
\hline 401 & 400 & Changed Field conditions & Construction Related \\
\hline 402 & 400 & Changed Field conditions & Environmental Related \\
\hline 403 & 400 & Changed Field conditions & Materials Related \\
\hline 404 & 400 & Changed Field conditions & Right of Way Related \\
\hline 405 & 400 & Changed Field conditions & Soils Related \\
\hline 406 & 400 & Changed Field conditions & Staging Related \\
\hline 407 & 400 & Changed Field conditions & Utilities Related \\
\hline 500 & 500 & Failed Material & \\
\hline 601 & 600 & Incentive/Disincentive & Contract Completion Time \\
\hline 602 & 600 & Incentive/Disincentive & Contract Payments \\
\hline 603 & 600 & Incentive/Disincentive & Cost Reduction \\
\hline 604 & 600 & Incentive/Disincentive & $\mathrm{A}+\mathrm{B}$ Contract \\
\hline 605 & 600 & Incentive/Disincentive & $\mathrm{A}+\mathrm{B}+\mathrm{C}$ Contract \\
\hline 701 & 700 & Standards/Specifications Update or Changes & Contract Completion Time \\
\hline 702 & 700 & Standards/Specifications Update or Changes & Contract Payments \\
\hline 703 & 700 & Standards/Specifications Update or Changes & Other \\
\hline
\end{tabular}




\section{B.2: DESCRIPTIONS OF PREVENTABLE CHANGE ORDERS}

\section{Errors and Omission - Contract Documents}

"Contract documents" include the proposal book, schedule of pay items, specifications, supplemental specifications, special provisions, plans, and standards. Designers are responsible for the correctness in the development of the required pay items, appropriate special provisions, and corresponding plans, plus the correct designation of INDOT recurring special provisions and standard drawings.

\section{Constructability}

These codes should be used when it is not physically possible to perform the construction without a change in the contract quantities or the addition or new items. The proper code will depend on the association with environmental, materials, soils, etc., matters.

\section{Scope Changes}

These codes should be used for significant changes in the character of work, or a change in the termini of the construction. The proper code will depend on the person or agency that initiated the changes. (i.e., Construction Engineering, public official, political, etc.)

\section{DESCRIPTIONS OF NON PREVENTABLE CHANGE ORDERS}

\section{Changes Field Conditions}

These codes should be used when the current actual field conditions differ from those shown on the plans. The proper code should reflect which conditions are different.

\section{Failed Materials}

This code should be used for deductions assessed by either the district or Failed Materials Committee because of the contractor using materials that did not comply with the specifications.

\section{Incentive/Disincentive}

These codes should be used anytime a contract contains incentive or disincentive payments for early/late completion of a project. This can be for intermediate opening to traffic periods, completion dates or times, etc. Also incentives are paid to the contracts for cost reduction or value engineering changes; and incentives/disincentives are generated by contracts, which contain $\mathrm{A}+\mathrm{B}$ or $\mathrm{A}+\mathrm{B}+\mathrm{C}$ bidding provisions. The code assigned to these different payment conditions should be chosen and used on the change order for documentation.

\section{Standards/Specifications Update or Changes}

These codes should be used if a specification is changed by the specification committee or by a memorandum from the central office, and the department wants all contracts currently active to change to the new specification requirements. 


\section{B.1: Change Order Classification Codes and Details}

Table B.2: Change Order Classification Code used at INDOT (INDOT, 2002)

\begin{tabular}{|c|c|c|c|}
\hline Code & Reason type & Name & Description \\
\hline 101 & \multirow{11}{*}{$\begin{array}{l}\text { Errors \& } \\
\text { Omissions } \\
\text { Contract } \\
\text { Document }\end{array}$} & Contract related & $\begin{array}{l}\text { Most usually, INDOT's responsibility. For example, delay in the } \\
\text { "Notice to proceed" can result in extending the contract }\end{array}$ \\
\hline 102 & & Design related & $\begin{array}{l}\text { Designer's bust - something wrong or left out. For example, wrong } \\
\text { elevation on bridge caps; or a mess in clear zone alignment, etc. }\end{array}$ \\
\hline 103 & & Environmental related & $\begin{array}{l}\text { Example: Hazardous materials not designated on plans, or buried } \\
\text { fuel tanks not identified }\end{array}$ \\
\hline 104 & & Materials related & $\begin{array}{l}\text { Materials either designated incorrectly or left out. Example: Leaving } \\
\text { out top mat of reinforcing steel in a bridge deck. }\end{array}$ \\
\hline 105 & & Permits & $\begin{array}{l}\text { Example: Permits not current - or not obtained, causing delay of } \\
\text { contract. }\end{array}$ \\
\hline 106 & & Quantity related & $\begin{array}{l}\text { Probably the most criticized segment of contract documents errors. } \\
\text { Quantities are critical for construction - both INDOT and } \\
\text { contractors errors and omissions can lead to unbalanced bidding by } \\
\text { contractors anticipating the necessary change orders. Can also } \\
\text { necessitate time extensions to the contract. }\end{array}$ \\
\hline 107 & & R/W Related & $\begin{array}{l}\text { When INDOT does not have all Right of Way cleared, this can cause } \\
\text { a change in the contractors sequence of construction, leading to time } \\
\text { extensions and additional costs. }\end{array}$ \\
\hline 108 & & Soils related & $\begin{array}{l}\text { Example: Unsuitable material requires the substitution of suitable } \\
\text { materials at increased negotiated cost. }\end{array}$ \\
\hline 109 & & Staging Related & $\begin{array}{l}\text { Sequencing of construction operations must not interfere with the } \\
\text { other public or private considerations. }\end{array}$ \\
\hline 110 & & Traffic control related & $\begin{array}{l}\text { Second most criticized design error and can cause added delays, } \\
\text { expense. }\end{array}$ \\
\hline 111 & & Utilities related & Utilities are not located, designated or are improperly identified. \\
\hline 201 & \multirow{9}{*}{$\begin{array}{l}\text { Construc- } \\
\text { tability }\end{array}$} & Construction related & $\begin{array}{l}\text { Any condition other than those designed below, that prevents } \\
\text { contractors to proceed unimpeded. }\end{array}$ \\
\hline 202 & & Design related & Example: Temporary runarounds too close to bridge construction. \\
\hline 203 & & Environmental related & Example: Hazardous materials omitted can cause redesign and delay. \\
\hline 204 & & Materials related & \\
\hline 205 & & R/W Related & $\begin{array}{l}\text { Insufficient Right of Way can require special equipment or situations } \\
\text { to require changes. }\end{array}$ \\
\hline 206 & & Soils related & $\begin{array}{l}\text { Example: Improperly designated peat bog required excessive } \\
\text { undercutting and replacement with special materials. }\end{array}$ \\
\hline 207 & & Staging Related & Sequencing cancels possibility of constructing properly. \\
\hline 208 & & Traffic control related & \\
\hline 209 & & Utilities related & Utilities causing delays and extra expense. \\
\hline 701 & \multirow{3}{*}{$\begin{array}{l}\text { Standards/ } \\
\text { Specifications } \\
\text { Update or } \\
\text { Changes }\end{array}$} & Contract completion time & $\begin{array}{l}\text { It should only be used if a specification change would increase or } \\
\text { decrease contract time requirements. }\end{array}$ \\
\hline 702 & & Contract payments & $\begin{array}{l}\text { It should be used whenever the specifications that apply to the } \\
\text { contract state different payment procedures than those stated in the } \\
\text { Schedule of Pay Items. }\end{array}$ \\
\hline 703 & & Other & $\begin{array}{l}\text { It should cover all other specifications changes such as material } \\
\text { changes, construction procedure changes, etc. }\end{array}$ \\
\hline
\end{tabular}




\section{Appendix C: How Departments of Transportation Classify Cost Overruns (Jacoby, 2001)}

ALASKA

A change order procedure is specified but categories are not assigned.

ARIZONA

1. Value Engineering

2. Additional or extra work out of scope

3. Quantity omissions

4. Plans revisions and oversights

5. Changed condition

6. Penalty or bonus

7. Other

ARKANSAS

Engineers provide written explanations for items above a specified amount.

1. Value Engineering

2. Erosion Control quantity or new item increases

3. Item Deductions

4. Incentives or disincentives for early or late completion.

5. Incentives for pavement smoothness or mix production properties.

\section{CALIFORNIA}

A three character alphanumeric code is assigned. The code indicates the type and possible cause of the change. The first character identifies the group and the second identifies the change within the group. The last character identifies the originator or the source.

\section{CONNECTICUT}

A. Agreed Days

B. Bridge Design Revision

C. Consultant Design Error

D. DOT Design Error

E. Environmental Protection

I. Routine Item Review

N Drainage Revisions

P. Adjustment of Contract Unit Price

R. Roadway Design Revision

S. Specification Change

T. Traffic Design Revision

\section{FLORIDA}

Florida has the following groups and sub-groups

1. Changed Conditions

2. Utility Delays

3. Weather Related Damage

4. Plans Modifications

5. Specification Modification

6. Value Engineering

7. Partnering

8. Actions/Inactions

9. Minor Changes 


\section{Appendix C (Continued)}

FLORIDA (continued)

10. Defective Materials

11. Contingency

12. Claim Settlement

\section{INDIANA}

Each group can have subgroups. The total subgroups defined are 44 .

Preventable

1. Errors and Omissions - Contract Documents

2. Constructability

3. Scope Changes

Non Preventable

4. Changed Field Conditions

5. Failed Materials

6. Incentive/Disincentive Provisions

7. Standards/Specifications - Update Changes.

\section{IOWA}

Iowa separates incentive payments from other change order costs. No other classification is used.

\section{KENTUCKY}

1. Minor Miscellaneous

2. Roadway Excavation

3. Slide Excavation

4. Change in Quantities due to insufficient Original Estimate

5. Shoulder repairs for Traffic Control purposes

6. Change in quantities Additional work or a Change in Scope

7. Fuel and Asphalt Adjustment.

8. Incentive Pay

\section{LOUISIANA}

Louisiana overruns and underruns greater than $5 \%$ must be explained in Change Order.

\section{MICHIGAN}

Michigan separates extra work items from increases in regular bid work items to classify reasons for contract changes and cost overruns. 


\section{Appendix C (Continued)}

\section{MINNESOTA}

They have developed a method to code the each change order item as to cause. The process has only been in place for a portion of the current fiscal year 2002. Each change order item is assigned one of the following codes. In future years, they will be able to assign overrun amounts to each category.

\begin{tabular}{ll}
\hline Acronym & Meaning \\
\hline AD & Administrative Decisions \\
\hline CD & Consultant Design Error \\
\hline CS & Claim Settlement \\
\hline DC & Design Change \\
\hline DE & Design Error \\
\hline DS & Differing Site Conditions \\
\hline ES & Staking Error \\
\hline IE & Inspection Error \\
\hline ND & Natural Disaster \\
\hline PP & Prompt Payment \\
\hline RA & Routine Adjustment \\
\hline SC & Consultant Staking Error \\
\hline UD & Utility Delay \\
\hline VE & Value Engineering \\
\hline
\end{tabular}

They do not have an effective method to identify time extensions. Contractors may granted additional time for excusable non-compensable delays (acts of God, acts of a public enemy, fires, floods, earthquakes, epidemics, quarantine restrictions, strikes, freight embargoes, unusually severe weather or other delays not caused by the contractor's fault or negligence).

In cases where the final value of all work performed exceeds the original contract amount, an extension in working days is granted to the contractor. The extension is made by increasing the contract time by the ratio of the total final cost of all work performed to the total amount of the original contract. Extensions are only computed if the contractor fails to complete the contract within the original time-frame.

NEW HAMPSHIRE

Written explanations

\section{NEW JERSEY}

A. Changes authorized by construction which are not in any other description of change. D.Traffic impact modification of safety enhancement

E. Additional work for Corrective Action comment, including work after completion date. F.Project Management change to add or delete work (scope change)

G.Change to address a Right of Way issue

H.Change to address a Utility issue

I.Change to address a Environmental issue

J.Change to address a error or omission in the contract.

K.Any other Project Management change based on field conditions.

L.Change in specification by the Department and/or Contractor.

M.Change in Material by the Department and/or Contractor

N.Implementation of a Value Engineering Proposal.

O.Implementation of a Contractor requested change 


\section{Appendix C (Continued)}

P.Implementation of any Third Party initiated change

Q.

$\mathrm{U}$.

V.

W.

X.Unique Situation, including Force Majeure, Enter Reason
Only a time adjustment and or mitigation of a delay Unused or deleted item material purchase.

Partnering Agreements

Incentive/Disincentive Payments (including bonus and penalty)

\section{NEW MEXICO}

01Design Oversight

02Modification by Construction Personal

03Traffic Control Modifications

04Decreasing/Increasing Quantities

05Deleting/Adding Items

06Contract Time Adjustments

07Force Accounts

08Incentive/Disincentive

09Price Adjustment

10 Claim Settlement

11Liquidated Damages

12Cost Savings Proposals/Suggestions

13Quantity

14 Other

15Grass Receipt Taxes

\section{NEW YORK}

01Changes in Contract Quantity

02Design Errors

03Increasing Project Scope

04Structure Deterioration Increase

05Roadway Deterioration Increase

06 Soils

07Landscape

08Structural Changes

09Administrative Changes

10Specification Change

11Maintenance of Traffic

12Materials Change.

13Traffic Signal

14Administrative Settlement

15Emergency

16Accelerations.

\section{NORTH DAKOTA}

The project engineer is required to complete an explanation which identifies the reason for the change 


\section{Appendix C (Continued)}

$\mathrm{OHIO}$

01 Normal Difference Plan and Actual Quantities. 02 Significant Diff Plan and Actual Quantities.

03 Changes Preventable for Field Conditions

04 Change Non Preventable for Field Conditions.

05 Alter Specifications

06 Work in Plans but not General Summary/Prop

07 Unclear plan note

08 Improper Materials Specified

09 Plan omissions

10 Non performed Cont Item

11 Preventable Maintenance of Traffic Revision

12 Non-Preventable Maintenance of Traffic Revision

13 Incorrect Soil Subsurface Data

14 Utility Relocation Delay

15 Improperly located utility

16 Unknown utility

17 Delay caused for reasons other than utility

18 Cost to accelerate work

19 Asphalt lot adjustments

20 Non Specification Materials.

21 Bituminous price adjustments

22 Owner Requested Change

23 Accepted Value Engineering Change

24 Claims Resolution/Avoidance Agreement

25 Smoothness Price Adjustments

26 Partnering Workshop.

PENNSYLVANIA

1. Balancing of overruns/underruns

2. Design Omissions

3. Design Errors

4. Unforeseen Field Conditions

5. Field Changes Directed by the Engineer

6. Required change in Scope of Work

7. Differing Site Conditions

8. Suspension of work ordered by Engineer

9. Other

\section{SOUTH DAKOTA}

1. Normal Variations in Quantities.

2. Work for others no cost to us

3. Design Changes

4. Value Engineering

5. Incentive/Disincentive

6. Haul Roads/Detours

7. Change in Scope and/or Work Beyond Termini

8. PCCP Restoration (Major)

9. Excavation Major 


\section{Appendix C (Continued)}

10. Changed Condition

11. Claims/Dispute Resolution

12. Asphalt Concrete Major

13. Railroad Projects

14. Utility Agreements

15. Differing Site Conditions

16. R.O.W Landowner issues

17. Asphalt Maintenance Repairs

18. Airport Projects

19. Plan Errors

20. Maintenance Contracts

21. Field Errors

22. Contractor Errors

23. Plan Change

24. Incentive/Disincentive

25. Lane Rental

TEXAS

Texas has six main groups and then each of these groups has as many as 13 subgroups. There are 39 total subgroups.

1. Design Error or Omission

2. Differing Site Conditions (Unforeseeable)

3. TxDOT Convenience

4. Third Party Accommodation

5. Contractor Convenience

6. Untimely Right of Way/Utilities

UTAH

There are six groups that are further categorized into 5 to 10 sub groups. The total amount of categories is 43. They also record the Division, Section or position that could have taken some action to prevent the need for the Change Order. There are 14 items here.

Group 1. Anticipated Supplemental Contract Work

Group 2. General Additions / Deletions / Adjustment

Group 3. Unforeseen Occurrences / Differing Site Conditions

Group 4. Differences/Conflicts in the Contract Documents

Group 5. Settlement of Claims and Disputes

Group 6. Cost Reduction Incentive Proposals / Alternative Design

\section{WASHINGTON}

What created the need for the change order?

AP Administrative Problem - Does not relate to the physical work

BC Budget Constraints - Deletion or modification was initiated because cost exceeded funding limits.

CC Changed Condition - Site conditions differed from design expectations.

CE Contractor Error

CS Claim Settlement

DR Disputes Board finding

EE Construction Engineering Error

EJ Engineer's Judgment 


\section{Appendix C (Continued)}

HZ Hazardous Material encountered.

IP Contractor's cost revision incentive

MP Interim Maintenance Problem Temporary maintenance is required.

PI Plans Error Insufficient Information was available to the designer

PM Plans Error Mistake

SC Specification Conflict Ambiguity

TP Third Party Request

UC Unanticipated Condition

What does the Change order do?

AD Administrative Change

CA Condition of Award

CR Correction Repair

DC Design Change

DE Delay Compensation

EP Extra Pay Required

MO Quantity Variation

MR Material's Spec Revision

OR Other Spec Revision

RS Revised Scope

SA Schedule Adjustment

WC Work method Change

\section{WISCONSIN}

CR Cost Reduction

MI Miscellaneous

PC Plan Change

PI Plan Inadequacy

RO Request by Others

SE Safety Enhancement

SS Change/Credit Standards and Specifications 


\section{Appendix D: Weather Data Organization}

Table D.1: Quality and Correction of the Weather Data

\begin{tabular}{|c|c|c|c|c|c|}
\hline Number & Normal county & Problem & Replace by: & Final county & $\begin{array}{c}\text { Final } \\
\text { Number }\end{array}$ \\
\hline 1 & Adams & NT in sep 00 , jul01 and 02 & Wells & Adams & 1 \\
\hline 2 & Allen & NT, no 01 to 02 & Whitley & Allen & 2 \\
\hline 3 & Bartholomew & $\mathrm{OK}$ & & Bartholomew & 3 \\
\hline 4 & Benton & $\mathrm{OK}$ & & Benton & 4 \\
\hline 5 & Blackford & $\mathrm{OK}$ & & Blackford & 5 \\
\hline 6 & Boone & OK & & Boone & 6 \\
\hline 7 & Brown & NT & Bartholomew & Brown & 7 \\
\hline 8 & Carroll & nothing & Cass & Cass & 9 \\
\hline 9 & Cass & $\mathrm{OK}$ & & Cass & 9 \\
\hline 10 & Clark & nothing & Jackson & Jackson & 36 \\
\hline 11 & Clay & nothing & Owen & Owen & 60 \\
\hline 12 & Clinton & no jan to jun 99 & Tippecanoe & Clinton & 12 \\
\hline 13 & Crawford & nothing & Dubois & Dubois & 19 \\
\hline 14 & Daviess & no 98 to 00 & Martin & Daviess & 14 \\
\hline 15 & Dearborn & no 96 to $97 \&$ end02 & Decatur & Dearborn & 15 \\
\hline 16 & Decatur & $\mathrm{OK}$ & & Decatur & 16 \\
\hline 17 & Dekalb & nothing & Whitley & Whitley & 92 \\
\hline 18 & Delaware & $\mathrm{OK}$ & & Delaware & 18 \\
\hline 19 & Dubois & $\mathrm{OK}$ & & Dubois & 19 \\
\hline 20 & Elkhart & BT & Marshall & Elkhart & 20 \\
\hline 21 & Fayette & nothing & Henry & Henry & 33 \\
\hline 22 & Floyd & NT, no 00 to 02 & Jackson & Floyd & 22 \\
\hline 23 & Fountain & NT 98 to 02 & Montgomery & Fountain & 23 \\
\hline 24 & Franklin & no 96 to 97 & Decatur & Franklin & 24 \\
\hline 25 & Fulton & no 99 & Cass & Fulton & 25 \\
\hline 26 & Gibson & nothing & Knox & Knox & 42 \\
\hline 27 & Grant & NT 02 & Blackford & Grant & 27 \\
\hline 28 & Greene & NT & Owen & Greene & 28 \\
\hline 29 & Hamilton & no 96 to 99 & Madison & Hamilton & 29 \\
\hline 30 & Hancock & $\mathrm{OK}$ & & Hancock & 30 \\
\hline 31 & Harrison & NT & Madison & Harrison & 31 \\
\hline 32 & Hendricks & no jan to feb96 & Marion & Hendricks & 32 \\
\hline 33 & Henry & $\mathrm{OK}$ & & Henry & 33 \\
\hline 34 & Howard & NT 97 to 02 & Tipton & Howard & 34 \\
\hline 35 & Huntington & nothing & Wells & Wells & 90 \\
\hline 36 & Jackson & $\mathrm{OK}$ & & Jackson & 36 \\
\hline 37 & Jasper & $\mathrm{OK}$ & & Jasper & 37 \\
\hline 38 & Jay & $\mathrm{OK}$ & & Jay & 38 \\
\hline 39 & Jefferson & NT & Jackson & Jefferson & 39 \\
\hline 40 & Jennings & nothing & Jackson & Jackson & 36 \\
\hline 41 & Johnson & NT dec 97 to jan00 & Morgan & Johnson & 41 \\
\hline 42 & Knox & $\mathrm{OK}$ & & Knox & 42 \\
\hline 43 & Kosciusko & $\mathrm{NT}$ & Marshall & Kosciusko & 43 \\
\hline 44 & Lagrange & no 01 to 02 & Whitley & Lagrange & 44 \\
\hline 45 & Lake & $\mathrm{OK}$ & & Lake & 45 \\
\hline
\end{tabular}

$\mathrm{NT}=$ no temperature data, $\mathrm{NS}=$ no snow data, $\mathrm{BT}=$ bad quality of the temperature data 


\section{Appendix D: Weather Data Organization (Continued)}

Table D.1: Quality and Correction of the Weather Data

\begin{tabular}{|c|c|c|c|c|c|}
\hline Number & Normal county & Problem & Replace by: & Final county & $\begin{array}{c}\text { Final } \\
\text { Number }\end{array}$ \\
\hline 46 & Laporte & $\mathrm{OK}$ & & Laporte & 46 \\
\hline 47 & Lawrence & $\mathrm{OK}$ & & Lawrence & 47 \\
\hline 48 & Madison & $\mathrm{OK}$ & & Madison & 48 \\
\hline 49 & Marion & $\mathrm{OK}$ & & Marion & 49 \\
\hline 50 & Marshall & $\mathrm{OK}$ & & Marshall & 50 \\
\hline 51 & Martin & $\mathrm{OK}$ & & Martin & 51 \\
\hline 52 & Miami & NT & Cass & Miami & 52 \\
\hline 53 & Monroe & $\mathrm{OK}$ & & Monroe & 53 \\
\hline 54 & Montgomery & $\mathrm{OK}$ & & Montgomery & 54 \\
\hline 55 & Morgan & $\mathrm{OK}$ & & Morgan & 55 \\
\hline 56 & Newton & NT, no 02 & Jasper & Newton & 56 \\
\hline 57 & Noble & BT & Whitley & Noble & 57 \\
\hline 58 & Ohio & nothing & Decatur & Decatur & 16 \\
\hline 59 & Orange & nothing & Lawrence & Lawrence & 47 \\
\hline 60 & Owen & $\mathrm{OK}$ & & Owen & 60 \\
\hline 61 & Parke & nothing & Vermillion & Vermillion & 83 \\
\hline 62 & Perry & no 01 & Dubois & Perry & 62 \\
\hline 63 & Pike & nothing & Dubois & Dubois & 19 \\
\hline 64 & Porter & $\mathrm{OK}$ & & Porter & 64 \\
\hline 65 & Posey & NT sept00 to 02 , no 97 & Knox & Posey & 65 \\
\hline 66 & Pulaski & no 01 & Jasper & Pulaski & 66 \\
\hline 67 & Putnam & $\mathrm{OK}$ & & Putnam & 67 \\
\hline 68 & Randolph & $\mathrm{OK}$ & & Randolph & 68 \\
\hline 69 & Ripley & NT NS 96 to 97 & Decatur & Ripley & 69 \\
\hline 70 & Rush & $\mathrm{OK}$ & & Rush & 70 \\
\hline 71 & SaintJoseph & NT 01 & La Porte & SaintJoseph & 71 \\
\hline 72 & Scott & no 01 to 02 & Jackson & Scott & 72 \\
\hline 73 & Shelby & NT & Rush & Shelby & 73 \\
\hline 74 & Spencer & no 97 to 01 & Dubois & Spencer & 74 \\
\hline 75 & Starke & NT & La Porte & Starke & 75 \\
\hline 76 & Steuben & no $\operatorname{dec} 00$ to 01 & Whitley & Steuben & 76 \\
\hline 77 & Sullivan & NT & Vigo & Sullivan & 77 \\
\hline 78 & Switzerland & nothing & Jackson & Jackson & 36 \\
\hline 79 & Tippecanoe & $\mathrm{OK}$ & & Tippecanoe & 79 \\
\hline 80 & Tipton & $\mathrm{OK}$ & & Tipton & 80 \\
\hline 81 & Union & BT, no 96 to 97 & Rush & Union & 81 \\
\hline 82 & Vandenburgh & NT, no 97 & Knox & Vandenburgh & 82 \\
\hline 83 & Vermillion & $\mathrm{OK}$ & & Vermillion & 83 \\
\hline 84 & Vigo & $\mathrm{OK}$ & & Vigo & 84 \\
\hline 85 & Wabash & NT jan to jun00 \& oct to nov01 & Whitley & Wabash & 85 \\
\hline 86 & Warren & NT & Benton & Warren & 86 \\
\hline 87 & Warrick & no 97 to 98 & Dubois & Warrick & 87 \\
\hline 88 & Washington & no 98 to 02 & Jackson & Washington & 88 \\
\hline 89 & Wayne & no 96 to 97 & Randolph & Wayne & 89 \\
\hline 90 & Wells & $\mathrm{OK}$ & & Wells & 90 \\
\hline 91 & White & BT & Jasper & White & 91 \\
\hline 92 & Whitley & $\mathrm{OK}$ & & Whitley & 92 \\
\hline 99 & Divers & & & & \\
\hline
\end{tabular}

$\mathrm{NT}=$ no temperature data, $\mathrm{NS}=$ no snow data, $\mathrm{BT}=$ bad quality of the temperature data 
Appendix E: Additional Descriptive Statistics

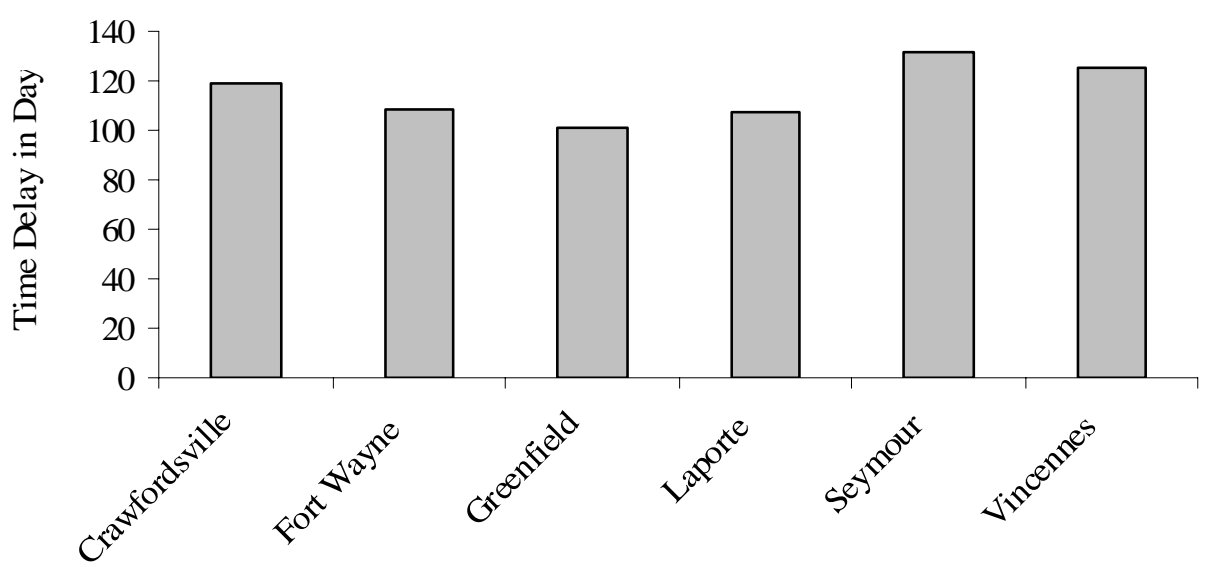

Figure E.1: Distribution of the Average Time Delay per Contract by District

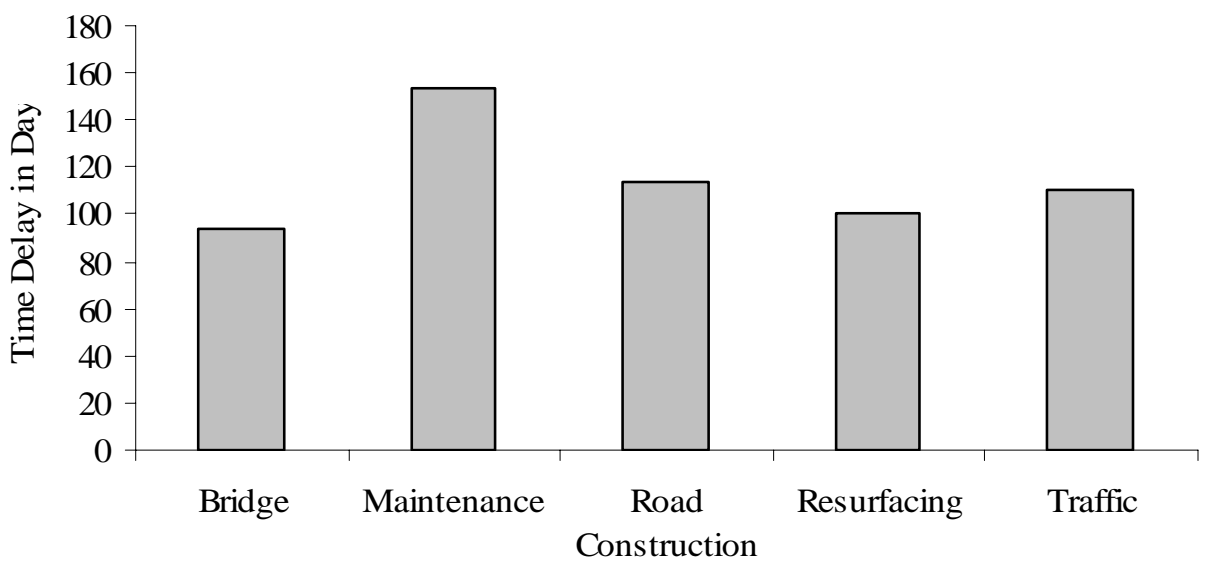

Figure E.2: Distribution of the Average Time Delay per Contract by Project Type 


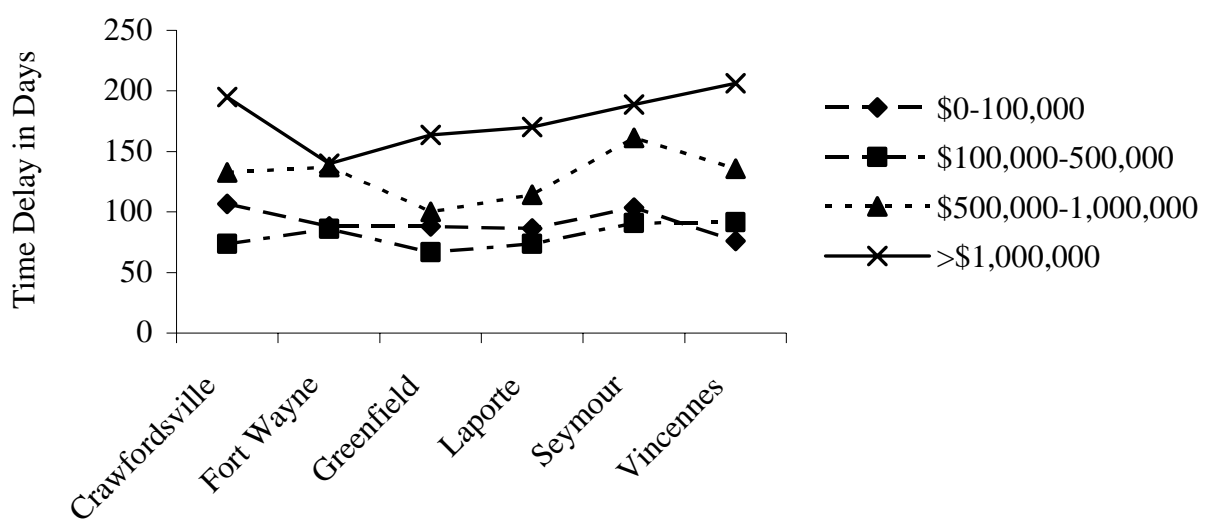

Figure E.3: Distribution of Average Time Delay per Contract by Bid Amount Category and by District

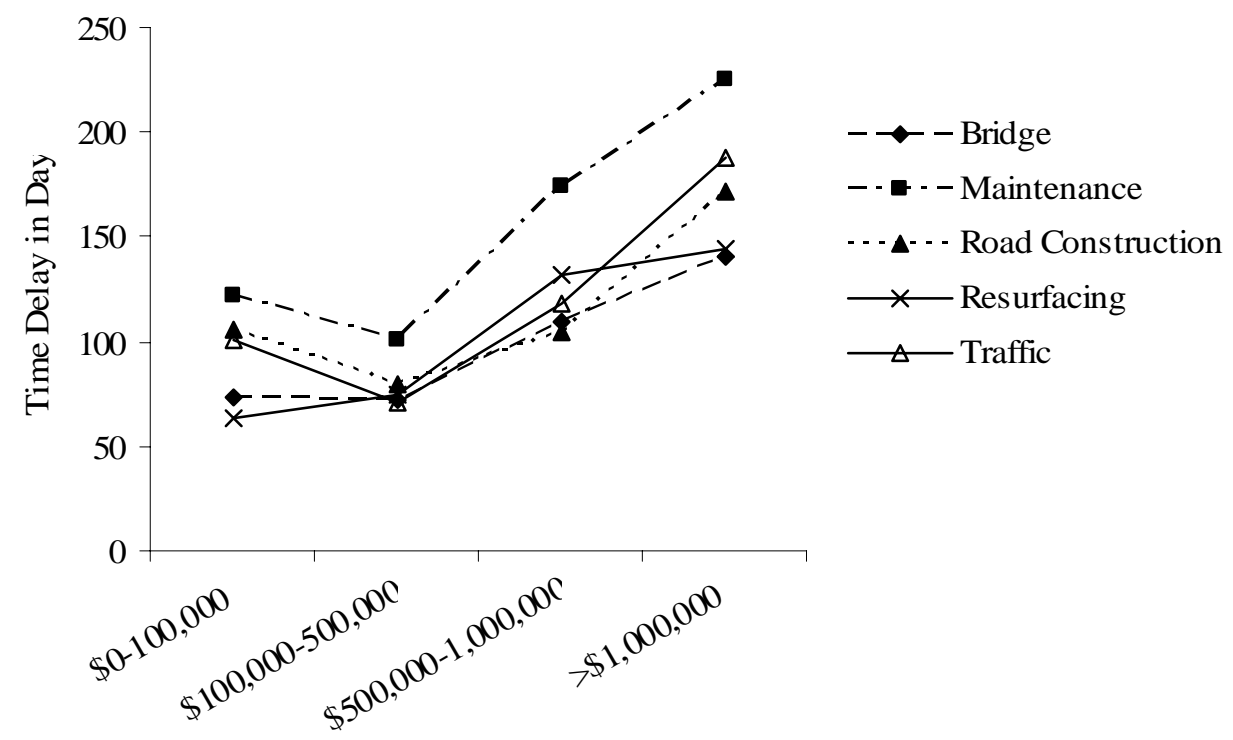

Figure E.4: Distribution of Average Time Delay per Contract by Project Type and Bid Amount Category 


\section{Appendix E: Additional Descriptive Statistics (Continued)}

Bridge Project

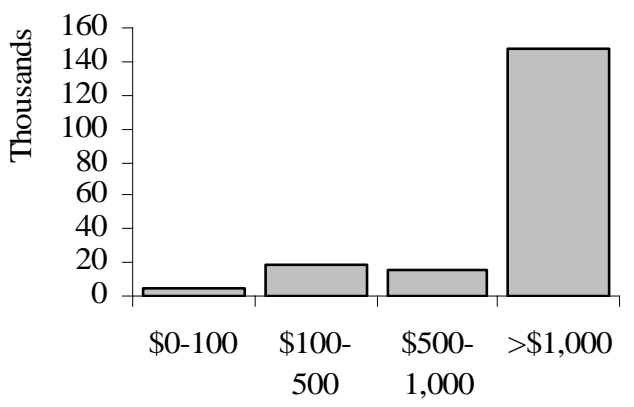

Road Construction Project

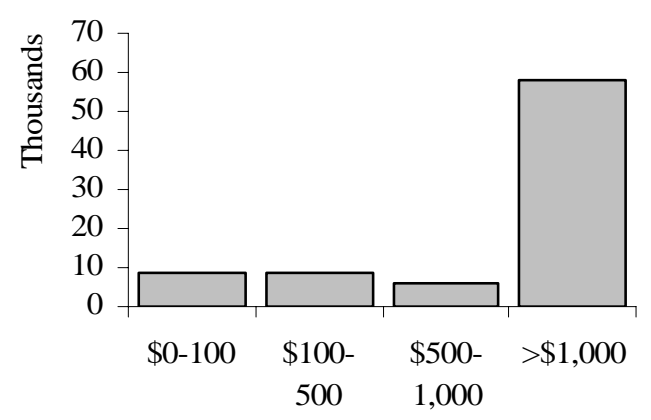

Traffic Project

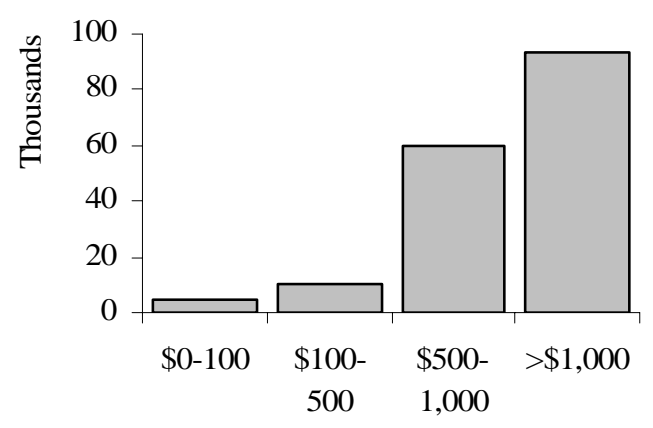

Maintenance Project

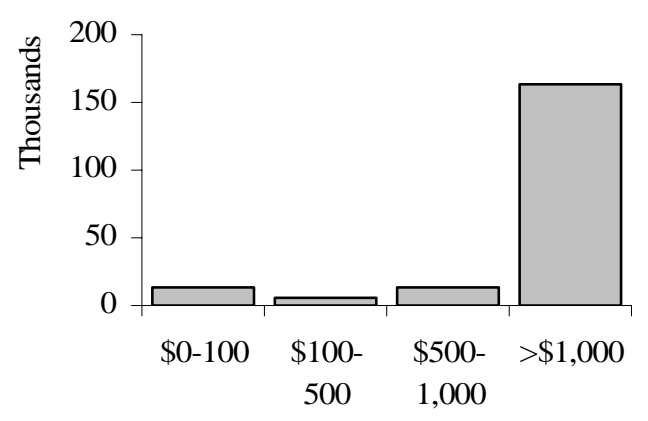

Resurfacing Project

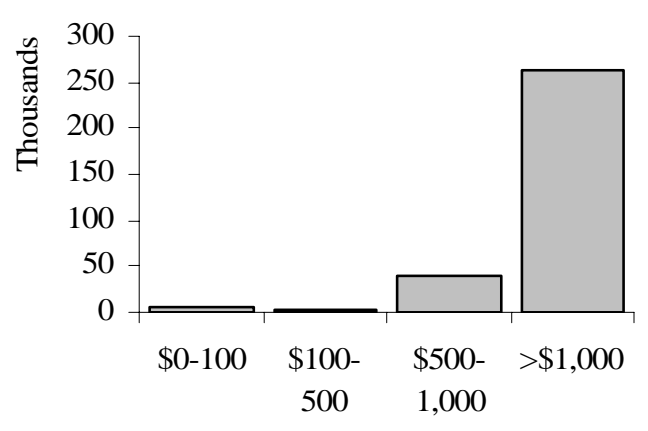

Traffic Maintenance Project

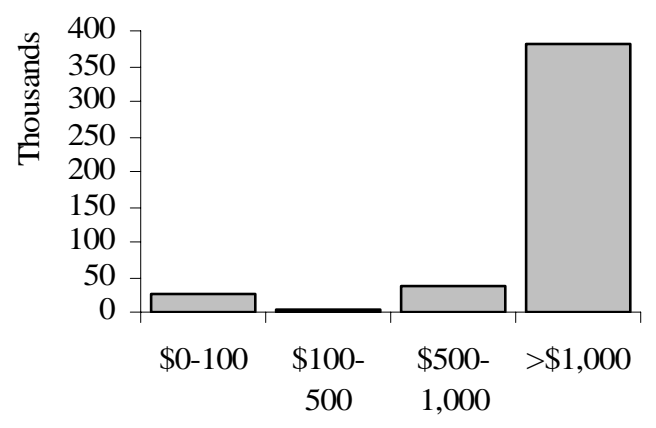

Figure E.5: Distribution of Cost Overrun Amounts (\$1,000’s) by Project Type and by Bid Amount Category 


\section{Appendix E: Additional Descriptive Statistics (Continued)}

Bridge Project

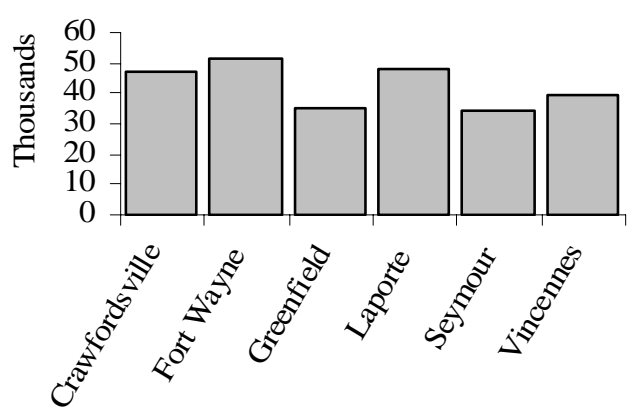

Road Construction Project

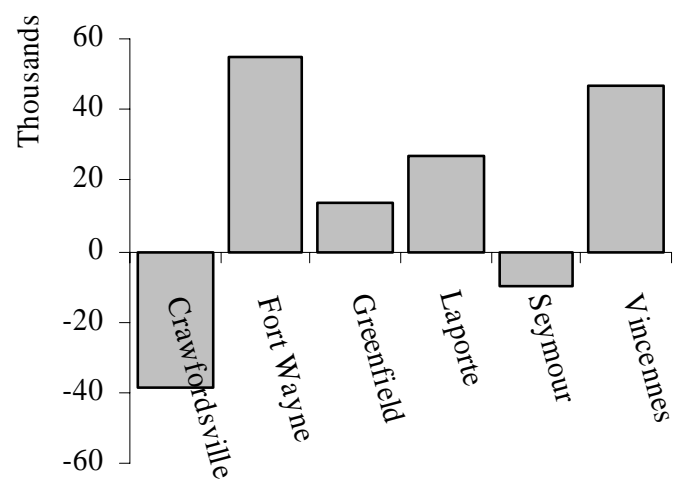

Traffic Project

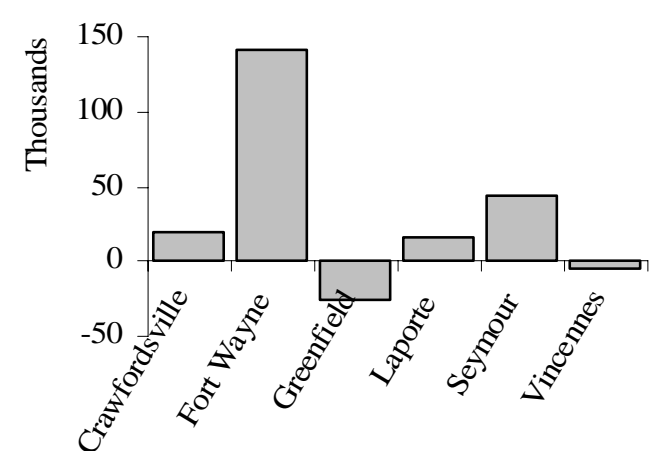

Maintenance Project

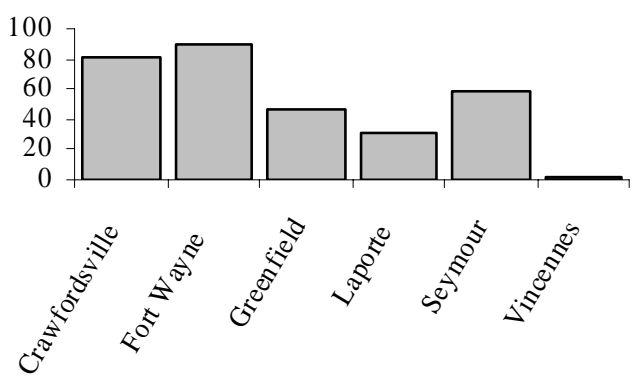

Resurfacing Project

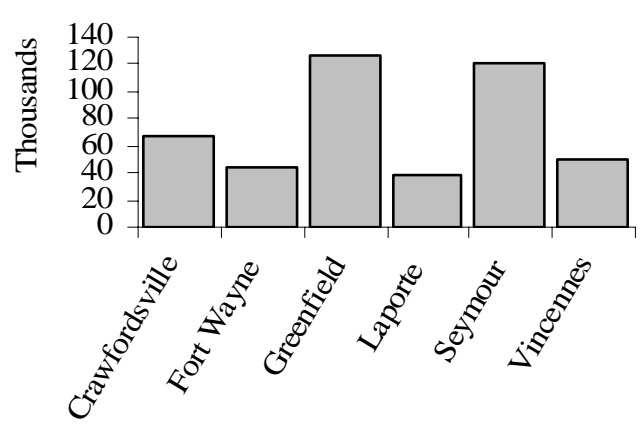

Traffic Maintenance Project

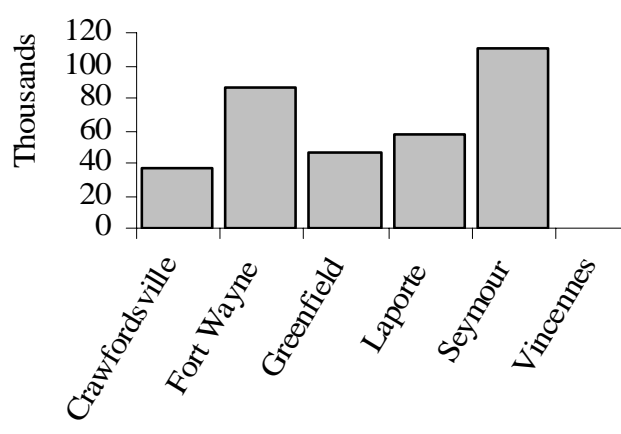

Figure E.6: Distribution of Cost Overrun Amounts (\$1,000’s) by Project Type and by District 


\section{Appendix E: Additional Descriptive Statistics (Continued)}

Crawfordsville Project

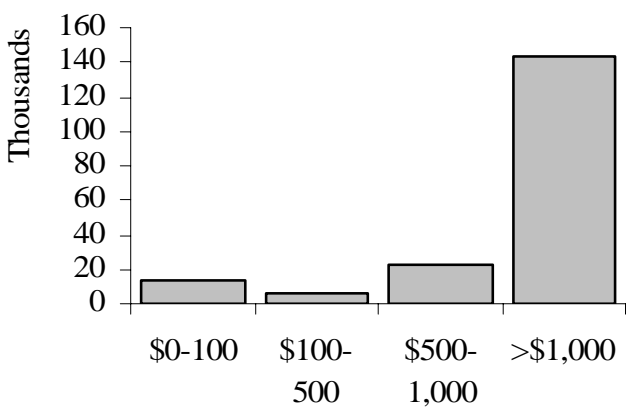

Greenfield Project

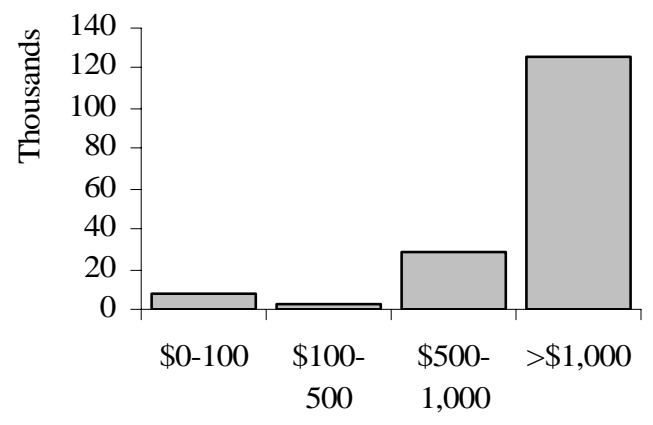

Seymour Project

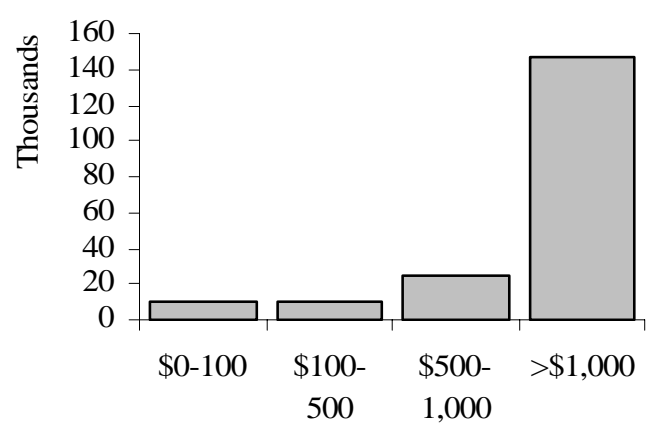

Fort Wayne Project

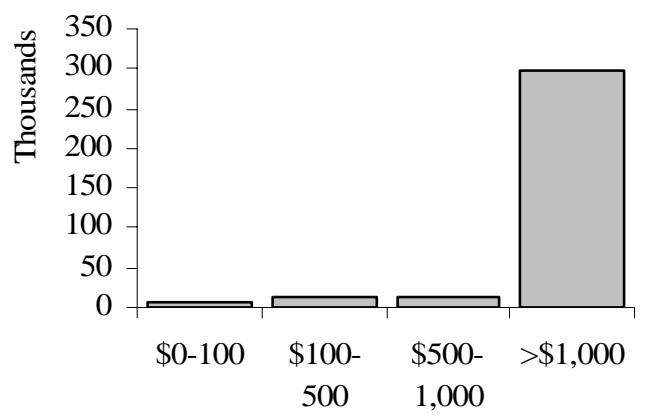

Laporte Project

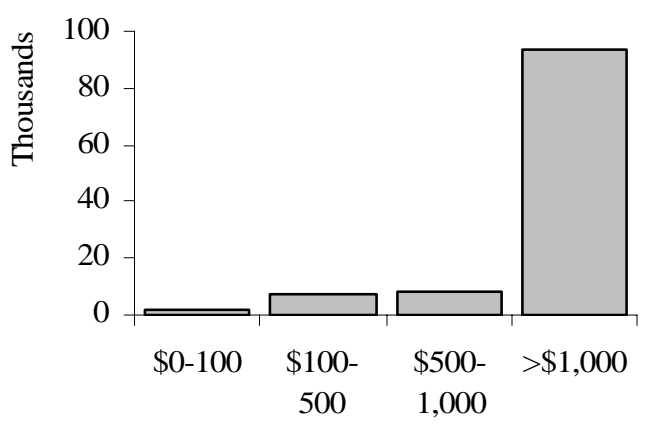

Vincennes Project

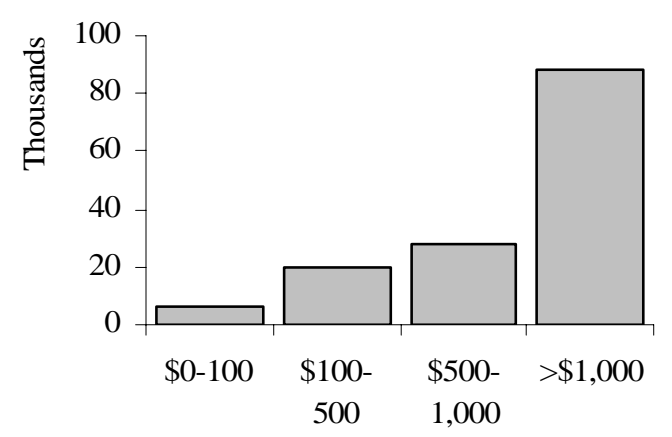

Figure E.7: Distribution of Cost Overrun Amounts (\$1,000’s) by District and by Bid Amount Category 


\section{Appendix E: Additional Descriptive Statistics (Continued)}

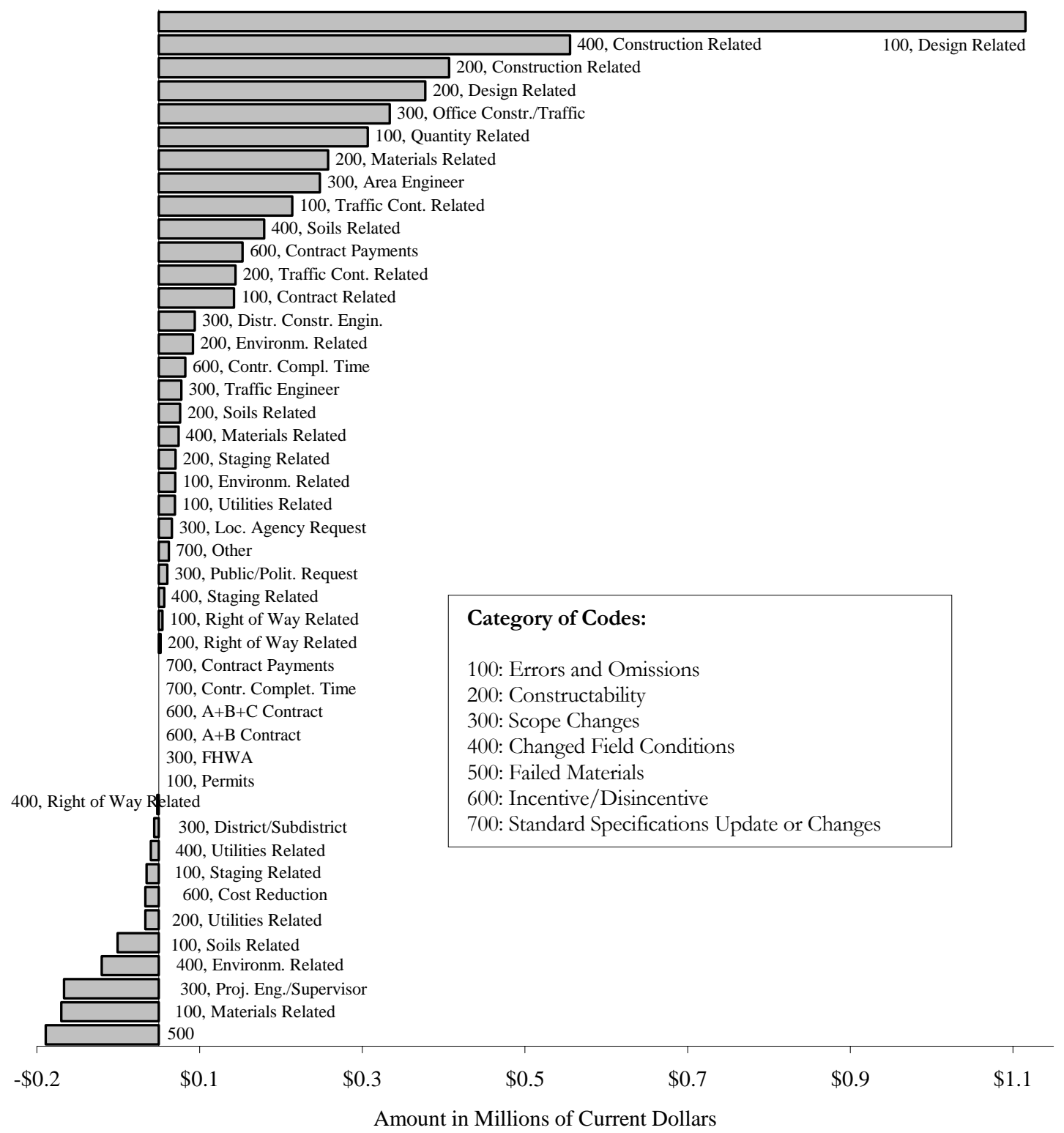

Figure E.8: Reasons for Change Orders in Bridge Projects 


\section{Appendix E: Additional Descriptive Statistics (Continued)}

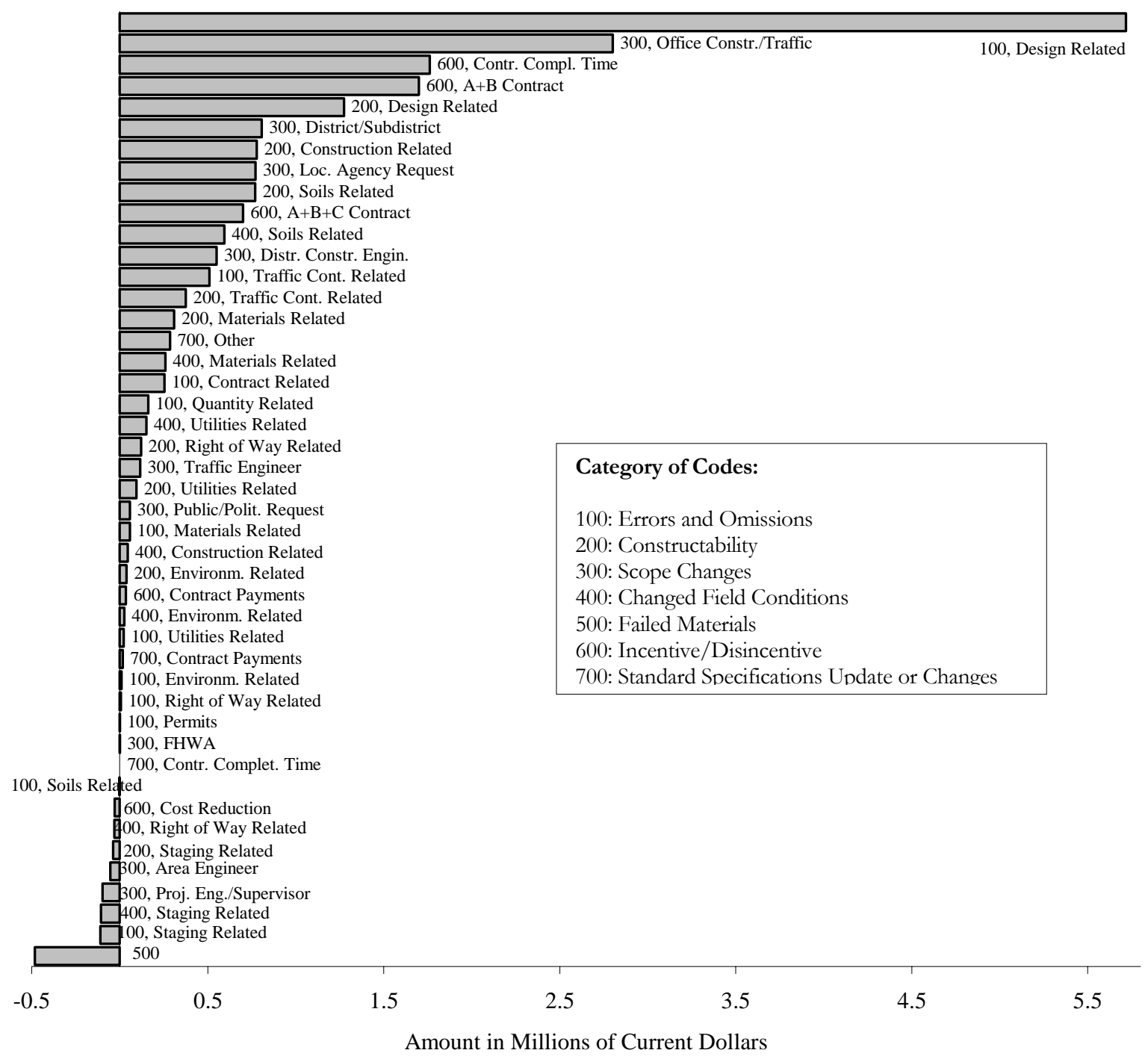

Figure E.9: Reasons for Change Orders in Road Construction Projects 


\section{Appendix E: Additional Descriptive Statistics (Continued)}

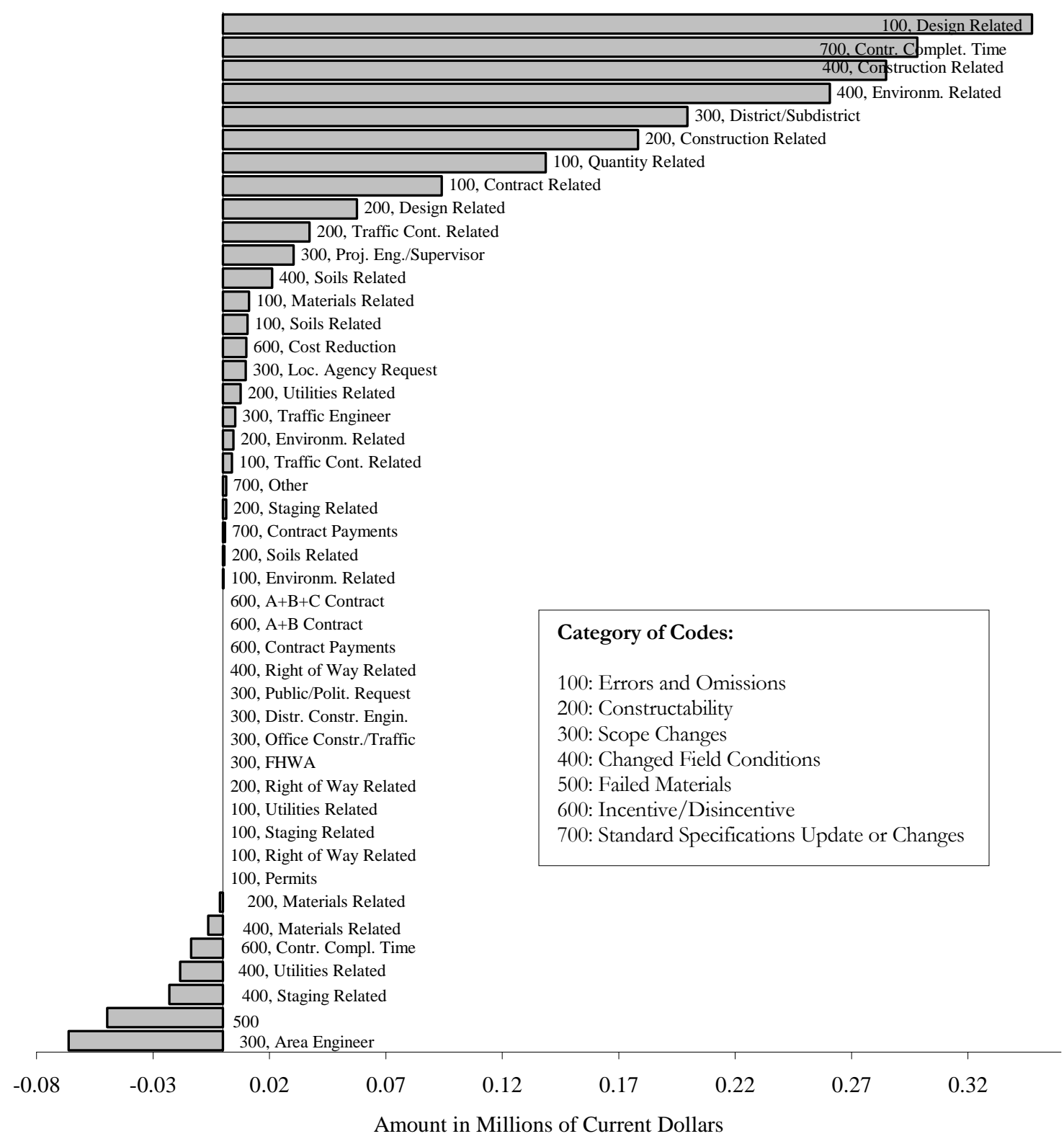

Figure E.10: Reasons for Change Orders in Maintenance Projects 


\section{Appendix E: Additional Descriptive Statistics (Continued)}

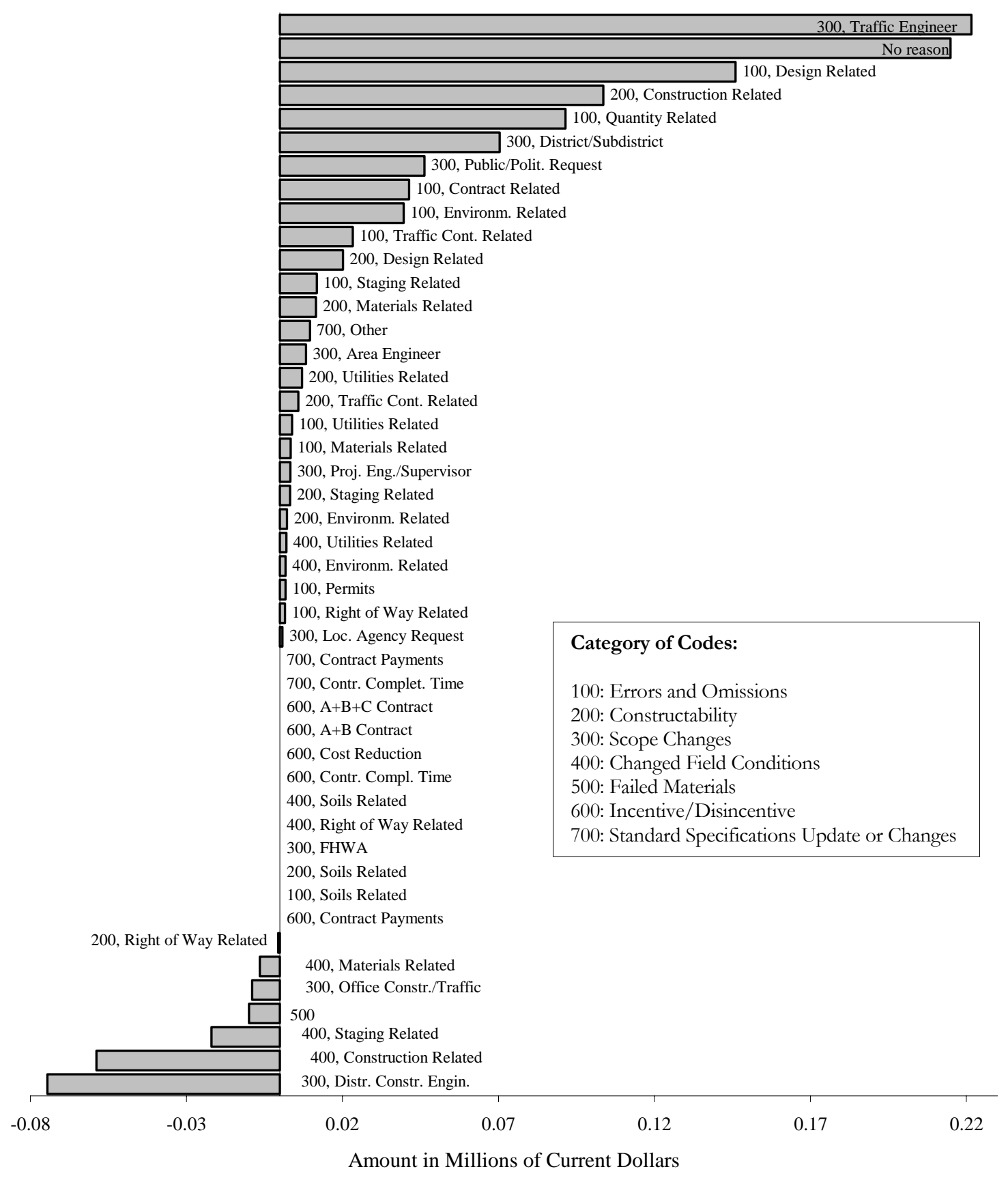

Figure E.11: Reasons for Change Orders in Traffic Projects 


\section{Appendix E: Additional Descriptive Statistics (Continued)}

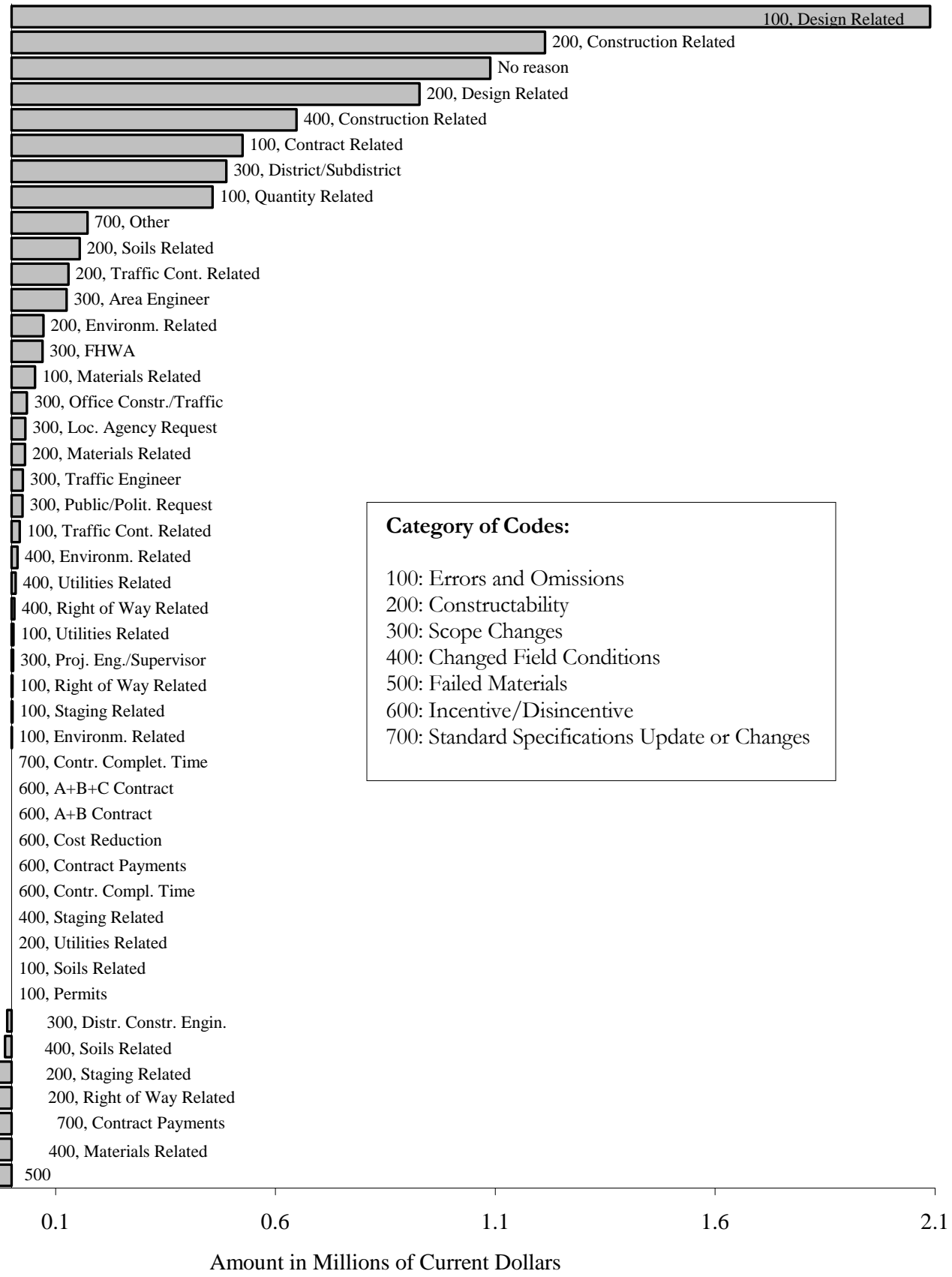

Figure E.12: Reasons for Change Orders in Resurfacing Projects 


\section{Appendix E: Additional Descriptive Statistics (Continued)}

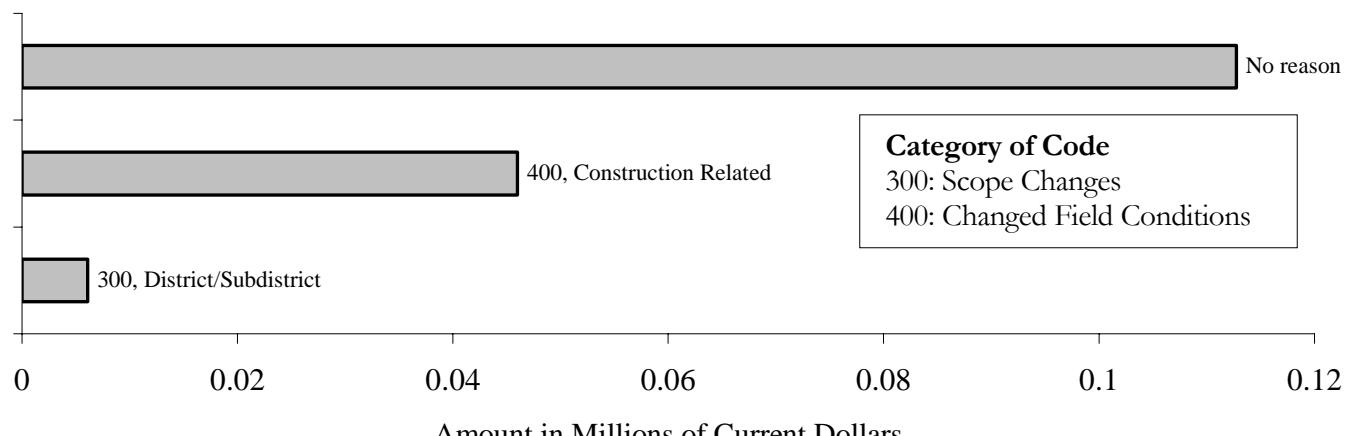

Amount in Millions of Current Dollars

Figure E.13: Reasons for Change Orders in Traffic Maintenance Projects

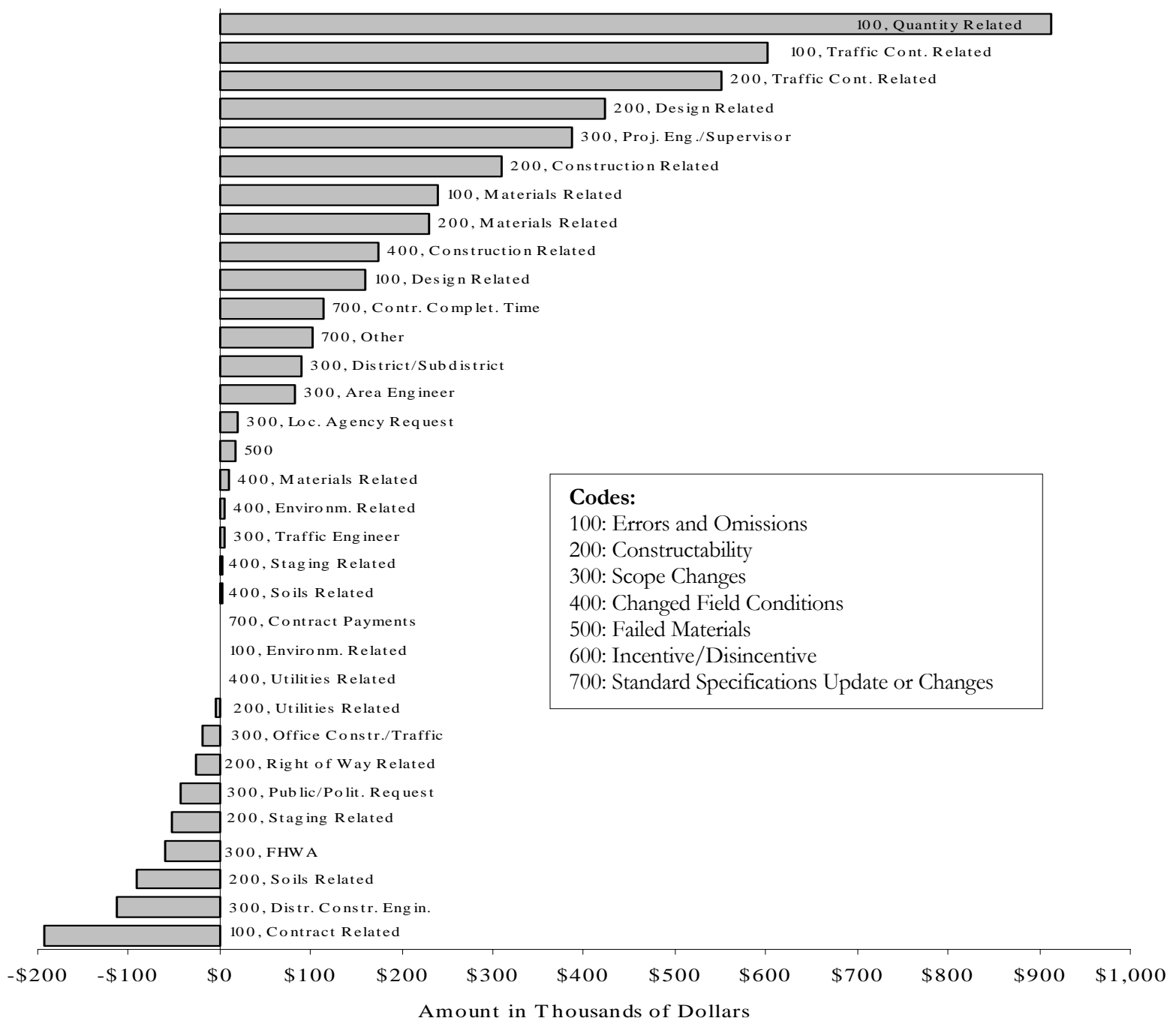

Figure E.14: Reasons for Change Orders in Crawfordsville District 


\section{Appendix E: Additional Descriptive Statistics (Continued)}

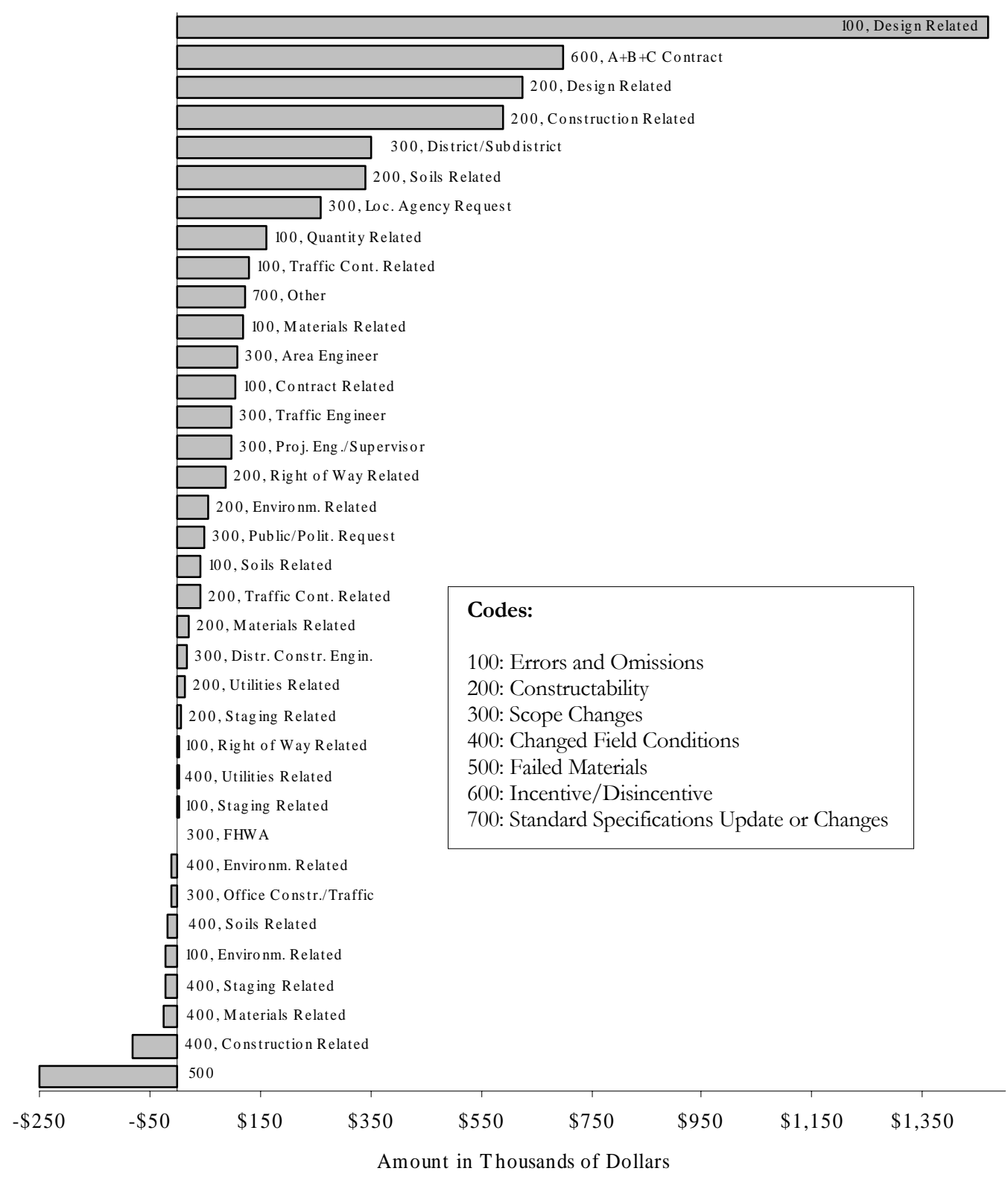

Figure E.15: Reasons for Change Orders in Fort Wayne District 
Appendix E: Additional Descriptive Statistics (Continued)

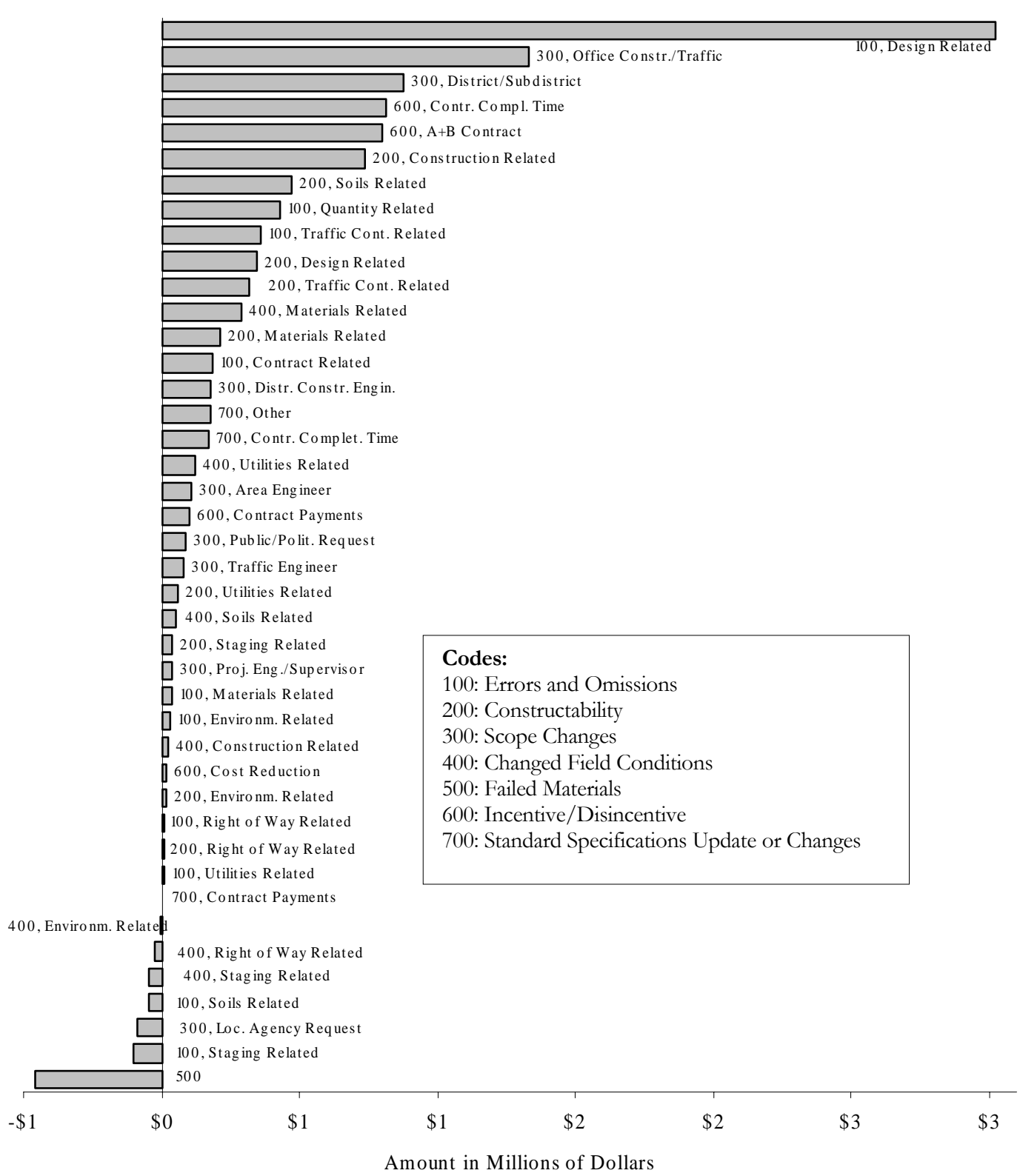

Figure E.16: Reasons for Change Orders in Greenfield District 


\section{Appendix E: Additional Descriptive Statistics (Continued)}

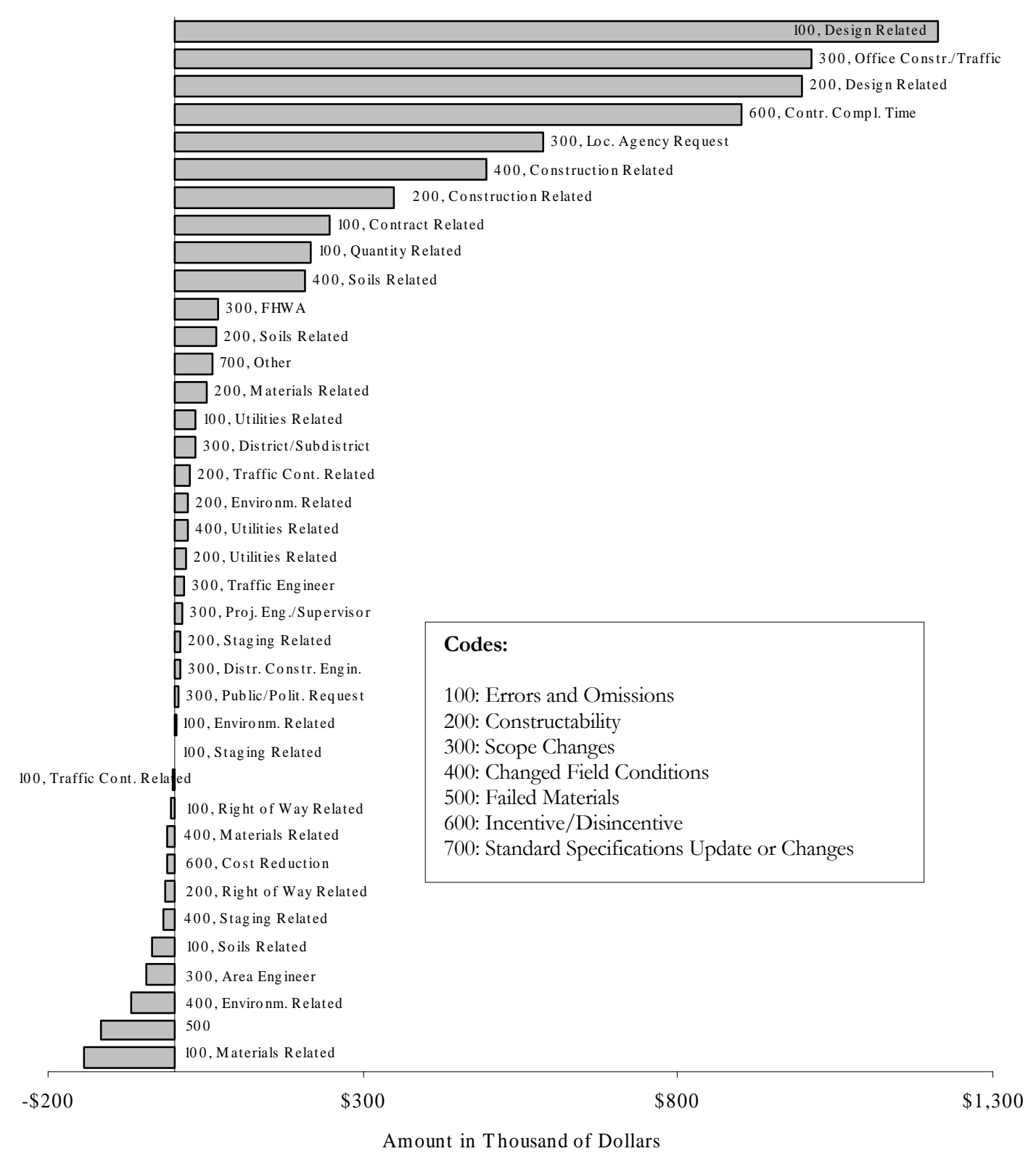

Figure E.17: Reasons for Change Orders in La Porte District 


\section{Appendix E: Additional Descriptive Statistics (Continued)}

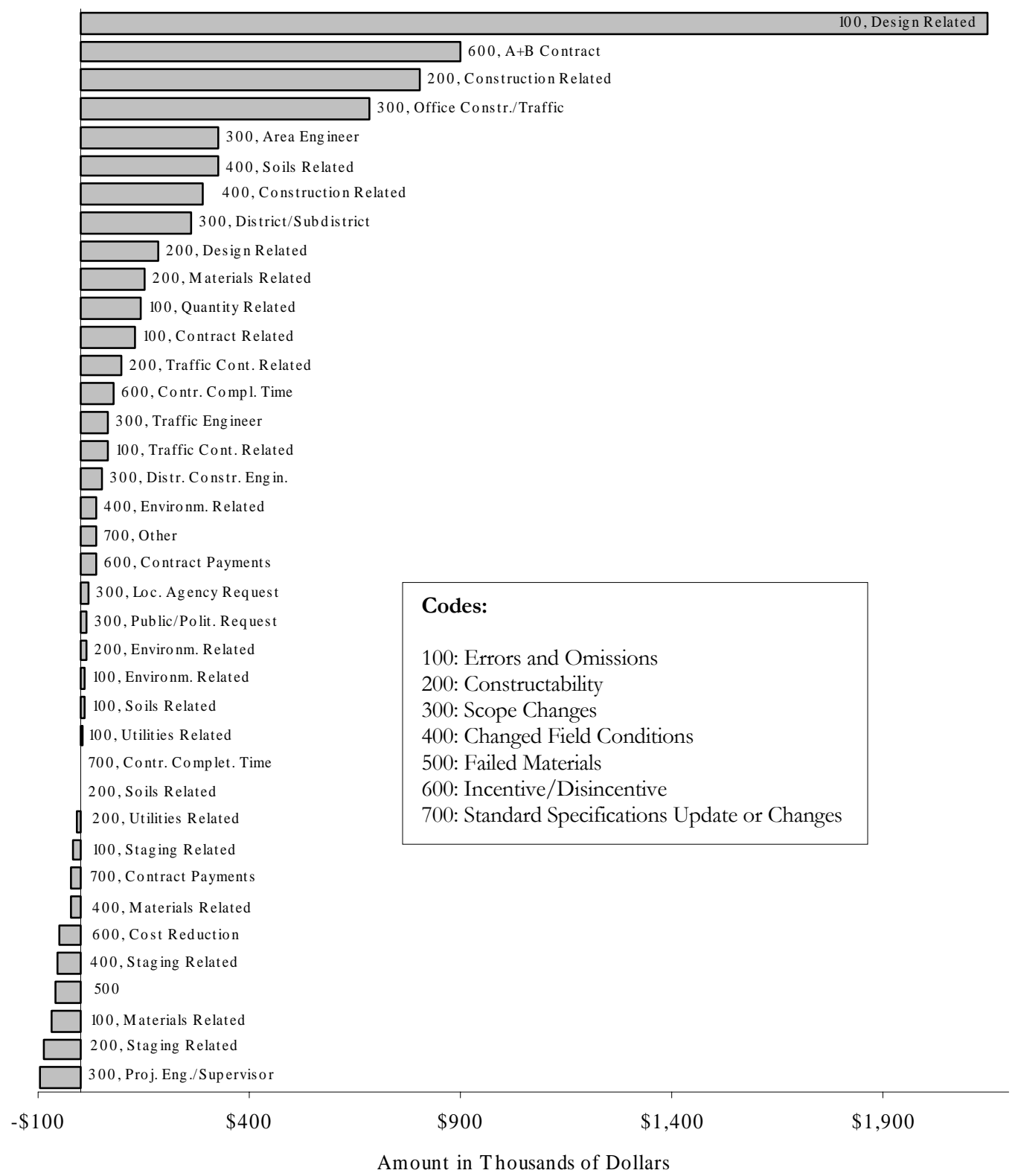

Figure E.18: Reasons for Change Orders in Seymour District 
Appendix E: Additional Descriptive Statistics (Continued)

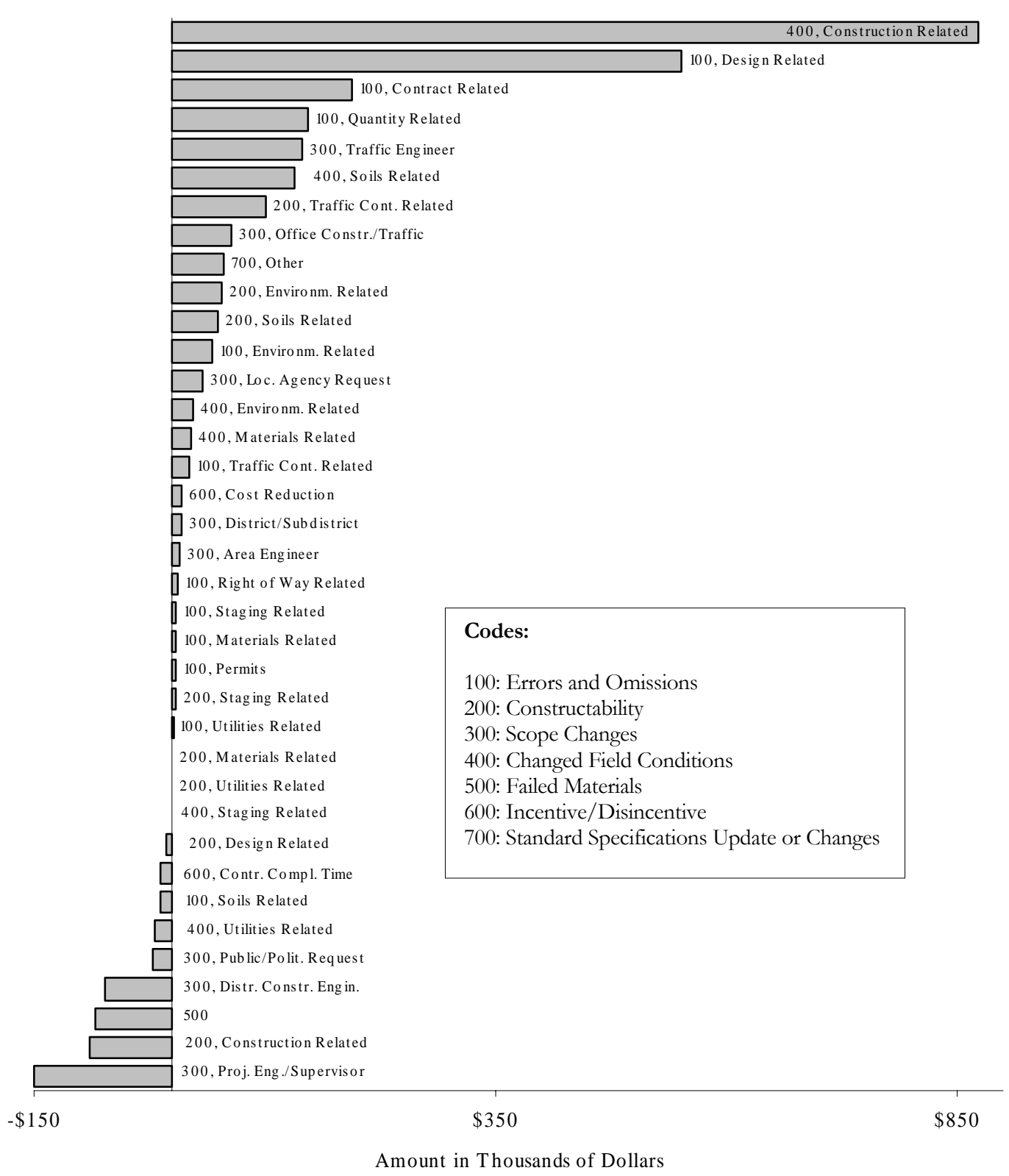

Figure E.19: Reasons for Change Orders in Vincennes District 


\section{Appendix E: Additional Descriptive Statistics (Continued)}
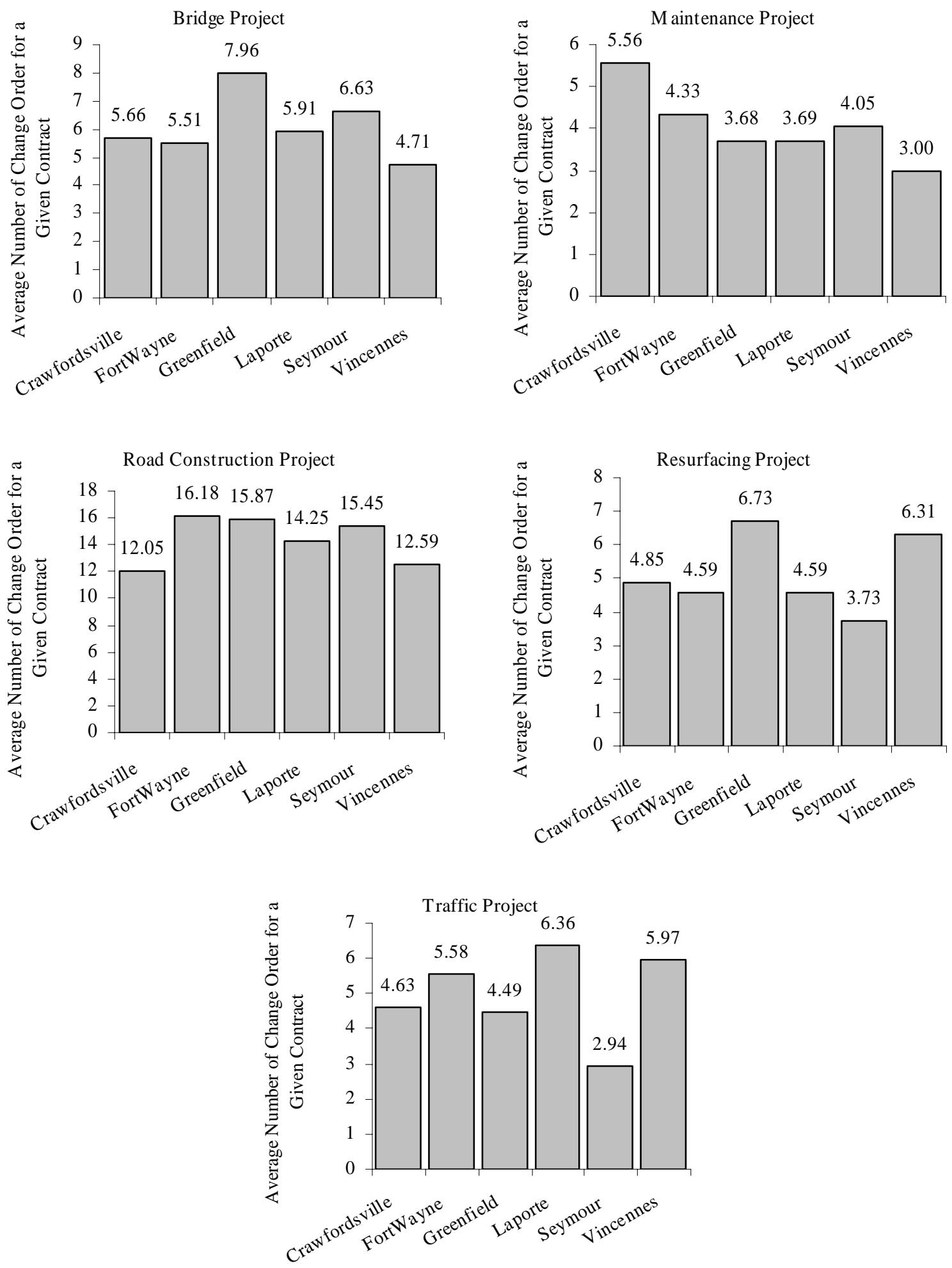

Figure E.20: Distribution of the Average Number of Change Orders by Project Type and by District 


\section{Appendix E: Additional Descriptive Statistics (Continued)}

Crawfordsville
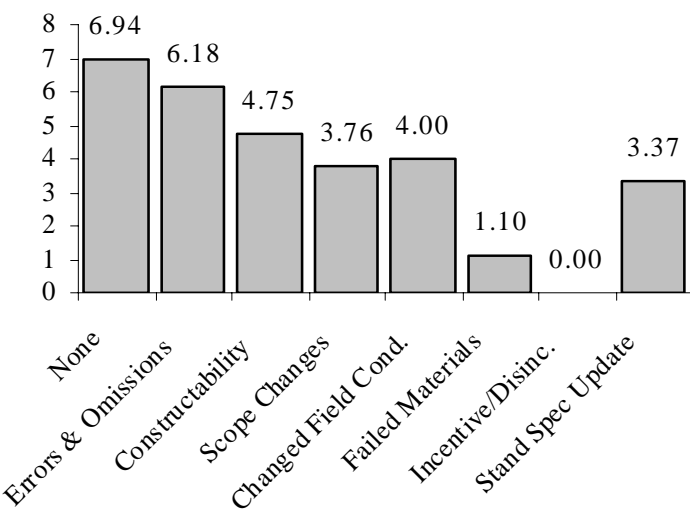

Greenfield

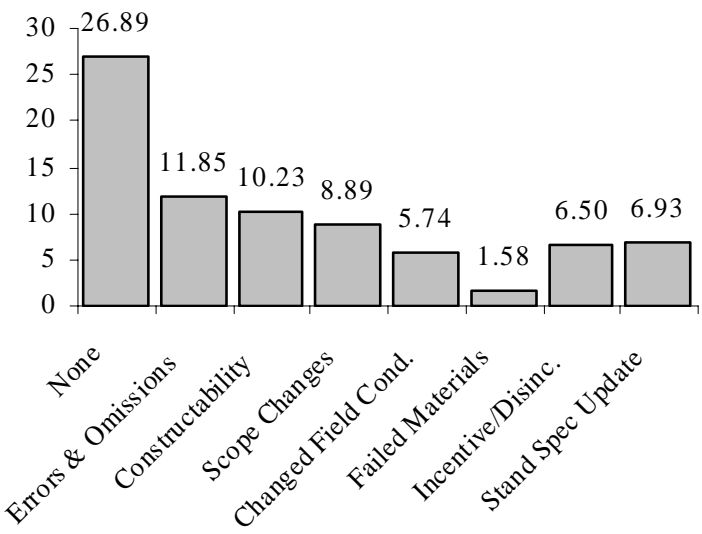

Sey mour

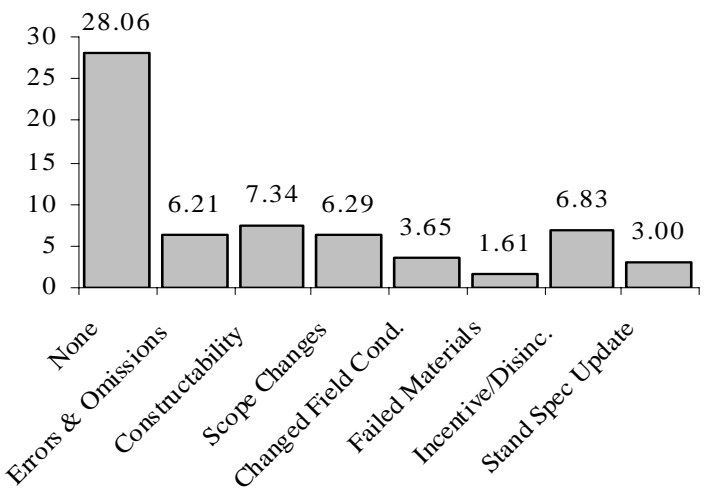

Fortwayne

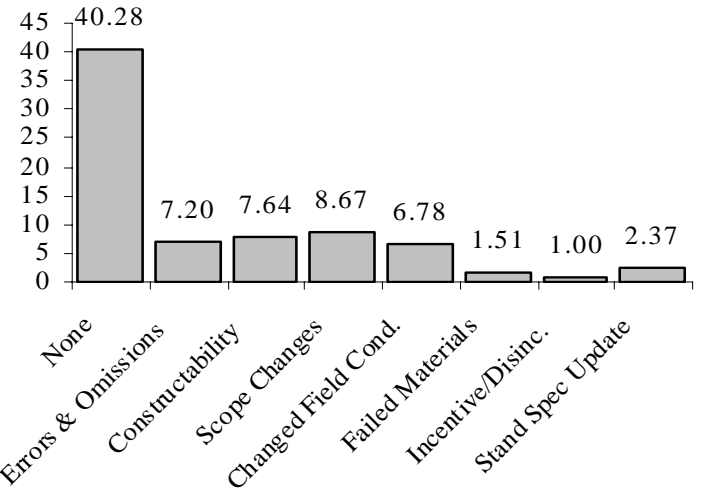

Lap orte

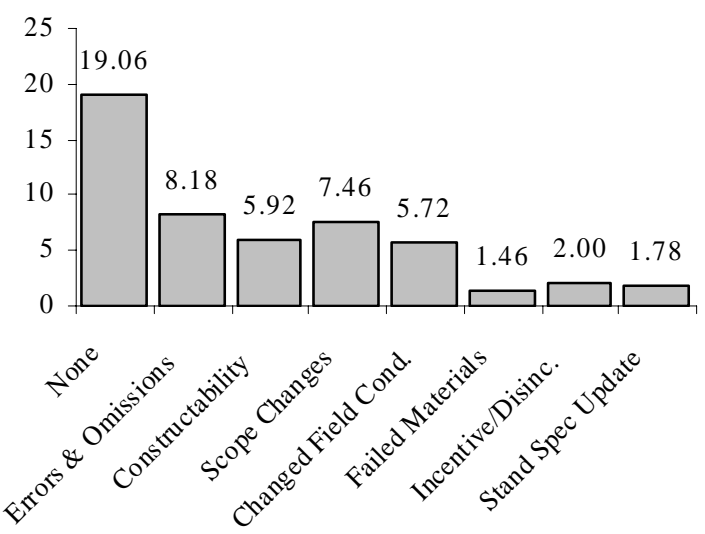

Vincennes

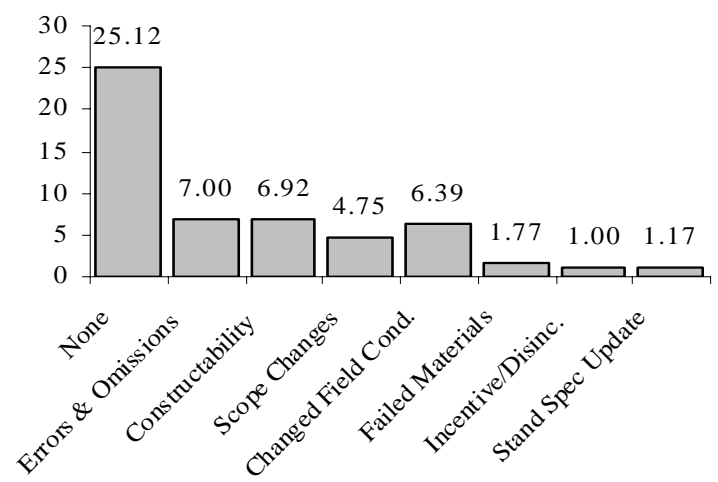

Figure E.21: Distribution of the Average Number of Change Orders by District and by Reason Category 


\section{Appendix E: Additional Descriptive Statistics (Continued)}

Bridge Project
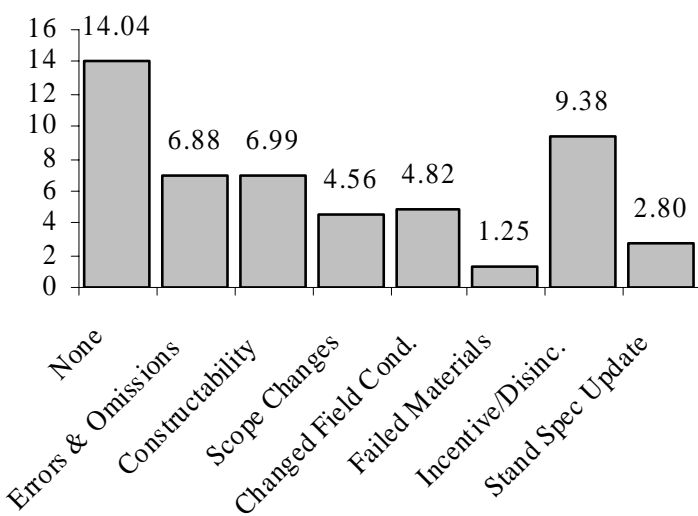

Road Construction Project
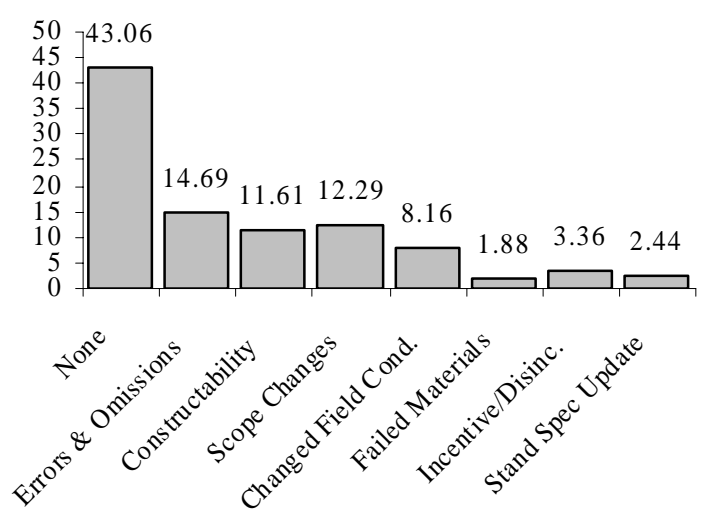

M aintenance Project
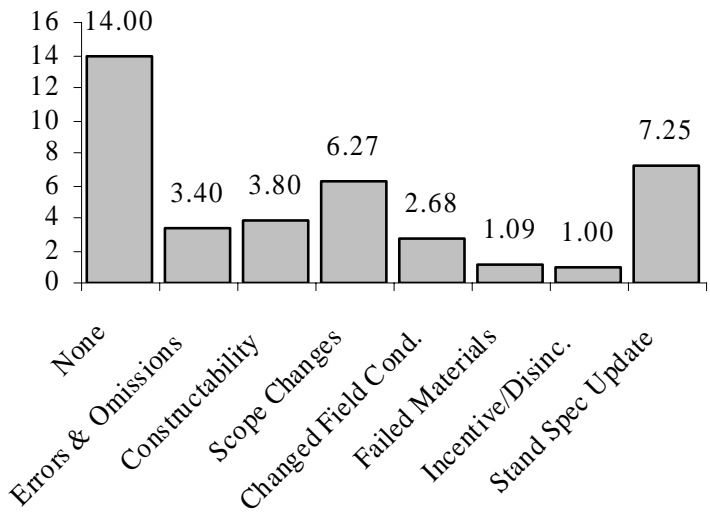

$$
\text { Resurfacing Project }
$$

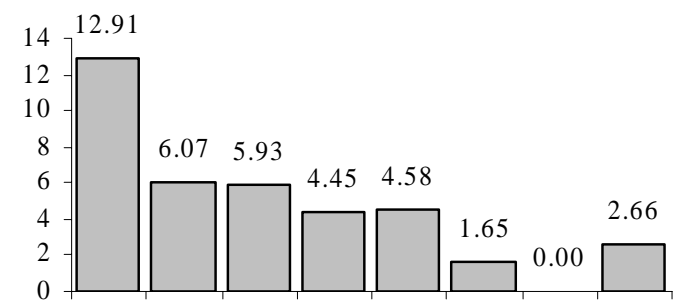

Traffic Project

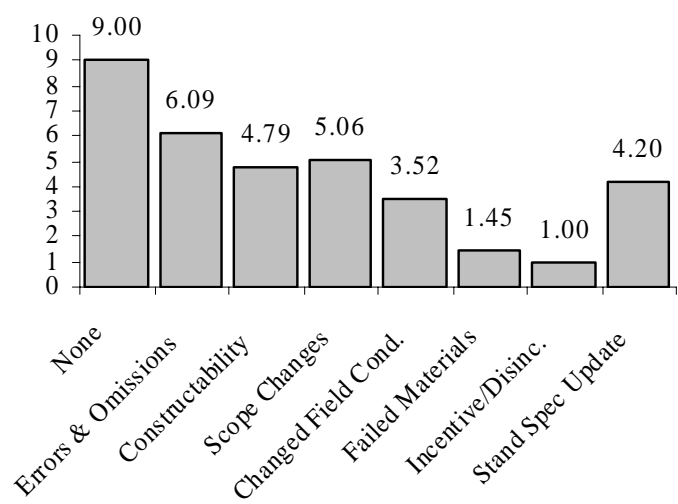

Figure E.22: Distribution of the Average Number of Change Orders by Project Type and by Reason Category 


\section{Appendix F: Statistical Analysis}

Table F.1: Analysis of Means of the Combination of 5 Variables

\begin{tabular}{|c|c|c|c|c|c|c|c|c|c|}
\hline 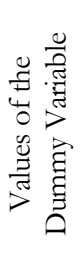 & 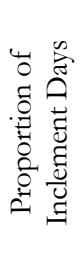 & 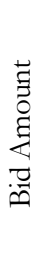 & 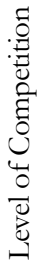 & 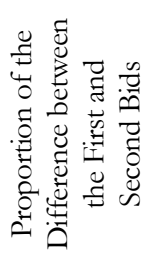 & 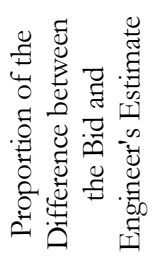 & & 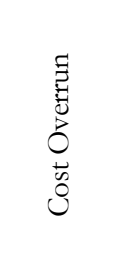 & 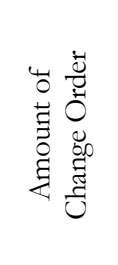 & 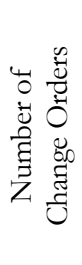 \\
\hline 1 & 1 & 1 & 1 & 1 & 1 & $\begin{array}{c}\text { Mean } \\
\mathrm{N} \\
\text { Std. Deviation }\end{array}$ & $\begin{array}{c}-\$ 4,994 \\
16 \\
\$ 23,529\end{array}$ & $\begin{array}{c}\$ 125,913 \\
16 \\
\$ 208,032\end{array}$ & $\begin{array}{c}28 \\
7 \\
19\end{array}$ \\
\hline 2 & 2 & 1 & 1 & 1 & 1 & $\begin{array}{c}\text { Mean } \\
\mathrm{N} \\
\text { Std. Deviation }\end{array}$ & $\begin{array}{c}\$ 4,715 \\
21 \\
\$ 24,018\end{array}$ & $\begin{array}{c}\$ 107,751 \\
21 \\
\$ 212,482\end{array}$ & $\begin{array}{l}14 \\
10 \\
12\end{array}$ \\
\hline 3 & 1 & 2 & 1 & 1 & 1 & $\begin{array}{c}\text { Mean } \\
\mathrm{N} \\
\text { Std. Deviation }\end{array}$ & $\begin{array}{c}-\$ 180,692 \\
18 \\
\$ 813,479\end{array}$ & $\begin{array}{c}\$ 78,515 \\
18 \\
\$ 91,124\end{array}$ & $\begin{array}{l}19 \\
10 \\
14\end{array}$ \\
\hline 4 & 1 & 1 & 2 & 1 & 1 & $\begin{array}{c}\text { Mean } \\
\mathrm{N} \\
\text { Std. Deviation }\end{array}$ & $\begin{array}{c}\$ 11,079 \\
23 \\
\$ 27,712\end{array}$ & $\begin{array}{c}\$ 89,165 \\
23 \\
\$ 100,679\end{array}$ & $\begin{array}{c}15 \\
6 \\
16\end{array}$ \\
\hline 5 & 1 & 1 & 1 & 2 & 1 & $\begin{array}{c}\text { Mean } \\
\mathrm{N} \\
\text { Std. Deviation }\end{array}$ & $\begin{array}{c}\$ 16,440 \\
14 \\
\$ 77,430\end{array}$ & $\begin{array}{c}\$ 74,981 \\
14 \\
\$ 119,807\end{array}$ & $\begin{array}{c}27 \\
4 \\
18\end{array}$ \\
\hline 6 & 1 & 1 & 1 & 1 & 2 & $\begin{array}{c}\text { Mean } \\
\mathrm{N} \\
\text { Std. Deviation }\end{array}$ & $\begin{array}{c}-\$ 1,749 \\
10 \\
\$ 29,782\end{array}$ & $\begin{array}{c}\$ 103,942 \\
10 \\
\$ 132,293\end{array}$ & $\begin{array}{l}4 \\
3 \\
1\end{array}$ \\
\hline 7 & 2 & 2 & 1 & 1 & 1 & $\begin{array}{c}\text { Mean } \\
\mathrm{N} \\
\text { Std. Deviation }\end{array}$ & $\begin{array}{c}-\$ 61,304 \\
40 \\
\$ 544,241\end{array}$ & $\begin{array}{c}\$ 162,970 \\
40 \\
\$ 367,981\end{array}$ & $\begin{array}{l}31 \\
12 \\
39\end{array}$ \\
\hline 8 & 2 & 1 & 2 & 1 & 1 & $\begin{array}{c}\text { Mean } \\
\mathrm{N} \\
\text { Std. Deviation }\end{array}$ & $\begin{array}{c}\$ 2,997 \\
25 \\
\$ 46,160\end{array}$ & $\begin{array}{c}\$ 257,371 \\
25 \\
\$ 878,659\end{array}$ & $\begin{array}{l}44 \\
12 \\
87\end{array}$ \\
\hline 9 & 2 & 1 & 1 & 2 & 1 & $\begin{array}{c}\text { Mean } \\
\mathrm{N} \\
\text { Std. Deviation }\end{array}$ & $\begin{array}{c}-\$ 16,097 \\
25 \\
\$ 66,673\end{array}$ & $\begin{array}{c}\$ 149,959 \\
25 \\
\$ 269,729\end{array}$ & $\begin{array}{l}18 \\
12 \\
14\end{array}$ \\
\hline 10 & 2 & 1 & 1 & 1 & 2 & $\begin{array}{c}\text { Mean } \\
\mathrm{N} \\
\text { Std. Deviation }\end{array}$ & $\begin{array}{c}-\$ 6,266 \\
14 \\
\$ 43,354\end{array}$ & $\begin{array}{c}\$ 49,812 \\
14 \\
\$ 52,685\end{array}$ & $\begin{array}{l}11 \\
4 \\
8\end{array}$ \\
\hline 11 & 1 & 2 & 2 & 1 & 1 & $\begin{array}{c}\text { Mean } \\
\mathrm{N} \\
\text { Std. Deviation }\end{array}$ & $\begin{array}{c}\$ 88,684 \\
19 \\
\$ 155,447\end{array}$ & $\begin{array}{c}\$ 87,350 \\
19 \\
\$ 121,458\end{array}$ & $\begin{array}{c}21 \\
6 \\
28\end{array}$ \\
\hline
\end{tabular}




\section{Appendix F: Statistical Analysis (continued)}

Table F.2: Analysis of Means of the Combination of 5 Variables (continued)

\begin{tabular}{|c|c|c|c|c|c|c|c|c|c|}
\hline 12 & 1 & 2 & 1 & 2 & 1 & $\begin{array}{c}\text { Mean } \\
\mathrm{N} \\
\text { Std. Deviation }\end{array}$ & $\begin{array}{c}\$ 17,705 \\
13 \\
\$ 125,284\end{array}$ & $\begin{array}{c}\$ 168,835 \\
13 \\
\$ 291,000\end{array}$ & $\begin{array}{c}23 \\
6 \\
24\end{array}$ \\
\hline 13 & 1 & 2 & 1 & 1 & 2 & $\begin{array}{c}\text { Mean } \\
\mathrm{N} \\
\text { Std. Deviation }\end{array}$ & $\begin{array}{c}\$ 27,423 \\
10 \\
\$ 103,725\end{array}$ & $\begin{array}{c}\$ 32,946 \\
10 \\
\$ 47,005\end{array}$ & $\begin{array}{l}3 \\
2 \\
3\end{array}$ \\
\hline 14 & 1 & 1 & 2 & 2 & 1 & $\begin{array}{c}\text { Mean } \\
\mathrm{N} \\
\text { Std. Deviation }\end{array}$ & $\begin{array}{c}\$ 715 \\
8 \\
\$ 14,511\end{array}$ & $\begin{array}{c}\$ 39,338 \\
8 \\
\$ 130,707\end{array}$ & $\begin{array}{c}31 \\
6 \\
33\end{array}$ \\
\hline 15 & 1 & 1 & 2 & 1 & 2 & $\begin{array}{c}\text { Mean } \\
\mathrm{N} \\
\text { Std. Deviation }\end{array}$ & $\begin{array}{c}\$ 9,202 \\
40 \\
\$ 34,037\end{array}$ & $\begin{array}{c}\$ 15,146 \\
40 \\
\$ 27,496\end{array}$ & $\begin{array}{l}11 \\
14 \\
14\end{array}$ \\
\hline 16 & 1 & 1 & 1 & 2 & 2 & $\begin{array}{c}\text { Mean } \\
\mathrm{N} \\
\text { Std. Deviation }\end{array}$ & $\begin{array}{c}-\$ 980 \\
25 \\
\$ 32,747\end{array}$ & $\begin{array}{c}\$ 94,898 \\
25 \\
\$ 359,242\end{array}$ & $\begin{array}{l}6 \\
8 \\
6\end{array}$ \\
\hline 17 & 2 & 2 & 2 & 1 & 1 & $\begin{array}{c}\text { Mean } \\
\mathrm{N} \\
\text { Std. Deviation }\end{array}$ & $\begin{array}{c}\$ 81,090 \\
35 \\
\$ 302,818\end{array}$ & $\begin{array}{c}\$ 56,103 \\
35 \\
\$ 120,501\end{array}$ & $\begin{array}{l}15 \\
16 \\
17\end{array}$ \\
\hline 18 & 2 & 2 & 1 & 2 & 1 & $\begin{array}{c}\text { Mean } \\
\mathrm{N} \\
\text { Std. Deviation }\end{array}$ & $\begin{array}{c}\$ 53,718 \\
20 \\
\$ 141,988\end{array}$ & $\begin{array}{c}\$ 36,825 \\
20 \\
\$ 60,113\end{array}$ & $\begin{array}{l}9 \\
8 \\
7\end{array}$ \\
\hline 19 & 2 & 1 & 2 & 2 & 1 & $\begin{array}{c}\text { Mean } \\
\mathrm{N} \\
\text { Std. Deviation }\end{array}$ & $\begin{array}{c}\$ 7,438 \\
19 \\
\$ 50,019\end{array}$ & $\begin{array}{c}\$ 69,796 \\
19 \\
\$ 134,364\end{array}$ & $\begin{array}{c}32 \\
8 \\
49\end{array}$ \\
\hline 20 & 1 & 2 & 2 & 2 & 1 & $\begin{array}{c}\text { Mean } \\
\mathrm{N} \\
\text { Std. Deviation }\end{array}$ & $\begin{array}{c}\$ 265,718 \\
5 \\
\$ 560,792\end{array}$ & $\begin{array}{c}\$ 140,254 \\
5 \\
\$ 159,312\end{array}$ & $\begin{array}{c}12 \\
2 \\
11\end{array}$ \\
\hline 21 & 2 & 2 & 1 & 1 & 2 & $\begin{array}{c}\text { Mean } \\
\mathrm{N} \\
\text { Std. Deviation }\end{array}$ & $\begin{array}{c}-\$ 38,604 \\
15 \\
\$ 101,747 \\
\end{array}$ & $\begin{array}{c}\$ 151,591 \\
15 \\
\$ 261,754 \\
\end{array}$ & $\begin{array}{r}9 \\
4 \\
11\end{array}$ \\
\hline 22 & 2 & 1 & 2 & 1 & 2 & $\begin{array}{c}\text { Mean } \\
\mathrm{N} \\
\text { Std. Deviation }\end{array}$ & $\begin{array}{c}-\$ 2,239 \\
34 \\
\$ 35,677 \\
\end{array}$ & $\begin{array}{c}\$ 30,314 \\
34 \\
\$ 46,016 \\
\end{array}$ & $\begin{array}{l}10 \\
18 \\
7 \\
\end{array}$ \\
\hline 23 & 1 & 2 & 2 & 1 & 2 & $\begin{array}{c}\text { Mean } \\
\mathrm{N} \\
\text { Std. Deviation }\end{array}$ & $\begin{array}{c}\$ 57,063 \\
12 \\
\$ 232,396\end{array}$ & $\begin{array}{c}-\$ 8,848 \\
12 \\
\$ 86,294\end{array}$ & $\begin{array}{l}4 \\
3 \\
2\end{array}$ \\
\hline 24 & 2 & 1 & 1 & 2 & 2 & $\begin{array}{c}\text { Mean } \\
\mathrm{N} \\
\text { Std. Deviation }\end{array}$ & $\begin{array}{c}-\$ 1,443 \\
17 \\
\$ 30,904\end{array}$ & $\begin{array}{c}\$ 60,082 \\
17 \\
\$ 75,891\end{array}$ & $\begin{array}{c}11 \\
6 \\
19\end{array}$ \\
\hline 25 & 1 & 2 & 1 & 2 & 2 & $\begin{array}{c}\text { Mean } \\
\mathrm{N} \\
\text { Std. Deviation }\end{array}$ & $\begin{array}{c}\$ 184,081 \\
9 \\
\$ 272,348\end{array}$ & $\begin{array}{c}\$ 19,130 \\
9 \\
\$ 40,568\end{array}$ & $\begin{array}{c}11 \\
4 \\
12\end{array}$ \\
\hline
\end{tabular}




\section{Appendix F: Statistical Analysis (continued)}

Table F.3: Analysis of Means of the Combination of 5 Variables (continued)

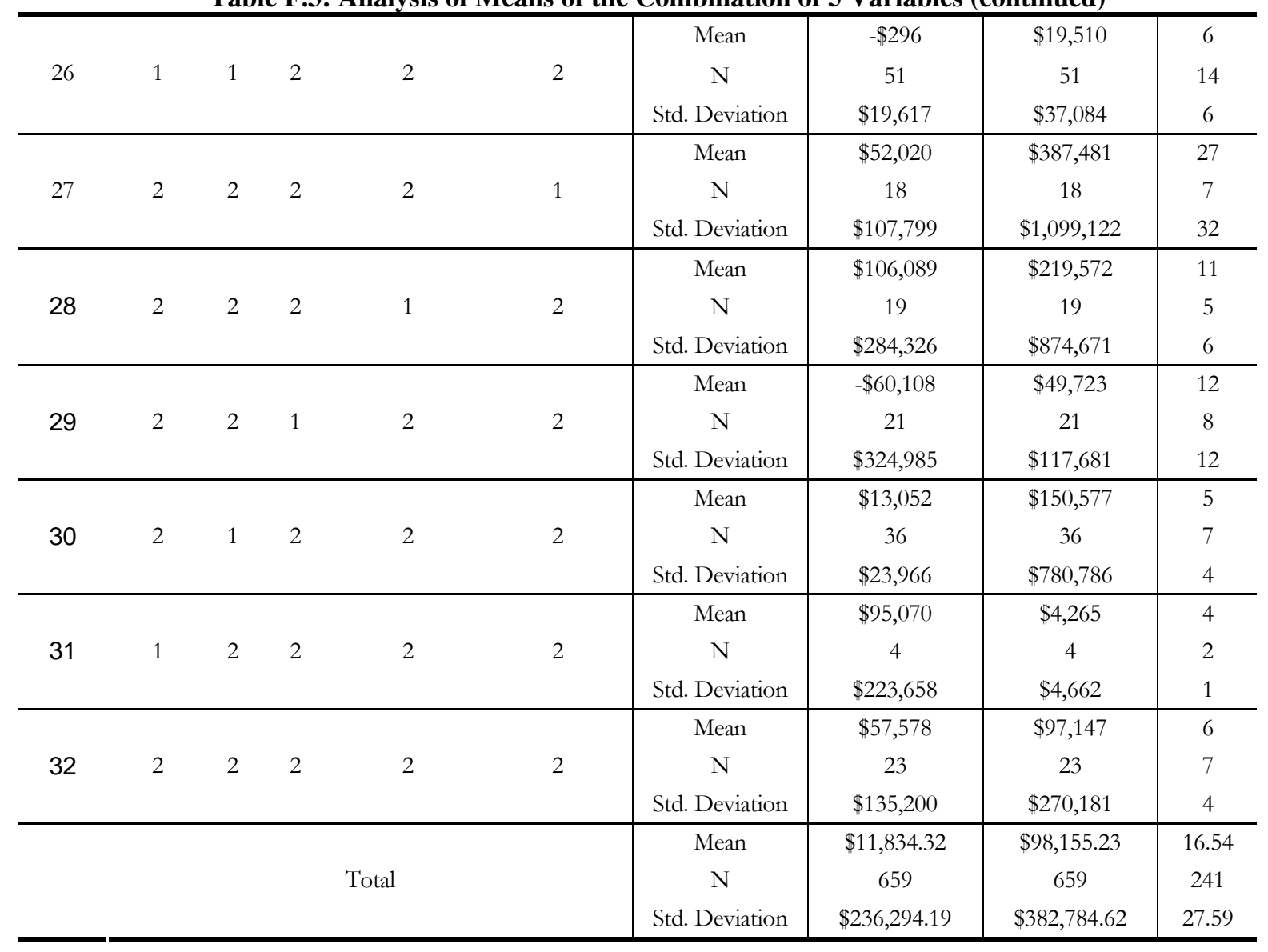

$\mathrm{N}$ : Number of observations 


\section{Appendix F: Statistical Analysis (continued)}

Table F.4: Analysis of Means of the Combination of Three Variables

\begin{tabular}{|c|c|c|c|c|c|c|c|c|}
\hline \multirow{2}{*}{ 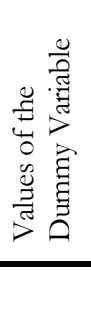 } & \multirow[t]{2}{*}{ 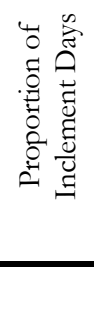 } & \multirow[t]{2}{*}{ 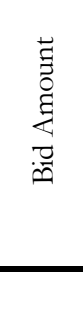 } & \multicolumn{2}{|l|}{ 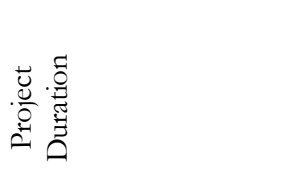 } & \multirow{2}{*}{ 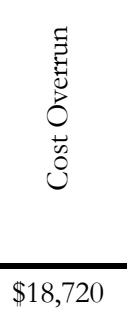 } & \multirow{2}{*}{ 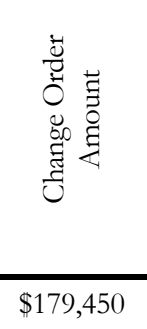 } & \multirow{2}{*}{ 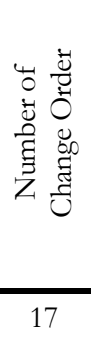 } & \multirow{2}{*}{ 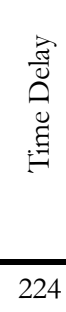 } \\
\hline & & & & Mean & & & & \\
\hline \multirow[t]{3}{*}{1} & 1 & 1 & 1 & $\mathrm{~N}$ & 136 & 136 & 55 & 136 \\
\hline & & & & Std. Deviation & $\$ 60,177$ & $\$ 608,941$ & 26 & 177 \\
\hline & & & & Mean & $\$ 2,276$ & $\$ 90,937$ & 13 & 52 \\
\hline \multirow[t]{3}{*}{2} & 2 & 1 & 1 & $\mathrm{~N}$ & 459 & 459 & 178 & 459 \\
\hline & & & & Std. Deviation & $\$ 29,981$ & $\$ 571,477$ & 17 & 54 \\
\hline & & & & Mean & $\$ 26,483$ & $\$ 80,618$ & 15 & 233 \\
\hline \multirow[t]{3}{*}{3} & 1 & 2 & 1 & $\mathrm{~N}$ & 160 & 160 & 64 & 160 \\
\hline & & & & Std. Deviation & $\$ 173,599$ & $\$ 198,187$ & 16 & 131 \\
\hline & & & & Mean & $\$ 43,463$ & $\$ 267,168$ & 50 & 143 \\
\hline \multirow[t]{3}{*}{4} & 1 & 1 & 2 & $\mathrm{~N}$ & 164 & 164 & 18 & 164 \\
\hline & & & & Std. Deviation & $\$ 215,445$ & $\$ 762,879$ & 37 & 182 \\
\hline & & & & Mean & $\$ 7,984$ & $\$ 124,529$ & 22 & 104 \\
\hline \multirow[t]{3}{*}{5} & 2 & 2 & 1 & $\mathrm{~N}$ & 178 & 178 & 68 & 178 \\
\hline & & & & Std. Deviation & $\$ 249,861$ & $\$ 428,465$ & 25 & 63 \\
\hline & & & & Mean & $-\$ 1,235$ & $\$ 319,306$ & 86 & 7 \\
\hline \multirow[t]{3}{*}{6} & 2 & 1 & 2 & $\mathrm{~N}$ & 177 & 177 & 26 & 177 \\
\hline & & & & Std. Deviation & $\$ 23,773$ & $\$ 1,004,387$ & 100 & 46 \\
\hline & & & & Mean & $\$ 159,903$ & $\$ 280,464$ & 49 & 183 \\
\hline \multirow[t]{3}{*}{7} & 1 & 2 & 2 & $\mathrm{~N}$ & 480 & 480 & 79 & 480 \\
\hline & & & & Std. Deviation & $\$ 626,856$ & $\$ 1,197,695$ & 50 & 199 \\
\hline & & & & Mean & $\$ 36,971$ & $\$ 221,914$ & 41 & 36 \\
\hline \multirow[t]{5}{*}{8} & 2 & 2 & 2 & $\mathrm{~N}$ & 194 & 194 & 22 & 194 \\
\hline & & & & Std. Deviation & $\$ 224,851$ & $\$ 658,118$ & 37 & 69 \\
\hline & & & & Mean & $\$ 51,378$ & $\$ 194,670$ & 27 & 118 \\
\hline & & Total & & $\mathrm{N}$ & 1948 & 1948 & 510 & 1948 \\
\hline & & & & Std. Deviation & $\$ 343,901$ & $\$ 816,090$ & 41 & 154 \\
\hline
\end{tabular}




\section{Appendix F: Statistical Analysis (continued)}

Table F.5: Pair-wise Comparison of Cost Overrun by Bid Amount

\begin{tabular}{cc|cc|c}
\hline \multicolumn{2}{c|}{ Low Bid Amount Contracts } & \multicolumn{2}{|c|}{ High Bid Amount Contracts } & \multirow{2}{*}{$\mathrm{x}=\mathrm{CO}_{\text {highbid }}-\mathrm{CO}_{\text {low bid }}$} \\
\cline { 1 - 3 } Inclement Days & Cost Overrun & Inclement Days & \multicolumn{1}{c}{ Cost overrun } & \\
\hline 0.00 & $\$ 37,930$ & 0.01 & $\$ 2,824,638$ & $\$ 2,786,708$ \\
\hline 0.05 & $\$ 73,446$ & 0.04 & $\$ 3,677,451$ & $\$ 3,604,005$ \\
\hline 0.08 & $\$ 299,875$ & 0.07 & $\$ 514,309$ & $\$ 214,435$ \\
\hline 0.08 & $\$ 53,415$ & 0.07 & $\$ 514,309$ & $\$ 460,894$ \\
\hline 0.09 & $\$ 164,567$ & 0.07 & $\$ 514,309$ & $\$ 349,742$ \\
\hline 0.12 & $\$ 26,250$ & 0.13 & $\$ 632,958$ & $\$ 606,708$ \\
\hline 0.13 & $\$ 25,000$ & 0.13 & $\$ 1,251,777$ & $\$ 1,226,777$ \\
\hline 0.14 & $\$ 56,800$ & 0.14 & $\$ 3,774,226$ & $\$ 3,717,426$ \\
\hline 0.27 & $\$ 91,740$ & 0.22 & $\$ 449,190$ & $\$ 357,450$ \\
\hline 0.28 & $\$ 100,552$ & 0.23 & $\$ 650,905$ & $\$ 550,353$ \\
\hline 0.28 & $\$ 154,500$ & 0.23 & $\$ 1,525,794$ & $\$ 1,371,294$ \\
\hline 0.30 & $\$ 326,754$ & 0.33 & $\$ 2,207,406$ & $\$ 1,880,652$ \\
\hline 0.31 & $\$ 93,220$ & 0.33 & $\$ 2,207,406$ & $\$ 2,114,186$ \\
\hline 0.32 & $\$ 19,834$ & 0.33 & $\$ 2,207,406$ & $\$ 2,187,572$ \\
\hline 0.32 & $\$ 60,000$ & 0.33 & $\$ 2,207,406$ & $\$ 2,147,406$ \\
\hline 0.32 & $\$ 60,025$ & 0.33 & $\$ 2,207,406$ & $\$ 2,147,381$ \\
\hline 0.33 & $\$ 157,778$ & 0.33 & $\$ 2,207,406$ & $\$ 2,049,628$ \\
\hline 0.37 & $\$ 51,355$ & 0.36 & $\$ 384,796$ & $\$ 333,441$ \\
\hline 0.38 & $\$ 92,233$ & 0.38 & $\$ 1,083,608$ & $\$ 991,376$ \\
\hline 0.39 & $\$ 66,329$ & 0.38 & $\$ 1,083,608$ & $\$ 1,017,279$ \\
\hline 0.42 & $\$ 333,718$ & 0.42 & $\$ 1,990,781$ & $\$ 1,657,063$ \\
\hline
\end{tabular}

$S_{x}=\sqrt{\frac{1}{n-1} \sum(x-\bar{x})^{2}}=1873888.42$

$\mathrm{n}=21$

$\bar{x}=\$ 1,512,942$

t-stat $=3.7$

$t_{(0.05,20)}=2.09$

|t-stat $\mid$ is greater than $t_{(0.05,20)}$, so the hypothesis $\mathrm{H}_{0}: \mu_{\mathrm{A}}-\mu_{\mathrm{B}}=0$ is rejected. 


\section{Appendix F: Statistical Analysis (continued)}

Table F.6: Pair-wise Comparison of Time Delay by Bid Amount

\begin{tabular}{|c|c|c|c|c|}
\hline \multicolumn{2}{|c|}{ Low Bid Amount Contracts } & \multicolumn{2}{|c|}{ High Bid Amount Contracts } & \multirow{2}{*}{$\mathrm{x}=\mathrm{TD}_{\text {highbid }}-\mathrm{TD}_{\text {low bid }}$} \\
\hline Duration & Time Delay & Duration & Time Delay & \\
\hline 30 & 168 & 30 & 136 & -32 \\
\hline 50 & 161 & 50 & 180 & 19 \\
\hline 59 & 166 & 55 & 57 & -109 \\
\hline 60 & 208 & 65 & 238 & 30 \\
\hline 76 & 118 & 70 & 70 & -48 \\
\hline 76 & 118 & 70 & 298 & 180 \\
\hline 76 & 118 & 75 & 101 & -17 \\
\hline 76 & 118 & 75 & 323 & 205 \\
\hline 76 & 118 & 75 & 117 & -1 \\
\hline 83 & 520 & 80 & 252 & -268 \\
\hline 95 & 426 & 100 & 192 & -234 \\
\hline 110 & 70 & 110 & 128 & 58 \\
\hline 112 & 13 & 120 & 283 & 270 \\
\hline 129 & 180 & 123 & 111 & -69 \\
\hline 129 & 180 & 131 & 38 & -142 \\
\hline 129 & 180 & 131 & 53 & -127 \\
\hline 129 & 180 & 136 & 112 & -68 \\
\hline 129 & 180 & 140 & 11 & -169 \\
\hline 129 & 180 & 142 & 105 & -75 \\
\hline 129 & 180 & 143 & 39 & -141 \\
\hline 205 & 41 & 160 & 518 & 477 \\
\hline 205 & 41 & 168 & 143 & 102 \\
\hline 205 & 41 & 185 & 133 & 92 \\
\hline 205 & 41 & 218 & 82 & 41 \\
\hline 236 & 13 & 221 & 41 & 28 \\
\hline 236 & 13 & 261 & 298 & 285 \\
\hline 236 & 13 & 266 & 31 & 18 \\
\hline 418 & 380 & 521 & 473 & 93 \\
\hline 418 & 380 & 544 & 137 & -243 \\
\hline
\end{tabular}

$s_{x}=\sqrt{\frac{1}{n-1} \sum(x-\bar{x})^{2}}=168.17$

$\mathrm{n}=29$

$\bar{x}=5.34$

$\mathrm{t}$-stat $=0.17$

$t_{(0.05,28)}=2.05$

|t-stat $\mid$ is not greater than $t_{(0.05,28)}$, so the hypothesis $H_{0}: \mu_{A}-\mu_{B}=0$ cannot be rejected. 


\section{Appendix F: Statistical Analysis (continued)}

Table F.7: Pair-wise Comparison of Number of Change Orders by Bid Amount

\begin{tabular}{cc|cc|c}
\hline \multicolumn{2}{c|}{ Low Bid Amount Contracts } & \multicolumn{2}{c|}{ High Bid Amount Contracts } \\
$\begin{array}{c}\text { Proportion of } \\
\text { Inclement Days }\end{array}$ & $\begin{array}{c}\text { Number of } \\
\text { Change Orders }\end{array}$ & $\begin{array}{c}\text { Proportion of } \\
\text { Inclement Days }\end{array}$ & $\begin{array}{c}\text { Number of } \\
\text { Change Orders }\end{array}$ & \\
\hline 0.12 & 5 & 0.03 & 17 & 12 \\
\hline 0.14 & 4 & 0.04 & 40 & 36 \\
\hline 0.28 & 49 & 0.18 & 9 & -40 \\
\hline 0.31 & 25 & 0.34 & 44 & 19 \\
\hline 0.32 & 17 & 0.34 & 44 & 27 \\
\hline 0.32 & 25 & 0.34 & 44 & 19 \\
\hline 0.37 & 48 & 0.35 & 16 & -32 \\
\hline 0.38 & 7 & 0.47 & 26 & 19 \\
\hline
\end{tabular}

$s_{x}=\sqrt{\frac{1}{n-1} \sum(x-\bar{x})^{2}}=28.97, \mathrm{n}=8, \bar{x}=7.5, \mathrm{t}$-stat $=10.93, t_{(0.05,7)}=2.37, \mid \mathrm{t}$-stat $\mid$ is greater than $\mathrm{t}$, so the hypothesis $\mathrm{H}_{0}: \mu_{\mathrm{A}}-\mu_{\mathrm{B}}=0$ is rejected

Table F.8: Pair-wise Comparison of Time Delay by Duration

\begin{tabular}{cc|cc|c}
\hline \multicolumn{2}{c|}{ Low Duration Contracts } & \multicolumn{2}{|c|}{ High Duration Contracts } & \multirow{2}{*}{$\mathrm{x}=\mathrm{TD}_{\text {high dur }}-\mathrm{TD}_{\text {low dur }}$} \\
\cline { 1 - 3 } Bid Amount & Time Delay & Bid Amount & Time Delay & \\
\hline$\$ 60,025$ & 70 & $\$ 60,000$ & 13 & -57 \\
\hline$\$ 73,446$ & 229 & $\$ 66,329$ & 13 & -216 \\
\hline$\$ 157,778$ & 208 & $\$ 154,500$ & 180 & -28 \\
\hline$\$ 164,567$ & 161 & $\$ 154,500$ & 180 & 19 \\
\hline$\$ 333,718$ & 166 & $\$ 326,754$ & 41 & -125 \\
\hline$\$ 349,815$ & 136 & $\$ 355,749$ & 38 & -98 \\
\hline$\$ 370,789$ & 252 & $\$ 376,075$ & 31 & -221 \\
\hline$\$ 384,796$ & 70 & $\$ 376,075$ & 31 & -39 \\
\hline$\$ 632,958$ & 180 & $\$ 514,309$ & 112 & -68 \\
\hline$\$ 1,157,880$ & 238 & $\$ 650,905$ & 53 & -185 \\
\hline$\$ 1,329,502$ & 323 & $\$ 1,083,608$ & 11 & -312 \\
\hline$\$ 1,378,000$ & 192 & $\$ 1,251,777$ & 283 & 91 \\
\hline$\$ 1,990,780.79$ & 117 & $\$ 1,525,794$ & 41 & -76 \\
\hline$\$ 2,207,405.80$ & 57 & $\$ 1,800,395.70$ & 143 & 86 \\
\hline$\$ 2,268,327.80$ & 298 & $\$ 2,824,638.16$ & 518 & 390 \\
\hline
\end{tabular}

$s_{x}=\sqrt{\frac{1}{n-1} \sum(x-\bar{x})^{2}}=179.78$

$\mathrm{n}=16, \bar{x}=-38.69, \mathrm{t}$-stat $=-0.86, \mathrm{t}_{(0.05,15)}=2.13$

|t-stat $\mid$ is not greater than $t_{(0.05,15)}$, so it shows that in these conditions, the hypothesis cannot be rejected. 


\section{Appendix F: Statistical Analysis (continued)}

Table F.9: Pair-wise Comparison of Cost Overrun by Proportion of Inclement Weather Days

\begin{tabular}{|c|c|c|c|c|}
\hline \multicolumn{2}{|c|}{ Low Proportion of Inclement Days Contracts } & \multicolumn{2}{|c|}{ High Proportion of Inclement Days Contracts } & \multirow{2}{*}{$\mathrm{x}=\mathrm{CO}_{\text {high prop }}-\mathrm{CO}_{\text {low prop }}$} \\
\hline Bid Amount & Cost Overrun & Bid Amount & Cost Overrun & \\
\hline$\$ 25,000$ & $\$ 23,500$ & $\$ 20,000$ & $-\$ 1,458$ & $-\$ 24,958$ \\
\hline$\$ 26,250$ & $\$ 1,609$ & $\$ 20,000$ & $-\$ 1,458$ & $-\$ 3,067$ \\
\hline$\$ 37,930$ & $\$ 55,560$ & $\$ 33,800$ & $\$ 0$ & $-\$ 55,560$ \\
\hline$\$ 53,415$ & $\$ 53,415$ & $\$ 54,574$ & $\$ 377$ & $-\$ 53,038$ \\
\hline$\$ 56,800$ & $\$ 56,800$ & $\$ 56,579$ & $-\$ 2,307$ & $-\$ 59,107$ \\
\hline$\$ 73,446$ & $\$ 147$ & $\$ 70,773$ & $-\$ 9,635$ & $-\$ 9,782$ \\
\hline$\$ 164,567$ & $-\$ 2,247$ & $\$ 157,778$ & $-\$ 3,839$ & $-\$ 1,592$ \\
\hline$\$ 299,875$ & $\$ 163,271$ & $\$ 298,348$ & $-\$ 36,815$ & $-\$ 200,086$ \\
\hline$\$ 370,789$ & $-\$ 13,598$ & $\$ 376,075$ & $\$ 14,064$ & $\$ 27,662$ \\
\hline$\$ 449,190$ & $-\$ 3,213$ & $\$ 494,637$ & $\$ 49,522$ & $\$ 52,735$ \\
\hline$\$ 514,309$ & $\$ 27,095$ & $\$ 563,805$ & $\$ 121,273$ & $\$ 94,178$ \\
\hline$\$ 632,958$ & $\$ 24,563$ & $\$ 664,860$ & $\$ 134,268$ & $\$ 109,705$ \\
\hline$\$ 650,905$ & $\$ 724$ & $\$ 664,860$ & $\$ 134,268$ & $\$ 133,544$ \\
\hline$\$ 709,989$ & $\$ 57,704$ & $\$ 683,060$ & $-\$ 54,108$ & $-\$ 111,812$ \\
\hline$\$ 1,157,880$ & $\$ 121,108$ & $\$ 1,221,284$ & $\$ 31,697$ & $-\$ 89,411$ \\
\hline$\$ 1,251,777$ & $\$ 56,448$ & $\$ 1,221,284$ & $\$ 31,697$ & $-\$ 24,751$ \\
\hline$\$ 1,329,502$ & $\$ 161,027$ & $\$ 1,294,730$ & $\$ 79,242$ & $-\$ 81,785$ \\
\hline$\$ 1,525,794$ & $\$ 166,319$ & $\$ 1,765,197$ & $\$ 52,440$ & $-\$ 113,879$ \\
\hline$\$ 1,800,396$ & $\$ 280,388$ & $\$ 1,765,197$ & $\$ 52,440$ & $-\$ 227,948$ \\
\hline$\$ 1,863,220$ & $\$ 33,253$ & $\$ 1,990,781$ & $-\$ 299,693$ & $-\$ 332,945$ \\
\hline$\$ 2,268,328$ & $-\$ 603,942$ & $\$ 2,135,460$ & $\$ 97,522$ & $\$ 701,464$ \\
\hline$\$ 2,824,638$ & $\$ 738,290$ & $\$ 2,878,030$ & $-\$ 794,847$ & $-\$ 1,533,137$ \\
\hline
\end{tabular}

$$
\begin{aligned}
& s_{x}=\sqrt{\frac{1}{n-1} \sum(x-\bar{x})^{2}}=\$ 386,596 \\
& \mathrm{n}=22 \\
& \bar{x}=-\$ 81,980.60 \\
& \mathrm{t} \text {-stat }=-0.99 \\
& t_{(0.05,21)}=2.08
\end{aligned}
$$

|t-stat $\mid$ is not greater than $t_{(0.05,21)}$, so the hypothesis $H_{0}: \mu_{A}-\mu_{B}=0$ cannot be rejected. 


\section{Appendix F: Statistical Analysis (continued)}

Table F.10: Pair-wise Comparison of Time Delay by Proportion of Inclement Weather Days

\begin{tabular}{|c|c|c|c|c|}
\hline \multicolumn{2}{|c|}{ Low Proportion of Inclement Days Contracts } & \multicolumn{2}{|c|}{ High Proportion of Inclement Days Contracts } & \multirow{2}{*}{$\mathrm{x}=\mathrm{TD}_{\text {high prop }}-\mathrm{TD}_{\text {low prop }}$} \\
\hline Bid Amount & Time Delay & Bid Amount & Time Delay & \\
\hline$\$ 25,000$ & 894 & $\$ 20,000$ & -36 & -930 \\
\hline$\$ 26,250$ & 118 & $\$ 33,800$ & 118 & 0 \\
\hline$\$ 53,415$ & 520 & $\$ 54,574$ & -65 & -585 \\
\hline$\$ 56,800$ & 426 & $\$ 56,579$ & 36 & -390 \\
\hline$\$ 73,446$ & 229 & $\$ 70,773$ & 9 & -220 \\
\hline$\$ 164,567$ & 161 & $\$ 157,778$ & 208 & 47 \\
\hline$\$ 299,875$ & 380 & $\$ 298,348$ & 17 & -363 \\
\hline$\$ 370,789$ & 252 & $\$ 376,075$ & 31 & -221 \\
\hline$\$ 449,190$ & 180 & $\$ 494,637$ & -2 & -182 \\
\hline$\$ 514,309$ & 112 & $\$ 494,637$ & -2 & -114 \\
\hline$\$ 632,958$ & 238 & $\$ 664,860$ & 149 & -89 \\
\hline$\$ 650,905$ & 53 & $\$ 664,860$ & 149 & 96 \\
\hline$\$ 709,989$ & 82 & $\$ 683,060$ & 105 & 23 \\
\hline$\$ 1,157,880$ & 323 & $\$ 1,221,284$ & -7 & -330 \\
\hline$\$ 1,251,777$ & 283 & $\$ 1,221,284$ & -7 & -290 \\
\hline$\$ 1,329,502$ & 192 & $\$ 1,294,730$ & -34 & -226 \\
\hline$\$ 1,525,794$ & 41 & $\$ 1,378,000$ & 117 & 76 \\
\hline$\$ 1,800,396$ & 143 & $\$ 1,765,197$ & 111 & -32 \\
\hline$\$ 2,268,328$ & 298 & $\$ 2,207,406$ & 128 & -170 \\
\hline$\$ 2,824,638$ & 518 & $\$ 2,207,406$ & 128 & -390 \\
\hline
\end{tabular}

$s_{x}=\sqrt{\frac{1}{n-1} \sum(x-\bar{x})^{2}}=331.35$

$\mathrm{n}=20$

$\bar{x}=-214.5$

$\mathrm{t}$-stat $=-2.89$

$t_{(0.05,19)}=2.09$

|t-stat $\mid$ is greater than $t_{(0.05,19)}$, so the hypothesis $\mathrm{H}_{0}: \mu_{\mathrm{A}}-\mu_{\mathrm{B}}=0$ is rejected. 


\section{Appendix F: Statistical Analysis (continued)}

Table F.11: Pair-wise Comparison of Cost Overrun by Level of Competition

\begin{tabular}{|c|c|c|c|c|}
\hline \multicolumn{2}{|c|}{ Low Level of Competition Contracts } & \multicolumn{2}{|c|}{ High Level of Competition Contracts } & \multirow{2}{*}{$\mathrm{x}=\mathrm{CO}_{\text {high lev }}-\mathrm{CO}_{\text {low lev }}$} \\
\hline Bid Amount & Cost Overrun & Bid Amount & Cost Overrun & \\
\hline$\$ 47,438$ & $\$ 1,525$ & $\$ 45,897$ & $-\$ 6$ & $-\$ 1,531$ \\
\hline$\$ 68,966$ & $-\$ 18,852$ & $\$ 68,184$ & $-\$ 3,052$ & $\$ 15,800$ \\
\hline$\$ 87,716$ & $-\$ 1,484$ & $\$ 83,469$ & $\$ 4,685$ & $\$ 6,169$ \\
\hline$\$ 95,535$ & $-\$ 1,297$ & $\$ 109,627$ & $-\$ 38,841$ & $-\$ 37,544$ \\
\hline$\$ 158,719$ & $-\$ 13,535$ & $\$ 160,800$ & $\$ 9,339$ & $\$ 22,874$ \\
\hline$\$ 218,861$ & $\$ 36,172$ & $\$ 230,150$ & $\$ 12,296$ & $-\$ 23,876$ \\
\hline$\$ 275,696$ & $\$ 36,495$ & $\$ 278,815$ & $\$ 27,313$ & $-\$ 9,181$ \\
\hline$\$ 289,775$ & $-\$ 3,215$ & $\$ 293,961$ & $-\$ 2,232$ & $\$ 983$ \\
\hline$\$ 321,111$ & $-\$ 31,466$ & $\$ 324,002$ & $-\$ 17,244$ & $\$ 14,222$ \\
\hline$\$ 333,063$ & $-\$ 333,063$ & $\$ 351,705$ & $\$ 65,842$ & $\$ 398,905$ \\
\hline$\$ 787,791$ & $\$ 8,424$ & $\$ 784,892$ & $\$ 8,991$ & $\$ 567$ \\
\hline$\$ 799,830.07$ & $\$ 58,373$ & $\$ 784,892$ & $\$ 8,991$ & $-\$ 49,382$ \\
\hline$\$ 844,536.42$ & $\$ 50,475$ & $\$ 784,892$ & $\$ 8,991$ & $-\$ 41,484$ \\
\hline$\$ 954,261.25$ & $\$ 150,902$ & $\$ 914,029$ & $\$ 101,152$ & $-\$ 49,750$ \\
\hline$\$ 1,210,478.00$ & $\$ 341,522$ & $\$ 1,135,999$ & $-\$ 8,244$ & $-\$ 349,766$ \\
\hline$\$ 1,345,130.20$ & $\$ 185,325$ & $\$ 1,135,999$ & $-\$ 8,244$ & $-\$ 193,569$ \\
\hline$\$ 1,659,635.91$ & $-\$ 7,719$ & $\$ 1,553,340$ & $\$ 135,908$ & $\$ 143,627$ \\
\hline$\$ 2,398,743.45$ & $\$ 262,411$ & $\$ 2,490,470$ & $\$ 316,622$ & $\$ 54,211$ \\
\hline$\$ 2,559,114.38$ & $-\$ 41,544$ & $\$ 2,490,470$ & $\$ 316,622$ & $\$ 358,166$ \\
\hline
\end{tabular}

$s_{x}=\sqrt{\frac{1}{n-1} \sum(x-\bar{x})^{2}}=\$ 163,384$

$\mathrm{n}=19$

$\bar{x}=\$ 13,655$

t-stat $=0.364$

$t_{(0.05,18)}=2.1$

|t-stat $\mid$ is not greater than $t_{(0.05,18)}$, so the hypothesis $\mathrm{H}_{0}: \mu_{\mathrm{A}}-\mu_{\mathrm{B}}=0$ cannot be rejected. 


\section{Appendix F: Statistical Analysis (continued)}

Table F.12: Pair-wise Comparison of Number of Change Orders by Level of Competition

\begin{tabular}{|c|c|c|c|c|}
\hline \multicolumn{2}{|c|}{ High Level of Competition Contracts } & \multicolumn{2}{|c|}{ Low Level of Competition Contracts } & \multirow{2}{*}{$\mathrm{x}=\mathrm{ChO}_{\text {high lev }}-\mathrm{ChO}_{\text {low lev }}$} \\
\hline Bid Amount & Number of Change Orders & Bid Amount & Number of Change Orders & \\
\hline$\$ 47,438$ & 22 & $\$ 52,250$ & 3 & -19 \\
\hline$\$ 68,966$ & 59 & $\$ 68,184$ & 3 & -56 \\
\hline$\$ 158,719$ & 16 & $\$ 181,518$ & 7 & -9 \\
\hline$\$ 218,861$ & 37 & $\$ 243,870$ & 21 & -16 \\
\hline$\$ 275,696$ & 58 & $\$ 293,961$ & 12 & -46 \\
\hline$\$ 289,775$ & 18 & $\$ 293,961$ & 12 & -6 \\
\hline$\$ 333,063$ & 10 & $\$ 351,705$ & 28 & 18 \\
\hline$\$ 1,210,478$ & 10 & $\$ 1,099,659$ & 9 & -1 \\
\hline$\$ 1,659,636$ & 16 & $\$ 1,553,340$ & 2 & -14 \\
\hline$\$ 2,559,114$ & 60 & $\$ 2,490,470$ & 36 & -24 \\
\hline
\end{tabular}

$s_{x}=\sqrt{\frac{1}{n-1} \sum(x-\bar{x})^{2}}=28.05$

$\mathrm{n}=10$

$\bar{x}=-17.3$

t-stat $=-1.95$

$t_{(0.05,9)}=2.26$

|t-stat $\mid$ is not greater than $t_{(0.05,9)}$, so the hypothesis $\mathrm{H}_{0}: \mu_{\mathrm{A}}-\mu_{\mathrm{B}}=0$ cannot be rejected. 


\section{Appendix F: Statistical Analysis (continued)}

Table F.13: Pair-wise Comparison of Cost Overrun by Proportion of the Difference between the First and Second Bid

\begin{tabular}{|c|c|c|c|c|}
\hline \multicolumn{2}{|c|}{ Low First and Second Contracts } & \multicolumn{2}{|c|}{ High First and Second Contracts } & \multirow{2}{*}{$\mathrm{x}=\mathrm{CO}_{\text {high prop }}-\mathrm{CO}_{\text {low prop }}$} \\
\hline Bid Amount & Cost Overrun & Bid Amount & Cost Overrun & \\
\hline$\$ 47,438$ & $\$ 1,525$ & $\$ 51,205$ & $\$ 2,4612$ & $\$ 936$ \\
\hline$\$ 95,535$ & $-\$ 1,297$ & $\$ 87,716$ & $-\$ 1,484$ & $-\$ 187$ \\
\hline$\$ 148,767$ & $-\$ 23,065$ & $\$ 125,290$ & $\$ 0$ & $\$ 23,065$ \\
\hline$\$ 171,375$ & $-\$ 9,092$ & $\$ 176,181$ & $\$ 11,203$ & $\$ 20,294$ \\
\hline$\$ 206,323$ & $\$ 14,805$ & $\$ 196,405$ & $-\$ 12,628$ & $-\$ 27,433$ \\
\hline$\$ 212,894$ & $-\$ 13,692$ & $\$ 218,861$ & $\$ 36,172$ & $\$ 49,863$ \\
\hline$\$ 221,854$ & $-\$ 3,586$ & $\$ 218,861$ & $\$ 36,172$ & $\$ 39,758$ \\
\hline$\$ 281,325$ & $\$ 86,699$ & $\$ 274,696$ & $-\$ 21,712$ & $-\$ 108,411$ \\
\hline$\$ 289,775$ & $-\$ 3,215$ & $\$ 297,000$ & $-\$ 160$ & $\$ 3,055$ \\
\hline$\$ 351,977$ & $\$ 6,258$ & $\$ 333,063$ & $-\$ 333,063$ & $-\$ 339,320$ \\
\hline$\$ 354,737$ & $-\$ 14,237$ & $\$ 333,063$ & $-\$ 333,063$ & $-\$ 318,825$ \\
\hline$\$ 374,321$ & $\$ 8,424$ & $\$ 333,063$ & $-\$ 333,062$ & $-\$ 341,487$ \\
\hline$\$ 397,842$ & $-\$ 23,099$ & $\$ 406,470$ & $-\$ 56,557$ & $-\$ 33,458$ \\
\hline$\$ 415,480$ & $-\$ 93,293$ & $\$ 406,470$ & $-\$ 56,557$ & $\$ 36,736$ \\
\hline$\$ 595,304$ & $\$ 63,6134$ & $\$ 570,247$ & $-\$ 8,959$ & $-\$ 72,572$ \\
\hline$\$ 687,444$ & $-\$ 13,226$ & $\$ 665,551$ & $\$ 6,353$ & $\$ 19,579$ \\
\hline$\$ 690,314$ & $-\$ 42,846$ & $\$ 665,551$ & $\$ 6,353$ & $\$ 49,199$ \\
\hline$\$ 777,922$ & $\$ 14,711$ & $\$ 787,791$ & $\$ 8,424$ & $-\$ 6,287$ \\
\hline$\$ 788,912$ & $\$ 27,283$ & $\$ 787,791$ & $\$ 8,424$ & $-\$ 18,859$ \\
\hline$\$ 859,312$ & $\$ 77,554$ & $\$ 844,536$ & $\$ 50,475$ & $-\$ 27,078$ \\
\hline$\$ 869,273$ & $-\$ 180,615$ & $\$ 844,536$ & $\$ 50,475$ & $\$ 231,090$ \\
\hline$\$ 896,017$ & $-\$ 2,483$ & $\$ 924,815$ & $-\$ 181,869$ & $-\$ 179,386$ \\
\hline$\$ 1,308,800$ & $-\$ 35,393$ & $\$ 1,250,449$ & $\$ 216,030$ & $\$ 251,423$ \\
\hline$\$ 1,345,130$ & $\$ 185,325$ & $\$ 1,360,891$ & $\$ 30,612$ & $-\$ 154,712$ \\
\hline$\$ 1,564,035$ & $\$ 605,794$ & $\$ 1,579,812$ & $\$ 221,319$ & $-\$ 384,475$ \\
\hline$\$ 1,605,823$ & $-\$ 112,336$ & $\$ 1,579,812$ & $\$ 221,319$ & $\$ 333,655$ \\
\hline$\$ 2,398,743$ & $\$ 262,411$ & $\$ 2,559,114$ & $-\$ 41,544$ & $-\$ 303,956$ \\
\hline$\$ 5,589,000$ & $\$ 386,246$ & $\$ 5,436,363$ & $-\$ 258,966$ & $-\$ 645,212$ \\
\hline
\end{tabular}

$$
\begin{aligned}
& s_{x}=\sqrt{\frac{1}{n-1} \sum(x-\bar{x})^{2}}=\$ 219,693.58 \\
& \mathrm{n}=28 \\
& \bar{x}=-\$ 67,964.52 \\
& \mathrm{t}-\text { stat }=-1.64 \\
& t_{(0.05,27)}=2.05
\end{aligned}
$$

|t-stat $\mid$ is not greater than $t_{(0.05,27)}$, so the hypothesis $\mathrm{H}_{0}: \mu_{\mathrm{A}}-\mu_{\mathrm{B}}=0$ cannot be rejected. 


\section{Appendix F: Statistical Analysis (continued)}

Table F.14: Pair-wise Comparison of Time Delay by Proportion of the Difference between the First and Second Bid

\begin{tabular}{|c|c|c|c|c|}
\hline \multicolumn{2}{|c|}{$\begin{array}{c}\text { Low First and Second } \\
\text { Contracts }\end{array}$} & \multicolumn{2}{|c|}{ High First and Second } & \multirow{2}{*}{$\mathrm{x}=\mathrm{TD}_{\text {high prop }}-\mathrm{TD}_{\text {low prop }}$} \\
\hline Bid Amount & Time Delay & Bid Amount & Time Delay & \\
\hline$\$ 171,375$ & 50 & $\$ 196,405$ & 197 & 147 \\
\hline$\$ 212,894$ & 74 & $\$ 264,778$ & 64 & -10 \\
\hline$\$ 354,737$ & 16 & $\$ 321,111$ & 215 & 199 \\
\hline$\$ 374,321$ & 18 & $\$ 321,111$ & 215 & 197 \\
\hline$\$ 382,510$ & 60 & $\$ 321,111$ & 215 & 155 \\
\hline$\$ 385,051$ & 7 & $\$ 321,111$ & 215 & 208 \\
\hline$\$ 415,480$ & 59 & $\$ 514,001$ & 30 & -29 \\
\hline$\$ 1,564,035$ & 66 & $\$ 1,250,449$ & 54 & -12 \\
\hline$\$ 2,246,000$ & 101 & $\$ 2,559,114$ & 378 & 277 \\
\hline$\$ 2,398,743$ & 25 & $\$ 2,559,114$ & 378 & 353 \\
\hline
\end{tabular}

$$
\begin{aligned}
& s_{x}=\sqrt{\frac{1}{n-1} \sum(x-\bar{x})^{2}}=202.69 \\
& \mathrm{n}=10 \\
& \bar{x}=148.5 \\
& \mathrm{t} \text {-stat }=2.32 \\
& t_{(0.05,9)}=2.26 \\
& \mid \text { t-stat } \mid \text { is greater than } t_{(0.05,9)}
\end{aligned}
$$




\section{Appendix F: Statistical Analysis (continued)}

Table F.15: Pair-wise Comparison of Cost Overrun by Proportion of the Difference between the Bid and the Engineer's Estimate

\begin{tabular}{|c|c|c|c|c|}
\hline \multicolumn{2}{|c|}{ Low Bid and Engineer } & \multicolumn{2}{|c|}{ High Bid and Engineer } & \multirow{2}{*}{$\mathrm{x}=\mathrm{CO}_{\text {high prop }}-\mathrm{CO}_{\text {low prop }}$} \\
\hline Bid Amount & Cost Overrun & Bid Amount & Cost Overrun & \\
\hline$\$ 40,046$ & $\$ 1,332$ & $\$ 49,349$ & $-\$ 7,954$ & $-\$ 9,286$ \\
\hline$\$ 50,624$ & $-\$ 7,222$ & $\$ 49,349$ & $-\$ 7,954$ & $-\$ 732$ \\
\hline$\$ 107,231$ & $-\$ 12,589$ & $\$ 110,535$ & $-\$ 110,535$ & $-\$ 97,947$ \\
\hline$\$ 108,666$ & $\$ 8,230$ & $\$ 110,535$ & $-\$ 110,535$ & $-\$ 118,766$ \\
\hline$\$ 111,493$ & $-\$ 11,572$ & $\$ 110,535$ & $-\$ 110,535$ & $-\$ 98,963$ \\
\hline$\$ 111,743$ & $-\$ 106$ & $\$ 110,535$ & $-\$ 110,535$ & $-\$ 110,429$ \\
\hline$\$ 160,568$ & $\$ 64,629$ & $\$ 154,087$ & $\$ 64,940$ & $\$ 312$ \\
\hline$\$ 163,745$ & $-\$ 32,601$ & $\$ 165,438$ & $-\$ 5,029$ & $\$ 27,572$ \\
\hline$\$ 214,307$ & $\$ 3,598$ & $\$ 219,993$ & $\$ 53,543$ & $\$ 49,945$ \\
\hline$\$ 220,950$ & $\$ 6,614$ & $\$ 219,993$ & $\$ 53,543$ & $\$ 46,929$ \\
\hline$\$ 222,729$ & $\$ 6,639$ & $\$ 219,993$ & $\$ 53,543$ & $\$ 46,904$ \\
\hline$\$ 222,928$ & $\$ 1,046$ & $\$ 219,993$ & $\$ 53,543$ & $\$ 52,497$ \\
\hline$\$ 258,715$ & $\$ 30,314$ & $\$ 257,420$ & $-\$ 123,949$ & $-\$ 154,262$ \\
\hline$\$ 297,600$ & $-\$ 20,226$ & $\$ 257,420$ & $-\$ 123,949$ & $-\$ 103,723$ \\
\hline$\$ 299,263$ & $\$ 22,737$ & $\$ 257,420$ & $-\$ 123,949$ & $-\$ 146,686$ \\
\hline$\$ 648,159$ & $-\$ 51,441$ & $\$ 635,916$ & $\$ 141,152$ & $\$ 192,593$ \\
\hline$\$ 733,820$ & $\$ 21,715$ & $\$ 768,272$ & $\$ 128,054$ & $\$ 106,338$ \\
\hline$\$ 734,473$ & $-\$ 34,928$ & $\$ 768,272$ & $\$ 128,054$ & $\$ 162,982$ \\
\hline$\$ 756,861$ & $-\$ 9,970$ & $\$ 768,272$ & $\$ 128,054$ & $\$ 138,024$ \\
\hline$\$ 779,079$ & $-\$ 9,717$ & $\$ 768,272$ & $\$ 128,054$ & $\$ 137,771$ \\
\hline$\$ 1,177,461$ & $\$ 107,468$ & $\$ 1,234,770$ & $-\$ 133,610$ & $-\$ 241,077$ \\
\hline$\$ 1,654,231$ & $\$ 180,076$ & $\$ 1,648,050$ & $-\$ 13,851$ & $-\$ 193,927$ \\
\hline$\$ 1,707,4856$ & $-\$ 2,061$ & $\$ 1,648,050$ & $-\$ 13,851$ & $-\$ 11,790$ \\
\hline$\$ 3,550,067$ & $\$ 603,123$ & $\$ 4,197,041$ & $\$ 308,228$ & $-\$ 294,896$ \\
\hline
\end{tabular}

$s_{X}=\sqrt{\frac{1}{n-1} \sum(x-\bar{x})^{2}}=\$ 133,201.78$

$\mathrm{n}=24$

$\bar{x}=-\$ 25,859.06$

$\mathrm{t}$-stat $=-0.95$

$t_{(0.05,23)}=2.07$

|t-stat $\mid$ is not greater than $t_{(0.05,23)}$, so the hypothesis $\mathrm{H}_{0}: \mu_{\mathrm{A}}-\mu_{\mathrm{B}}=0$ cannot be rejected 
Appendix G: Arizona Department of Transportation Management of Cost and Time Overrun
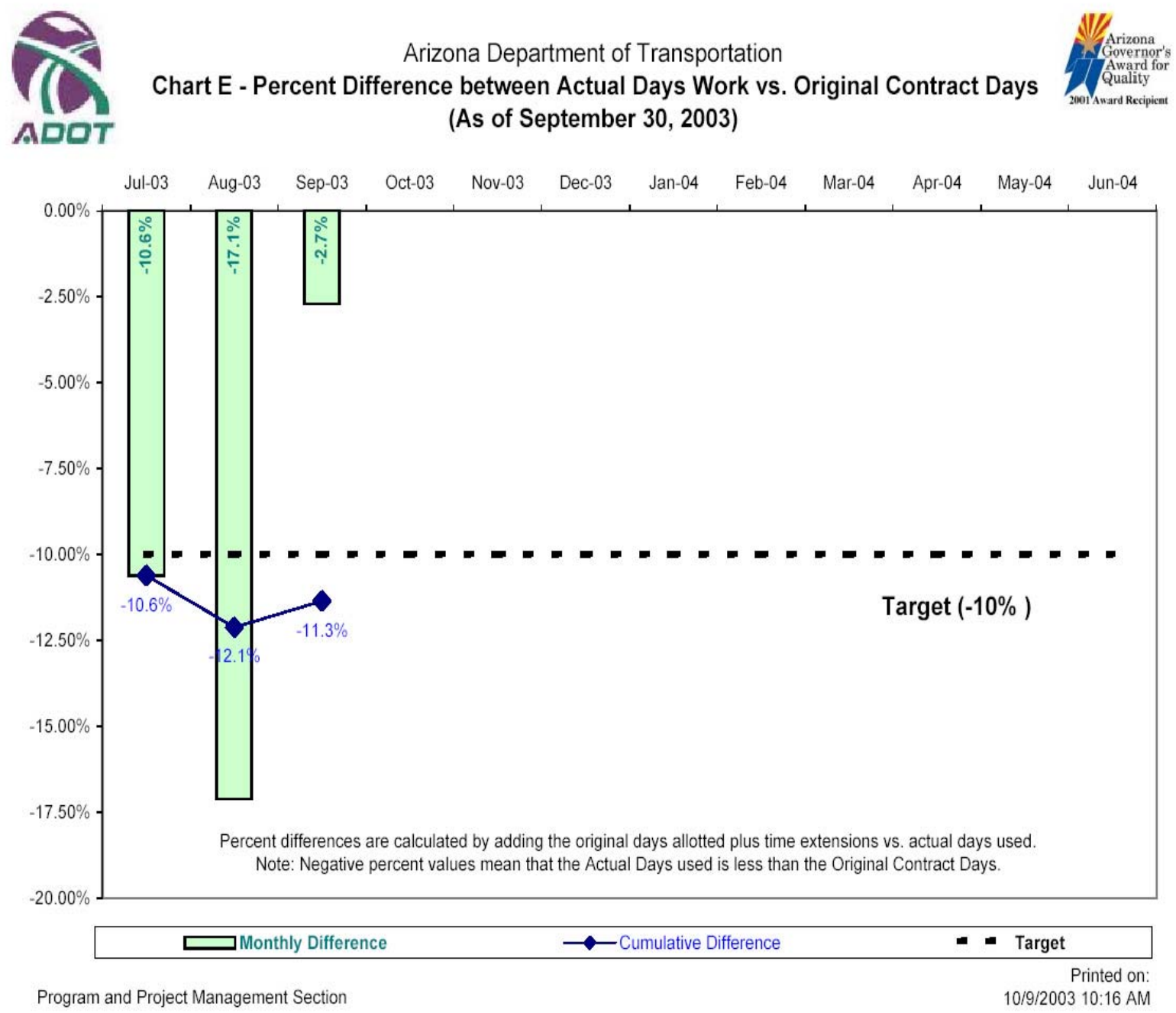

Figure G.1: Arizona Time Overrun Management 
Appendix G: Arizona Department of Transportation Management of Cost and Time Overrun

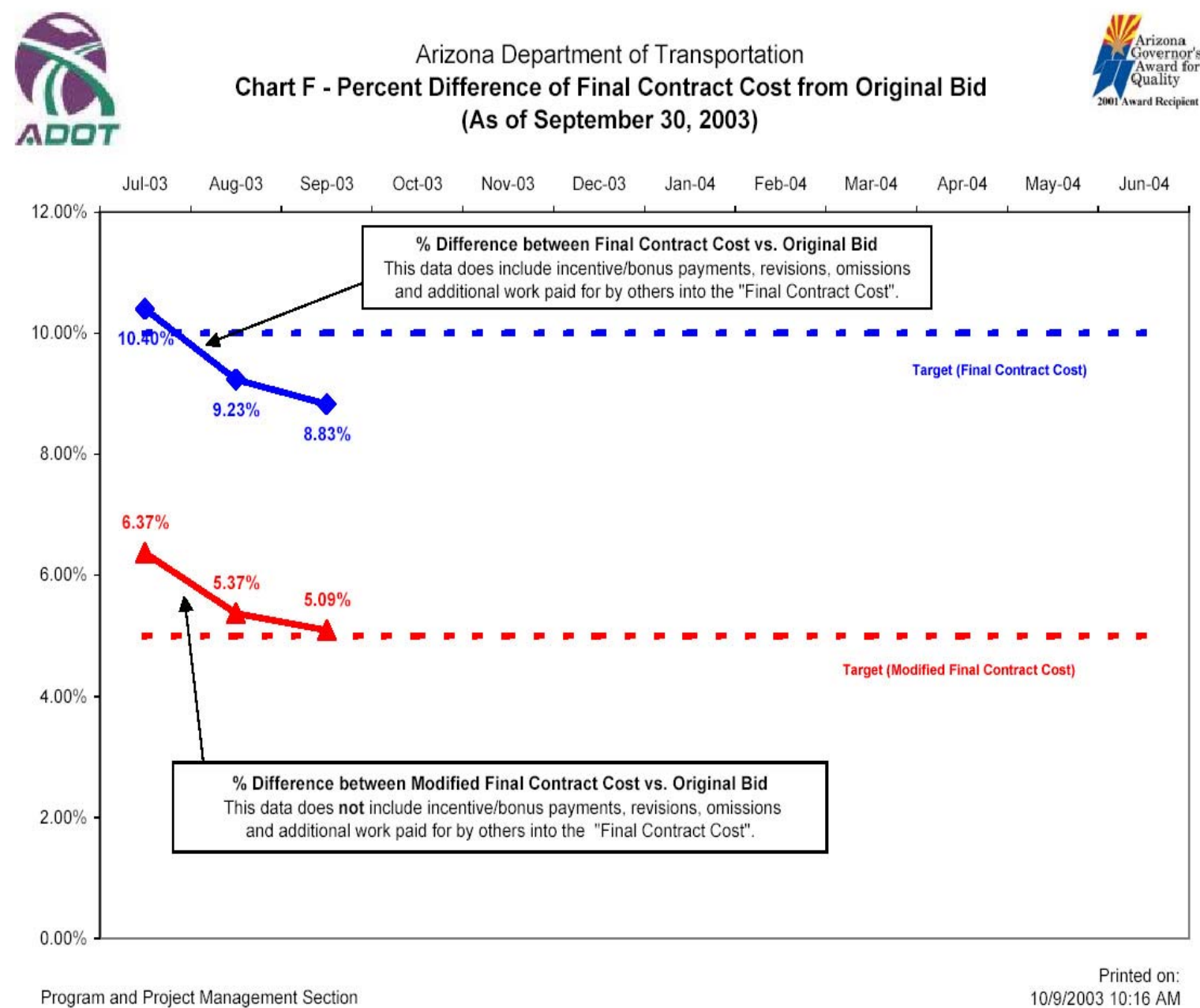

Figure G.2: Arizona Cost Overrun Management 